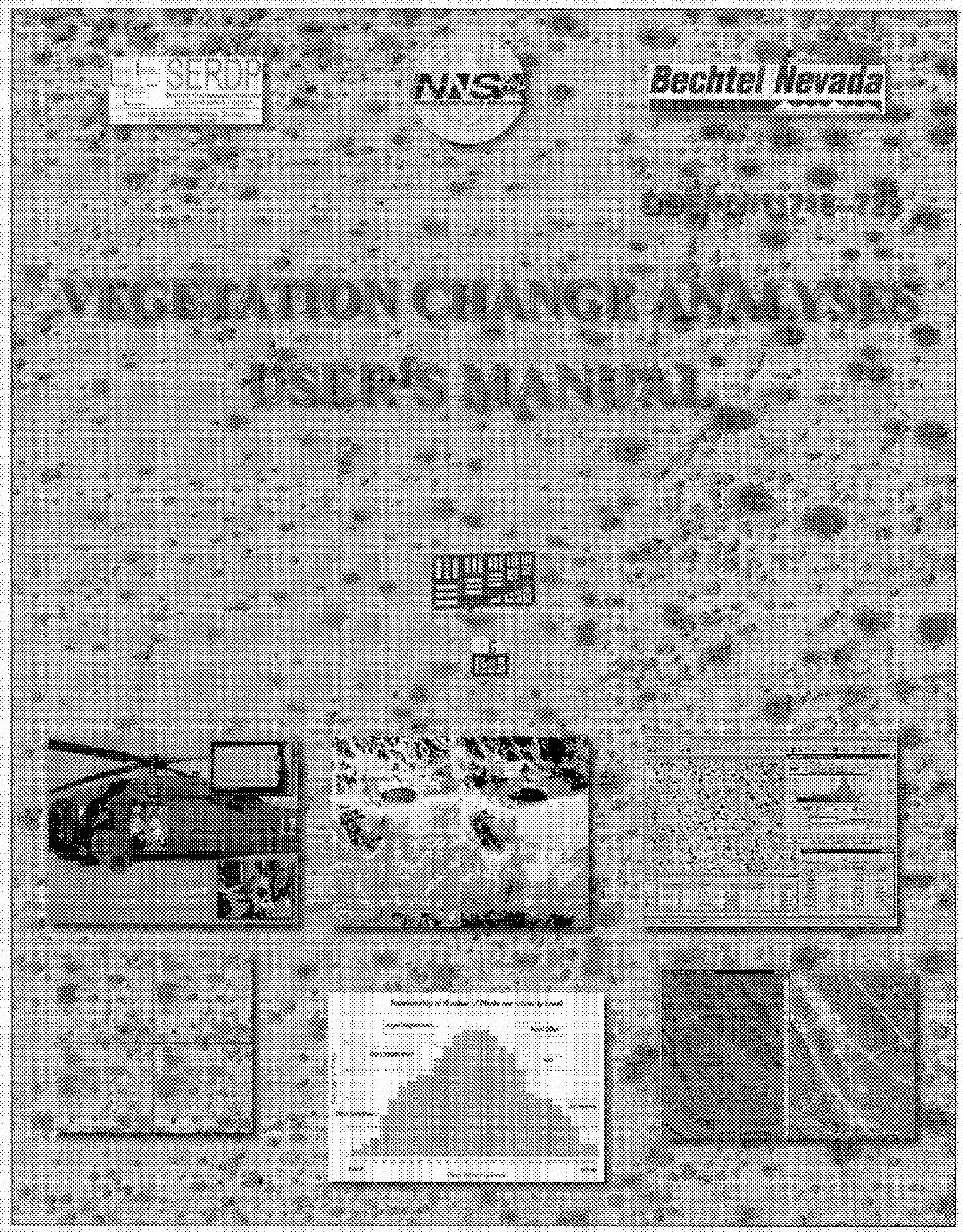




\section{DISCLAIMER STATEMENT}

Reference herein to any specific commercial product, process, or service by trade name, trademark, manufacturer, or otherwise, does not necessarily constitute or imply its endorsement, recommendation, or favoring by the U.S. Government or any agency thereof or its contractors or subcontractors.

\section{AVAILABILITY STATEMENT}

Available for sale to the public from:

U.S. Department of Commerce

National Technical Information Service

5285 Port Royal Road

Springfield, VA 22161-0002

Telephone: 800.553 .6847

Fax: 703.605.6900

E-Mail: orders@ntis.fedworld.gov

Online ordering: http://www.ntis.gov/ordering.htm

Available electronically at http://www.doe.gov.bridge

Available for a processing fee to the U.S. Department of Energy and its contractors, in paper, from:

U.S. Department of Energy

Office of Scientific and Technical Information

P.O. Box 62

Oak Ridge, TN 37831-0062

Telephone: 865.576 .8401

Fax: 865.576.5728

E-Mail: reports@adonis.osti.gov 


\title{
Vegetation Change Analysis USER'S MANUAL
}

October 1, 2002

Dennis J. Hansen

W. Kent Ostler

\author{
Prepared by \\ Bechtel Nevada \\ Ecological Services \\ P.O. Box 98521 \\ Las Vegas, NV 89193-8521
}

\author{
Prepared for the \\ U.S. Department of Energy \\ National Nuclear Security Administration \\ Nevada Operations Office \\ Environment, Safety, and Health Division \\ P.O. Box 98518 \\ Las Vegas, NV 89193-8518
}

The work was supported by the Strategic Environmental Research and Development Program, under Work Order AGRW74RDV90120347. DOE/NV/11718-729. 


\section{THIS PAGE INTENTIONALLY LEFT BLANK}




\section{ACKNOWLEDGEMENTS}

Funding was provided by the U.S. Department of Defense (DoD) through the programs of the Strategic Environmental Research and Development Program (SERDP) (http://www.serdp.org) [Diagnostic Tools and Reclamation Technologies for Mitigating Impacts of DoD/DOE Activities in Arid Areas - Project Number CS-1131]. Work was performed under the direction of the U.S. Department of Energy (DOE), National Nuclear Security Administration Nevada Operations Office, Environment, Safety, and Health Division, located in Las Vegas, Nevada. Appreciation is expressed to scientists and staff at these organizations who provided funding, guidance, and encouragement.

Collaborators included scientists and staff from Bechtel Nevada, Las Vegas, Nevada; Mr. Mickey Quillman from the U.S. Army's National Training Center (NTC), Fort Irwin, California; Mr. Wayne Johnson, Ms. Ruth Sparks, Mr. Dan Pantone, Mr. Brian Croft, and Mr. Jay Becker from Charis Corporation, Fort Irwin, California; Dr. Steven D. Warren, from the Center for Environmental Management of Military Lands from Colorado State University, Fort Collins, Colorado; U.S. Army Construction Engineers Research Laboratory (USACERL); and Dr. Christopher Lee from California State University-Dominguez Hills, California. Fort Irwin, the Army's NTC located near Barstow, California in the Mojave Desert, was selected as the primary test site for development and testing of the new technologies.

The Technical Advisory Team was comprised of Dr. Cyrus McKell, President of Applied Ecological Services in Salt Lake City, Utah, who served as chairman and six other specialists in the areas of remote sensing, reclamation, and arid-land ecology: Dr. Merrill Ridd from the University of Utah, Salt Lake City, Utah; Dr. Charles Hutchinson from the University of Arizona's Office of Arid Land Studies, Tucson, Arizona; Dr. Kathryn Thomas from the University of Northern Arizona, Flagstaff, Arizona; Dr. Von Winkel (formerly with Science Applications International) from the Las Vegas Valley Water District, Las Vegas, Nevada; Dr. Steven Monsen, from the U.S. Forest Service Shrub Science Laboratory, Provo, Utah; Dr. Richard Gebhardt from the USACERL, Champaign, Illinois.

Appreciation is also expressed to other SERDP principal investigators who provided valuable feedback and assistance. These included: Dr. Paul Tueller from the University of Nevada Reno, Reno, Nevada; Dr. Douglas Ramsey from Utah State University, Logan, Utah; Dr. Tom Frank and Dr. Scott Tweddell from the USACERL, Champaign, Illinois, and Dr. Dave Moaat from the Desert Research Institute, University of Nevada, Reno, Reno, Nevada.

Several DoD facilities and government agencies provided site tours, imagery, and opportunities to exchange information and techniques. These included Ms. Valerie Morrill at Yuma Proving Grounds in Arizona, who was instrumental in drawing attention to the needs of DoD sites and encouraging the work. Others scientists included those at Dugway Proving Grounds in Utah; Camp Williams in Utah; Hill Air Force Base in Utah; Nellis Air Force Base in Nevada; Tonopah Test Range in Nevada; Fort Bliss in Texas; White Sands Missile Range in New Mexico; the Jornada Experiment Range in New Mexico; the U.S. Department of Agriculture's Agricultural Research Service, High Plains Grassland Research Station in Wyoming; the Marine Corps Air Ground Control Center in California; the U.S. Army Yakima Training Center in Washington, 
Fort Hunter Liggett in California; the Orchard Training Area, Idaho Army National Guard in Idaho; and the Idaho National Engineering and Environmental Laboratory in Idaho. 


\section{TABLE OF CONTENTS}

ACKNOWLEDGEMENTS

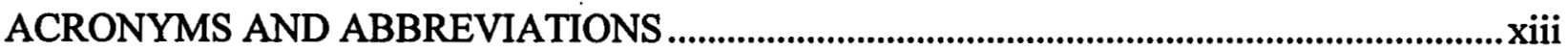

ABSTRACT

1.0 INTRODUCTION

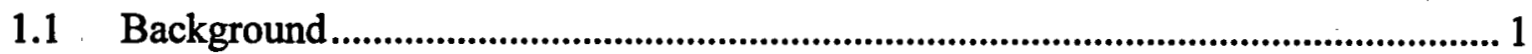

1.2 Goals and Objectives ....................................................................................................... 2

1.3 SERDP Users Manuals ................................................................................................ 2

1.4 Relationship to Other Users Manuals and Technologies........................................... 2

2.0 MEASUREMENT OF PLANT BIOMASS AND COVER ................................................ 5

$2.1 \quad$ Plant Biomass and Cover

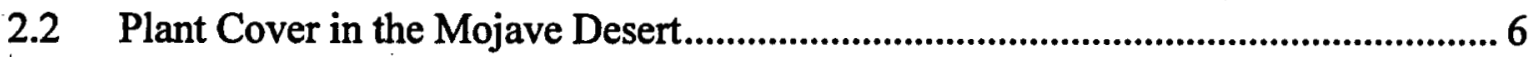

2.3 Considerations for Measuring Plant Cover........................................................... 6

2.4 Methods of Measuring Plant Cover ........................................................................ 7

2.4.1 Semiquantitative Methods ................................................................... 7

2.4.2 Quantitative Methods......................................................................................... 7

2.5 Line-Intercept Method ................................................................................................ 8

2.5.1 Application of Aerial Photographs for Line Intercepts.................................... 9

2.5.1.1 Photographic Scale for Aerial Photographs................................... 9

2.5.1.2 Optimal Scale for Aerial Photographs .......................................... 10

2.6 Digital Techniques for the Measurement of Plant Cover ........................................ 11

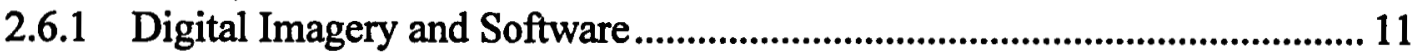

2.6.2 Background for Digital Imagery ............................................................. 12

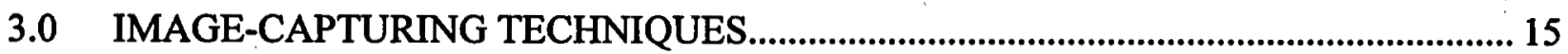

3.1 Types of Platforms for Capturing Images............................................................ 15

3.1.1 Tripods and Hand-Held Poles.................................................................. 15 


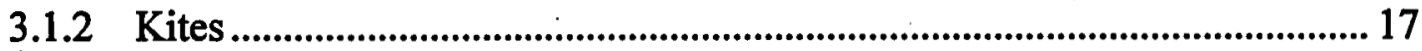

3.1.3 Blimps and Balloons................................................................................... 18

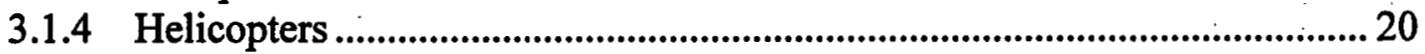

3.1.5 Fixed-Wing Aircraft.............................................................................................. 23

3.1.6 Satellites................................................................................................... 25

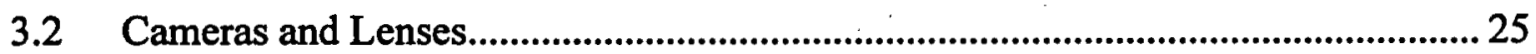

3.3 Films and Digital Recording Media............................................................................. 26

3.3.1 Small-Format Films ............................................................................26

3.3.2 Large-Format Films ........................................................................... 26

3.3.3 Digital Recording Media................................................................................... 27

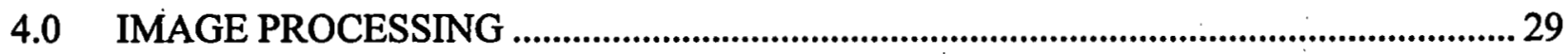

4.1 Digital Images and Image Editing Software..............................................................2 29

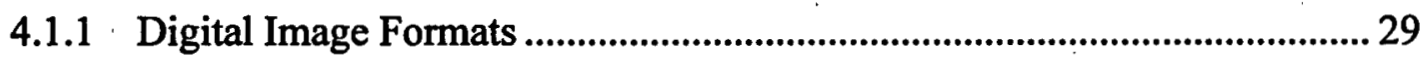

4.1.2 Image-Editing and -Enhancing Software....................................................... 30

4.1.3 Georeferencing Software ................................................................................... 33

4.2 Measurement of Plant Cover by Digital Techniques...................................................... 33

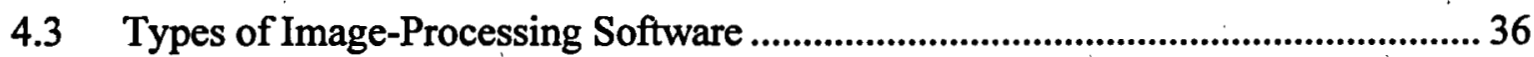

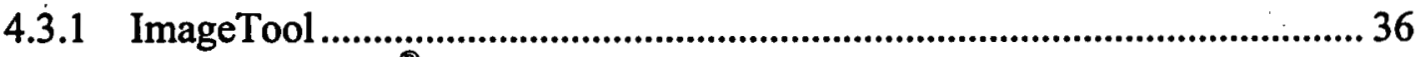

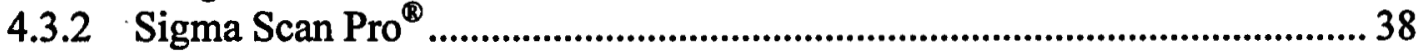

4.3.2.1 Procedures for Setting Intensity Thresholds...................................... 39

4.3.2.2 Applying Filters to Remove Object Noise.................................... 42

4.3.2.3 Creating an Intensity Threshold Mask of Shrub Canopy Cover... 43

4.3.2.4 Saving Threshold Masks for Canopy Cover as a TIFF Image...... 44

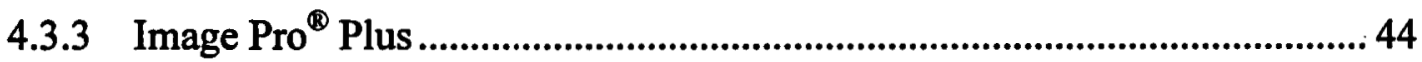

4.3.3.1 Loading Image Files ........................................................................ 45

4.3.3.2 Selecting Proper Threshold Values................................................ 46

4.3.3.3 Vignette Correction.............................................................................. 48

4.3.3.4 Selecting Which Measurements are to be Counted ....................... 49

4.3.3.5 Selecting an Area of Interest to be Counted ................................... 49

4.3.3.6 Changing the Count Options..............................................................5 50

4.3.3.7 Viewing Statistics of Measured Parameters ..................................... 51

4.3.3.8 Unselecting Objects that Should Not be Counted........................... 51

4.3.3.9 Creating a Mask of Shrub Silhouettes ........................................ 52

4.3.3.10 Saving Images............................................................................ 52

4.3.3.11 Printing Images .................................................................................... 54 


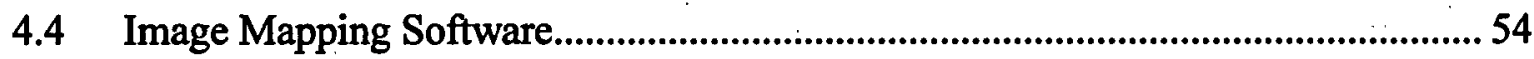

4.4.1 SERDP Image Converter .......................................................................... 55

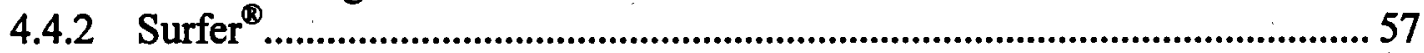

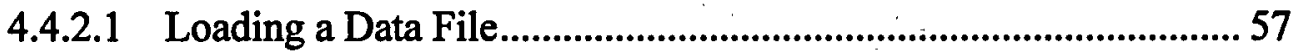

4.4.2.2 Loading a Data File to Create a Contour Map.............................. 59

4.4.2.3 Exporting a Surfer ${ }^{\circledR}$ Map as a TIFF File ........................................... 64

4.4.2.4 Cropping and Mosaicing Surfer ${ }^{\circledR}$ TIFF Images in Adobe

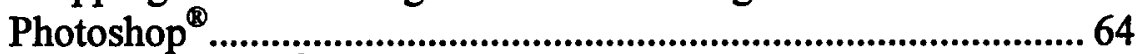

4.4.2.5 Exporting Surfer ${ }^{\circledR}$ Images as an ESRI Shapefile .............................. 66

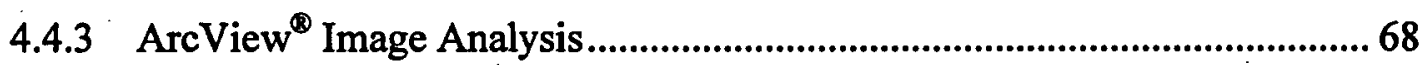

4.4.3.1 The Image Rectification Procedure ..................................................6 69

4.4.3.2 Saving the Georectified Image....................................................... 70

4.4.4 New GIS Software Tools ................................................................................ 70

4.4.4.1 ArcView ${ }^{\circledR} /$ ArcGis $^{\circledR}$.............................................................................. 71

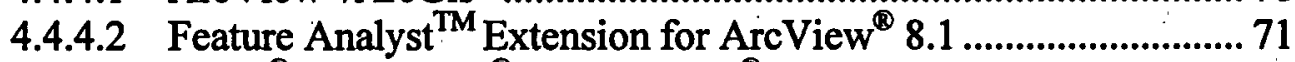

4.4.4.3 ENVI $^{\circledR}$, Geomatica $^{\circledR}$, and Imagine ${ }^{\circledR}$................................................. 72

5.0 CONCLUSIONS AND RECOMMENDATIONS.................................................................. 75

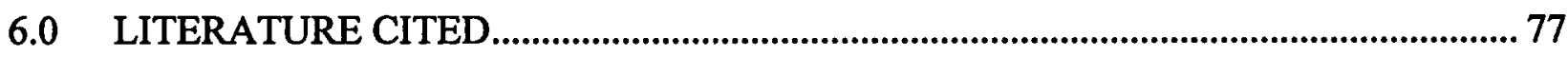

7.0 INTERNET WEB SITES AND LINKS ......................................... 80

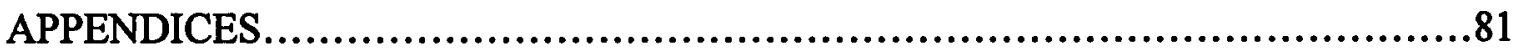




\section{LIST OF FIGURES}

Figure 2-1. An example of a line intercept in Mojave Desert vegetation. The white line represents the measuring tape. The red lines indicate the portions of the tape that intercept shrub canopy. The percent shrub cover is the total length of the red divided by the white.

Figure 2-2. Histogram of luminosity values showing the number of pixels ranging from 0 to 255 for the digital image of the shrub and soil on the upper left.

Figure 3-1. Example of hardware mounting bolts and hand-held swimming-pool skimming pole for taking aerial pictures.

Figure 3-2. Helium-filled blimp being readied for flight.

Figure 3-3. Blackhawk helicopter showing the location of two-camera mounting positions, side gun mount (left red arrow, lower right inset picture) and inside cargo hook door (right red arrow, upper right inset picture).

Figure 3-4. Example of an aerial photograph taken with a digital camera through a cargo hook door of a blackhawk helicopter at Fort Irwin, California.

Figure 3-5. Examples of radio-controlled remote camera shutter transmitter and receiver.

Figure 4-1. Example of image (1:24000) showing light halos from over-sharpening. .31

Figure 4-2. Example of Unsharp Mask in Adobe Photoshop ${ }^{\circledR}$ showing adjustment inputs. .32

Figure 4-3. Hypothetical histogram of features in a digital image of desert vegetation. .34

Figure 4-4. Examples of pull-down menus for creating gray-scale images and setting thresholds with ImageTool software.

Figure 4-5. Examples of pull-down menus for thresholding and saving images with IT software.

Figure 4-6. Selecting and opening a file in SigmaScan Pro .39

Figure 4-7. Selecting an intensity threshold for mono or color digital images. .39

Figure 4-8. Setting intensity thresholds while retaining the colored image. . .40 
Figure 4-9. (A) Color image to be thresholded. (B) Proper threshold level includes most vegetation, but minimizes inclusion of soil and litter. (C) Image with threshold set too low, not all plant canopies are covered within the area threshold. (D) Image threshold set too high, background soil and litter are included within the area threshold.

Figure 4-10. Converting image to gray scale and adjusting threshold values with slider bar.

Figure 4-11. Sigma Scan $\mathrm{Pro}^{\circledR}$ menus for using overlay filters to remove small pixels. . .43

Figure 4-12. Creating a mask of the intensity threshold overlay. . .43

Figure 4-13. Saving the mask file as a 24-bit TIFF image. .44

Figure 4-14. Opening file images in Image Pro ${ }^{\circledR}$ Plus, Version 4.1 ...............................................46

Figure 4-15. Selecting count/size and setting histogram threshold values.

Figure 4-16. Correction of vignetting using the Flatten Background Command. 48

Figure 4-17. Selecting the measurement parameters.

Figure 4-18. Selecting the area of interest and count options to be used. .50

Figure 4-19. Viewing statistics of measured parameters.

Figure 4-20. Unselecting objects that should not be measured. .52

Figure 4-21. Creating a mask of shrub silhouettes.

Figure 4-22. Inverting an image mask (upper left before conversion/lower right after conversion)

Figure 4-23. Saving a new image file.

Figure 4-24. Example of quality differences in a saved image (A) versus a screencaptured image (B).

Figure 4-25. Example of the Grid Export pop-up menu. .56

Figure 4-26. Example of the export file format. .57

Figure 4-27. Opening a grid data file. .58

Figure 4-28. Selecting the proper gridding method. .59 
Figure 4-29. Creating a contour map from a grid file......................................................................59

Figure 4-30. Setting the contour map properties. .................................................................60

Figure 4-31. Turning off numeric contour labels. ..................................................................61

Figure 4-32. Setting level properties. .............................................................................................61

Figure 4-33. Setting the $\mathrm{Z}$ level values....................................................................................62

Figure 4-34. Setting contour lines to blank values. ....................................................................63

Figure 4-35. Assigning colors to contour levels..................................................................63

Figure 4-36. Saving a map as a TIFF image......................................................................64

Figure 4-37. Hiding axis and labels when preparing a map as a shapefile..................................67

Figure 4-38. Exporting a Surfer ${ }^{\circledR}$ map as a shapefile. .......................................................................67

Figure 4-39. Setting the coordinates for the shapefile corners......................................................68

Figure 4-40. Applied linear stretch with (A) raw image and (B) image

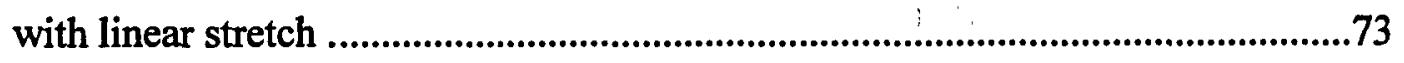

Figure 4-41. Rectified image effect: (A) raw image-note misshaped panels on the right side of image (B) rectified image ....................................................................73

\section{LIST OF TABLES}

Table 3-1. Comparison of platforms for capturing aerial images 


\section{ACRONYMS AND ABBREVIATIONS}

ASA

BMP

BN

CD

cm

CMYK

CIR

DoD

DOE

dpi

ENVI

ESRI

FAA

$\mathrm{ft}^{3}$

GIS

GPS

IT

ITAM

JPG

KAP

lbs

LCTA

$\mathrm{m}^{2}$

$\mathrm{m}^{3}$

$\mathrm{MB}$

$\mathrm{mm}$

MrSID

NASA

NTS

PDF

RGB
American Standards Association

Blimp Aerial Photography

Bechtel Nevada

Compact disks

centimeter

Cyan, Magenta, and Yellow and blacK

Color Infrared

U.S. Department of Defense

U.S. Department of Energy

disintegrations per inch

Environment for Visualizing Images

Environmental Systems Research Institute

Federal Aviation Administration

cubic feet

Geographic Information System

Global Positioning System

ImageTool

Integrated Training Area Management

Joint Photographic Experts Group

Kite Aerial Photography

pounds

Land Condition Trend Analysis

square meters

cubic meters

megabyte

millimeter

Multiresolution Seamless Image Database

National Aeronautics and Space Administration

Nevada Test Site

Portable Document Format

Red, Green, and Blue 
SAE

SERDP

TIFF

TMSES

USACERL

USAEC

UTHSCSA

UTM
Society of Automotive Engineers

Strategic Environmental Research and Development Program

Tagged Image File Format

Terrain Modeling and Soil Erosion Simulation

U.S. Army Construction Engineers Research Laboratory

U.S. Army Environmental Center

University of Texas Health Science Center, San Antonio

Universal Transverse Mercators 


\section{ABSTRACT}

Approximately 70 percent of all U.S. military training lands are located in arid and semi-arid areas. Training activities in such areas frequently adversely affect vegetation, damaging plants and reducing the resilience of vegetation to recover once disturbed. Fugitive dust resulting from a loss of vegetation creates additional problems for human health, increasing accidents due to decreased visibility, and increasing maintenance costs for roads, vehicles, and equipment. Diagnostic techniques are needed to identify thresholds of sustainable military use. A cooperative effort among U.S. Department of Energy, U.S. Department of Defense, and selected university scientists was undertaken to focus on developing new techniques for monitoring and mitigating military impacts in arid lands. This manual focuses on the development of new monitoring techniques that have been implemented at Fort Irwin, California. New mitigation techniques are described in a separate companion manual.

This User's Manual is designed to address diagnostic capabilities needed to distinguish between various degrees of sustainable and nonsustainable impacts due to military training and testing and habitat-disturbing activities in desert ecosystems. Techniques described here focus on the use of high-resolution imagery and the application of image-processing techniques developed primarily for medical research.

A discussion is provided about the measurement of plant biomass and shrub canopy cover in arid lands using conventional methods. Both semiquantitative methods and quantitative methods are discussed and reference to current literature is provided. A background about the use of digital imagery to measure vegetation is presented.

Image-capturing techniques using cameras mounted on tripods and hand-held poles, kites, blimps and balloons, helicopters, fixed-wing aircraft, and satellites are discussed. The pros and cons of using various types of cameras and lenses, films, and digital recording media are reviewed and evaluated.

Image processing using various approaches are described in detail with links to useful Web sites including the use of commercial image-processing software. Screen captures of key procedures of selected software are shown and described. Digital image formats are discussed. Classes of image-processing software include: (1) image editing and enhancing (e.g., Picture Window Pro ${ }^{\circledR}$ and Adobe Photoshop ${ }^{\circledR}$ ), and (2) georeferencing software (e.g., MrSID ${ }^{\circledR}$, DIME $^{\circledR}$ ). The historical background of measuring plant cover by digital techniques is presented. Several types of image-processing software are described. These include ImageTool, Sigma Scan Pro ${ }^{\circledR}$, and Image Pro Plus ${ }^{\circledR}$. A detailed description of the steps required to successfully measure shrub canopy cover is provided, including tips from experienced users, user precautions, and alternate approaches.

A discussion is also provided about image-mapping software such as Surfer ${ }^{\circledR}$ gridding and mapping software. An image conversion program written for this project is described and provided to users to convert TIF (tagged image file) images to Surfer ${ }^{-6}$ XYZ tabular grid files. Procedures are described to assist users in exporting maps to rectified shapefiles that can be used in geographic information systems for the purpose of shrub-cover change detection and the 
presentation of areas at various thresholds of use. Using these thematic layers permits managers to estimate cost for mitigation and establish priorities for future mitigation efforts.

Additionally an appendix is provided that describes (1) application of techniques used at the U.S. Army's National Training Center at Fort Irwin, California, to evaluate changes in vegetative cover using the new techniques described in this report; (2) a plant-damage assessment technique for evaluating military vehicular impacts to vegetation in the Mojave Desert; and (3) pertinent Internet Web sites and links to other related SERDP projects and government sites that focus on remote-sensing techniques for monitoring and mitigating training impacts. 


\subsection{INTRODUCTION}

This user's manual describes new remote sensing tools that use high or very high-resolution imagery for the purposes of measuring changes in plant canopy cover. Techniques developed during the preparation of this manual provide users with the means of bridging the gap between deficiencies common to remote sensing using satellite imagery and the high cost and time associated with detailed ground surveys. Innovative technologies described in this manual will provide valuable tools to ensure continuation of military testing and training which is currently threatened at many arid-land installations by deteriorating site conditions and will significantly reduce collection costs and time, while increasing data quality and reliability.

\subsection{BACKGROUND}

Approximately 70 percent of all U.S. military training lands are located in arid and semi-arid areas. Training activities may adversely affect vegetation, damaging plants and reducing the resilience of vegetation to recover once disturbed. The cumulative impacts result in a loss of plant cover, species diversity, plant reproduction, and soil resources such as organic matter and soil microorganisms needed to recycle soil nutrients. Fugitive dust resulting from a loss of vegetation creates additional problems for human health, increasing accidents due to decreased visibility and increasing maintenance costs for roads, vehicles, and equipment.

It is difficult to detect and monitor impacts to vegetation from military training in desert areas using conventional remote sensing techniques that rely on low-resolution satellite imagery. This is because the pixel sizes of satellite images are large (e.g., 10 to 30 square meters per pixel) while the shrub sizes are small ( 0.25 to 3 square meters in area). Vegetation cover in arid landscapes varies substantially with seasonal changes in climate. Cover is normally low, usually less than 25 percent in undisturbed areas and frequently less than 5 percent in heavily used areas. Sun light reflecting from soils in these desert areas frequently masks the smaller amount and quality of light that is reflected by vegetation making it impossible to accurately measure changes in vegetation cover. New diagnostic techniques are needed to identify thresholds of sustainable military use, and to accurately measure plant canopy cover in arid-land environments.

In 1999, a cooperative effort among U.S. Department of Energy (DOE), U.S. Department of Defense (DoD), and selected university scientists was undertaken to focus on mitigating military impacts in arid lands. Bechtel Nevada (BN) assembled a team of scientists to address these problems in arid lands. The research team included researchers and advisors from government, universities, and private industry. Collaborators include DOE National Nuclear Security Administration Nevada Operations Office (formerly known as DOE Nevada Operations Office [DOE/NV]) BN; DoD-Fort Irwin, Center for Ecological Management of Military Lands at Colorado State University; U.S. Army Construction Engineers Research Laboratory (USACERL), California State University-Dominguez Hills; and Weber State UniversityApplied Ecological Services, Inc. Fort Irwin, the Army's National Training Center (NTC) located near Barstow, California, in the Mojave Desert, was selected as the primary test site for development of new technologies. The approach focuses on specific problems at the NTC, but is 
suitable for other DoD and DOE facilities located in arid and semiarid areas. Diagnostic tools developed by this program may also be applicable to wetter areas of the United States.

\subsection{GOALS AND OBJECTIVES}

This manual is designed to address current gaps in diagnostic capabilities needed to distinguish between various degrees of sustainable and nonsustainable impacts due to military training and testing or earth-disturbing activities in desert ecosystems. These diagnostic tools will enable management to maximize utilization of limited training environs and thus increase operational readiness. Specific objectives of this manual include:

- Discuss the measurement of plant canopy cover in the Mojave Desert

- Describe the limitation and variability of conventional ground sampling techniques

- Evaluate image-capturing techniques for obtaining large-scale aerial imagery

- Evaluate image-processing software and techniques for measuring shrub cover

- Summarize findings and describe recommendations for new diagnostic techniques

\subsection{USERS MANUALS}

The technologies evaluated and tested are divided into two principal areas: (1) diagnostics and (2) restoration techniques. Technologies are described in two separate user's manuals:

Vegetation Change Analysis User's Manual. Dennis J. Hansen and W. Kent Ostler. 2002. DOE/NV/11718 - 729, Bechtel Nevada, Ecological Services, Las Vegas, NV 89193.

New Technologies to Reclaim Arid Lands User's Manual. W. Kent Ostler, David C. Anderson, Derek Hall, and Dennis J. Hansen. 2002. DOE/NV/11718-731, Bechtel Nevada, Ecological Services, Las Vegas, NV 89193.

These manuals were distributed in a workshop held in Las Vegas, Nevada, during the fall of 2002. The purpose of the workshop was to facilitate technology transfer by presenting the new technologies and assisting scientists working at selected military installations to understand how the these technologies could assist them in managing biological resources at their sites.

\subsection{RELATIONSHIP TO OTHER USER'S MANUALS AND TECHNOLOGIES}

Information about remote sensing has been assembled by the National Aeronautics and Space Administration (NASA) and the U.S. Army Environmental Center in the form of a Remote Sensing Tutorial. The objective of this tutorial is to provide organized tools to help land managers take advantage of existing remote sensing technology. 
Basic information about remote sensing organizations, links, conferences, publications, and sources of imagery can be located through the remote sensing Internet Virtual Library (http://www.vtt.fi/tte/research/tte1/tte14/virtual/).

The reader is also referred to a related Strategic Environmental Research and Development Program (SERDP) project that describes the effect of spatial resolution on vegetation cover, developing and testing a procedure to scale-up vegetation cover estimates, and development of procedures and models to estimate standing woody biomass in arid areas (Tweddale et al. 2002) 
THIS PAGE INTENTIONALLY LEFT BLANK 


\subsection{MEASUREMENT OF PLANT BIOMASS AND COVER}

An essential component of monitoring to determine the spatial extent and degree of military impact is the ability to accurately assess site changes through time as training areas undergo normal use under varying climatic conditions. Historically, monitoring techniques have been primarily limited to expensive, labor-intensive, ground collection of data such as plant canopy cover by line-point or line-intersect methods, and plant density by quadrant sampling techniques. Additionally, accessibility to the range by field biologists has been limited at some sites to only one week each month because of intensive military training exercises, making it difficult to obtain sufficient field data during narrow windows of opportunity.

Alternatives to ground-based monitoring techniques are those that focus on remote sensing. Traditionally, these techniques have used satellite imagery as a means of capturing and assessing vegetation conditions at a landscape-size area or scale. Information such as the intensity of a particular wavelength of light or ratio of wavelengths from individual area units of the satellite image (known as pixels) are then statistically correlated with data taken on the ground (e.g., canopy cover or plant density). Pixel size for most satellite images ranges from 10 meters square $\left(\mathrm{m}^{2}\right)$ to $30 \mathrm{~m}^{2}$ (328 feet square $\left[\mathrm{ft}^{2}\right]$ to $2,953 \mathrm{ft}^{2}$ ), which further restricts the usefulness of this technique because most shrubs are often less than $1 \mathrm{~m}^{2}\left(11 \mathrm{ft}^{2}\right)$ in size. This method is useful in areas where ground cover of vegetation is relatively high (e.g., $>30$ percent cover) and impacts to the vegetation result in spectral changes that are detectable in the digital images (Falkner, 1995). Such conditions are common for agricultural lands, grasslands, and forest areas, but this method is less useful in desert areas where plant canopy cover is often less than 10 percent and may be as low as 1 to 2 percent following intensive training impacts such as encampment.

Large-scale ecoregion management approaches have relied upon satellite imagery such as LANDSAT multispectral and thematic mapper, and Satellite pour L'Observation de la Terre panchromatic/multispectral images (Plumb and Pillsbury, 1986). For example, at Fort Irwin, California, the use of this approach has been successful in identifying broad disturbance patterns attributed to military training impacts over time (Lee, 1995). Fort Irwin was selected for development of new diagnostic tools because it is one of the largest military training facilities and it is where previous studies have provided a sound foundation of biological, modeling, and remote sensing information. Proposed work was designed to be built on this foundation of existing site information.

Despite the usefulness of conventional remote-sensing techniques, data deficiencies still exist in applying these techniques to assess the sustainability of training impacts. The deficiencies are associated with the inability to obtain additional levels of detail needed to determine essential characteristics of the vegetation such as shrub cover, density, and species composition. These parameters are needed to establish recovery thresholds where increasing costs and rest-rotational use patterns may restrict short-term use in order to sustain long-term testing and training.

Because training impacts are ongoing at most military training areas and precise location of these impacts are somewhat unpredictable, a method for rapidly monitoring the condition of soils and vegetation is needed to determine the condition of vegetation, assess its resiliency to training 
impacts, assess impact severity, and direct land maintenance activities. A method for rapid capture of field data is required. Such rapid detection methods are being developed as part of this project using aerial photography and hand-held digital cameras to record selected ground details. These techniques can utilize permanent transects or photo points to assess year-to-year trends and to be compatible with current sampling formats used in the LCTA. The focus of BN's research has been to develop techniques that bridge the gap between the labor-intensive and costly ground collection techniques and remote-sensing techniques using satellite imagery which is less expensive, yet less precise in detecting vegetation change. A discussion follows of techniques used to measure plant biomass and shrub canopy cover and how they can be used to monitor vehicle and training impacts.

\subsection{PLANT BIOMASS AND COVER}

Among the most important parameters used to describe vegetation are plant biomass and plant cover. These parameters are important for describing plant dominance, community structure, and wildlife habitat. They are used to estimate animal forage, protection of the soil from erosion, and ecosystem functions such as transpiration rates and water budgets or cycles. Plant cover is usually highly correlated with plant biomass and generally much easier to measure. Historically, plant cover has been considered the vertical projection of vegetation parts onto the ground or the amount of ground covered or shaded by a plant. Perturbations to the plant community or changes in the ecosystem often result in changes in plant cover; therefore, changes in vegetative cover can be thought of as an indication of perturbations or disturbance.

\subsection{PLANT COVER IN THE MOJAVE DESERT}

Vegetation in the Mojave Desert is often sparse and inter-plant spacings are large. Plant cover in the desert is dynamic and can change suddenly and dramatically through the growing season. Plants respond favorably to soil moisture following precipitation events by producing new leaves and branches which increase plant cover. With the loss of soil moisture by evapotranspiration plants begin to shed leaves to obtain a more favorable shoot-to-root ratio and plant cover is reduced. Shallow-rooted species are forced to adjust to drying soils before more deeply-rooted species because of the lack of available soil moisture near the soil surface. Prolonged drought up to several years in duration may result in reductions in plant cover and die back of most aboveground perennial plant biomass. It may also result in the death of many individual plants. In extreme cases perennial species may be replaced by annual species that are capable of avoiding unusually dry soil conditions for up to several decades.

\subsection{CONSIDERATIONS FOR MEASURING PLANT COVER}

The selection of methods used to measure plant cover is dependent on the objectives of the research effort. The measurement of lichen cover on a small rock surface responding to local air pollution may require a very different technique than the measurement of forest canopy cover losses due to clear cutting in the Amazon jungle. Often of greater initial value are qualitative or semiquantitative trends rather than absolute accuracy and precision inherent in some quantitative methods. The relative differences in cover are often far more revealing than the absolute values 
in evaluating trends over time. In other words, it may be more important for a manager to know in what direction a plant community is trending and the relative rate of change of those changes rather than the exact seral stage and rate of change. Thus, the level of accuracy (the extent to which a measured value approaches the true value) and precision (the level of numerical exactness) needed will vary depending on the manager's objectives, the scale of the problem, the statistical confidence level required, and the resources available to answer the question.

\subsection{METHODS OF MEASURING PLANT COVER}

\subsubsection{Semiquantitative Methods}

Measures of plant cover have included semiquantitative and quantitative methods (Bonham, 1989; Kent and Coker, 1992). Semiquantitative methods, such as those of Braun Blanquet, Daubenmire, and Domin-Krajina, include cover scales, classes, or ratings that represent a range of percent cover values (Bonham, 1989). Six to twelve cover classes or ratings permit a rapid characterization of plant cover within a plant community and often give good relative comparisons between communities or stands. The scales are usually more sensitive to lower cover values or changes in these cover values and less sensitive to higher cover values or their changes. For example, a scale value (cover rating of 1) at the low end of the scale may range from only a trace of cover up to 1 percent cover (range of 1 percent cover), while the next scale value (cover rating of 2) may be from 1 to 5 percent cover (range of 4 percent cover), while values further up the scale (cover rating of 4) may be 50 to 75 percent cover (range of 25 percent cover). In short, the interval of cover in most semiquantitative methods is unequal and often skewed at the lower end of the scale.

Most often the semiquantitative techniques have been used to describe plant cover within forests where cover is quite variable by species. Use of these semiquantitative methods is more sensitive to species with lower cover as might be needed to detect invading species or small plants infrequent in the plant community. These methods are based on that fact that precise measures of differences in percent cover (e.g., 1-5 percent) are usually not needed to describe plant communities because of the inherent variability in cover (e.g., 5-10 percent) over space and through the year (e.g., 3-5 percent) within the same plant community (Hessing, et. al., 1996).

\subsubsection{Quantitative Methods}

Quantitative methods for measuring percent cover have included such techniques as satellite image-processing methods, aerial photographic methods, mapping and charting using gridded quadrats or pantographs, ocular estimates of area (area-lists), intercept techniques (point intercept, grid quadrat frame, point frame, single points, cross-wire sighting, line intercept, combined line transect, and point intercept), loop methods, crown diameter and canopy closure methods, plotless methods, Bitterlich's variable-radius method, and the point-centered quarter method (Bonham, 1989; Kent and Coker, 1992). Considerable effort has been made in the past to compare methods for accuracy and to identify which techniques work best on different vegetation types. At the very heart of these efforts is the need to obtain the most accurate 


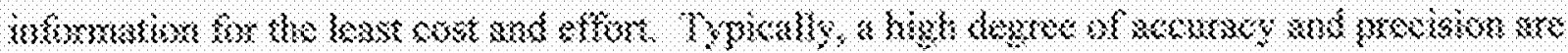

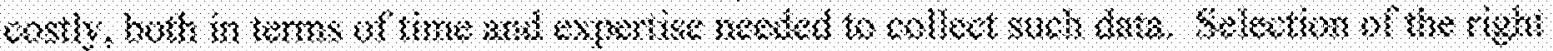

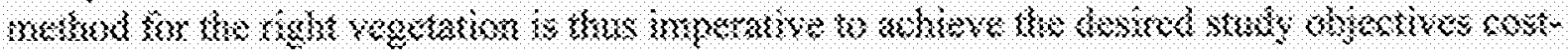
stextrols.

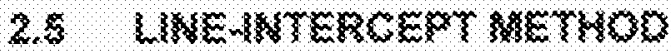

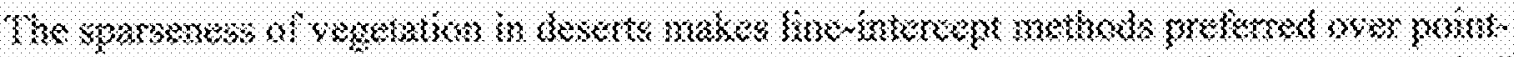

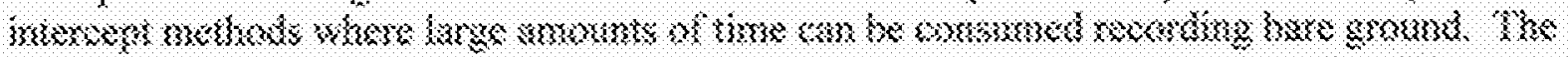

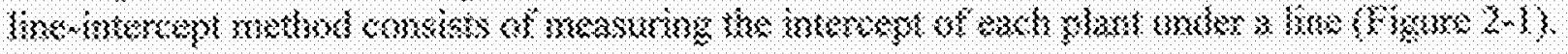

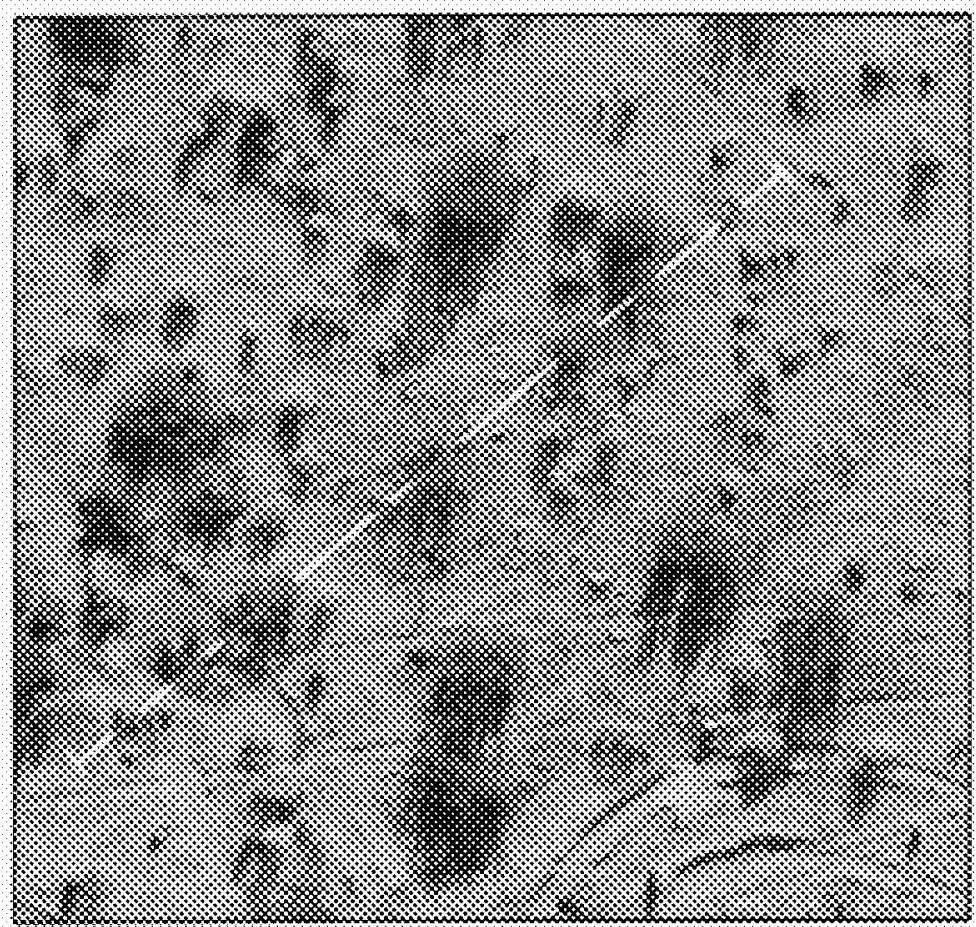

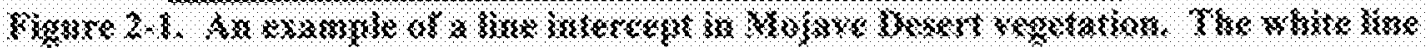

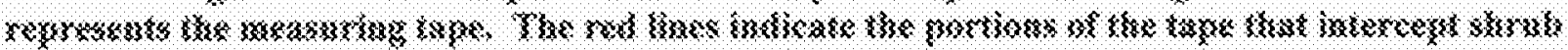

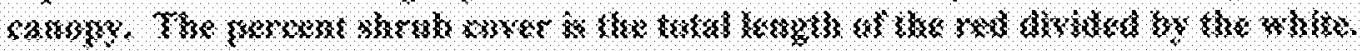

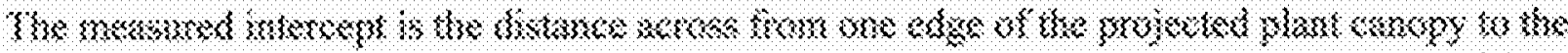

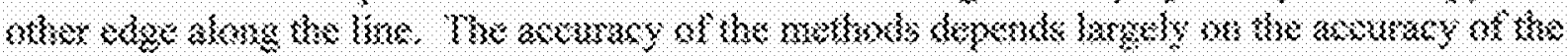

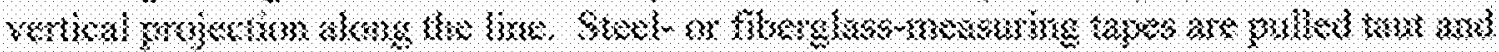

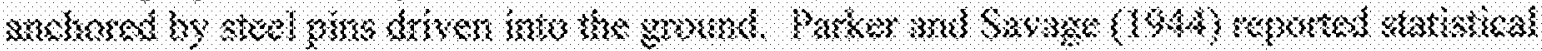

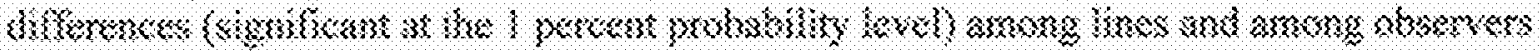

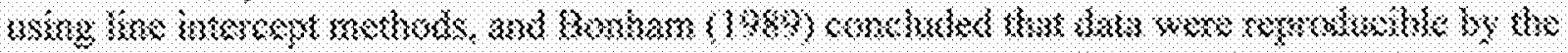

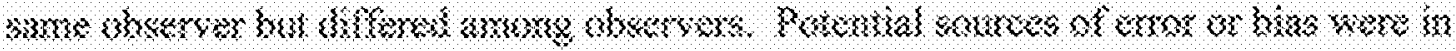

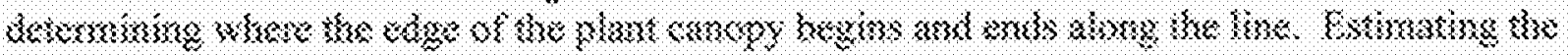

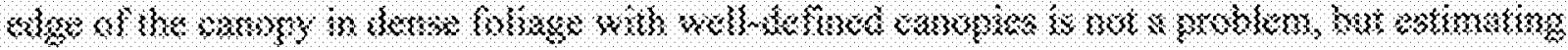

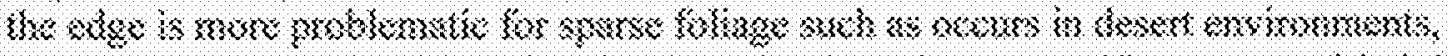

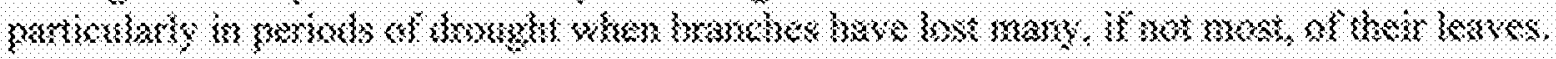


There may also be a small error factor that is associated with rounding the linear distance off to the nearest unit of measure (e.g., nearest 1 millimeter $(\mathrm{mm}), 1$ centimeter $(\mathrm{cm})$, or $10 \mathrm{~cm}$ ). Despite these sources of error, the measurement of plant cover using the line intercept method still provides one of the best methods to estimate cover in desert vegetation. Disadvantages of using the line-intercept method are that it is time consuming, generally requires two workers, and measures only a small portion of the total area being assessed.

In order to statistically estimate how many meters of line intercept are needed to adequately sample the mean shrub canopy cover of a Mojave Desert plant community at different confidence levels, 30, 10-meter-long line intercepts were randomly located along the north-south and east-west axis of a square plot. The transects were located within a relatively homogeneous, undisturbed plant community at the Nevada Test Site (NTS) according to methods described by Chambers and Brown (1983) and Bonham (1989). The community was dominated by creosote bush (Larrea tridentata) and white bursage (Ambrosia dumosa) with occasional Joshua trees (Yucca brevifolia).

The mean shrub canopy cover was estimated to be $29 \pm 1.5$ percent with a standard deviation of 8.398 and a sample number of 30,10 -meter transects. The number of 10 -meter transects required to achieve a 90 percent, 95 percent, and 99 percent confidence level was 24,34 , and 62 , respectively. It is estimated by Bonham (1989) that it requires approximately 30 seconds per meter per person for a two-person team to read and record the tape. To meet the minimal sampling at the 90 percent level this would require 24,10 -meter transects and require a team of two people approximately 2.0 hours to complete (i.e., 4.0 person hours). This estimate is based on an average of 30 seconds per meter per person for the line-intercept technique and does not take into account time required traveling to and from the site and preparing the tape for the measurements. Also, these estimates are based on undisturbed site conditions. In disturbed plant communities, the variability increases dramatically requiring more meters of transect to achieve a given level of statistical confidence. Experience by the authors at the NTS suggest that two trained technicians can complete no more than approximately 30,10-meter transects per day, suggesting that Bonham's estimates should be considered low for vegetation in the Mojave Desert.

\subsubsection{Application of Aerial Photographs for Line Intercepts}

Attempts to reduce the amount of field time needed to conduct line-intercept measurements have been made by photographing the vegetation at various scales (usually aerial photographs) during periods of optimal cover (e.g., during the spring when cover is near maximum and species identification is facilitated) and then overlaying measuring rulers or tapes to measure the intercept on the photograph or a 35-mm slide projected onto a wall or screen (Chambers and Brown, 1983). This provided the additional advantage of being able to measure more than one intercept line within a community and makes validation of prior measurements possible.

\subsubsection{Photographic Scale for Aerial Photographs}

Photographic scales used for analyses of aerial photographs for plant cover vary, but generally range between 1:2000 (1 horizontal unit on the photo equals 2,000 horizontal units on the 
ground) for shrublands to 1:16000 for woodlands, although Uuttera (Uuttera et al., 1998) concluded that at least a photo scale of 1:5000 was needed to determine spatial pattern of trees in forest stands in Finland. Photo scales less than 1:2000 (e.g., 1:1000) may be required for working in grasslands and may require modifications in the aircraft (helicopter vs. fixed wing), lens (telephoto lens vs. normal lens), or film speed (faster vs. slower speed films). Their use at these scales may be restricted to areas that are flat. The reason for this is that the aircraft goes so fast so close to the ground that blurring due to aircraft speed and safety become issues. The minimal altitude for a fix-wing aircraft is about 1,000 feet. Commercial aerial photographic services can usually accommodate these higher resolution needs with advanced planning. Forward motion compensation drives on newer cameras move the film to adjust for the speed of the aircraft to reduce blurring. Photographic scales larger than 1:16000 (e.g., 1:24000) are restricted to forested lands with large shrubs (e.g., mesquite [Prosopis spp.]) and study objectives where there is no need to differentiate between similar species (e.g., pinyon [Pinus monophylla] vs. Utah juniper [Juniperus osteosperma]) or individual plants of a species (e.g., oak [Quercus spp.] or willows [Salix spp.]).

\subsubsection{Optimal Scale for Aerial Photographs}

The optimal (film) scale for line-intercept analyses is generally that scale where photographic details permit the clear differentiation between species and their canopy edges. The optimal scale varies depending on the plant species in the community, the time of year, the time of day (sun angle $>30$ from the horizon or about 3 hours after sunrise to 3 hours before sunset) (Falkner, 1995), and the quality of the photographic lens (e.g., faster lenses like $f$ 1:1.7 reduce blurring,due to aircraft forward motion and coated lenses reduce slight color shifts bent by the glass lens elements, and film type (e.g., Kodak ${ }^{\circledR}$ Royal Gold has an extremely fine grain size and a very high resolution). Colored prints are preferred over color infrared (CIR) positive film or black and white prints. Because of the false red color of vegetation in CIR film, they are harder to interpret than normal color prints in desert environments with sparse vegetation. Photographic films may be enlarged on print paper by a factor 2 to 4 without sacrificing quality; however, greater enlargement merely enlarges film graininess, scratches, dust, or lint on the film; it does not compensate for lack of original lens sharpness. Printing to paper using an antivignette filter can enhance the quality of a picture by removing the normal darkening of the image at the edges of the photographs created by the lens elements. Alternatively, using just the center of the photographs can also help minimize the effects of vignetting (a normal overlap of photo coverage is about 60 percent end lap and 30 percent side lap).

A good method for determining the optimal scale is to select a flight line that crosses several plant communities of interest where the need to differentiate between species is greatest. Select several altitudes to fly resulting in multiple scale photos, for example: 1:2000 scale, 1:4000 scale, 1:8000 scale, 1:16000 scale, and 1:32000 scale. Film positives, negatives, or printed photographs can be analyzed for photo details and the optimal scale selected. Once the optimal scale is determined, a second flight can be made to record the areas of interest. Registration marks can be laid out on the ground using white cloth or plastic (e.g., $1 / 2$ meter wide and 2-4 meters in length in the shape of a cross pointing to the cardinal directions of north, south, east and west). The marks help guide the pilot and can be used to properly orient the photo for georectification in a Geographic Information System (GIS). If funding limits the overflight to 
just one flight, then it is best to obtain the largest scale (1:2000 to 1:4000) that you can afford. The smaller scale photos $(1: 16000$ to $1: 24000)$ can often be used to provide image backgrounds for GIS displays.

In the Mojave Desert, scientists at BN have determined that 1:2000 scale photographs were adequate for distinguishing between cover of Joshua tree, creosote bush, white bursage, and generic grass cover. A photo scale of 1:4000 could also be used, but was less capable of distinguishing grass cover. A photo scale of 1:8000 had difficulty in distinguishing small.shrubs, but was good for distinguishing cover of medium to large shrubs of creosote bush from Joshua tree. A photo scale of 1:16000 could only distinguish larger creosote bushes. Photo scales of $1: 24000$ or smaller $(1: 32000)$ were limited in use and scientists could only distinguish very large creosote or generic trees in pinyon-juniper habitat from sites located in the Great Basin Desert on the NTS.

\subsection{DIGITAL TECHNIQUES FOR THE MEASUREMENT OF PLANT COVER}

\subsubsection{Digital Imagery and Software}

The measurement of plant cover using software to evaluate digital images provides an even more efficient means of rapidly measuring image parameters than merely measuring intercepted plant cover on photographs or projected images by hand. With the availability and relatively low-cost digital scanners, cameras, and relatively fast personal computers, new approaches are being developed to measure plant canopy cover and to automate the calculation of percent coverage. Most of these techniques, however, are still in their infancy.

Previous applications and software development have been primarily used in the fields of medicinal, industrial, and GIS. They include such tools as fluorescence imaging, microscopic analysis, cell analysis, criminal forensics, industrial materials testing, and supervised/unsupervised classification. There has also been considerable development in imageprocessing software for manipulation of remote sensing satellite and aerial photography at relatively small scales (pixel sizes ranges from $30 \mathrm{~m}^{2}$ to $1 \mathrm{~m}^{2}$ with the newest IKONOS satellite imagery). These software include applications in GIS (e.g., ERDAS Imagine ${ }^{\circledR}$, and ESRI's ArcView Image Analysis ${ }^{\circledR}$ extension for ArcView, and Geomatica ${ }^{\text {. }}$. However, most of the : medical and industrial software has focused on microscopic images (magnification levels of $10 \mathrm{X}$ to $100 \mathrm{X}$ ), while GIS software has focused on satellite imagery for small-scale aerial photography not large-scale photography. There have been few applications of software packages to imagery of intermediate scales $(1: 1000$ to $1: 10000)$.

With the introduction of the personal computer, high-resolution digital printers, and the need to publish digital images on the Internet, a wealth of sophisticated image manipulation software tools, such as Adobe Photoshop ${ }^{\circledR}$, Corel Photo Paint ${ }^{\circledR}$, and Microsoft Paint ${ }^{\circledR}$, have also recently been developed. These permit the use of filters, sharpening techniques, histogram stretching, and other image-editing capabilities. 


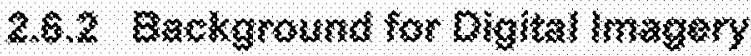

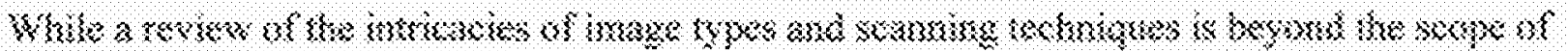

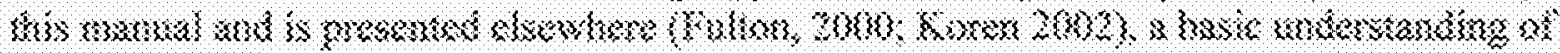

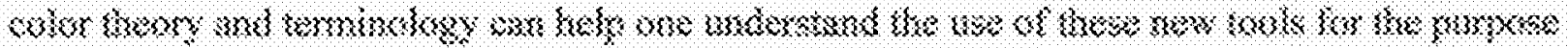

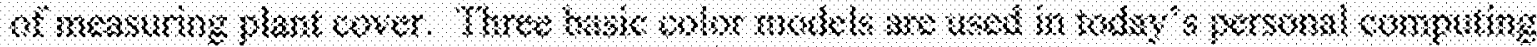

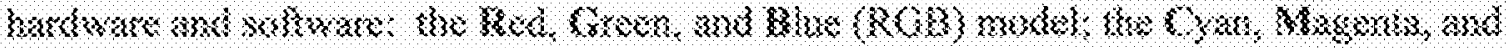

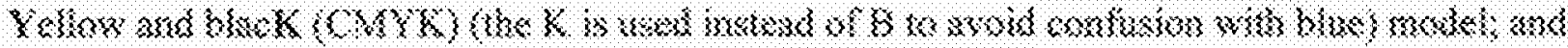
the ansy-sake morat.

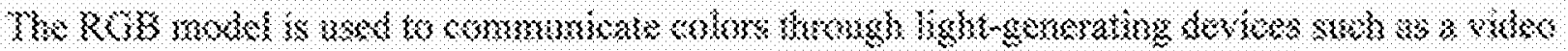

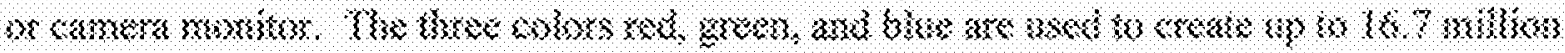

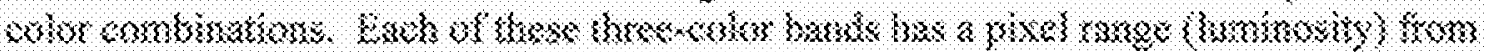

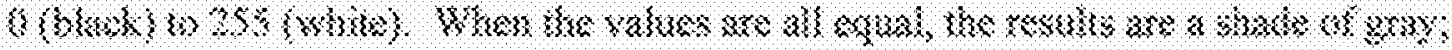

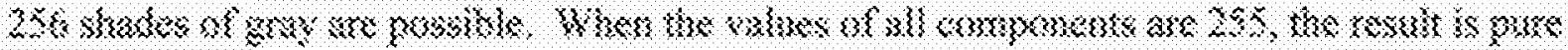

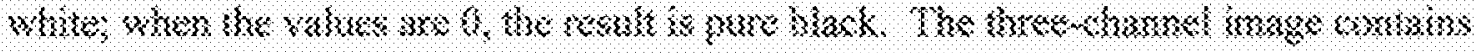

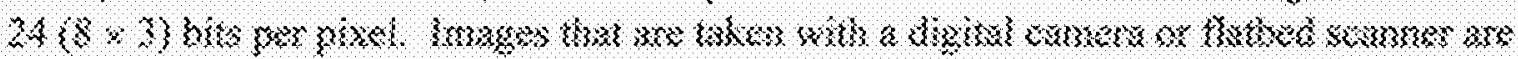

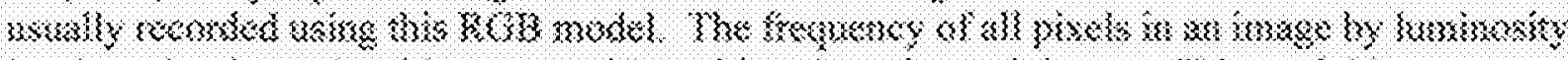

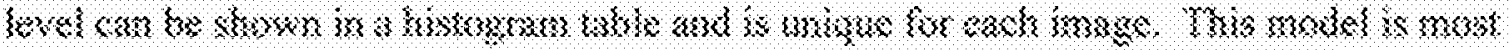

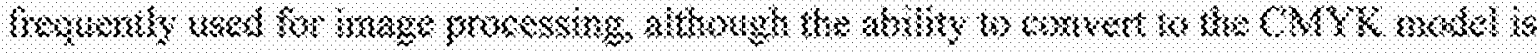

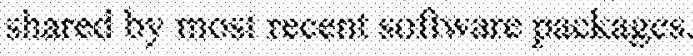

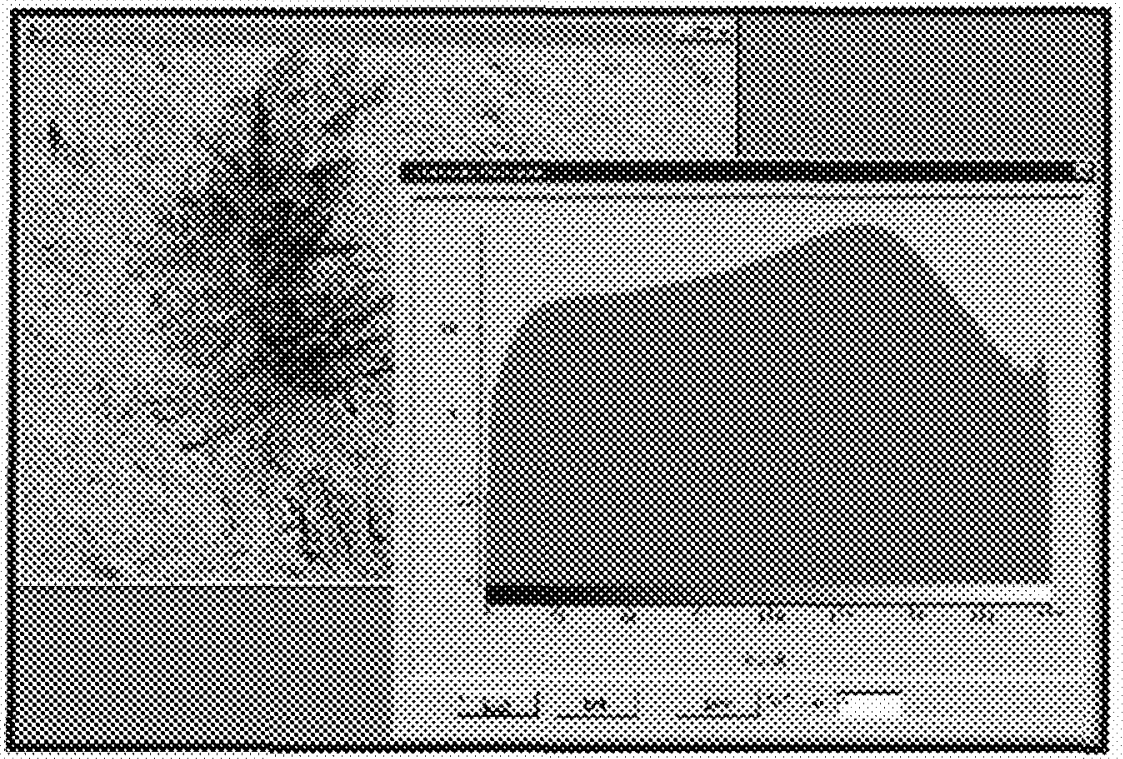

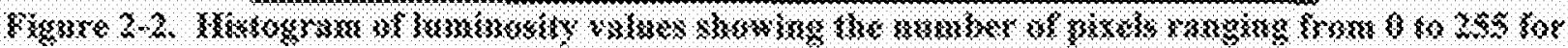

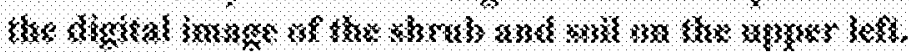

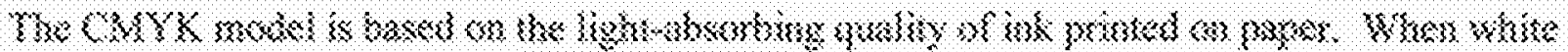

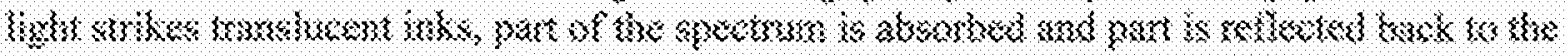

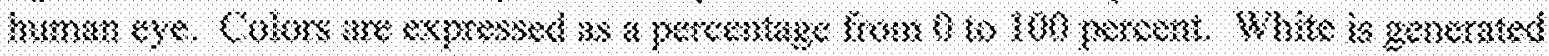

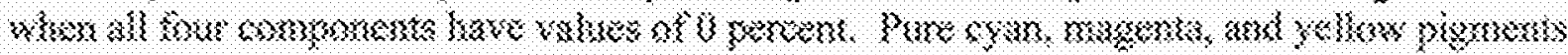

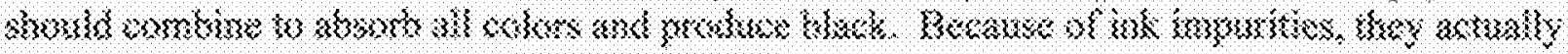


produce a muddy brown and must be combined with black ink to produce true black. The four-channel image contains $32(8 \times 4)$ bits per pixel. Printers use this model for creating inkjet color copies. It may also be used to create color separations for professional printers. Edited images from the image-processing software frequently use this model to print their final images. Subtle differences in color may occur between the image viewed on a monitor and the image viewed from the printer. Additional software to calibrate the monitor (e.g., gamma or whiteness level) and printers are available (e.g., PANTONE ${ }^{\circledR}$ Personal Color Calibrator).

The gray-scale model is a simplified black and white model from the RGB color model in which the channel values are combined into only one channel with 8 bits per pixel. There are 256 possible values for a pixel using this model with pixel values ranging from 0 (black) to 255 (white). Information for certain shades may be lost because the colors and their gray-scale counterparts are weighted, that is certain colors are weighted more than others to more closely match what the human eye perceives or to achieve a desired effect (e.g., darkening or lightening skies, soil, or vegetation). Most conversion software allows one to alter the weighting factors which has the effect of lightening or darkening the midtones. This may be helpful to accentuate the greens in vegetation or bleach out color from the reddish or brownish soil for better contrast between vegetation and soil. When the image to be analyzed is lacking in color information because of enlarging or because the film failed to capture differences in color as may happen with variations in exposure speed, chemical processing, or subdued lighting, then gray-scale images may convey all the information needed for measurements of plant cover. The file size of images converted to gray scales are about $1 / 3$ the file size of RGB files or $1 / 4$ the files size of CMYK files and can, therefore, conserve hard disk space or other storage space. 



\subsection{IMAGE-CAPTURING TECHNIQUES}

Many image-capturing techniques have been developed to provide imagery at a variety of scales and on different types of film and media. Digital recording equipment has been developed recently that provides images that equal or surpass the quality of many films and prints. Advances in film and flat-bed scanners also provide a means of converting images from film or prints to digital images. A discussion follows of the types of platforms for capturing images, cameras and lenses, and films and recording media.

\subsection{TYPES OF PLATFORMS FOR CAPTURING IMAGES}

The scale of the image is frequently determined by the camera lens and how close to the subject the camera is placed! Except for ground-based tripods or hand-held poles, most of the platforms for securing and positioning the camera are mounted on some sort of aircraft. There are pros and cons to all of the platforms described here. A comparison of platforms for capturing images is shown in Table 3-1. They range from relatively inexpensive to very expensive. The level of sophistication also varies significantly between platforms. Availability of imagery varies through the year based on availability of range time for the aircraft. The scale of the imagery is also highly determined by altitude, which in turn is federally regulated.

\subsubsection{Tripods and Hand-Held Poles}

When it is necessary to record panorama scenes or document large rectangular research plots, an oblique-angle (i.e., not a right angle) photo can be taken by standing on top of a vehicle (e.g., cab of a pickup truck) or from an elevated position such as a stepladder. An oblique-angle photo may also be used to capture silhouettes of shrubs for the purposes of measuring foliage density. The best color and contrast are obtained when the picture is taken in full sun with the sun angle at the back of the person taking the picture (i.e., facing away from the sun rather than looking into the sun where sunbursts and other reflections on the camera lens may obscure details and color).

It may also be desirable to capture images that are nadir (i.e., pointed directly down or at a right angle to the ground). This is helpful when attempting to document the details of vegetation in small plots from above (e.g., germinating seedlings in $1-2 \mathrm{~m}^{2}$ plots). The support pole is hand-held such as the one shown in Figure 3-1. Pictures can be taken using the self-timer feature (e.g., as when taking self-portraits). Digital cameras work best because they are lighter and permit viewing immediately following the exposure. If the picture alignment is not proper, the camera can be repositioned and the picture retaken before moving from the site. When photographing nadir pictures with film, use a wide-angle lens, a slow-speed film (enhances details), and crop the image to the plot boundaries. Mounting hardware is readily available at most stores and consists of a $1 / 4$ inch SAE (Society of Automotive Engineers)-thread type (which is the same as a tripod-thread type) with rubber (for friction) and metal (for support) washers to secure the pole to the camera. The camera angle can be adjusted by rotating (tightening or loosening) the camera on the mounting bolt. Telescoping aluminum poles work well as extensions (e.g., those used for painting, window washing, or skimming debris from swimming pools). Duct tape can be used to wrap around smaller poles to secure a snug fit. 


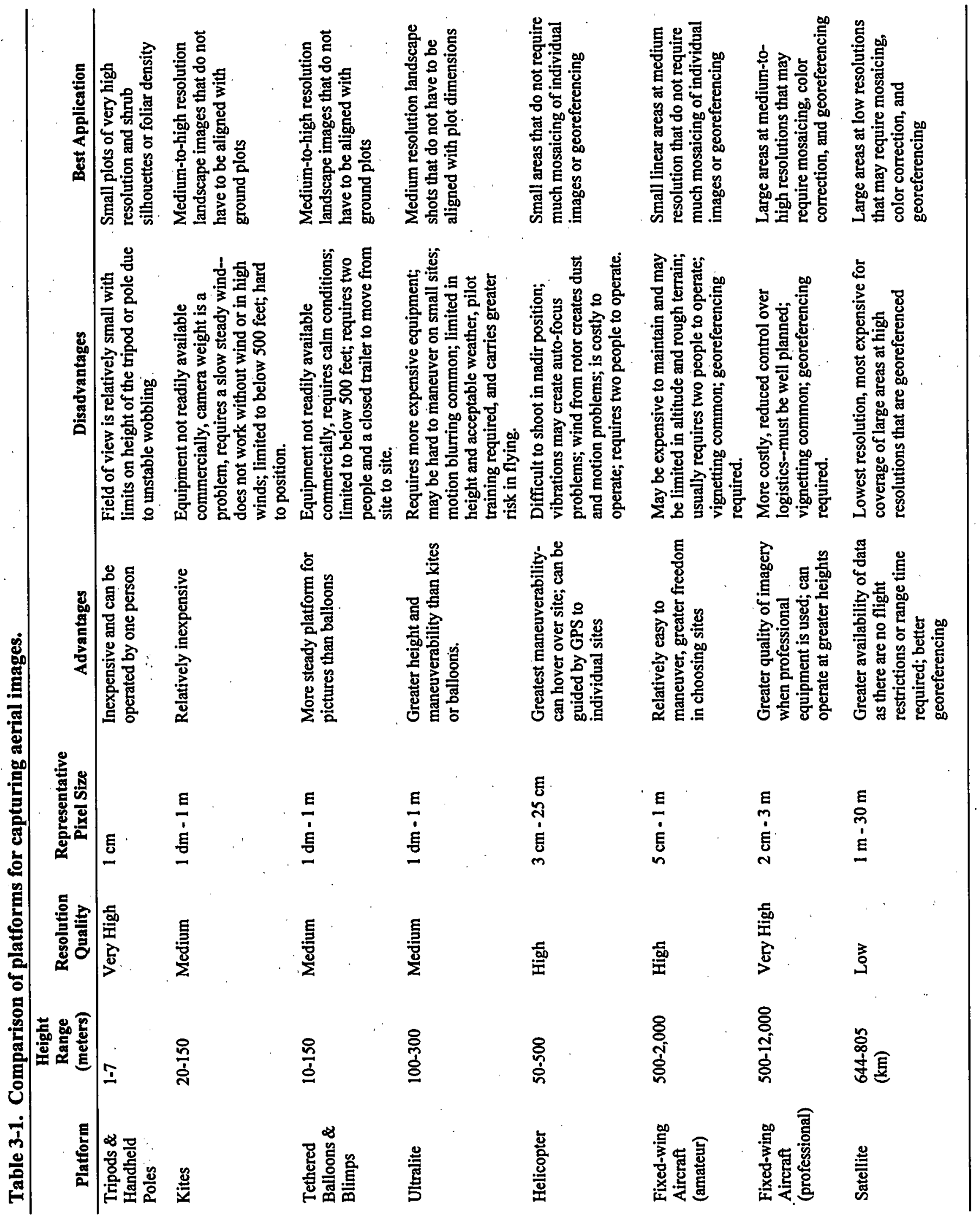




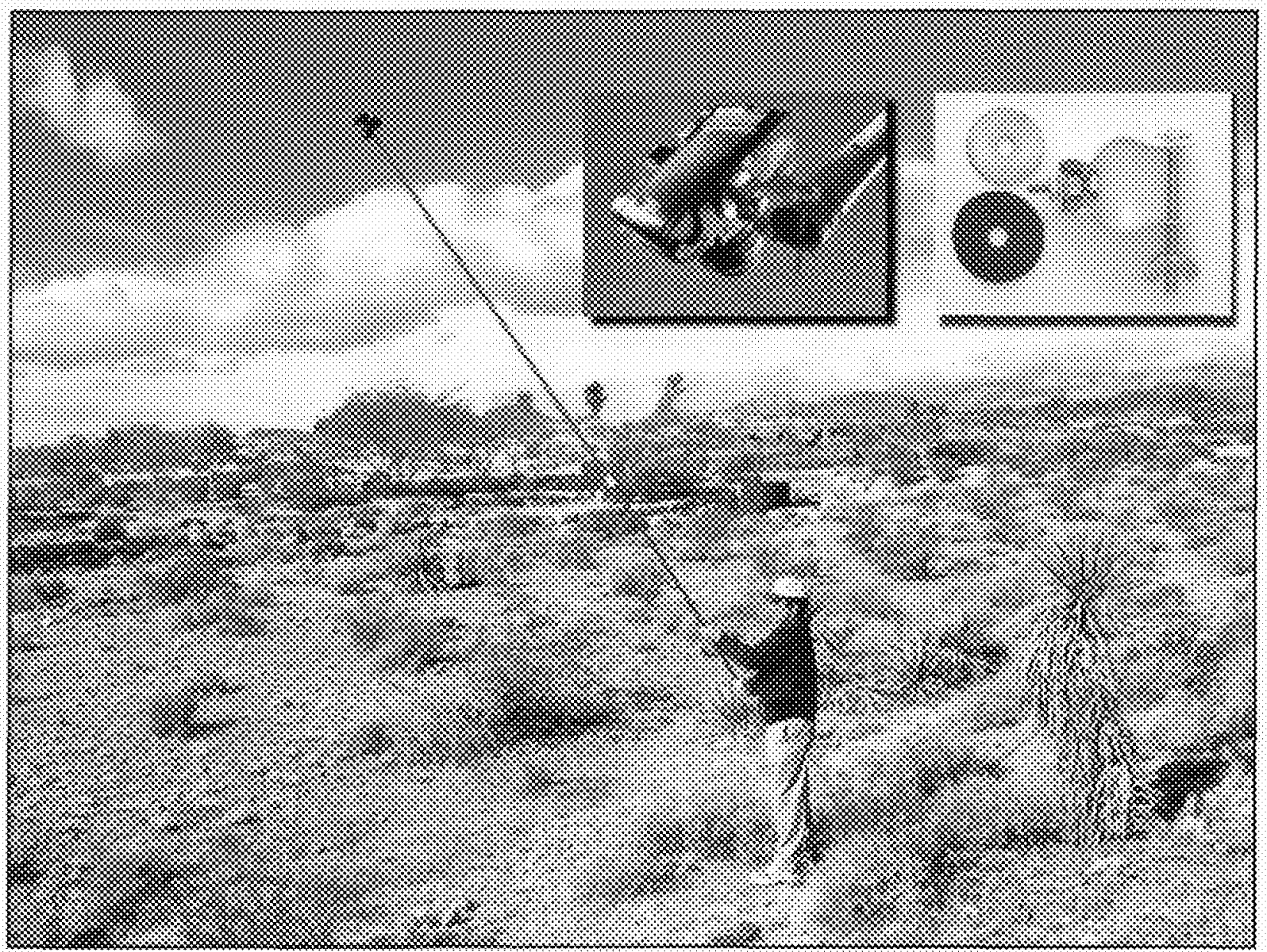

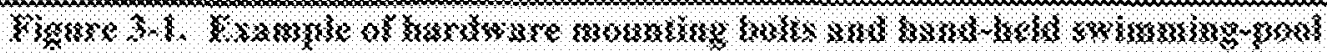

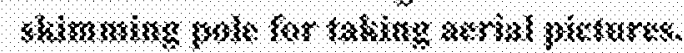

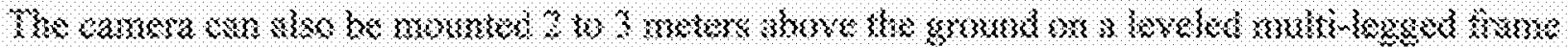

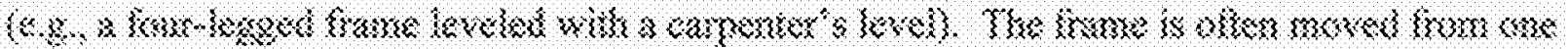

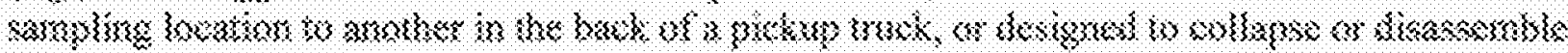

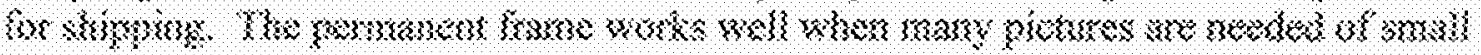

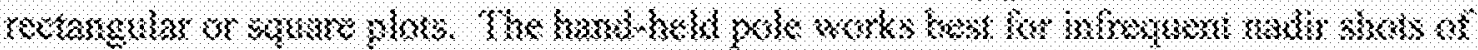

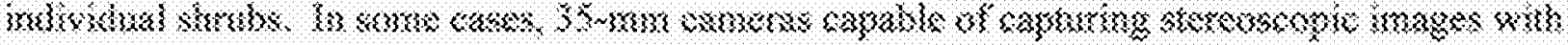

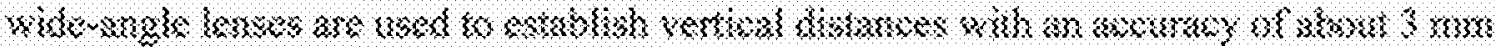

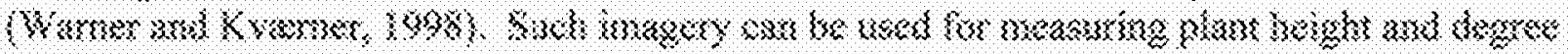
of and exusion.

\subsubsection{Kites}

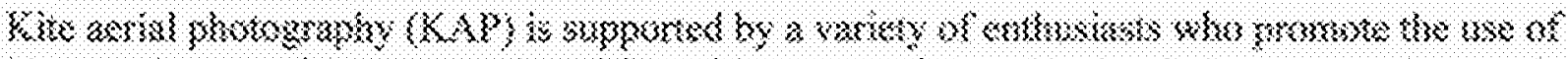

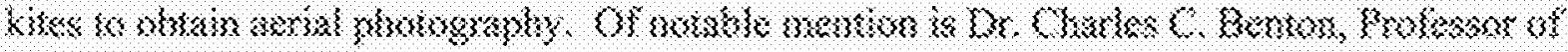

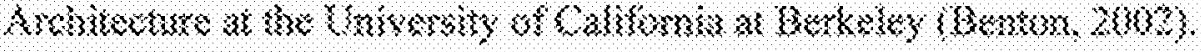


KAP is best suited to those who want oblique aerial photographs of the landscape that do not require alignment with rectangular plots on the ground or have to be repeated at exactly the same location over time. The disadvantages of using kites as a means of obtaining aerial photographs are that it requires a relatively high skill level in flying large kites (much more sophisticated than small recreational kites) and a need to secure, assemble, and operate electronic remote control camera equipment. It also requires proper wind conditions (e.g., 4 to 20 miles per hour (mph)) and a good deal of patience in fine-tuning the technique. Calm weather makes kite flying impossible, although low to medium wind speeds can be accommodated by selecting kites of different sizes (e.g., smaller kites for higher wind speeds and larger kites for lower wind speeds). In order to properly operate the system, it is helpful to have two people--one to secure the kite and one to walk the kite down. Because of the high tension on the line (250-pound test line), it is not recommended that the kite be pulled to the ground by winding the line on a reel (i.e., this may split or collapse the reel from the tension).

Due to U.S. Federal Aviation Administration (FAA) regulations, the maximum kite altitude that can be legally flown is 500 feet (higher altitudes, if permissible, have to be cleared with the FAA). These regulations require that visible flags be placed at spaced intervals on the kite string above 150 feet. It is a good idea to clear all kite flying on military training ranges as these ranges are frequently used by military helicopters. The flying angle of the line ranges from $50^{\circ}$ to $70^{\circ}$ (approximately 730 to 822 feet, respectively, of line at 500 feet altitude) depending on the type of kite.

Camera weight is critical, however, the development of new miniature video camcorders and transmitters (e.g., less than 1.5 inches $\times 1.5$ inches $\times 1.5$ inches) and digital cameras will make the future of KAP more promising. The choice of camera is usually (a) an inexpensive one because the kite can crash unexpectedly and (b) one with a fast, wide-angle lens (e.g., f/2 and $28 \mathrm{~mm}$ ) which gives a wider angle of view and faster shutter speed to reduce motion blur. An ultraviolet filter is recommended to protect the camera lens. Film usually consists of a 24-exposure roll with a medium-to-high speed (e.g., Kodak Royal Gold with an American Standards Association [ASA] of 200 to 400). A photo is frequently taken with every 100 feet of line let out (marked by black pen on the line). The focus is set at infinity so there is no need for auto-focusing cameras that actually hinder proper focusing due to the kite motion.

The cost to purchase a KAP system will range from $\$ 500$ to $\$ 1,000$ for a kite, camera, and remote controls. More advanced systems are rarely available from a single source and require the user to shop for parts from a variety of suppliers. Additionally, labor to put the system together and test and operate it should be factored in. This option is not recommended for the novice, but rather for those willing to learn a new sophisticated skill.

\subsubsection{Blimps and Balloons}

The first recorded air observations during a military battle were performed from a hot air balloon. More recently tethered balloons and blimps provide a means of supporting a camera and capturing images. The art of blimp aerial photography (BAP) is not as advanced as that of $\mathrm{KAP}$ because the balloons are reported to be more difficult to control in windy weather 


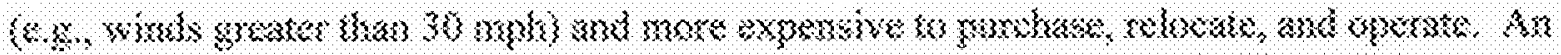

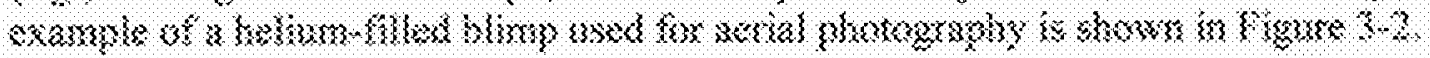

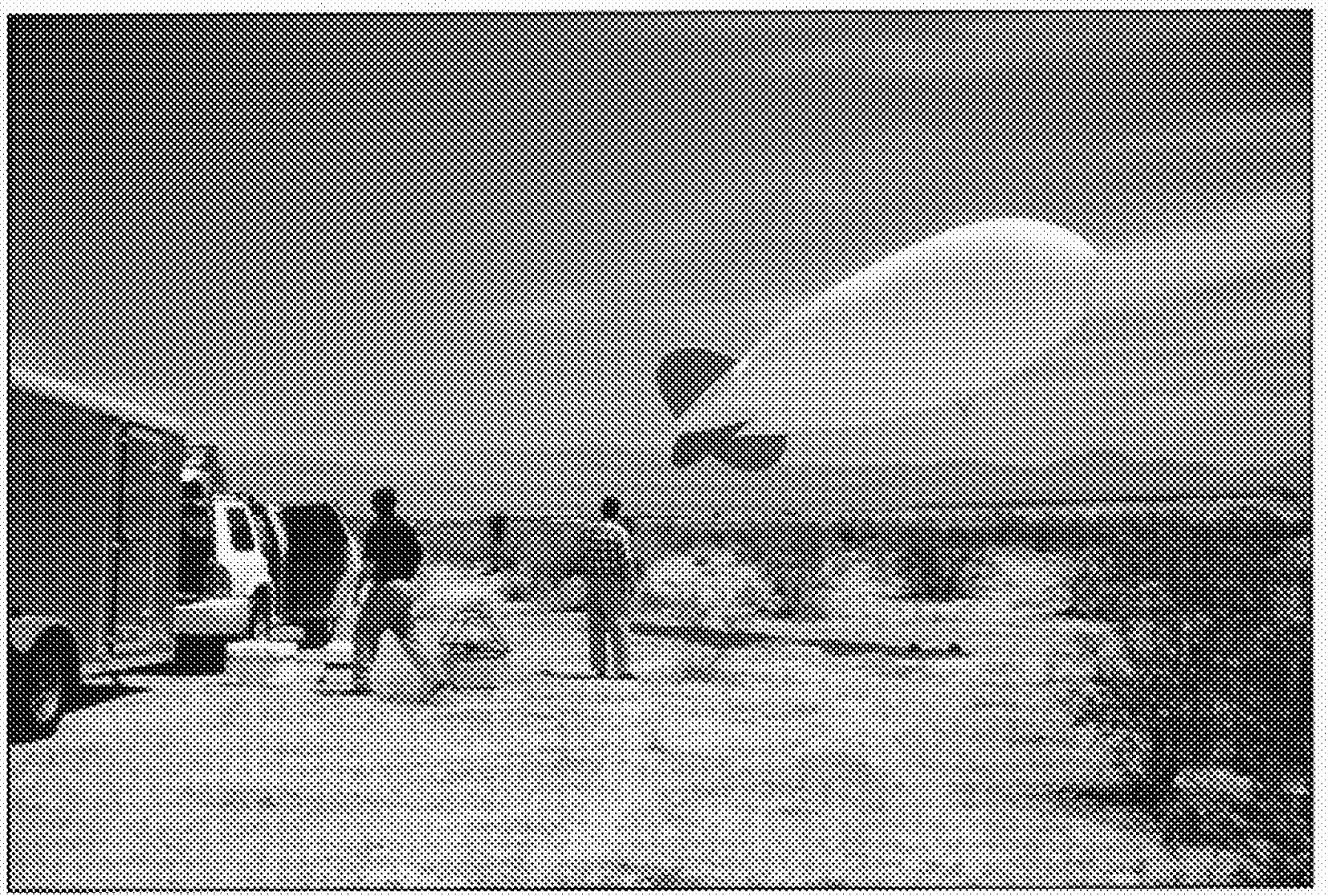

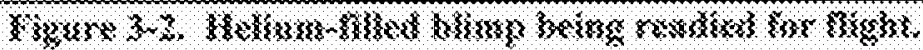

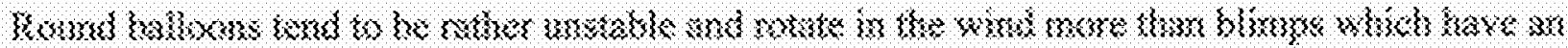

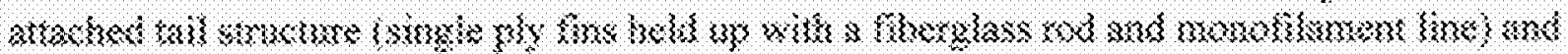

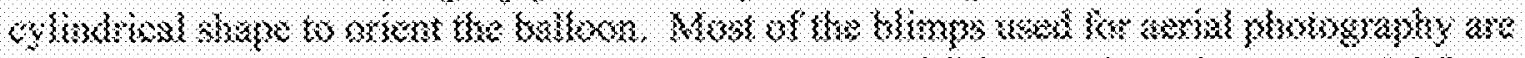

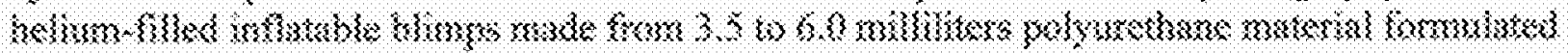

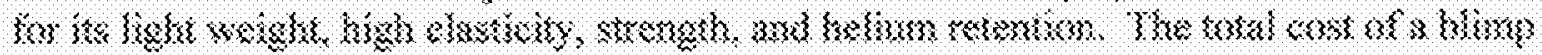

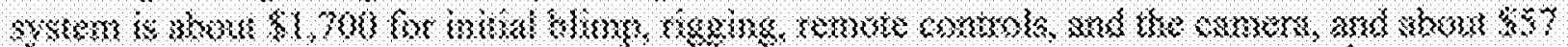

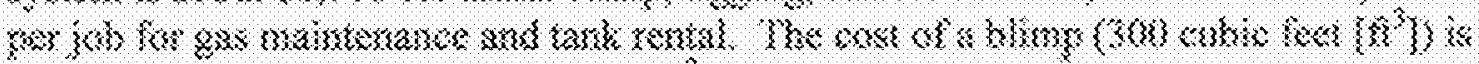

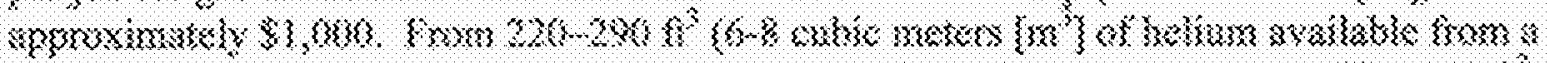

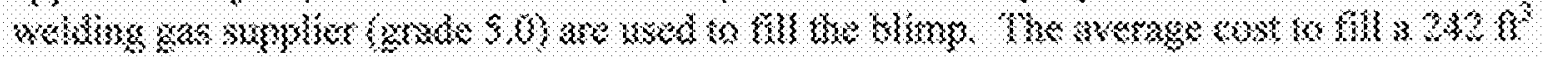

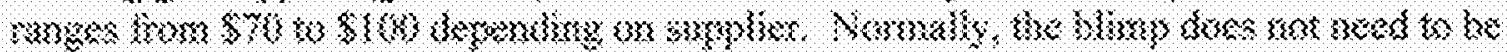

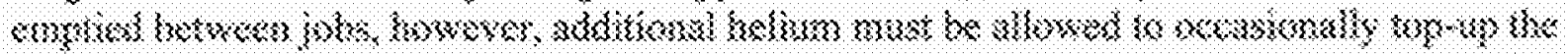

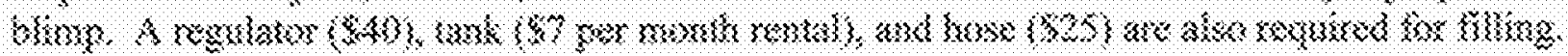


A blimp with a volume of approximately $300 \mathrm{ft}^{3}\left(8.5 \mathrm{~m}^{3}\right)$ will have a net lift of approximately 10 pounds (lbs) (4.5 kilograms). Small blimps with lifting capacity up to $47 \mathrm{lbs}$ are commercially available. It is recommended that the camera and rigging weight only about $1 / 3$ of the total lift: This allows sufficient lift for the weight of the line and any wind resistance. The buoyancy of the blimp is affected by temperature, barometric pressure, purity of the gas, and altitude (elevations above sea level). The regulated flight of a tethered (moored) blimp and balloon is the same as that for kites (500 feet above the ground).

The use of blimps is restricted in windy weather (wind speeds greater than 30 miles per hour [mph]). Winds tend to push the blimp to the ground and accelerate movement from side to side making it difficult to obtain good photographs. Unloading and landing blimps is also much more difficult in windy weather. Two people are recommended for launching the blimp. A covered trailer or truck is helpful if the blimp is to be transported to many sites, thereby, increasing operational costs. Deflating the balloon at each site is expensive, time consuming, and requires more care to prevent damage to the system. Radio-controlled positioning of the camera and shutter release are also more sophisticated and may require real-time feeds of black and white video signals to ensure that the camera is properly aimed at the target.

Like KAP more advanced systems for BAP are rarely available from a single source and require the user to shop for parts from a variety of suppliers. Additionally, labor to put the system together and test and operate it should be factored in. This option is not recommended for the novice, but rather for those willing to learn a new sophisticated skill. There are a few. commercialloperators that are skilled and provide aerial photography.

\subsubsection{Helicopters}

Helicopters provide one of the most versatile means of obtaining aerial photography. The aircraft is particularly well suited for moving directly from a base of operations to a target location. Global positioning systems (GPS) can help guide the aircraft to the approximate location. Ground targets (e.g., white plastic garbage sacks stapled in the form of an "+" on the ground) help the pilot locate the actual plot corners while in the air. Often helicopters are available on the base as part of related military training. Figure 3-3 shows a Blackhawk . helicopter. The cargo-hook door in the rear floor can be removed for easy nadir positioning of the camera. An alternative position is on the gun mount of the front-side window. Two people are preferred to obtain the best results. One person works with the pilot and directs the pilot, while the second person takes the pictures. Operators should be aware that taking pictures in this manner may make them vulnerable to air sickness due to the restricted field of vision through the door and the aircraft movement.

Because of vibrations caused by the rotors, camera motion may make auto-focusing features undesirable (e.g., the camera's computer seeks stationary vertical lines that may not exist). This may delay or prevent focusing or cause delays in shutter functions. Setting a camera on manual focus set at infinity works best. A fast lens (e.g., $\mathrm{f} / 2.8$ ) works best to control motion blur. A moderately fast speed film (e.g., Kodak Royal Gold film with an ASA of 200 to 400) can also increase focus and reduce motion blur. F-stop should be set to two stops below the maximum. 


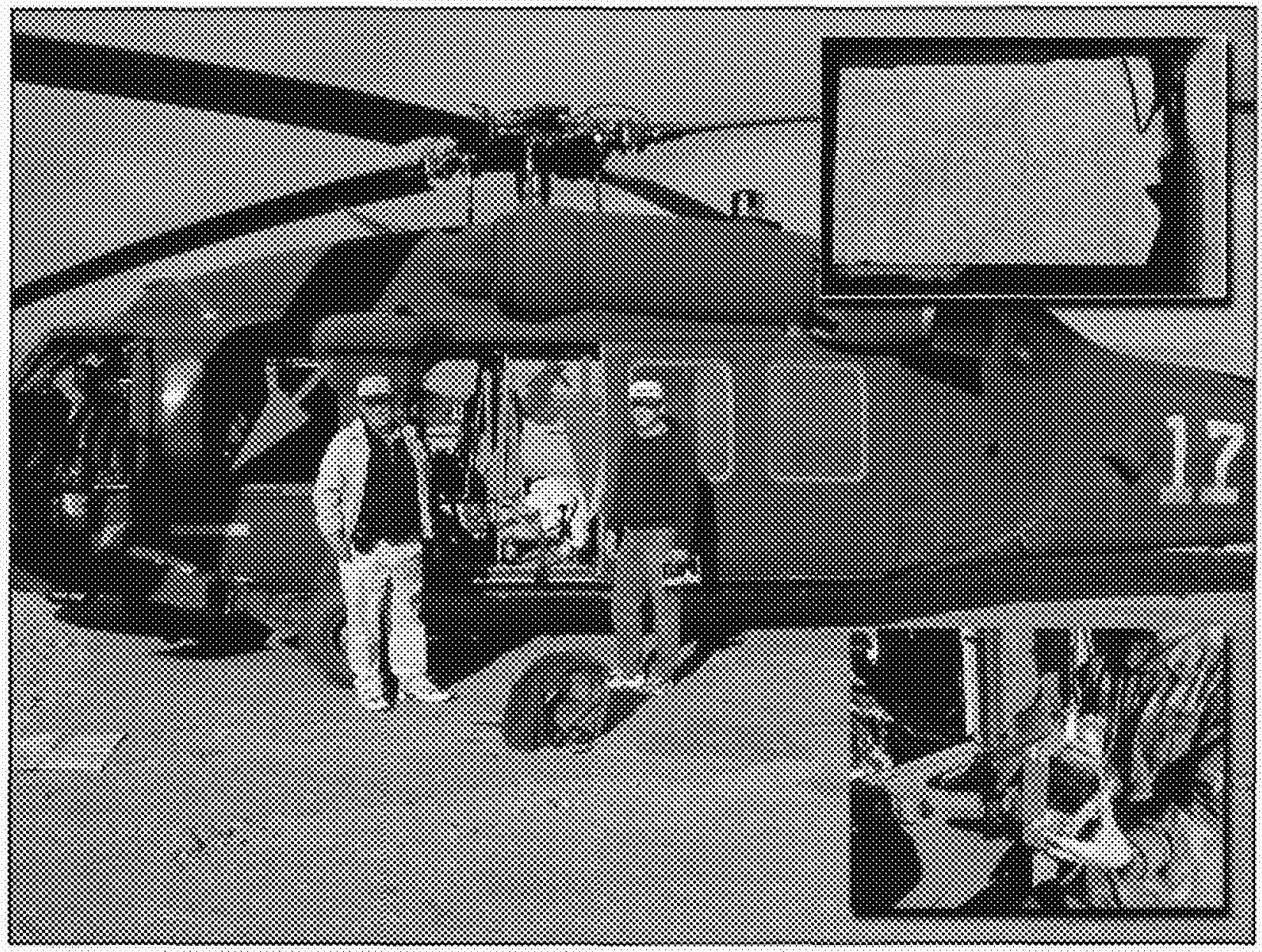

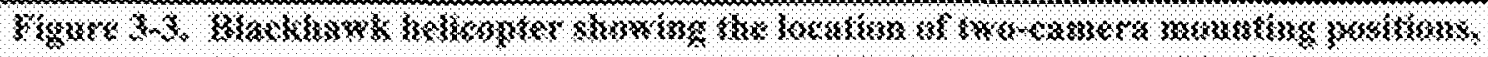

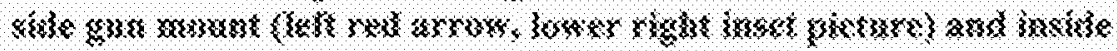

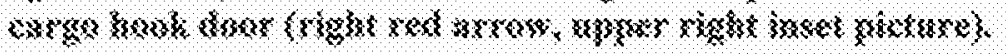

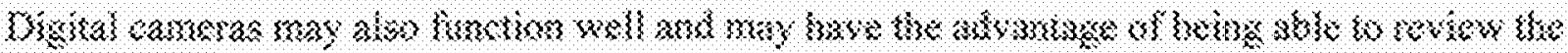

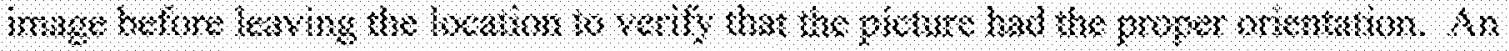

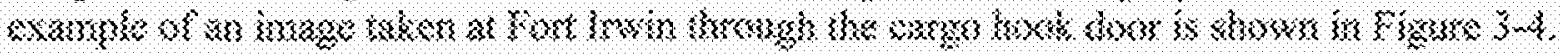

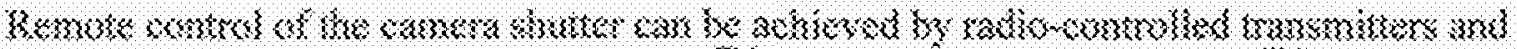

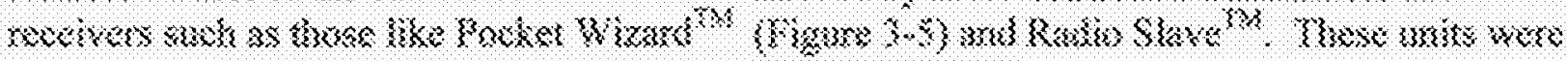

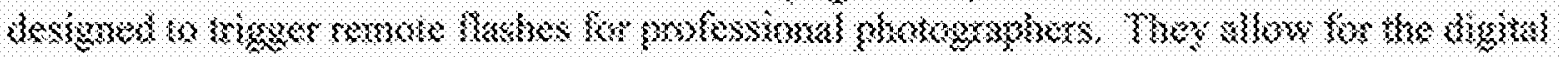

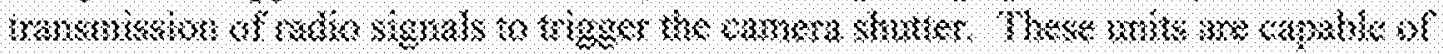

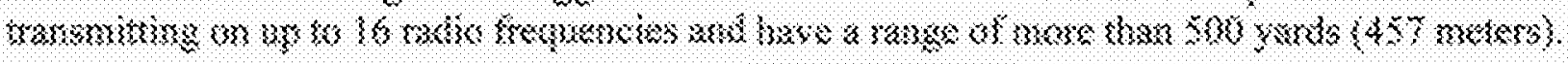




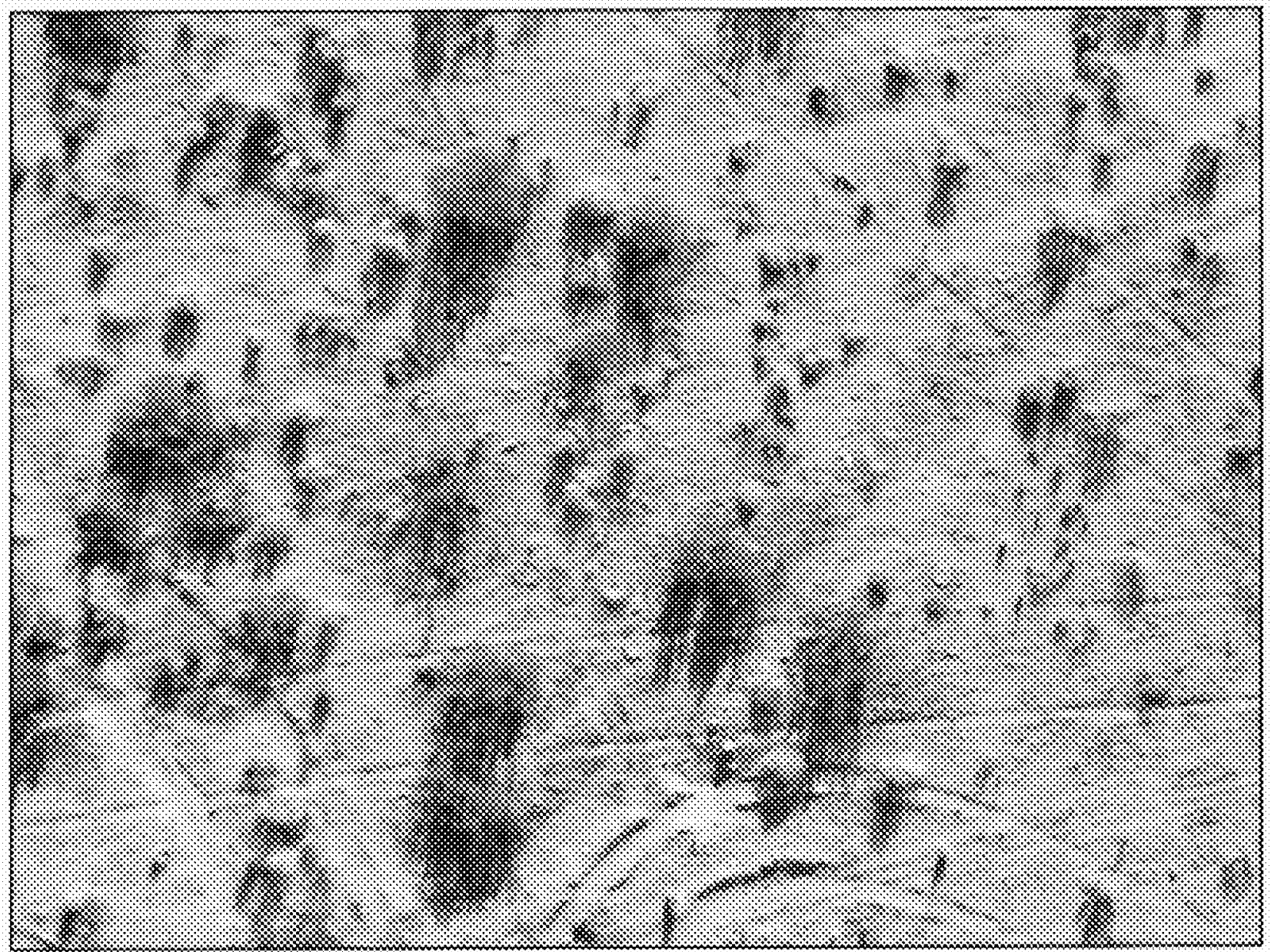

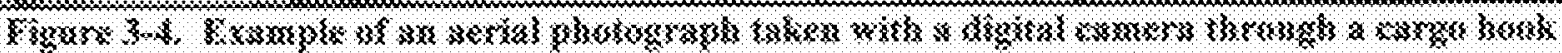

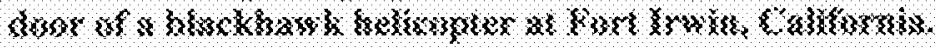

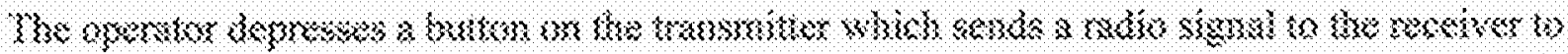

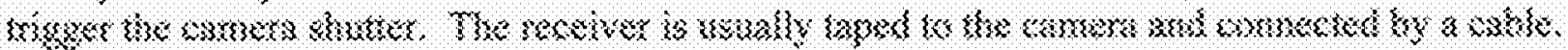

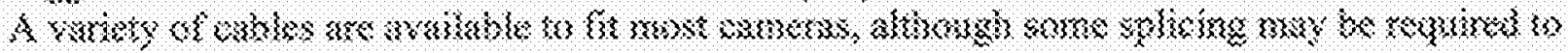

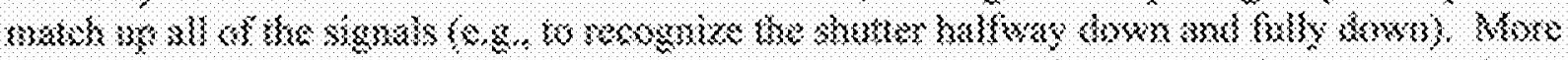

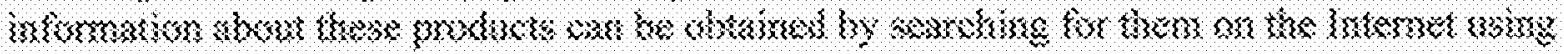

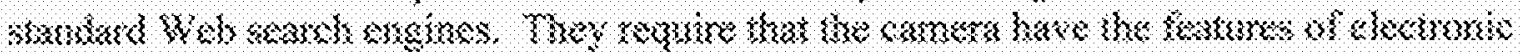

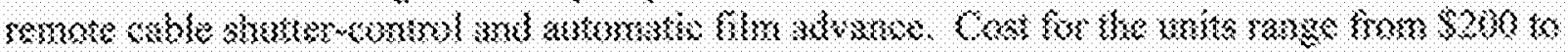

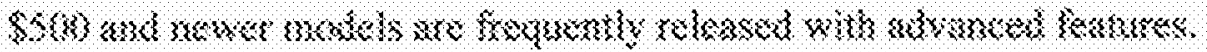




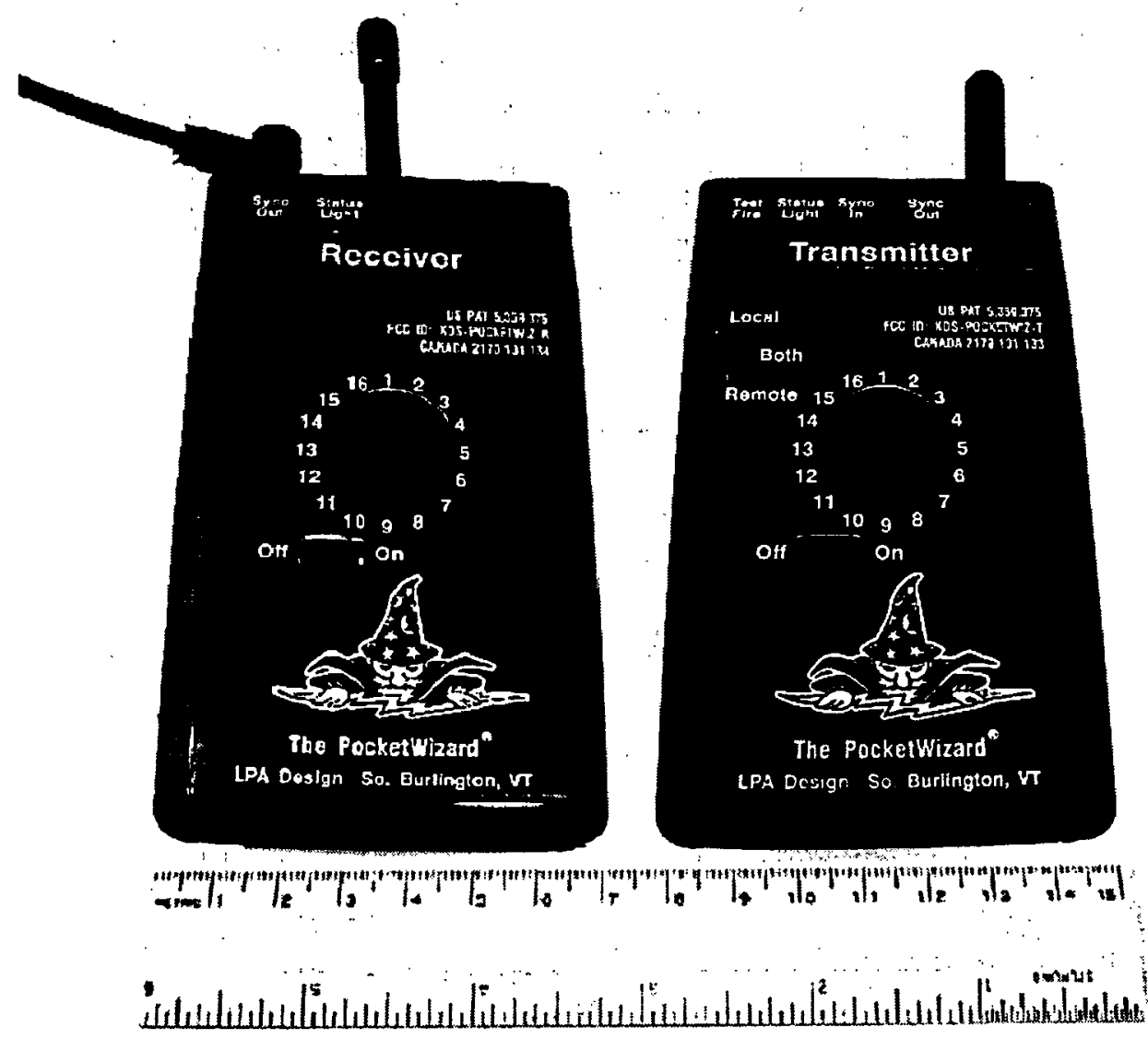

Figure 3-5. Examples of radio-controlled remote camera shutter transmitter and receiver.

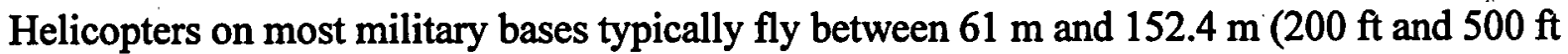

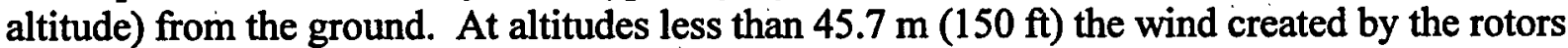
creates too much motion in the vegetation and stirs up dust that obscures details. Altitudes of greater than $152.4 \mathrm{~m}$ (500 ft) need to be coordinated with the U.S. Air Force to avoid conflicts. It is a good idea to review the flight plan and photographic objectives with the pilot well in advance to ensure that objectives can be met.

\subsubsection{Fixed-Wing Aircraft}

Fixed-wing aircraft have been the primary means of securing aerial photography for the past several decades. A variety of aerial coverage has been collected with varying degrees of quality. It is best suited for photo coverage of large areas, although narrow flight lines are also possible. The Remote Sensing Tutorial, developed by the National Aeronautics and Space Administration (NASA) also provides a history of remote sensing and other helpful information. Techniques for aerial photography are abundantly described in the literature. Excellent reference books are available elsewhere (e.g., Falkner, 1995). These books describe nearly everything that is needed by a novice to understand, use, and estimate costs with proper specifications for subcontractors.

Early photographs were primarily black and white photographs enlarged from large-format (22.8 $\mathrm{cm} \times 22.8 \mathrm{~cm}$ [ $9 \times 9 \mathrm{inch}])$ film negatives. Much of the early work was performed as part of the 
U.S. Geological Service and the Natural Resources Conservation (formerly known as U.S. Soil Conservation Service) in support of their topographic and soil-mapping efforts. More recently color and CIR photography have become available with the development of newer films. It remains the photographic method of choice for medium-resolution images and when continuous coverage of a large area is required.

There has been a steady improvement in the quality of large-format cameras, lenses, and film. Many historical photographs are often retained as "proof" books or contact prints and have inherent problems with unequal color and vignetting (a gradual darkening of the photograph at the corners of the photograph caused by the curvature of light passing through the camera lens). Enlargements overcame some of these problems by allowing the photo technician to dodge and burn the photograph during printing to produce a more uniform image. Improvements in the quality of cameras and lenses over time have also enhanced our ability to capture higher quality images. For example, improvements in lens speed (i.e., the number of elements and coatings on a lens to permit more light to be focused on the film ) have reduced motion blur and built-in GPS features record flight data such as location, altitude, and other information needed for georectification directly on the film.

Because of the specialized, and often costly equipment needed to conduct aerial surveys (e.g., a good lens on a large-format camera can often cost more than $\$ 100,000$ ), most of this work is subcontracted to commercial companies that perform such work routinely. Individuals seeking to do their own aerial surveys (e.g., using small aircraft and inexpensive cameras) will find useful information available from the publications of the American Society for Photogrammetry $\&$ Remote Sensing at http://www.asprs.org and the published proceedings of the Workshop on Videography \& Color Photography in Natural Resource Assessments (asprspub@pmds.com). Another useful reference is the Remote Sensing Users' Guide (Bright et al., 1997). The manual was produced by the U.S. Army Environmental Center (USAEC), U.S. Army Topographic Engineering Center, and the USACERL. SERDP projects have also produced informative Web sites providing information about remote sensing for military applications (http://www.serdp.org).

Some of the limitations in aerial photography from a fixed-wing aircraft include restrictions in the scale of the imagery and geospatial rectification. High-resolution imagery (e.g., $<1: 1000$ ) is limited because planes can fly only so slow and at so low of an altitude. At faster speeds motion blur is a problem. At lower altitudes safety may be an issue, especially in mountainous or rough terrain. Most commercial companies are only equipped with certain lenses and telephoto or zoom lenses are very expensive or not available. Several companies have developed software to help overcome undesirable features of aerial photography. For example, software is available for mosaicing, georeferencing, color balancing, and compressing (e.g., 1/100 to 1/500 compression ratios) digital images (e.g., DIME ${ }^{\circledR}$ software at and Multiresolution Seamless Image Database (MrSID) software. When seeking to convert aerial photographs to digital images it is best to scan the film directly to obtain the best digital image. Exceptions to this are when printing can eliminate vignetting by dodging and burning or using an antivignette filter. In this case an enlargement of the film may actually result in a higher-quality digital image than scanning directly from the film. 


\subsubsection{Satellites}

Information about satellite imagery is summarized in publications and web sites that focus on remote sensing. This information has been assembled by NASA and the USAEC in the form of The Remote Sensing Tutorial (NASA and the U.S. Air Force Academy) and a Remote Sensing Users Guide [Bright et al., 1997]. The objectives of this tutorial and guide are to provide organized tools to help land managers take advantage of existing remote-sensing technology. Descriptions of satellite imagery and other associated facts are well described in these sources. Examples of imagery and additional web site links are provided in these tools.

\subsection{CAMERAS AND LENSES}

The selection of the proper camera equipment is essential for success in the capture of aerial photographs and images. Cameras have traditionally been developed for recording on film, but have recently witnessed the surge of digital cameras with increasing image quality. The selection of cameras and lenses are beyond the scope of this manual. However, those interested in technical reviews of camera equipment may find abundant information on the Internet using Web search engines. For a good introduction to digital photography, the reader may consult a variety of Internet Web sites (e.g., Koren, 2002).

Key desirable camera features include:

- Motor driven with electronic shutter (allows radio-transmitted remote control of shutter)

- Ability to override auto-focus features in favor of manual focus (slight motion and vibrations of camera may make it difficult to focus using auto-focus)

- Ability to accept other high-quality commercial lenses

- Fast digital processing (storage of digital images) for rapid cycling of image (reduces delays)

Key desirable lens features include:

- Fast lenses (for reducing blurring due to camera motion and increasing depth of field or focus.)

- Aperture should be set to $2 \mathrm{f}$-stops below the maximum for sharpest images (e.g., $\mathrm{f} / 8$ for an $f / 16$ lens; assuming range is: $f / 2.8, f / 5.6, f / 8, f / 11$, and $f 16$ )

- Attachable coated lenses that accept filters (to protect the lens and reduce chromatic diffraction)

- Wide-angle (28-40 mm) lenses (yields a greater field of vision with better depth of field)

A description of light-weight instrumentation for remotely controlling the camera shutter was discussed in Section 3.1.4. 


\subsection{FILMS AND DIGITAL RECORDING MEDIA}

In 1999, Kodak reported that "an image taken on film can hold 16 times as much information as one taken using digital camera, such as the KODAK Professional DCS 420 Digital Camera (4 megabyte [MB] image size) (Kodak, 1999). However, with the development of newer megapixel cameras, that difference is rapidly shrinking. Koren (2002) estimates that the newer megapixel cameras (e.g., 6 to 10 megapixels per image) are comparable to, or better than, a 35$\mathrm{mm}$ film size. Digital cameras also reduce the problem of the film lying flat in the camera, a problem that was reported to have occurred in 60 percent of all $35 \mathrm{~mm}$ single-lens-reflex cameras examined, which reduces sharpness of the images up to 48 percent (Koren, 2002).

Slide films typically have smaller grains than negative films. Slide film does not scratch as quickly as negative film and when framed, is easier to handle; however, negatives have a much larger exposure latitude than slides. Slide film is easier to interpret than negative film in large-format size, but prints made from small-format films provide more detail. Proper exposure of slide film is more critical than negative film. Based on these qualities, the $35-\mathrm{mm}$ negative film is preferred when enlarging to $20.3 \mathrm{~cm} \times 25.4 \mathrm{~cm}\left(8^{\prime \prime} \times 10^{\prime \prime}\right)$ size and the $22.8 \mathrm{~cm} \times 22.8 \mathrm{~cm}$ [9" $\times$ 9"]) large-format positive slide film is preferred because it can be scanned directly with little loss of detail.

\subsubsection{Small-Format Films}

Films are frequently rated for their fineness (e.g., the relative size of the chemical grains that react with photons). Fine-grained films are generally slow-speed films, while coarse-grained films are generally faster-speed films. A compromise between the graininess of the film and the speed must be made. Film speeds of ASA 100 are best if the camera platform is not moving or is relatively stable (e.g., tripod on the ground with large f-stop settings). For unstable platforms (e.g., vibrations and movement near the ground), faster (i.e., higher) film speeds are preferred (e.g., ASA 200 to 400). Fine-grained films that are suitable for aerial photography in a smallformat size (e.g., $35 \mathrm{~mm}$ ) are available in speeds from ASA 100 to 400 and include:

- Kodak Royal Gold (extremely fine-grained negative film)

- Fuji Superia Reala (extremely fine-grained negative film)

- Kodak Ektachrome E200 (extremely fined-grained slide film)

- Fuji Provia (extremely fine-grained slide film)

\subsubsection{Large-Format Films}

The selection of the numbers and types of large-format films (e.g., $22.8 \mathrm{~cm} \times 22.8 \mathrm{~cm}[9$ " $\times 9$ "']) is more limited and some films may have to be made up custom and delivered just prior to use. An example of such custom film production is CIR films. Such film is extremely sensitive to heat and deteriorates rapidly once it is made. The purchaser often is obligated to purchase an

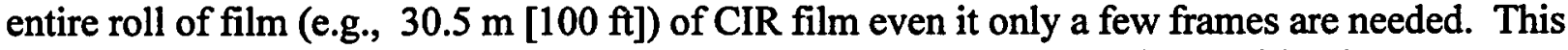
may increase the cost per frame. Arrangements can be made to coordinate with other photography needs at the installation to ensure that all the film is used. If necessary, 
experimentation can be performed (e.g., additional photos can be taken at different photo scales or additional exposure settings can be made). Because large-format films are typically used by commercial services, it is best to consult with them on recommended films that are compatible with their equipment and with which they have experience. Users may request examples of photos taken with various film types and qualities with commercial equipment to ensure that they are of acceptable quality.

Examples of unacceptable photo features for commercial services include:

- Poor image contrast (out-of-focus images that lack saturation, detail, and appear faded)

- Shadow length is too long as occurs when photos are taken too early or too late in the day

- Improper chemical processing (small discoloration blotches from water spotting or improper rinsing during processing may result in multicolored halos)

- Evidence of dust, scratches, and improper handling (accidental light leakage near edges)

\subsubsection{Digital Recording Media}

Removable memory chips of digital cameras come in several formats. The camera type and model will usually determine what type of memory is required. Memory cards usually range from $16 \mathrm{MB}$ to 1 gigabyte. Costs range from $\$ 100$ to $\$ 200$ per $100 \mathrm{MB}$, although costs continue to fall as new, higher-capacity storage media become commercially available. Compact disks (CD) (e.g., 3-in CD) and Digital Video Disks are being used in some cameras and digital camcorders as a means of saving images, thereby reducing costs of image storage. The size of the storage memory chip should be consistent with the size of images being recorded. Large megapixel images may require larger storage capacity than smaller images. The storage space required for individual images, depending on how much compression can be achieved for the given format.

Hand-held digital cameras capture images in a variety of sizes. Typical sizes (number of horizontal pixels by number of vertical pixels) are: $640 \times 480$ ( 0.3 megapixels), $800 \times 600$ (0.5 megapixels), 1,030 × 746 (0.8 megapixels), 1,280 × 960 (1.2 megapixels), 1,600 × 1,200 (1.9 megapixels), 2,048 × 1,360 (2.8 megapixels), $2,272 \times 1,704$ (4 megapixels), 2,496 × 1,662 (4.5 megapixels), and 2,560 $\times 1,920$ (5 megapixels). Image size is highly variable and is expected to change rapidly in the future, but usually maintains a ratio of about four units horizontal for each three units vertical (the same ratio as most computer monitors). [By comparison, 35-mm (actually 135 size) film has a ratio of about three units horizontal for each two units vertical (the $24 \times 36 \mathrm{~mm}$ negative size is slightly more rectangle in shape than a digital image).] File sizes for these formats range from about $350 \mathrm{k}$ for the smaller size images up to about 17.6 MB for the larger megapixel images (assuming 32-bit Tagged Image File Format [TIFF] or Joint Photographic Experts Group [JPG] file types). 


$$
\text { . }
$$

THIS PAGE INTENTIONALLY LEFT BLANK 


\subsection{IMAGE PROCESSING}

\subsection{DIGITAL IMAGES AND IMAGE EDITING SOFTWARE}

A variety of image formats are used to record information, store, and manipulate images. These images are produced by digital cameras and by a flat-bed or film-scanner from prints and film. These digital images can be considered raw images. Most of these images benefit from enhancements (image processing) that can be made to them using software that alters the raw image. A discussion follows about image formats and image-editing software.

\subsubsection{Digital Image Formats}

Digital images may be stored in various types of file formats. These file formats organize the storing of digital information of the image in various degrees of compression to conserve file storage space and adjust for the types of color information stored. The most common types of images used for image processing include the following:

- BMP - (file extension .bmp) Windows Bitmap is lossless compression originally designed by Microsoft to handle 24-bit data, but it cannot be compressed. It is seldom used except in Windows (e.g., in wallpaper and screensavers), but is accepted by most image-processing software.

- JPEG - (file extension .jpg - pronounced "Jay Peg") Joint Photographic Experts Group is a lossy compression format that can be compressed by increments to very small thumbnails. Because this format compresses the file each time it is saved, information is lost and it is not considered suitable for storage of master images. This format may be acceptable for image process if the master image file printout has a high resolution.

- TIFF - (file extension .tif) Tagged Image File Format was developed by Aldus, before Adobe bought them, and is the most widely supported format. This format is a large file and uses lossless compression.

- TIFF LZW - (file extension .lzw) Lempel-Ziv-Welch is a variation of the TIF format but is compressed (same compression as used by PKZIP). Not all image-processing software supports this format, but many do. This format is smaller ( 85 percent) than the TIF format.

- GEOTIF - (file extension .tif) Georectified tag Image File Format is a lossless compression format created for GIS that have a need to incorporate spatial coordinates with pixels. These files are larger than TIF files because they include geospatial coordinates.

- PNG - (file extension .png - pronounced "Ping") Portable Network Graphics is a lossless format that has many desirable features like supporting 24- and 48-bit color, compressing well, and is about 30 percent smaller than TIF LZW formats. This is a new format and has not yet been incorporated into all image-processing software. 
- PCD - (file extension .pcd) Photo CD is a proprietary format of Kodak. Images are scanned on a special high-quality film scanner that provides images with excellent color registration and resolving power-its main weakness is a slight loss of shadow detail when scanning transparency film. The image file size is about $5 \mathrm{MB}$ and contains options for downloading six image sizes $(64 \times 96 ; 128 \times 192 ; 256 \times 384 ; 512 \times 768 ; 1024 \times 1536 ; 2048 \times 3072)$. When converted to a TIFF format, the largest format size results in a file size of about 37 MB. This file format is created as part of the Kodak film processing and costs about $\$ 1$ per frame. It is very convenient and often cost-effective to request this file format and processing service when images are recorded on film. Other types of file formats not commonly used in image processing are:

- GIF - (file extension .gif - pronounced "Gif" like Gift) Graphic Interchange Format is a proprietary lossless compression format of CompuServe that uses only 256 color combinations (designed for the older 8-bit video boards) and is a larger file size than a 24-bit JPG file. This format is frequently used for Web site designs.

- PDF - (file extension .pdf) a format of Adobe Acrobat ${ }^{\circledR}$ used primarily for storing documents. This format is used because it maintains fidelity and integrity 100 percent when viewed across operating platforms and with different printers.

- PCX, PSD, CDR - (PaintShop ${ }^{\circledR}$ Pro, Photoshop ${ }^{\circledR}$, and Corel Draw ${ }^{\circledR}$. These are proprietary file formats for image-editing software. They contain many layers of additional information used by these software programs to keep track of editing history, layouts, styles, and other information. They are very large in size and not suitable for use in image processing. These types of files can be taken into the respective software programs and exported as one of the more accepted formats described above.

\subsubsection{Image-Editing and -Enhancing Software}

Several software packages are commercially available that permit editing and enhancing of digital images. Adobe Photoshop ${ }^{\circledR}$ is perhaps the most powerful and most expensive (e.g.; about $\$ 600$ ) software package. It contains an impressive suite of tools, including many third-party plug-ins that increase the power and standard features of the software. Advanced training is commercially available for this software in the form of workshops, third-party books, and online training. Adobe Photoshop ${ }^{\circledR}$ Elements (about $\$ 70$ ) is a scaled-down version of Adobe Photoshop ${ }^{\circledR}$ that provides a limited suite of tools and editing features. Corel Photo-Paint ${ }^{\circledR}$ (about $\$ 250)$ also provides basic tools for digital image processing, but lacks many of the advanced features of Adobe Photoshop ${ }^{\circledR}$. Picture Window Pro ${ }^{\circledR}$ is a low-priced (less than $\$ 100$ ) alternative to Adobe Photoshop ${ }^{\otimes}$ that provides many excellent features that are useful in editing digital images. This latter software package is designed primarily for photographers.

The most commonly used features of these software packages that are important for editing digital images of aerial photographs are:

- Converting image formats

- Cropping and rotating images to match alignments in historical plots or photos 


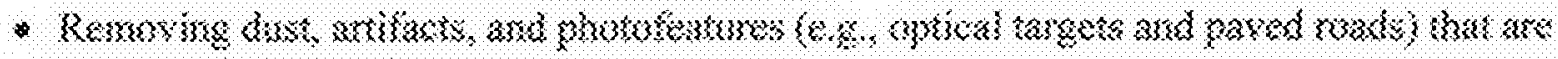

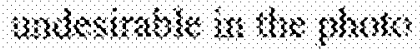

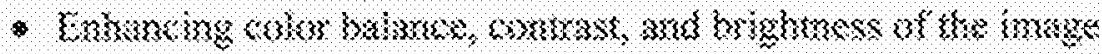

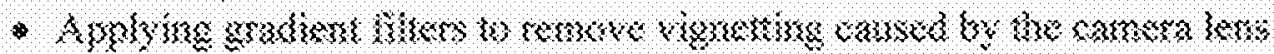

- Srazperting inages

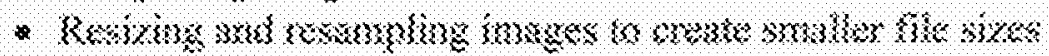

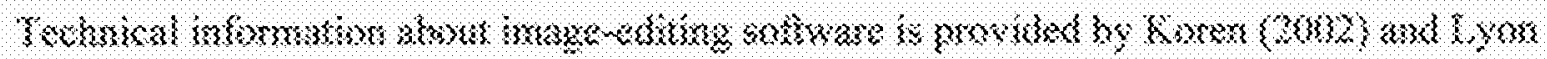
(2) $(0) 3$.

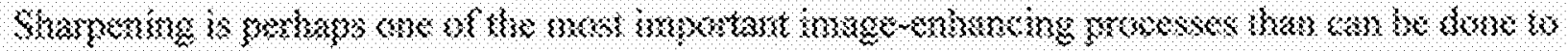

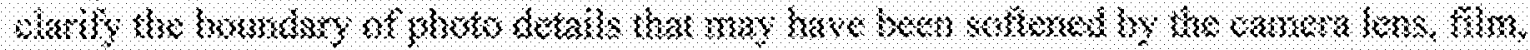

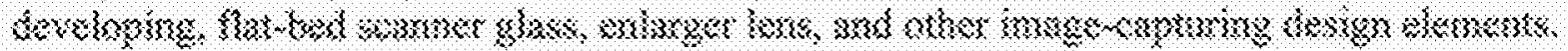

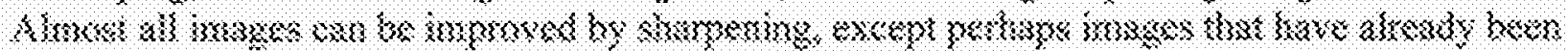

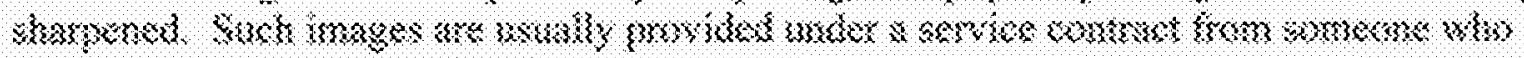

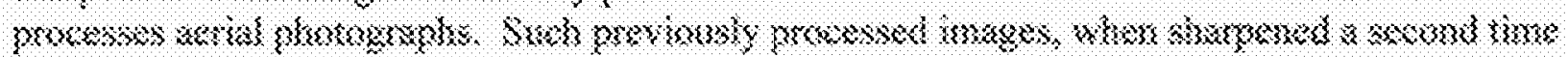

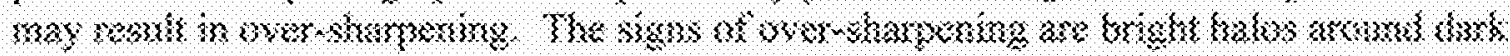

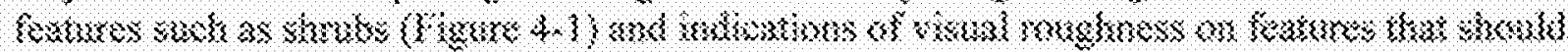

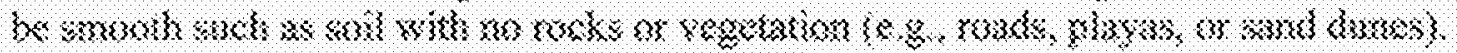

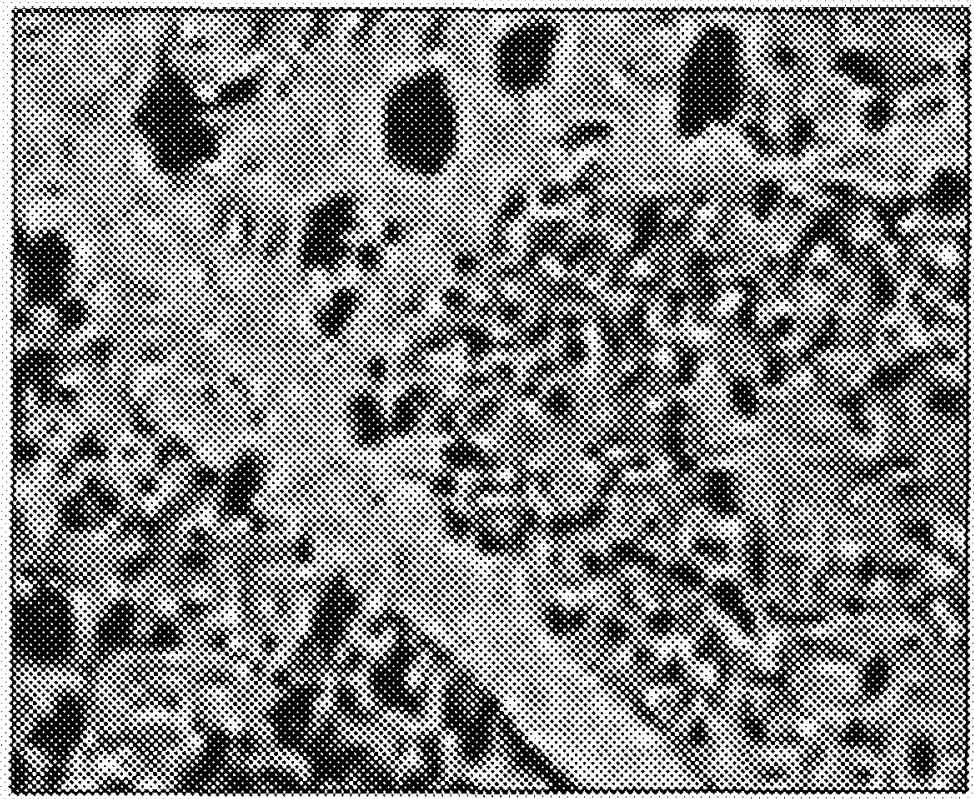

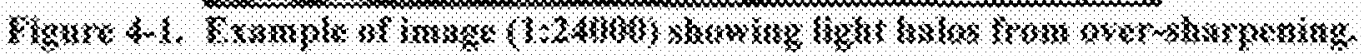

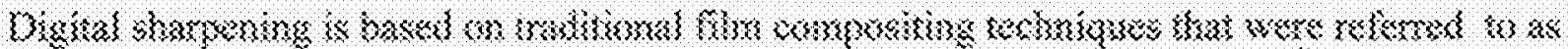

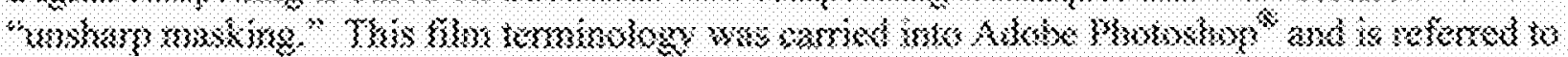

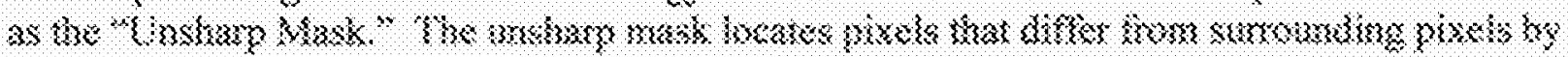

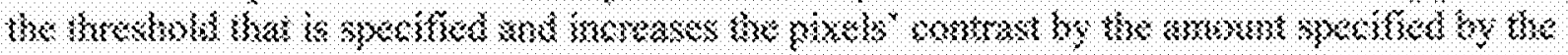

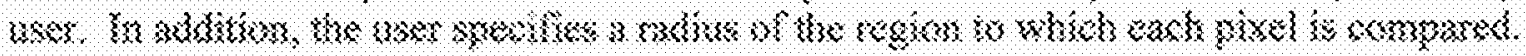




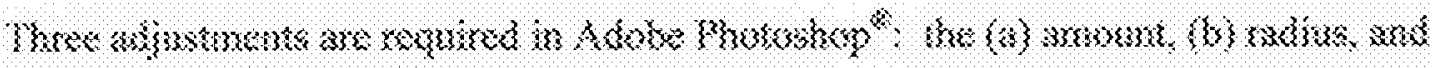

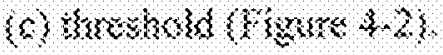

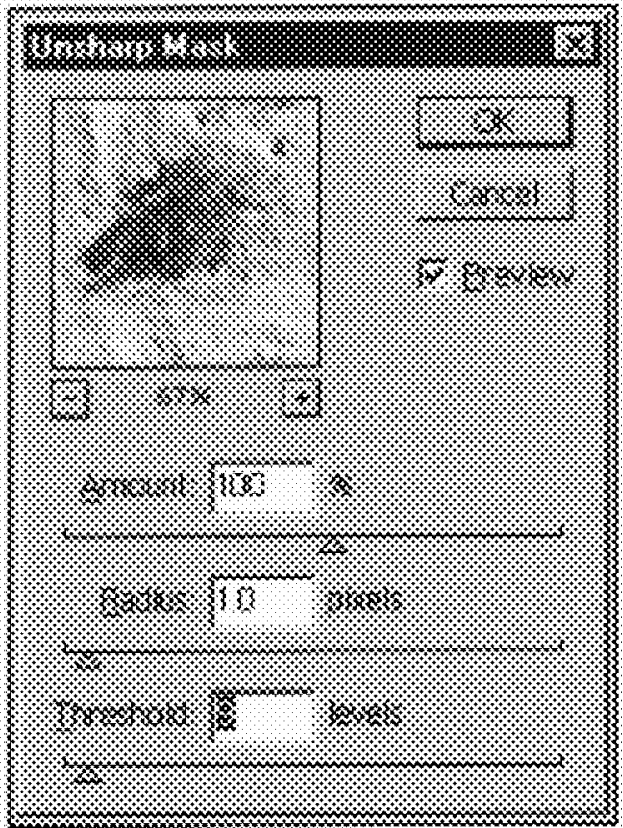

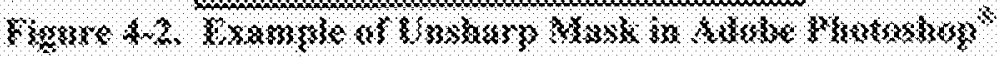

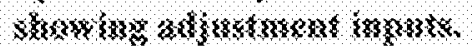

Key tatures and setrings indude:

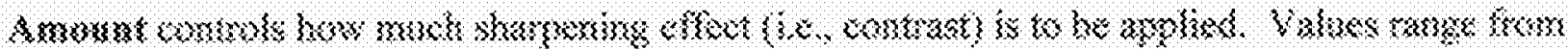

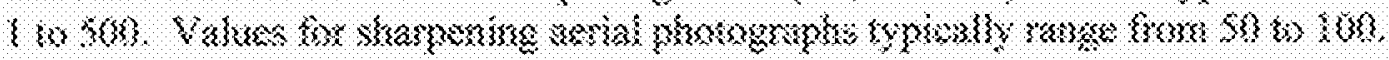

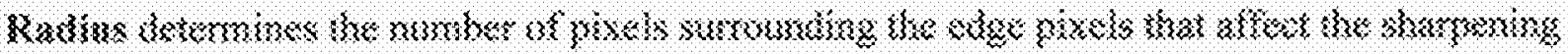

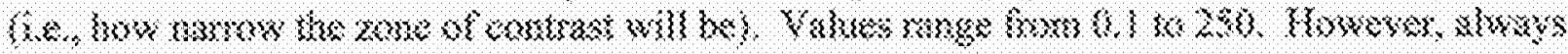

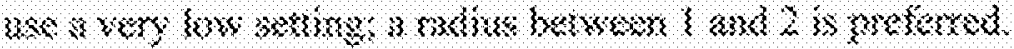

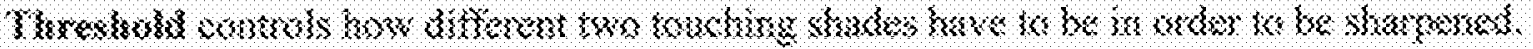

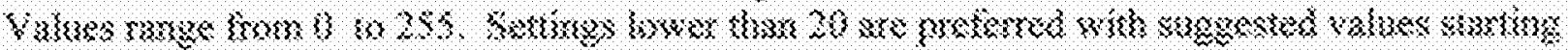

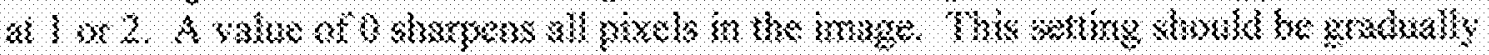

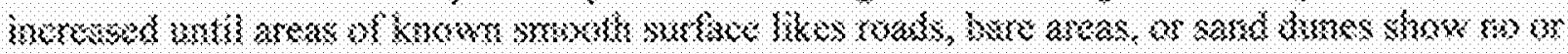

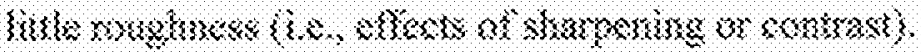

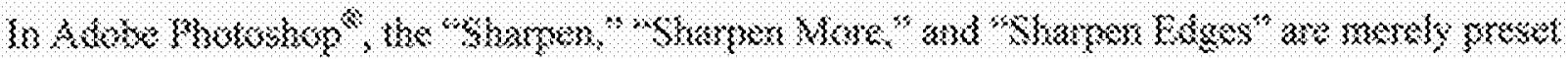

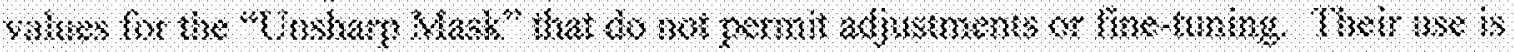

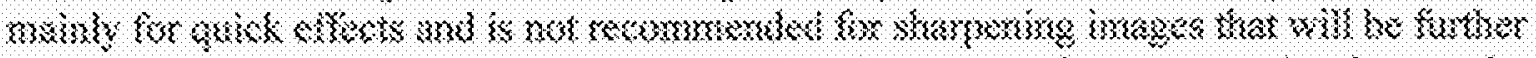

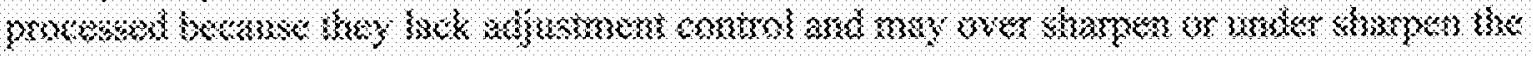
smzaze. 


\subsubsection{Georeferencing Software}

There is frequently a need to convert digital images into formats that include information about spatial locations. Because aircraft are constantly moving while taking pictures, the resulting pictures have distortions due to this motion. The center one-third of the image is generally the most correct if the photo was oriented in a nadir position, while the edges are the most distorted. Software packages have been developed to georeference or georectify the image as well as for mosaicing, georeferencing, color balancing, and compressing (e.g., 1/100 to 1/500 compression ratios) digital images (e.g., DIME ${ }^{\circledR}$ software and $\mathrm{MrSID}^{\circledR}$ software. Most of these software packages are considered expensive (e.g., $\$ 1,000$ to $\$ 15,000$ ). The licensing cost for the DIME software is an annual fee of $\$ 695$ and $\$ 15$ for each frame for mosaicing, georeferencing, and color balancing. The cost for MrSID ${ }^{\circledR}$ Geo software ranges from a free viewer to a complete workstation priced around $\$ 4,000$. Advanced training is available for these software packages.

A version of the MrSID ${ }^{\circledast}$ viewer (MrSID ${ }^{\circledast}$ GeoViewer Version 2.1) has been modified and enhanced for use by the U.S. Department of Defense. The viewer may be downloaded from: https://trms.7atc.army.mil. Please note that this site is only accessible from a military domain site and users should enter "https" not "http" when entering the Web site Uniform Resource Locator.

Some commercial aerial photography companies may provide these services as part of their contracted work, thereby eliminating the need for the software at the user end. Military installations with strong GIS support may already have this software for use in other applications. Contracting others to provide this service may also provide image correction for georeferencing and eliminate the need for purchasing the software directly.

\subsection{MEASUREMENT OF PLANT COVER BY DIGITAL TECHNIQUES}

The ability to measure plant cover using digital information is based on the correlation of light qualities recorded for a digital image with vegetation and other landscape features. As described; earlier color models (e.g., RGB model) record light values on an intensity scale ranging from 0 (darkest) to 255 (brightest) for each band of the model (e.g. red, green, and blue bands). Typically, information in the red band is most often correlated with vegetation and bare soil features. Information from all bands may be combined to form a single intensity value for each pixel. Histograms may summarize information from all pixels into a table of frequency values (i.e., the number of pixels at each intensity value). Figure 4-3 shows a hypothetical range of values for digital image pixels of a desert landscape.

Features with low intensity values include such things as basalt outcrops of rock, asphalt roads, and dark shadows. Vegetation consisted of a range of intensity values at the darker end of the intensity range. Some leaves are shaded and are therefore darker than leaves in the sunlight which appear lighter. Different colors of foliage may separate different species or sizes of plants. Dead plant material in the form of litter is usually lighter in color due to a loss of chlorophyll and water. Soils that contain organic matter (e.g., beneath or adjacent to shrubs) will usually be darker than soils that have little organic matter, but lighter than plant litter. Soils that 


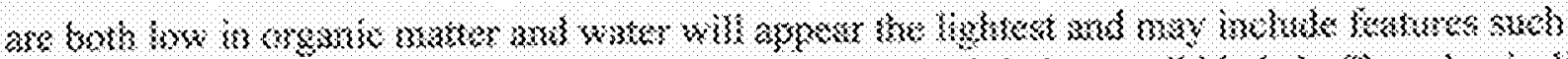

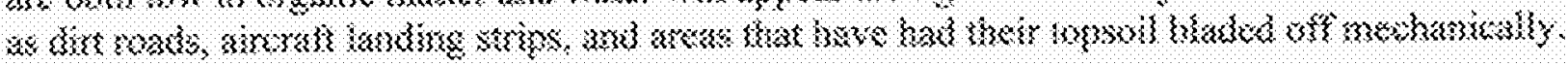

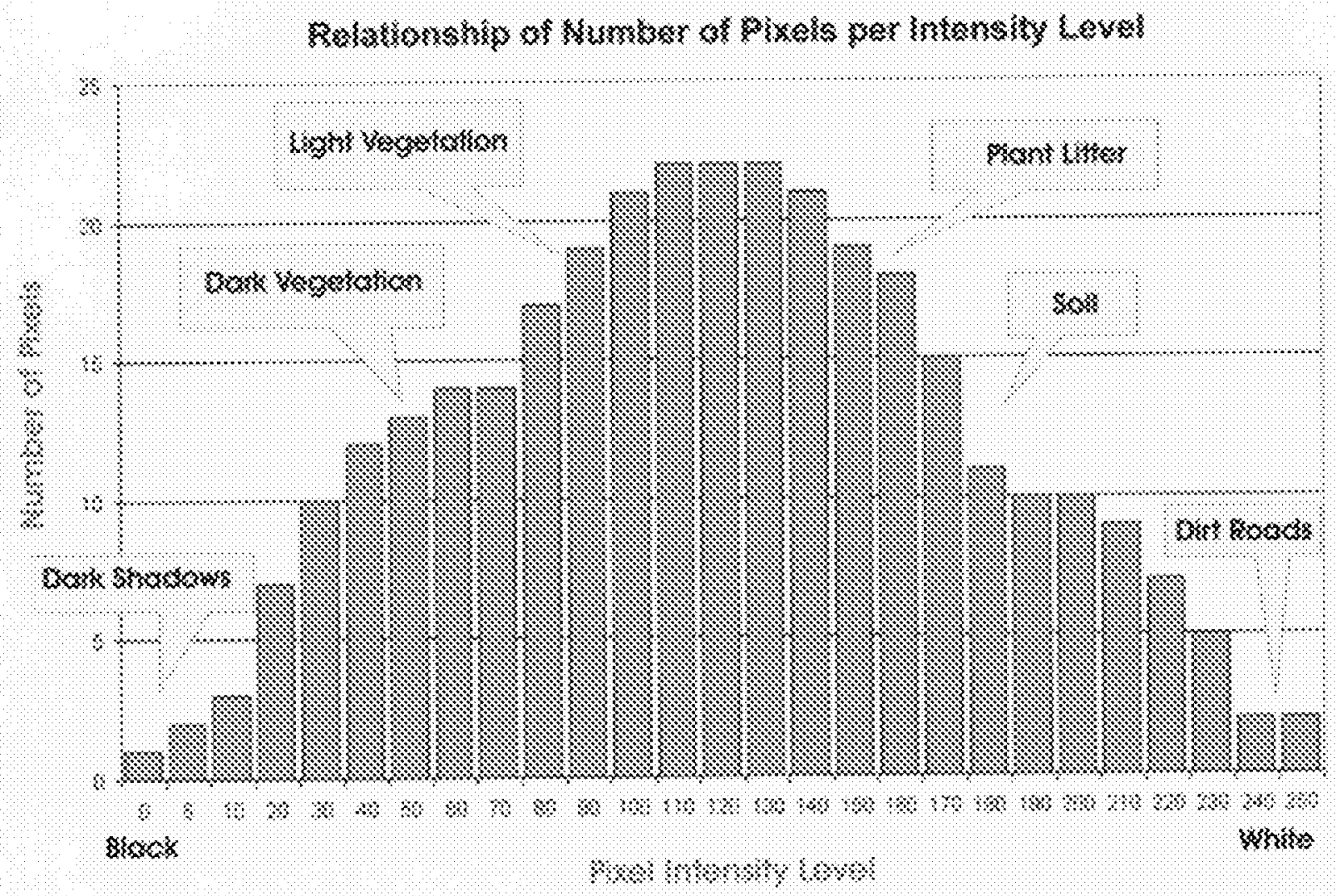

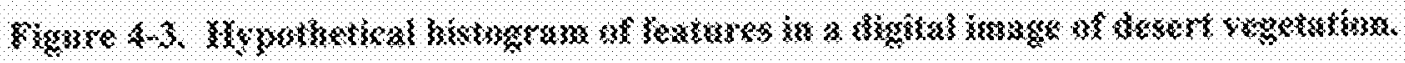

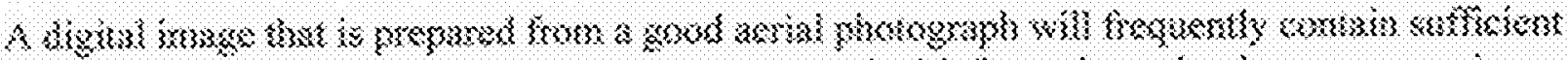

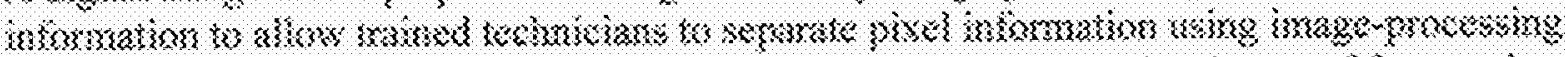

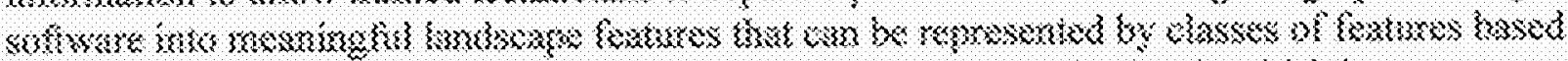

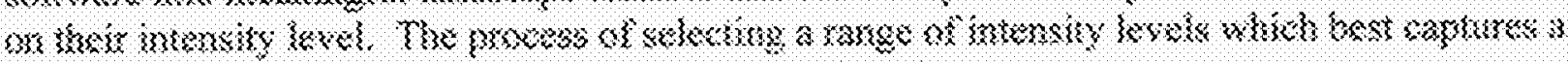

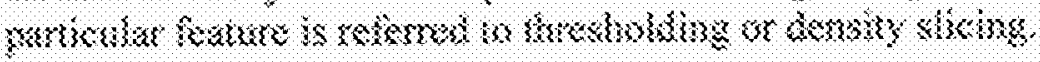

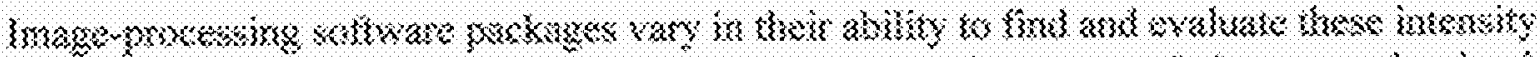

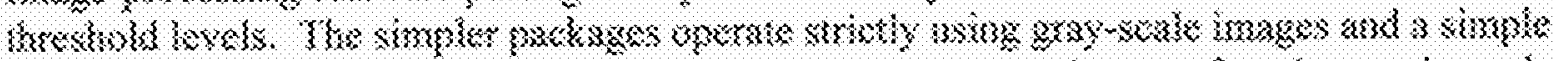

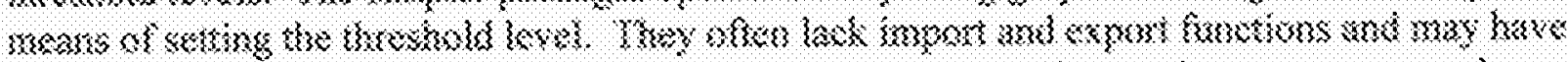

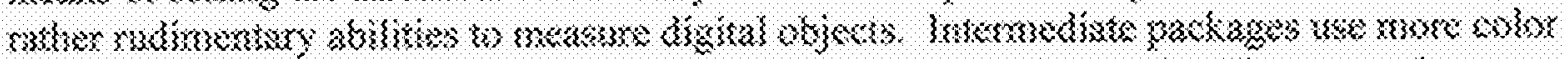

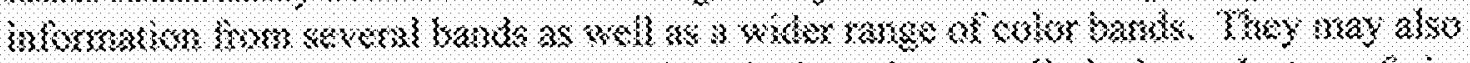

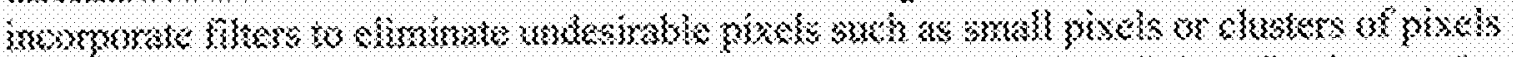

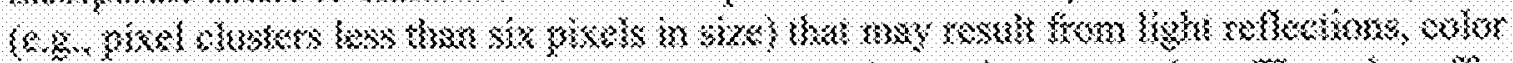

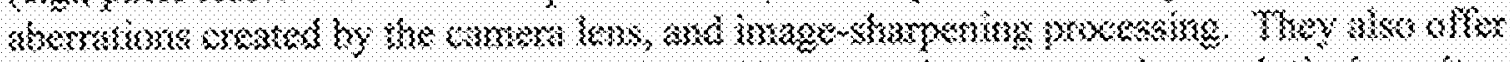

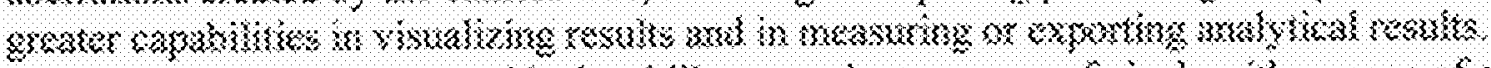

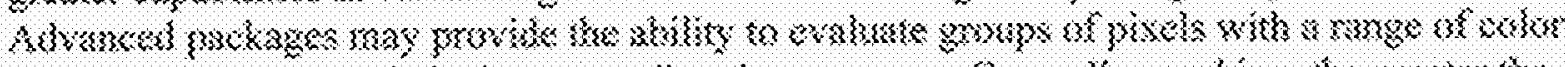

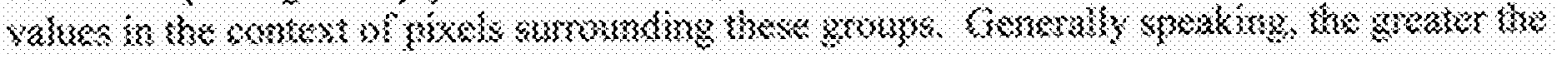


number of features and capabilities incorporated into the software the more complicated and expensive the software. However, such higher-end software, frequently automates extraction of features and permits greater accuracy at a cost savings to the user. This software may contain learning sets and programmable scripts to automate processing.

In addition to image-processing software, other image display software packages have been developed to expedite the extraction of data from data sets and the ability to display that information in screen-displayed images and high-quality printed maps. Two-dimensional graphing software permits statistical analyses of complex patterns to be displayed. Of rather recent development has been the use of GIS software that permits the display and higher analyses of data sets that are dissimilar (vegetation, soils, slope), except for their geographic position or location. This GIS software has become the standard tool for analyzing large data sets such as occur at military and government installations.

The measurement of plant cover by digital techniques incorporates a combination of software techniques to achieve optimal results. The continual development of new software and upgrade in software power and capabilities will result in a constant change in the tools available to help managers over time. The description of techniques and software described here should be thought of as a snapshot in time of a process that is ever-improving and increasing in power and applicability. When we first started this project there were only a couple of image-processing software packages with rather rudimentary features. Now there are dozens of packages with sophisticated features. While the techniques will at first appear rather challenging and complicated, they nevertheless, provide the only working and practical solution to solving the measurement of desert vegetation over large areas. It should also be kept in mind that the cost and availability of detailed large-scale imagery is becoming increasingly more available at lower cost. It is assumed that future imagery will be of even higher quality.

A description of selected software packages follow. It is likely that in the process of evaluating software other equally powerful, or more powerful, software packages exist. As software is updated, it is also probable that newer versions will contain enhancements that were not available at the time of the preparation of this manual. The mention of specific software packages does not imply any government endorsement for the product. Such products are named and described as an example of software that has come to the attention of the authors. It is also probable that not all of the software's capabilities or limitations have been comprehended by the authors, thereby, making it desirable to seek assistance directly from the software company's technical support and training services to better understand the complete power and limitations of the software. 


\subsection{TYPES OF IMAGE-PROCESSING SOFTWARE}

\subsubsection{ImageTool}

ImageTool (IT) is one of the best-known freeware software packages available. It has a surprising number of basic features, but is limited in sophisticated enhancement and measurement features, image size, and customer support. It is limited to images that are less than $33,371,877$ pixels $(5,775 \times 5,775$ or about $95.5 \mathrm{MB}$ of file space). Larger images have to be cropped or resized to be analyzed. While color images (e.g., 25-bit RGB TIFF images) can be opened, they must be converted to gray-scale images to be analyzed. It has a limited number of tools for enhancing contrast, stretching histograms, and color correction. Because it is freeware, users should not expect customer support nor training as offered by other commercial software packages.

The software was written using Borland's $\mathrm{C}++$ version 5.0.2 and the source code for the executable is available free of charge. IT was developed in the Department of Dental Diagnostic Science at the University of Texas Health Science Center, San Antonio, Texas (UTHSCSA). The program was developed by C. Donald Wilcox, S. Brent Dove, W. Doss McDavid, and David B. Greer. It incorporates many of the features of the original image-processing software of the National Institutes of Health (NIH), but has added features and many refinements. Version 3.0 of the UTHSCSA IT is available free of charge at the Internet Web site: http://ddsdx.uthscsa.edu/dig/itdesc.html (Web status as of May 1, 2002).

The first step in using IT is to download and unzip the software (software comes zipped and must be unzipped with software such as WinZip ${ }^{\oplus}$. WinZip ${ }^{\circledR}$ is available with a 21-day evaluation period from Nico Mak Computing, Inc. at http://www.winzip.com (Web status as of May 1,2002 ) ( $\$ 29.00$ single license user cost after the evaluation period). The unzipped files provide the software, user's documentation, images, and other plug-ins. The software can be installed using install-shield software supplied with the software, or by using the "Install" option within WinZip ${ }^{\circledR}$. The installed software will guide the installation to match the desired path and computer workstation. Next load an image (e.g., a color 24-bit RGB TIFF image) of appropriate size (e.g., less than 33 million pixels) by selecting the File command option on the toolbar at the top of the monitor display, and select Open Image F2. Enter the file and path for the image being opened.

To convert the color image to a gray-scale image, locate the command Processing in the toolbar at the top of the screen and select it by positioning the cursor over it and clicking the left button of the mouse. A pull-down submenu will appear. Next select the Color-to-Grayscale command option (Figure 4-4). After a few seconds a gray-scale image will appear positioned over the original color image. Enlarge this image (use the magnifying glass icon with the + sign on the toolbar) so that the details of vegetation and the soil surrounding the shrubs are clear.

The second step is to manually select the threshold of luminosity that best corresponds to the shrub canopy cover. This is done by using the gray-scale image. Select the Processing command from the toolbar. A pull-down submenu will appear. Next select the Threshold 


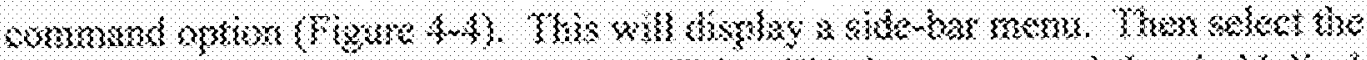

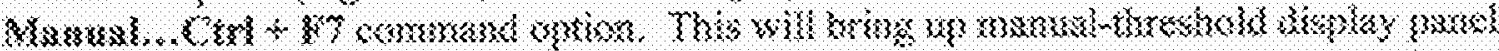

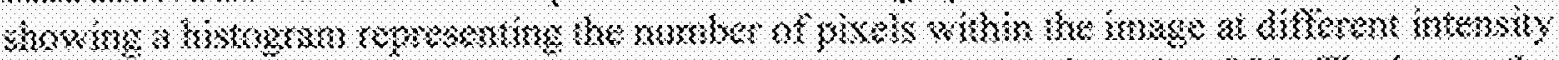

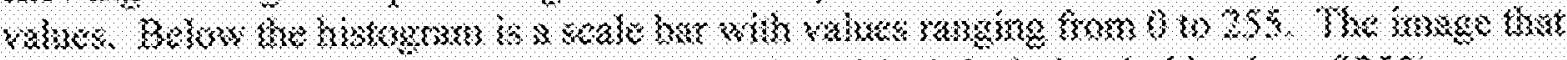

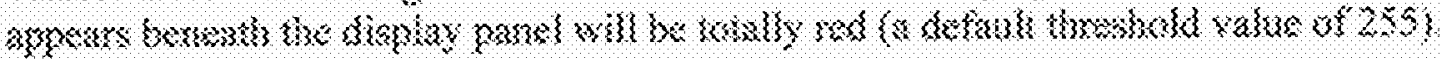

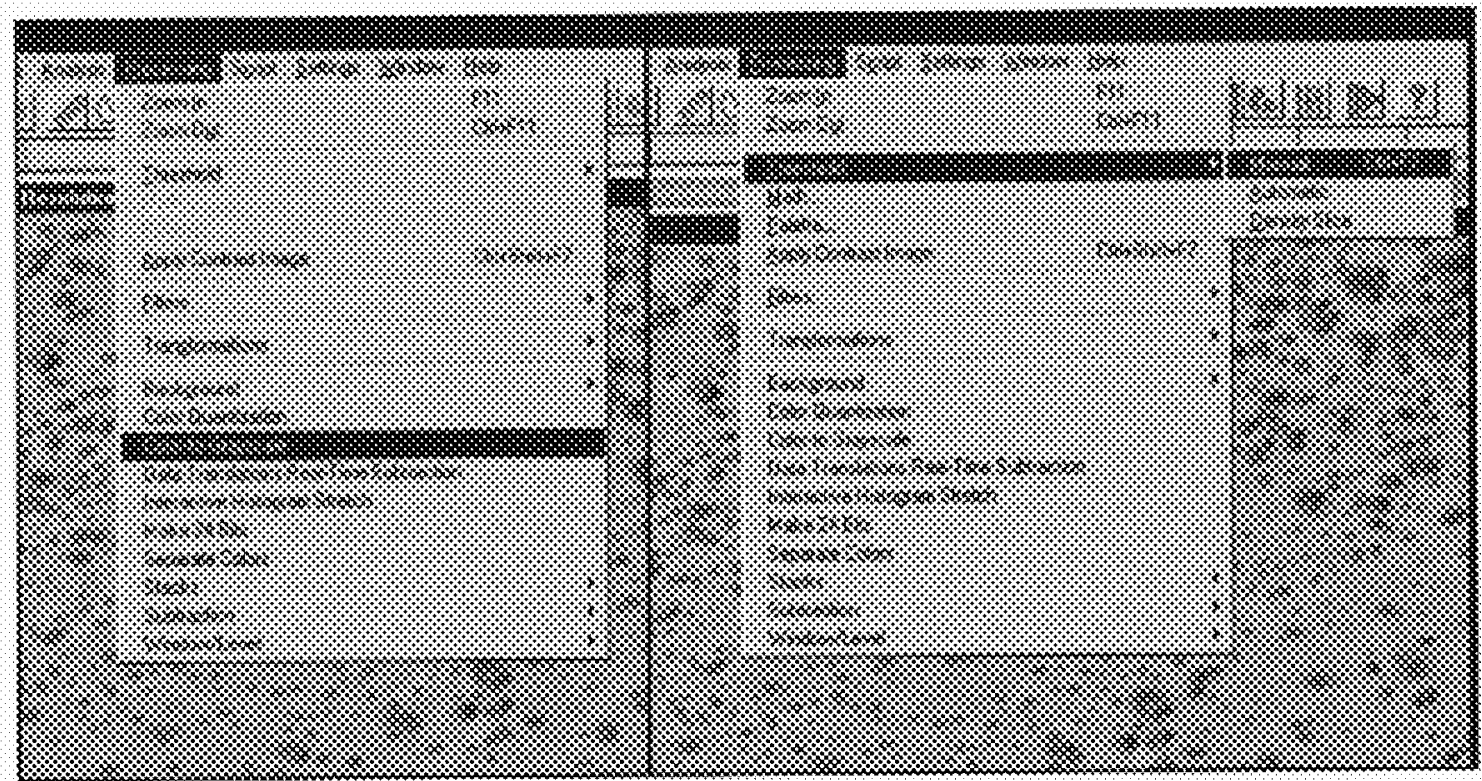

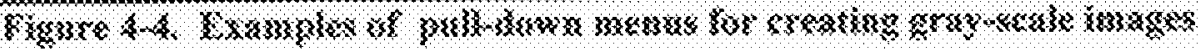

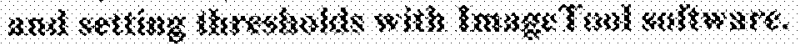

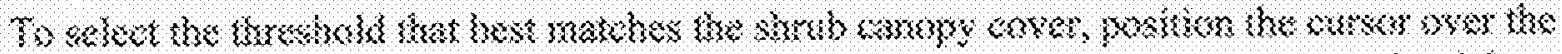

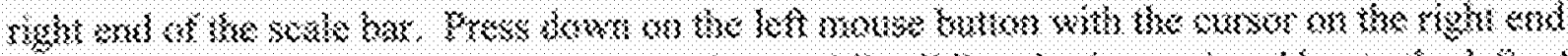

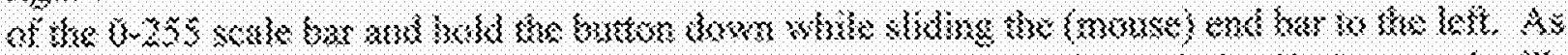

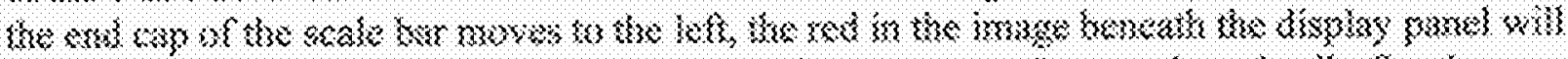

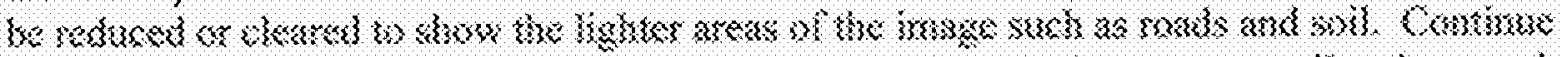

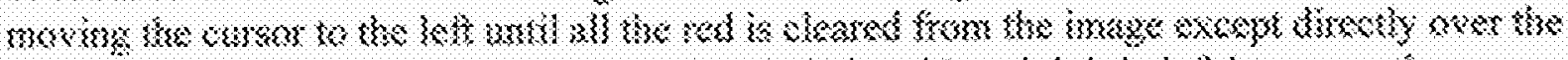

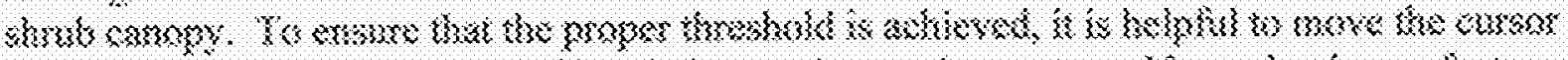

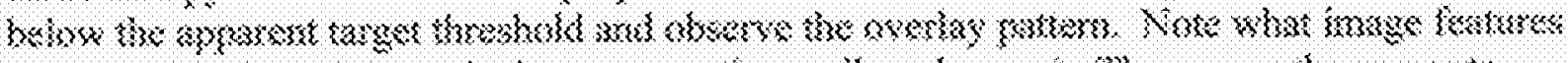

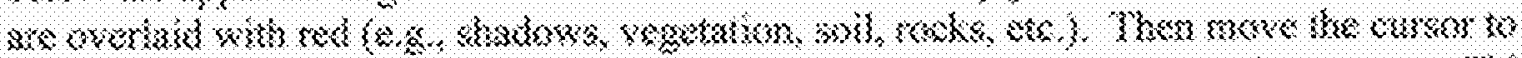

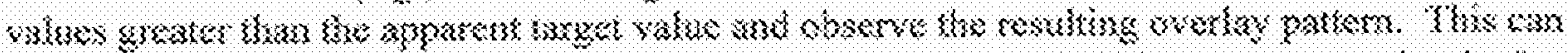

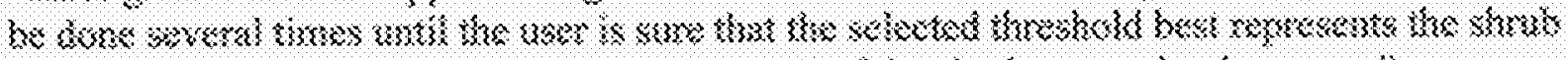

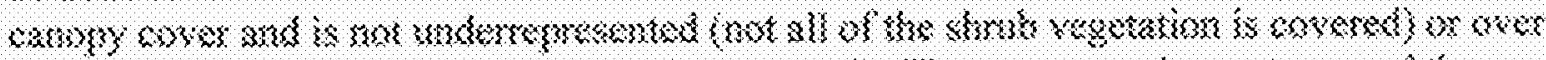

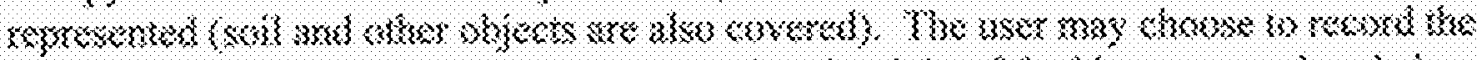

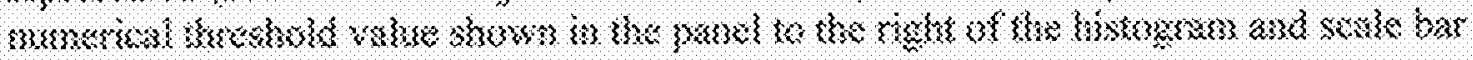
(6.8., $0-86)$.

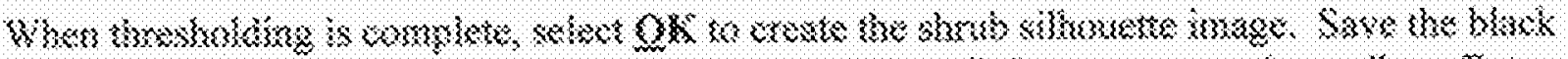

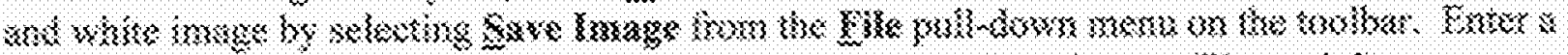

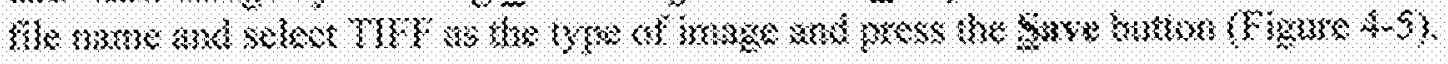




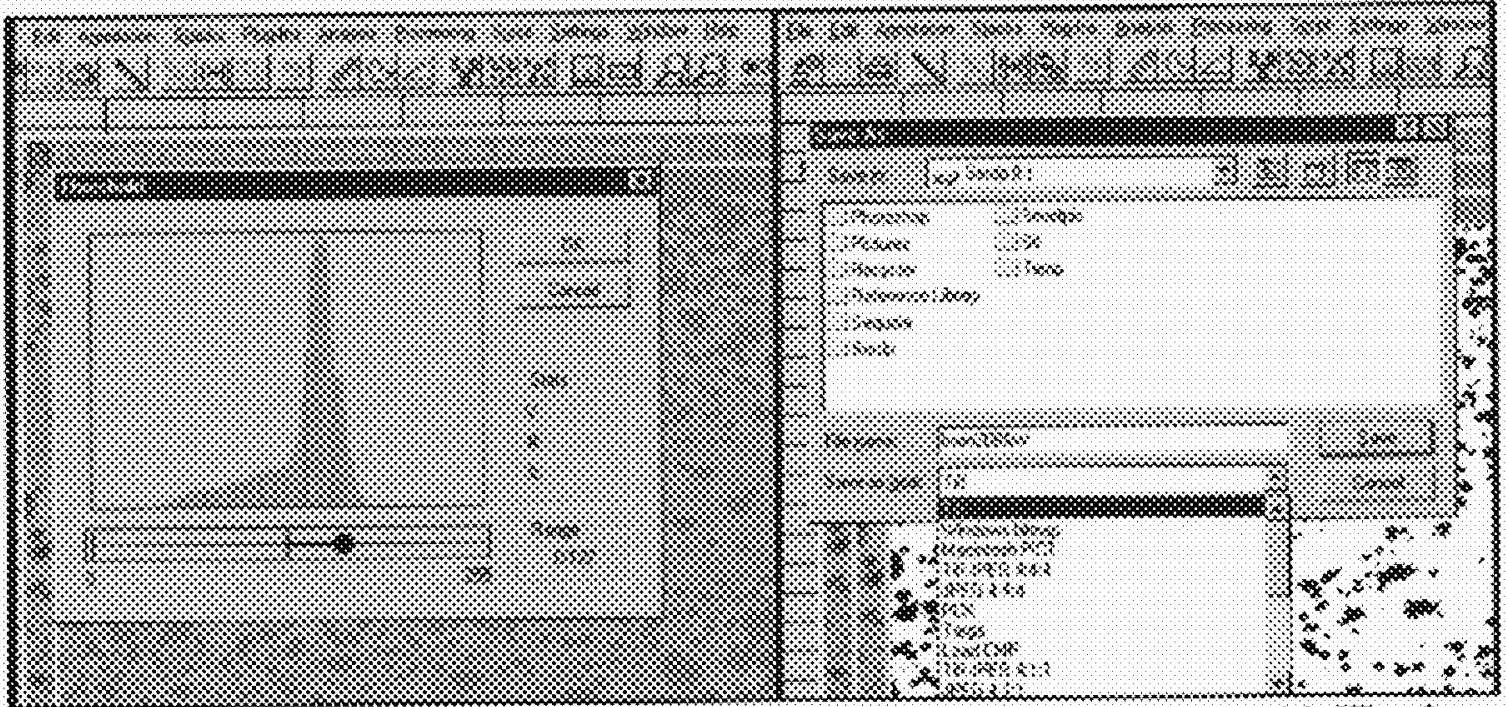

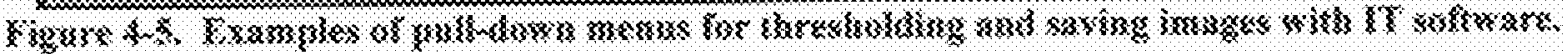

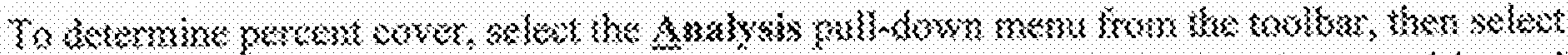

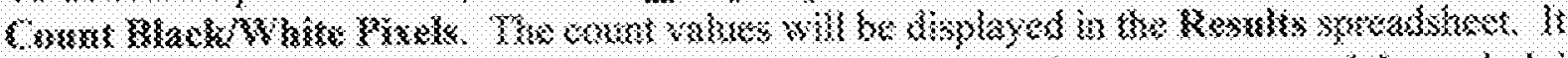

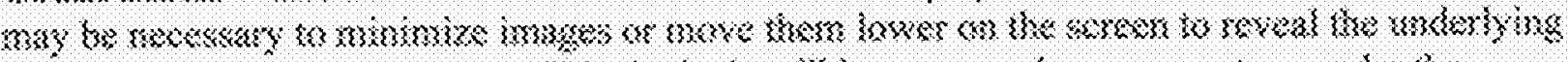

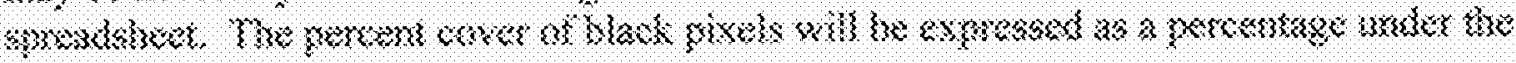

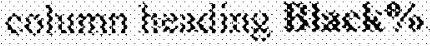

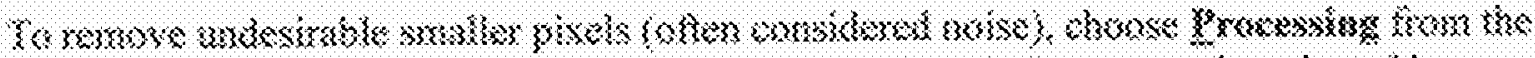

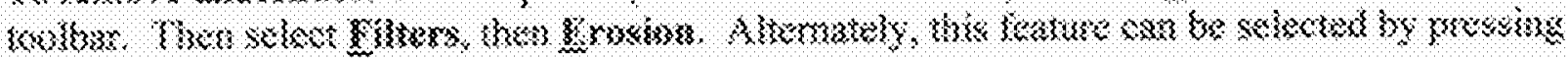

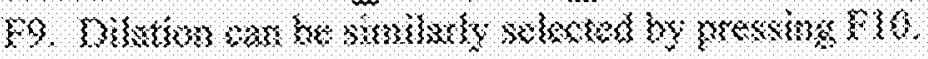

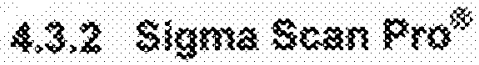

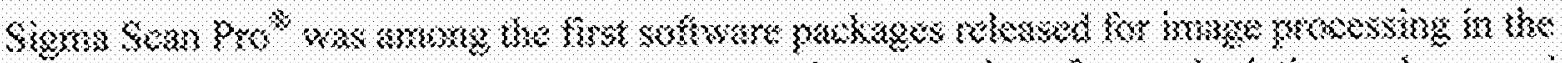

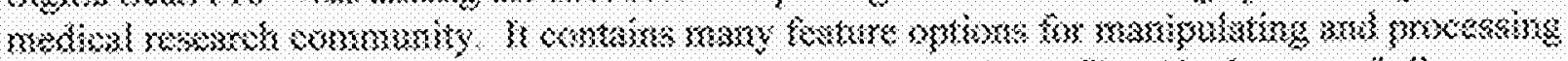

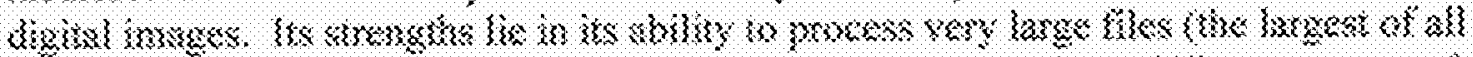

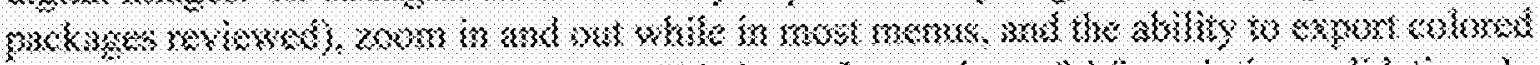

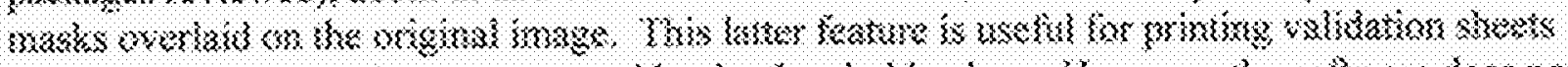

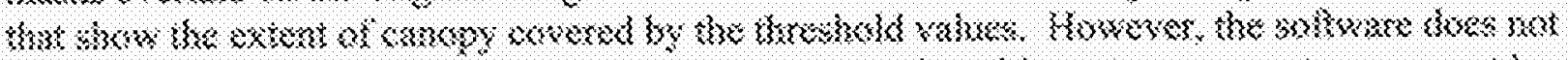

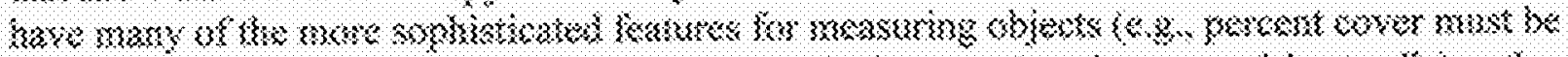

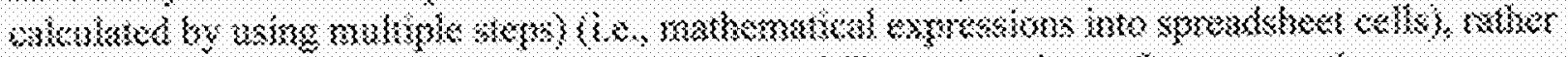

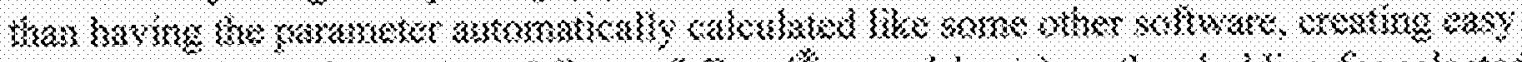

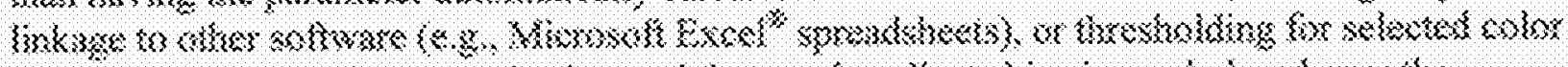

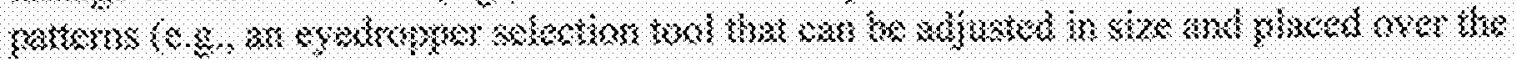
besireil obson. 


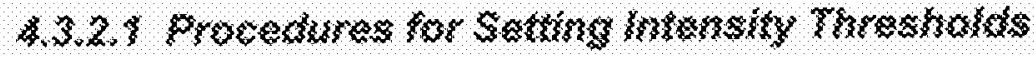

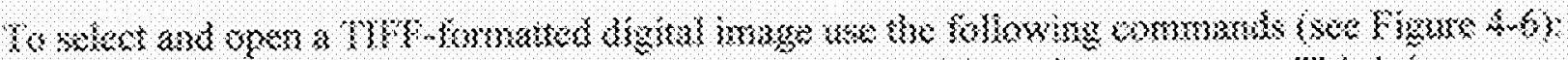

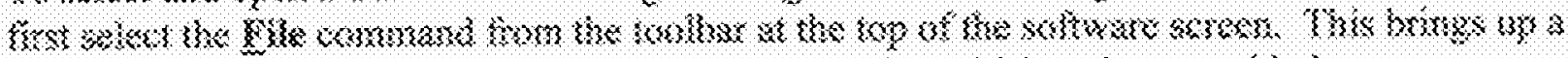

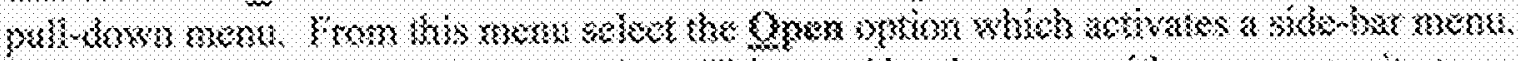

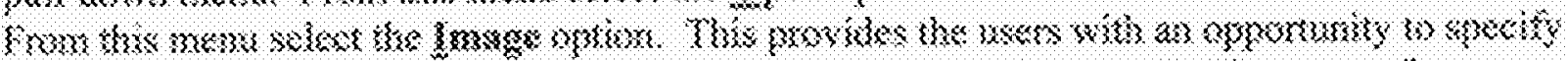

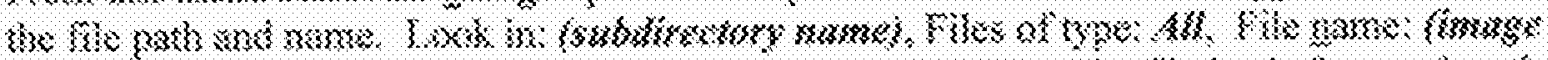

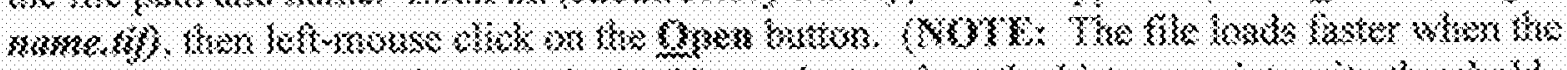

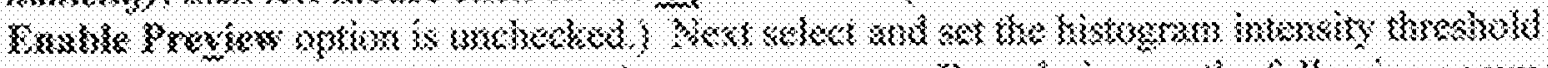

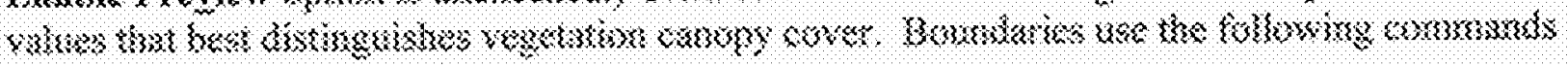

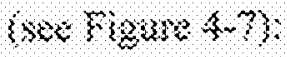

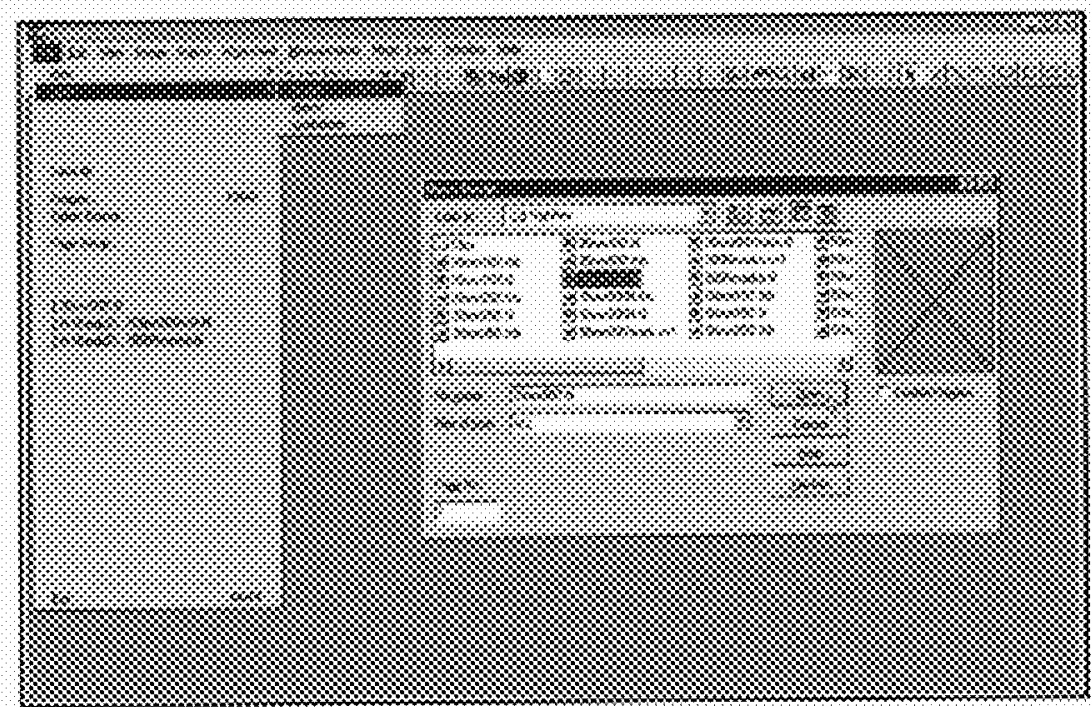

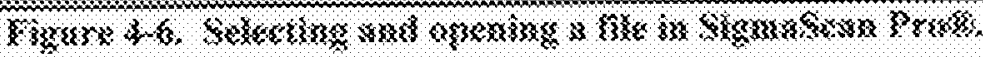

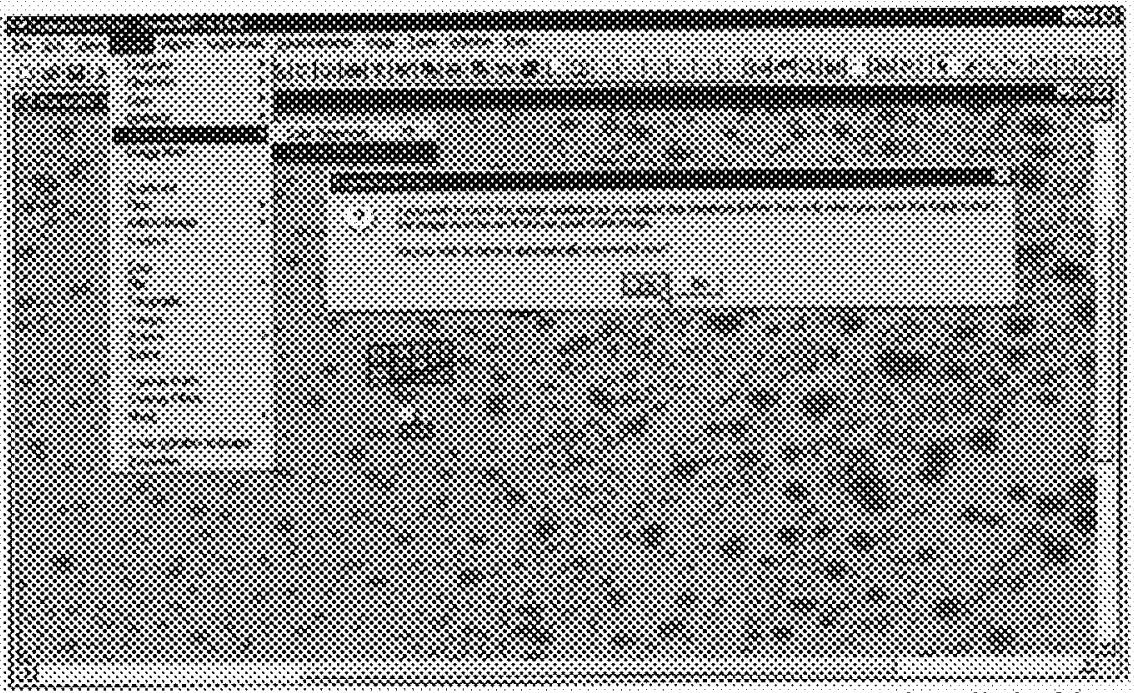

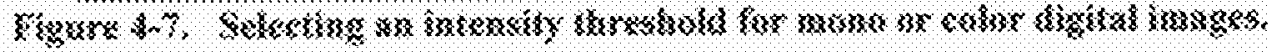




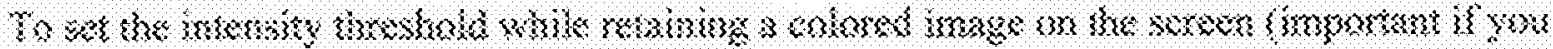

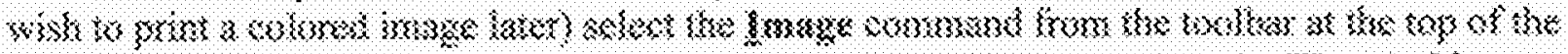

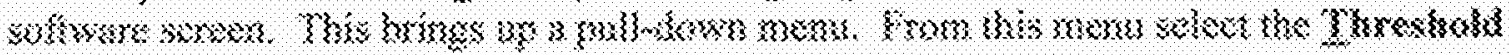

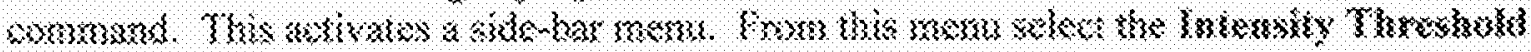

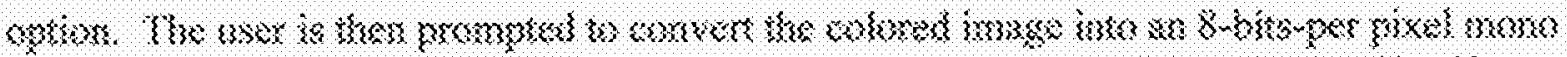

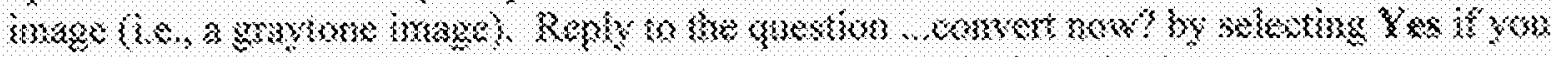

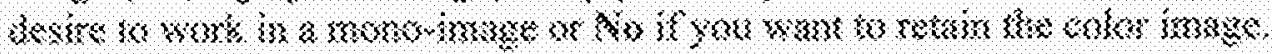

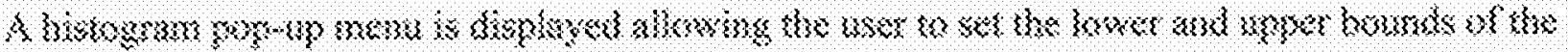

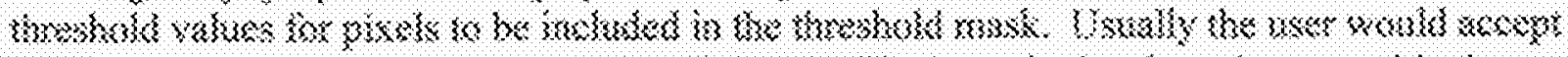

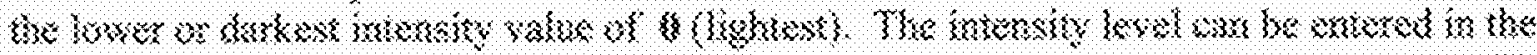

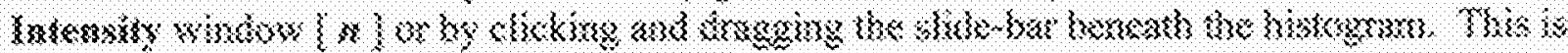

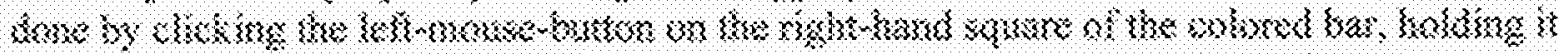

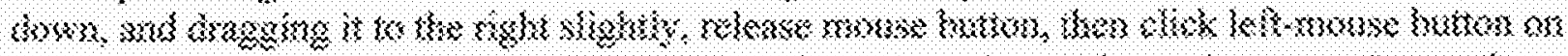

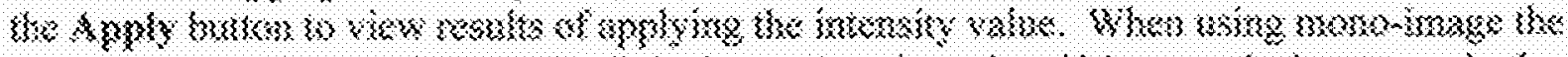

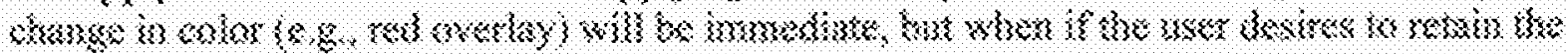

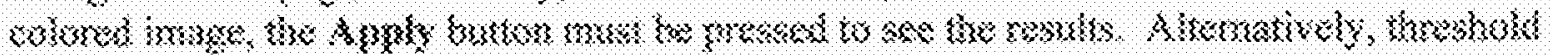

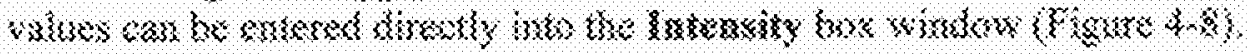

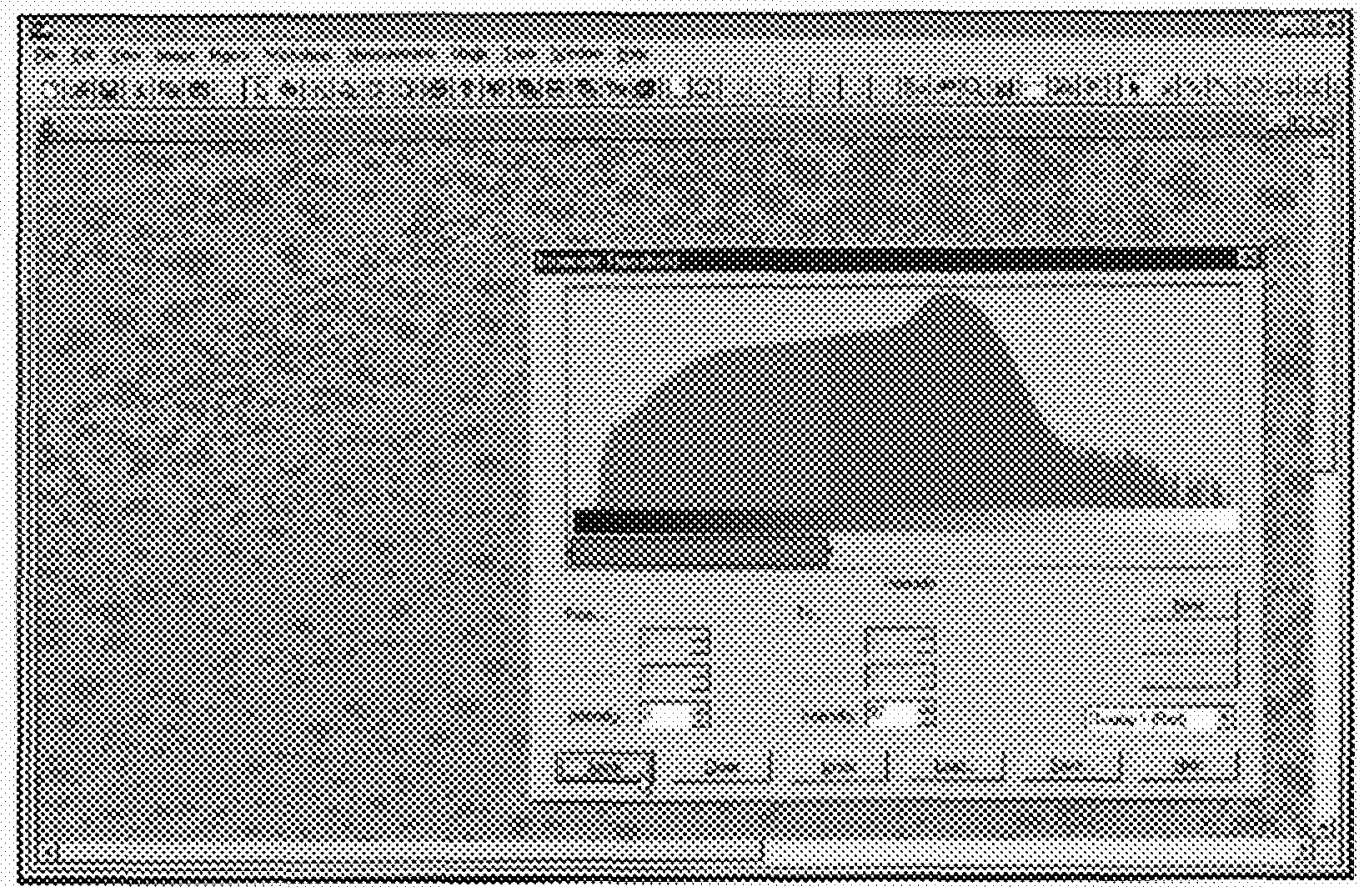

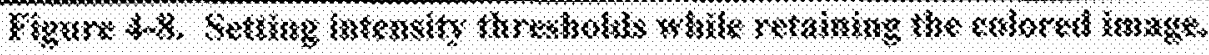

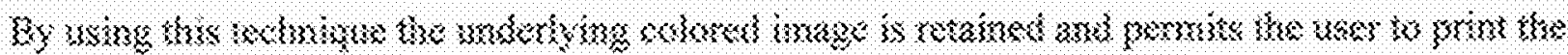

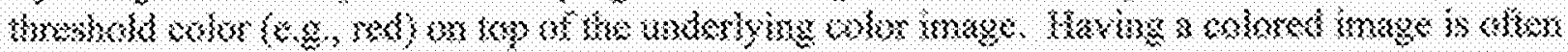

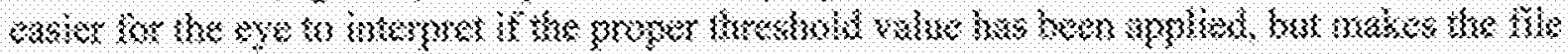

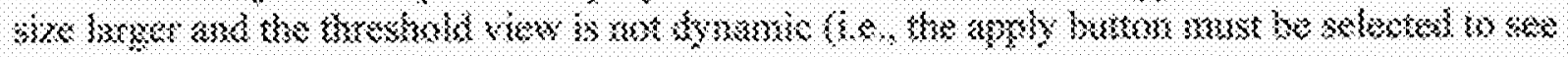
the sesuiss 


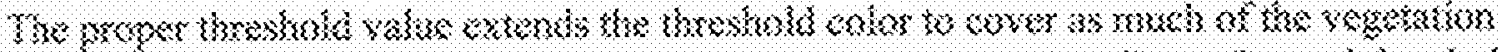

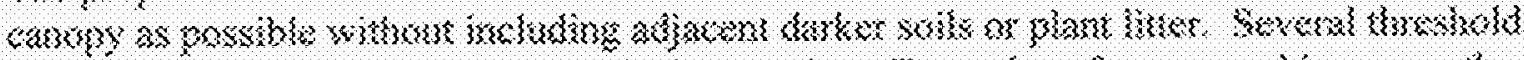

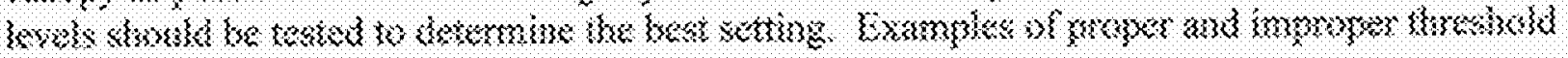

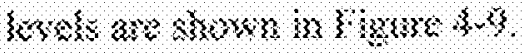

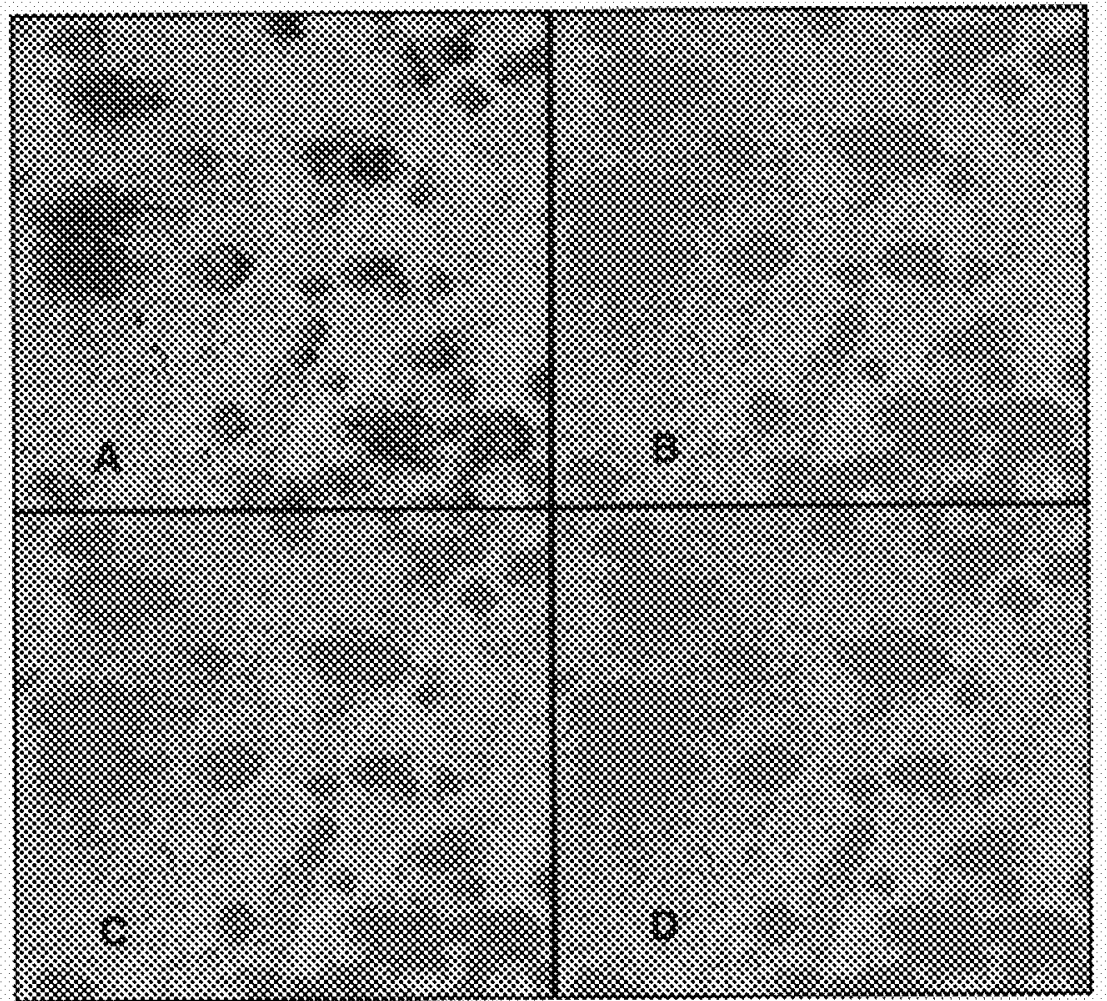

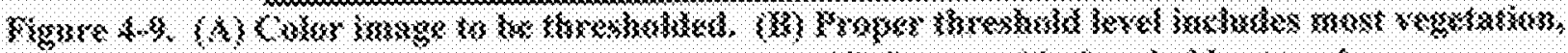

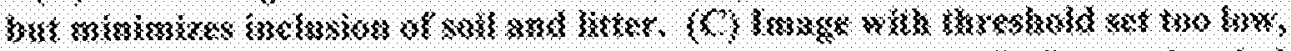

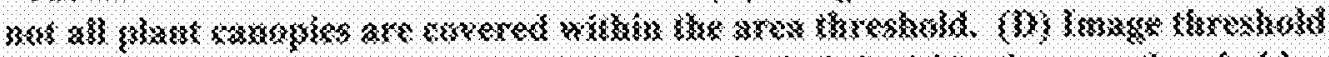
wh son high, back

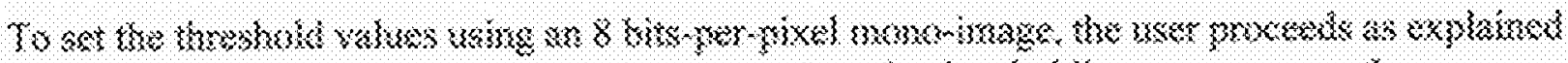

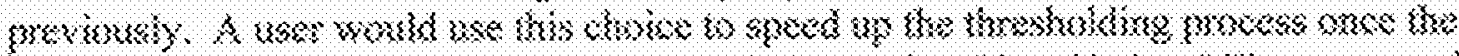

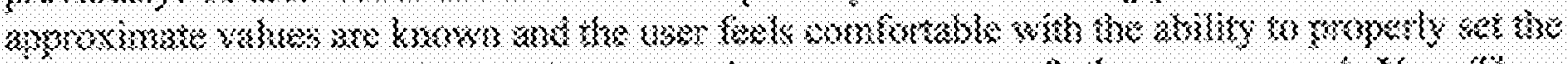

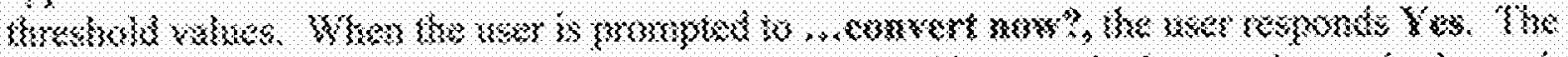

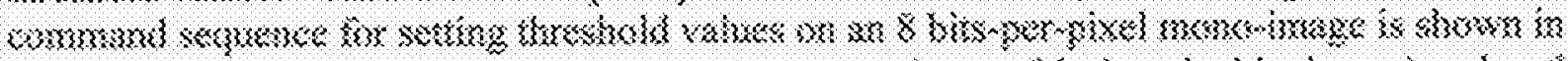

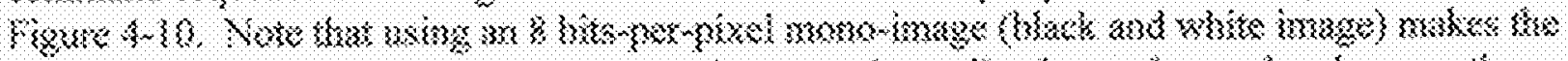

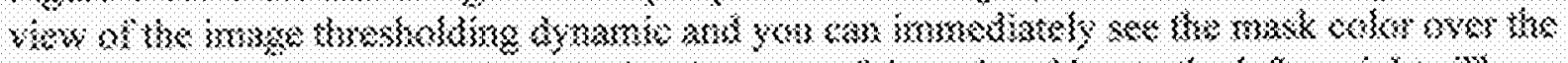

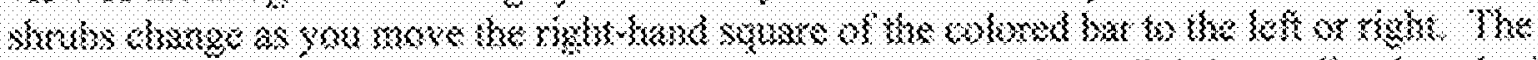

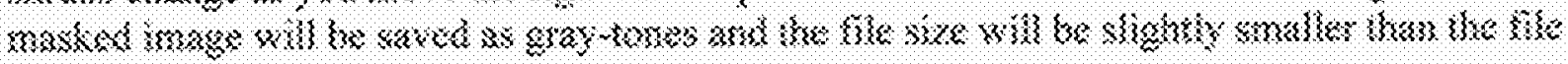

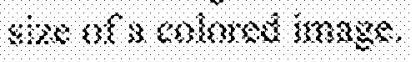




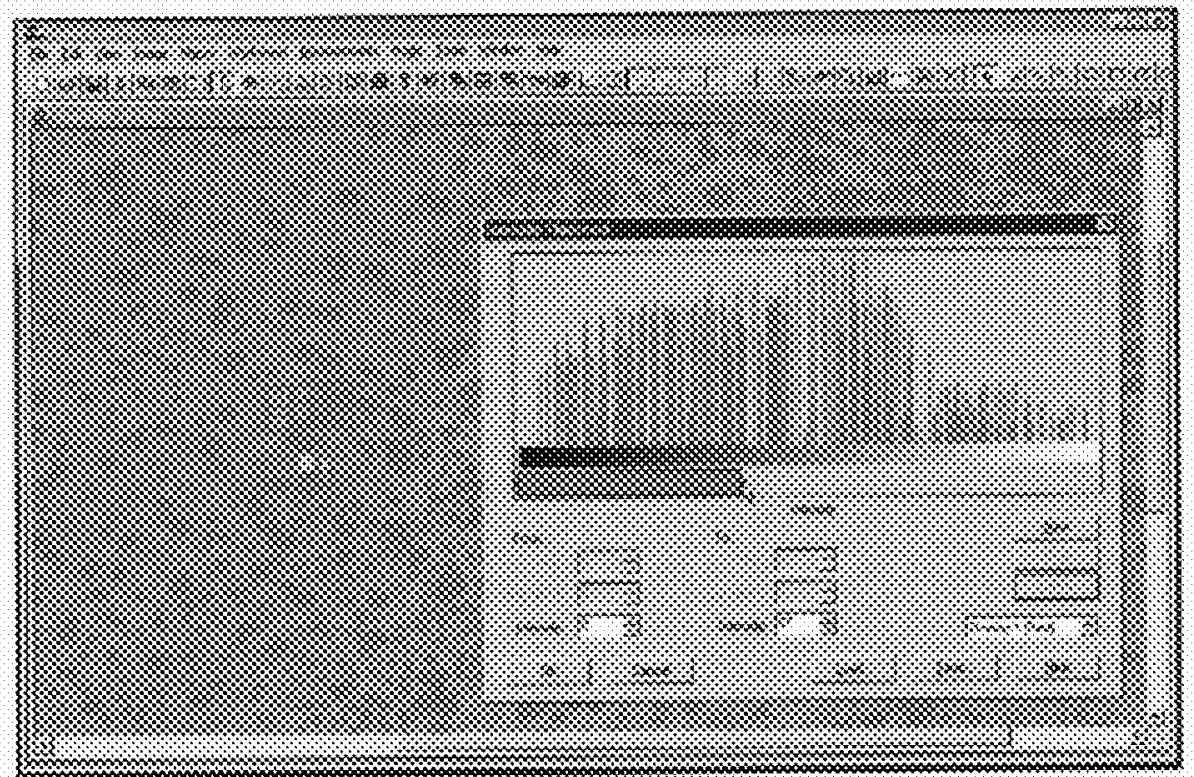

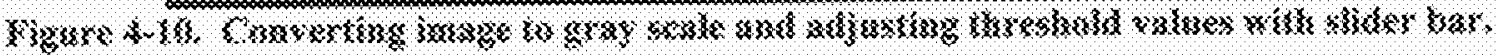

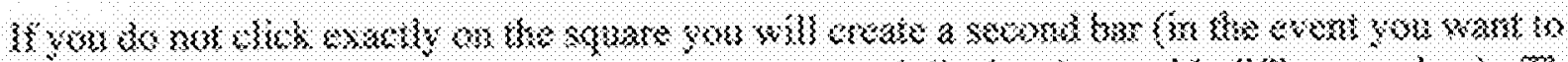

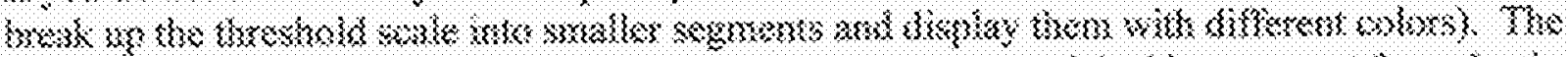

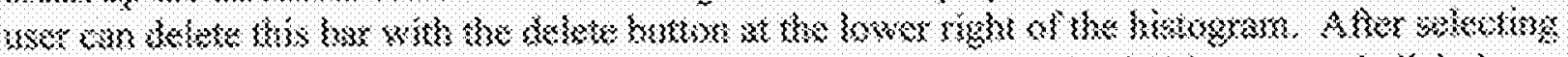

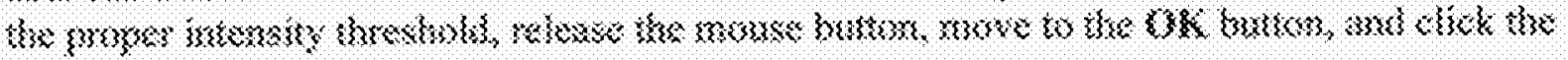
kefingroxis katkrom.

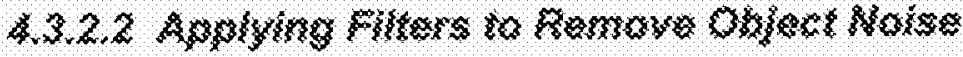

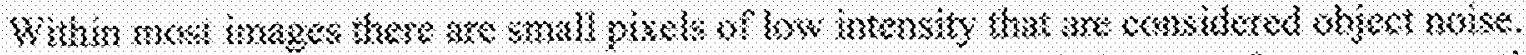

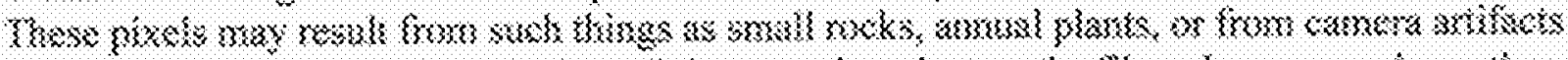

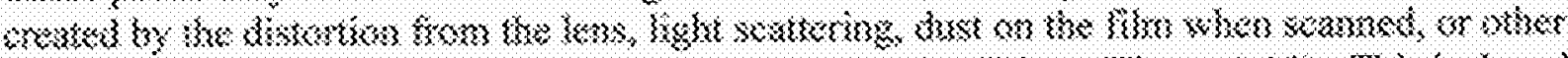

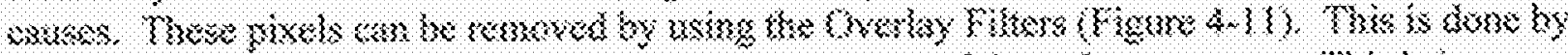

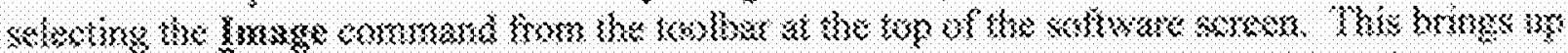

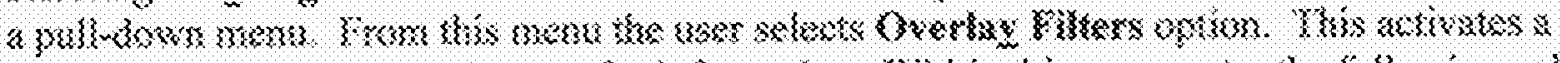

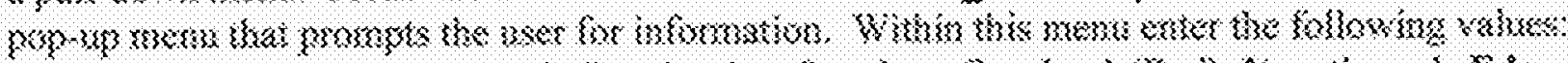

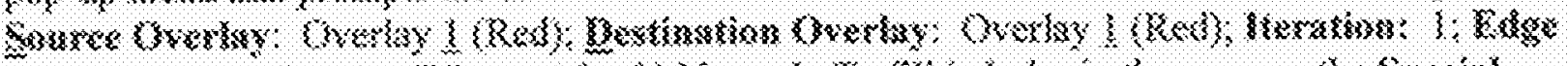

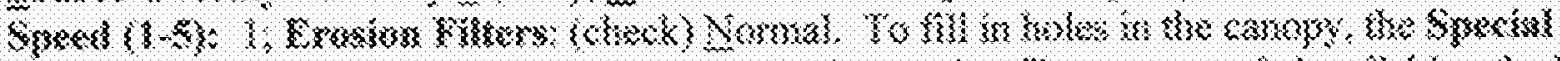

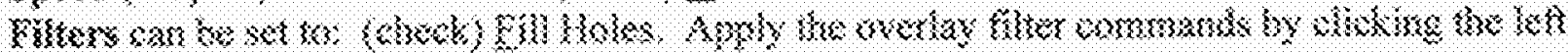

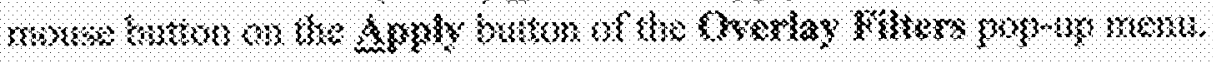



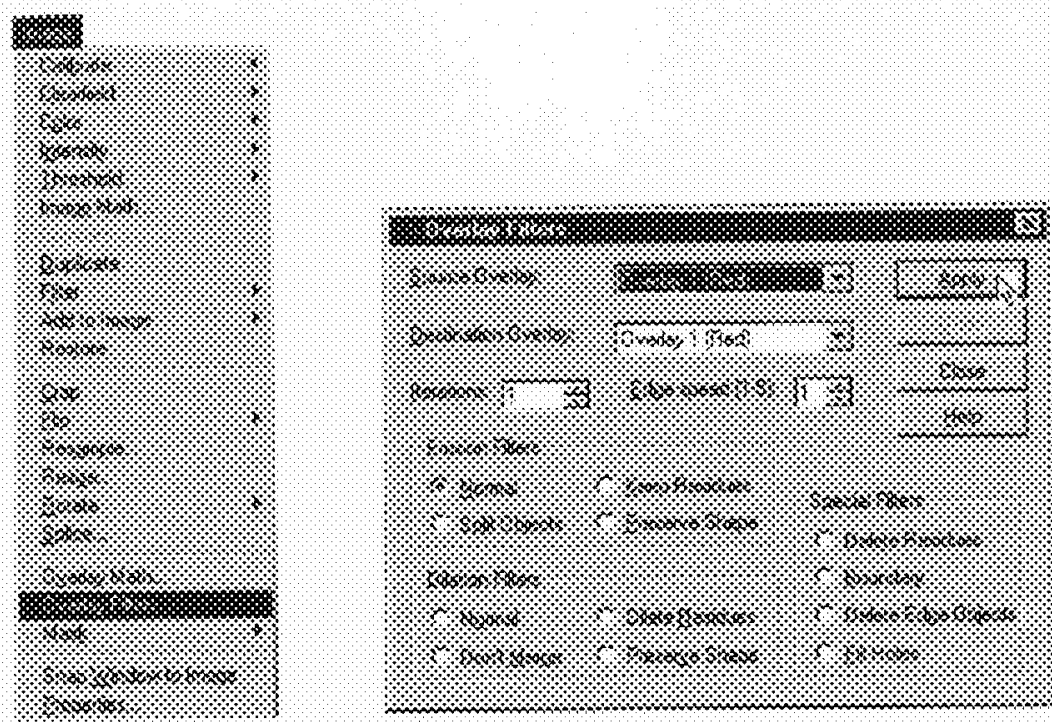

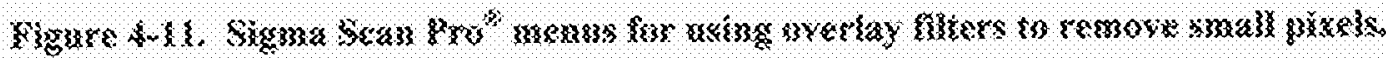

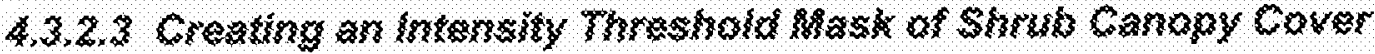

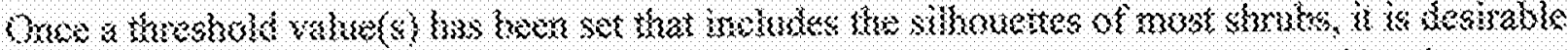

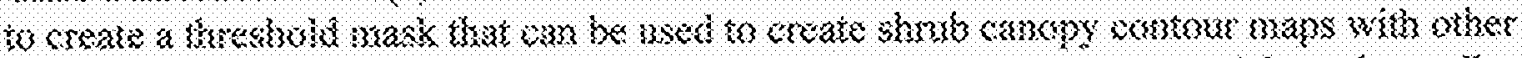

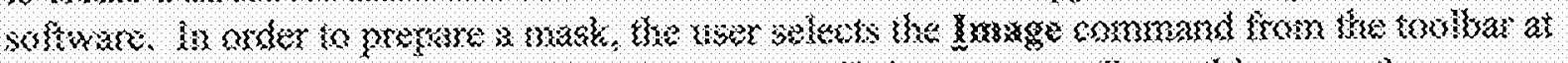

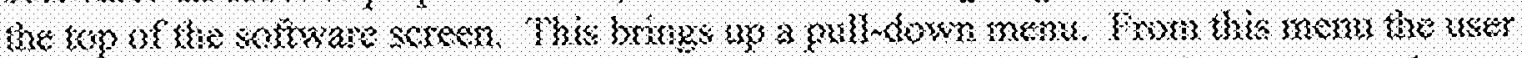

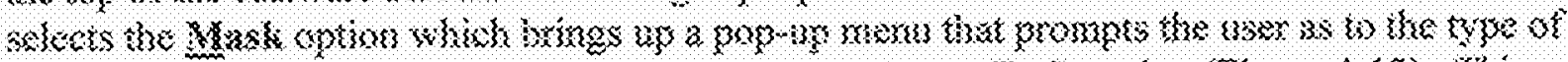

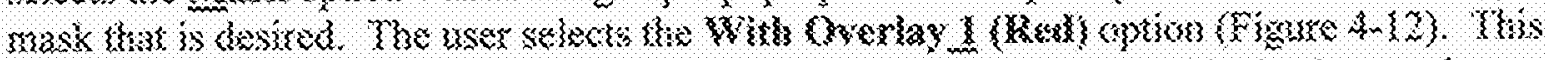

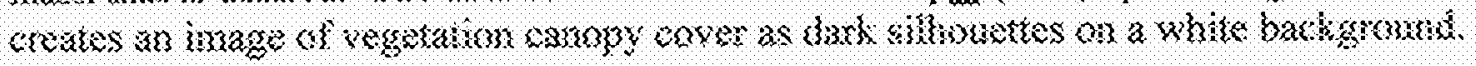

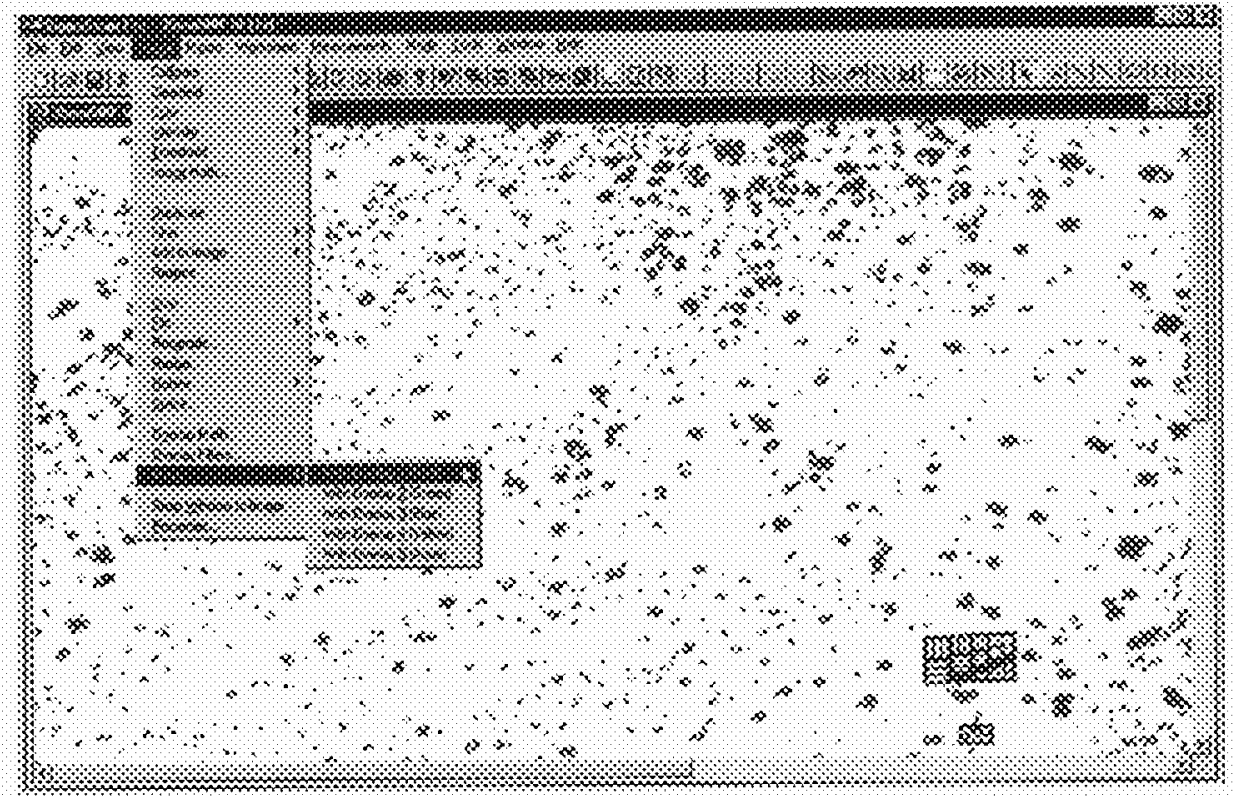

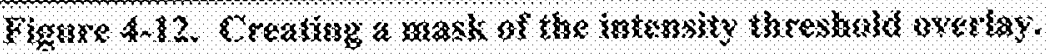




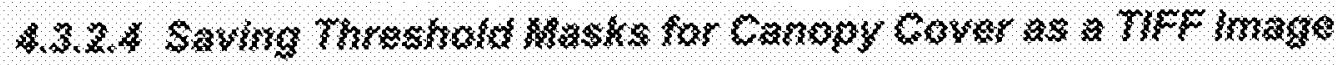

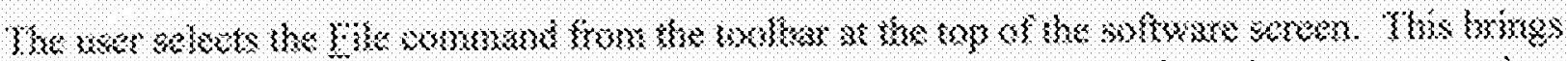

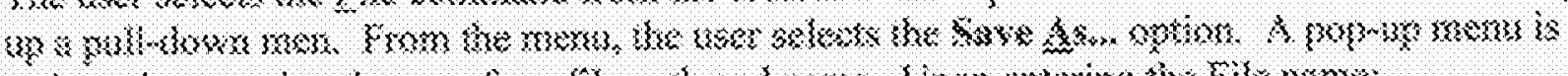

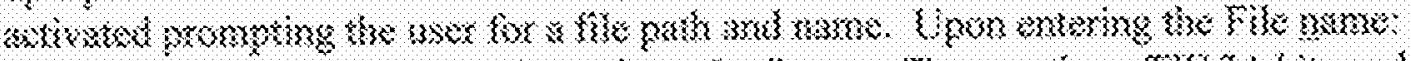

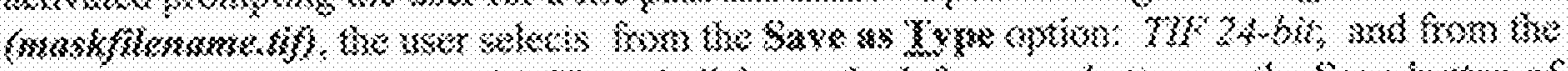

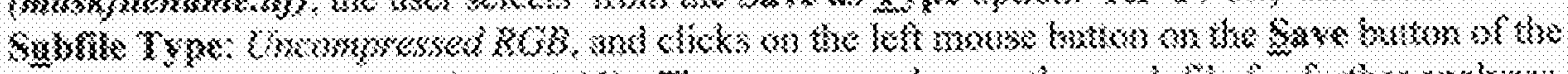

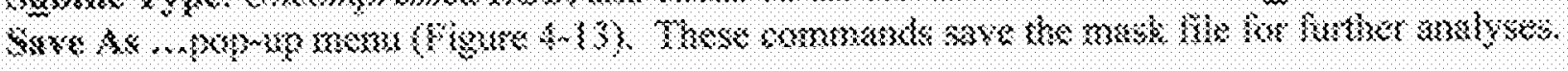

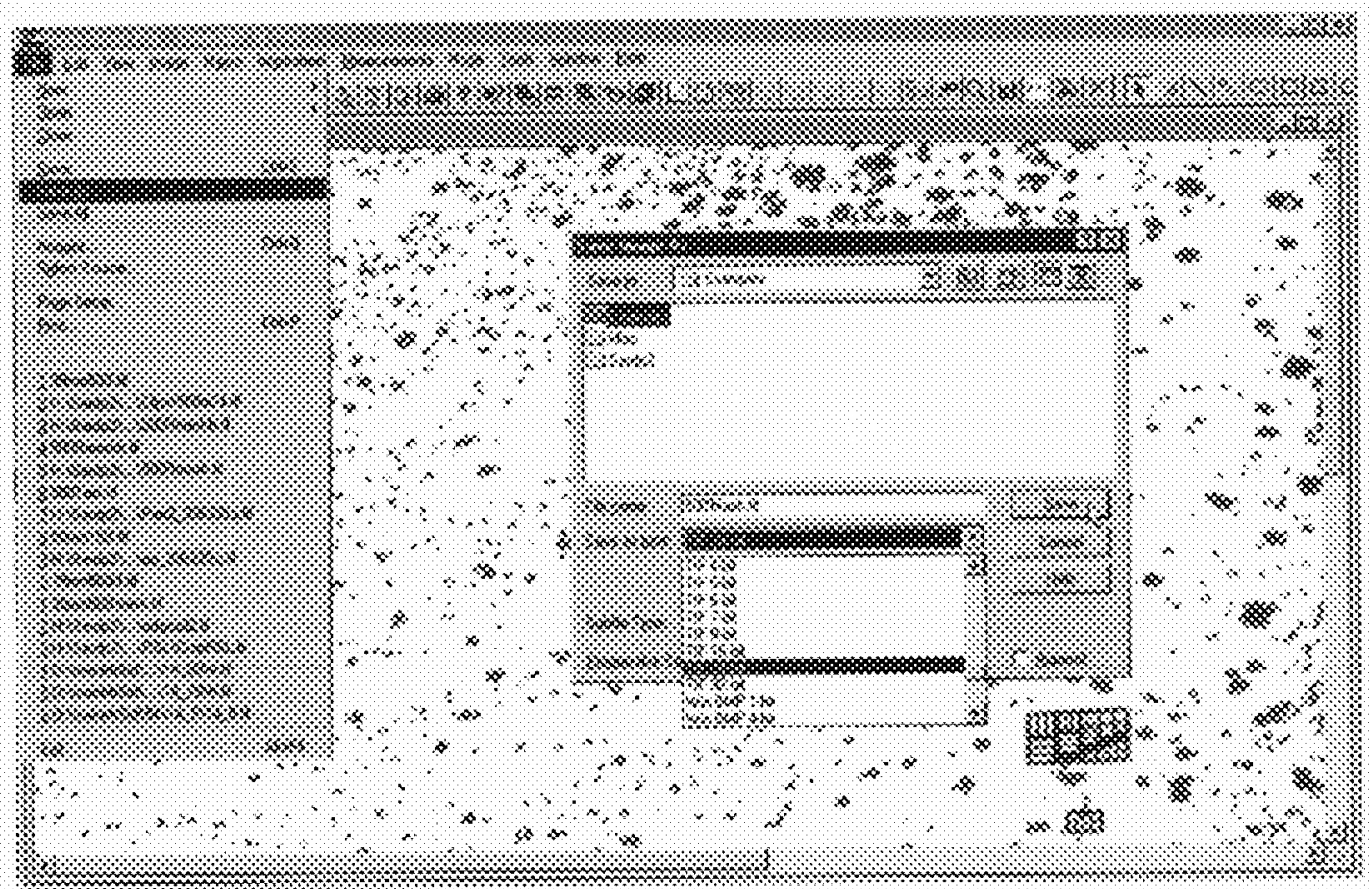

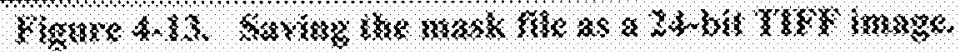

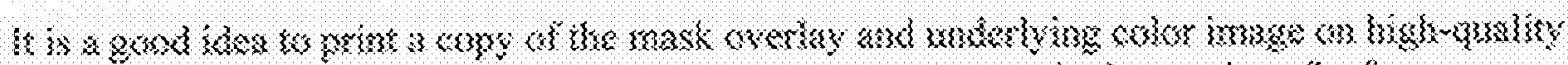

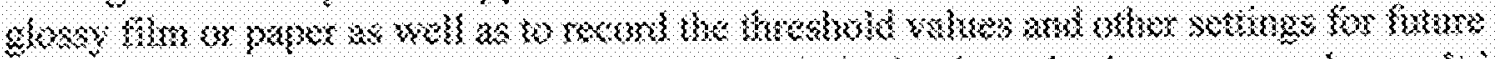

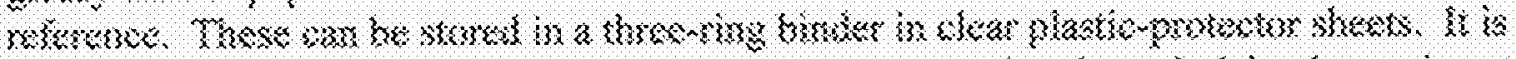

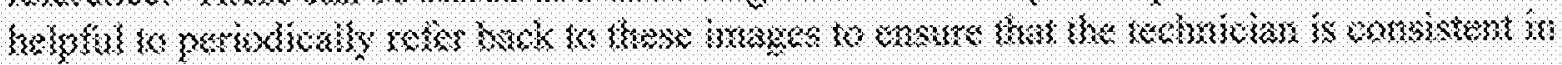

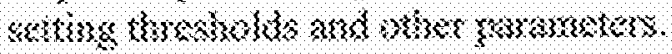

\subsection{3 mage}

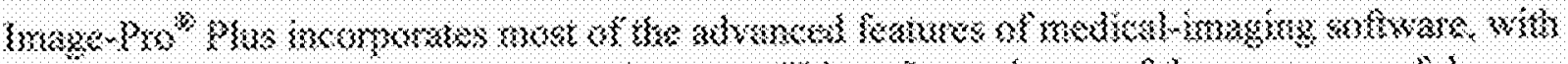

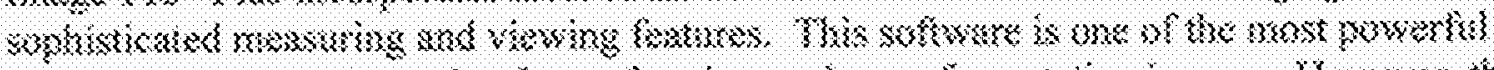

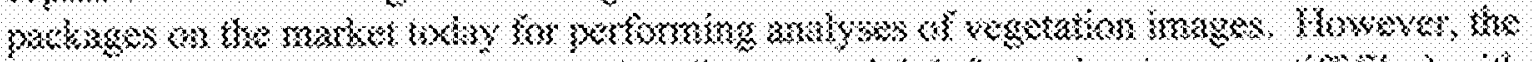

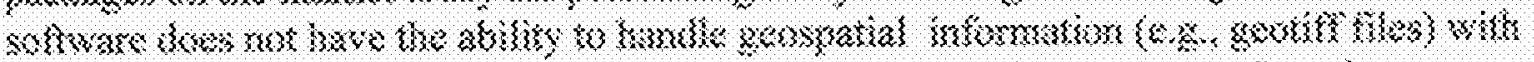

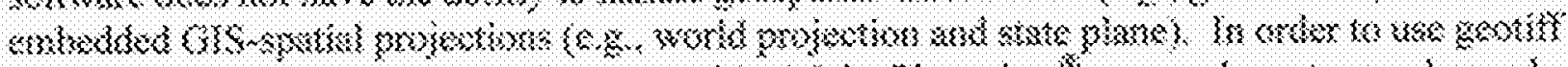

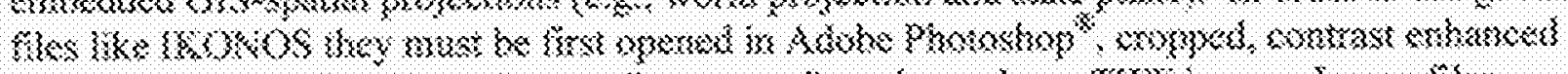

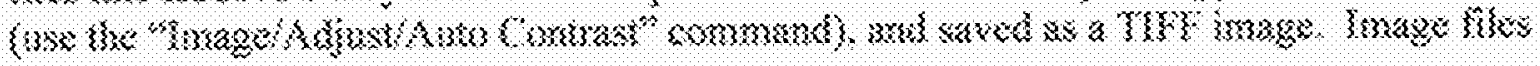


created by Image-Pro ${ }^{\circledR}$ Plus must then be imported into GIS software such as ArcView/Image Analyst ${ }^{\circledR}$, or ERDAS Imagine ${ }^{\circledR}$, and georeferenced when the geospatial coordinates of the image corners are known. Additionally, the size of the image that will load and process properly in Version 4.1 is restricted to about $150 \mathrm{MB}$. Large IKONOS images or scanned aerial photographs (e.g., $500 \mathrm{MB}$ ) will not load properly; however, smaller file sizes (e.g., $145 \mathrm{MG}$ of 9 inches [in] $\times 9$ in aerial photographs scanned at 800 disintegrations per inch [dpi]) will load and process properly. Future software versions may be enhanced to handle larger file sizes. The software also provides a simple means (i.e., flattening image) of correcting unequal colorbalance in an image due to vignetting (e.g., dark corners and a bright photo center caused by camera-lens distortion).

ImagePro® Plus,Version 4.1 has the ability to export image masks (e.g., 1,200 dpi black shrub silhouettes on a white background) at the same scale as the image from which they are processed, rather than having to rely on the screen-capture feature (e.g., pressing Shift-Print Screen then pasting the captured image into image-editing software such as Adobe Photoshop and saving it as a named TIFF-image file). Such screen-captured images typically have much lower resolutions (e.g., $72 \mathrm{dpi}$ ) than image files that can be saved without resizing the image. Hand-drawn notations added to the image or colored masks overlaid on the original photographic image must still be saved as screen-captured images.

The user's group that supports this software is relatively large and provides excellent opportunities to communicate with other users on a daily basis. Users seeking answers to questions can post questions on a user's group Internet site (register at http://www.solutionszone.com/ipednld/subscriber.asp or user groups at: http://www.mediacy.com). Users may also search the archive files available at: $\mathrm{http}: / / \mathrm{www} . \mathrm{mediacy} . \mathrm{com} / \mathrm{tech} / \mathrm{ipts}$ _ugml.html where such questions and comments are bundled and e-mailed to registered users daily. This can be a helpful source of solutions that is not contained in the user's guides.

\subsubsection{Loading Image Files}

Instructions provided here are based on ImagePro® Plus, Version 4.1 and may not necessarily reflect features or procedures available with newer versions. To open or load an image, select and press with the mouse cursor the File command from the toolbar at the top of the window (Figure 4-14). This activates a drop-down menu. Next select Open from the command list. This activates a pop-up menu Open File which displays the path and file name information. With the cursor on the Look in box, browse through the drive and file path on the hard drive and select the file name you wish to load. Double-click on the desired file name or press the Open button when the proper file name appears in the File name window to load the image. If the file is too large, an error message will pop up explaining that the image is too large. The image may have to be resized or cropped into smaller files sizes should this occur. 


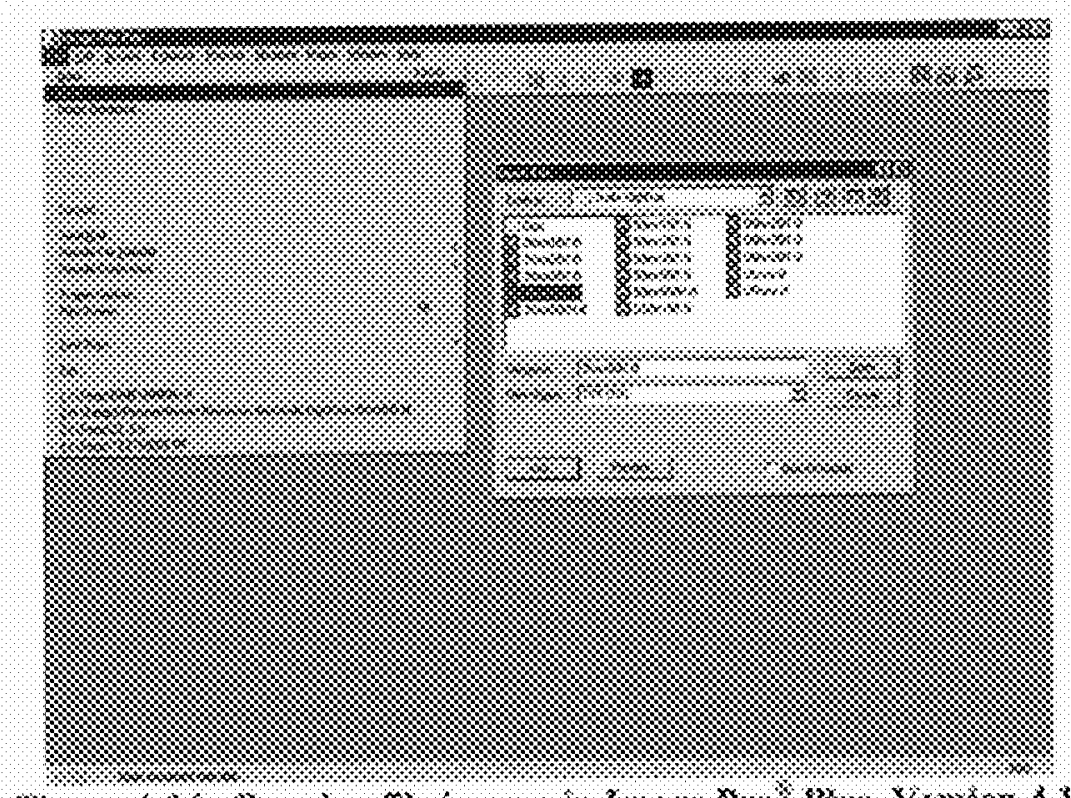

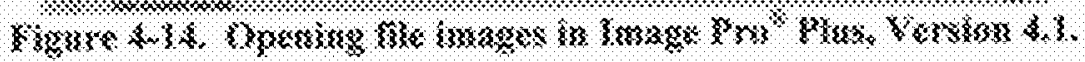

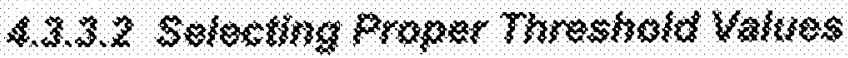

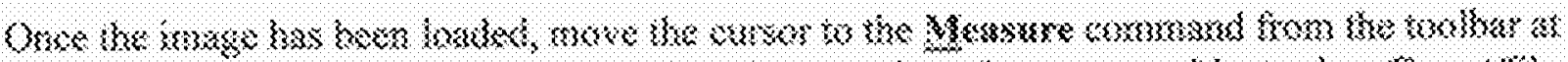

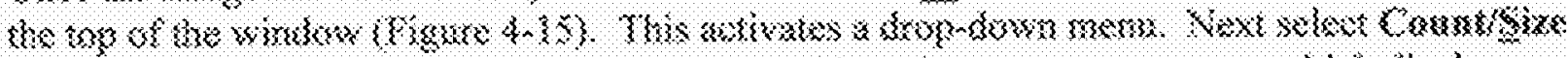

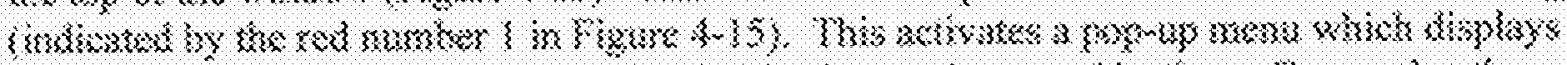

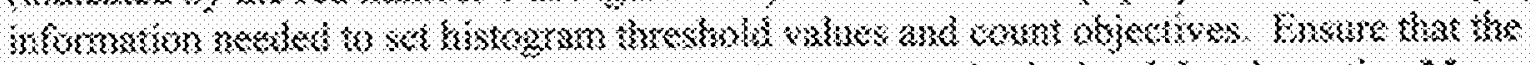

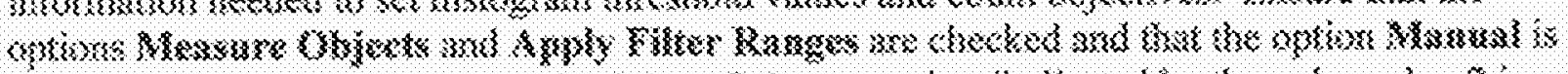

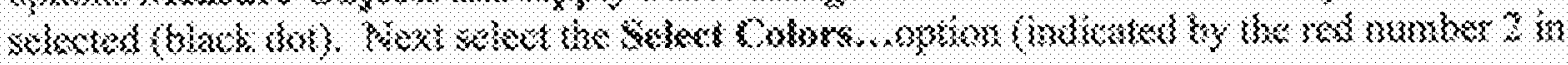

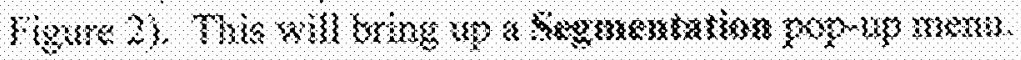

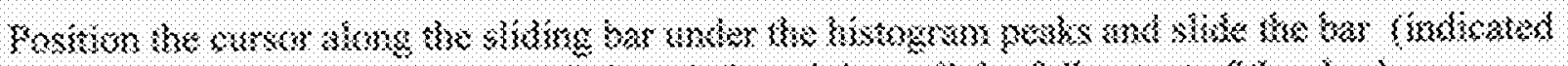

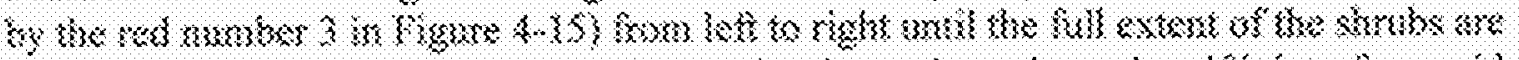

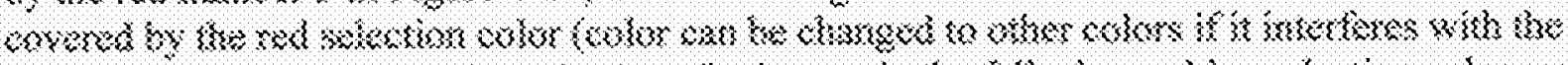

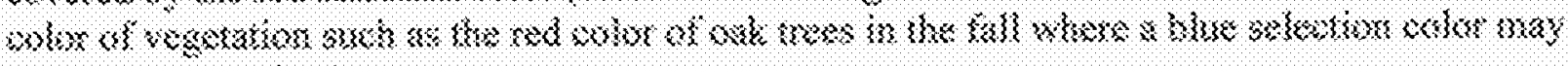
be asose anymopriazes.

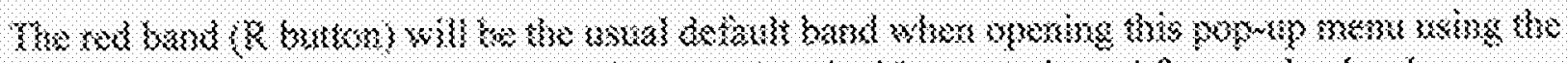

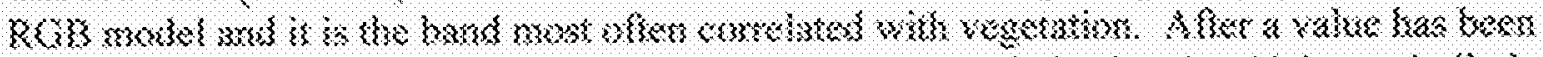

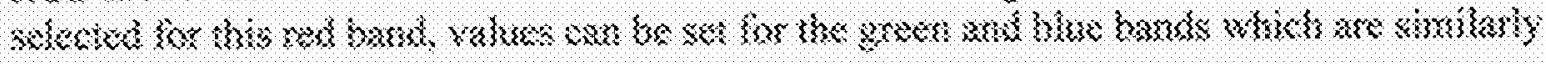
abismedi.

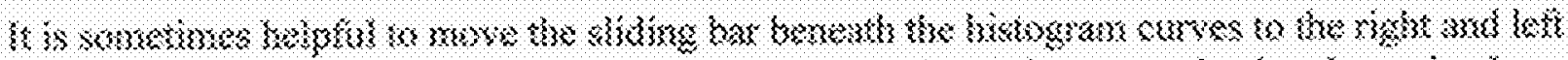

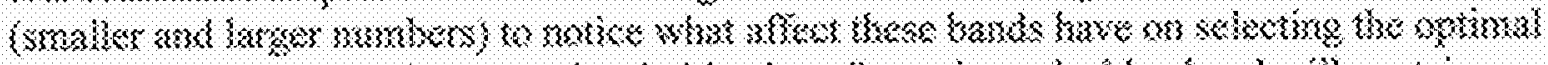

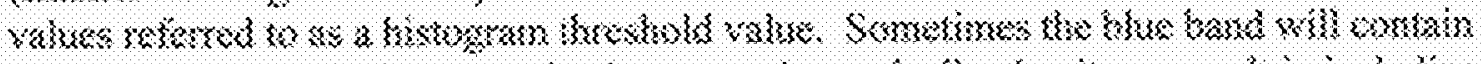

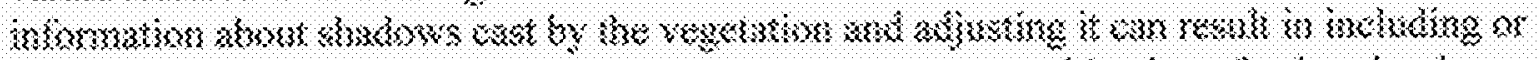

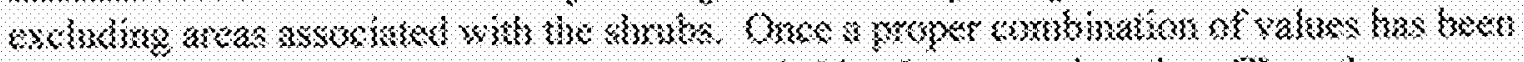

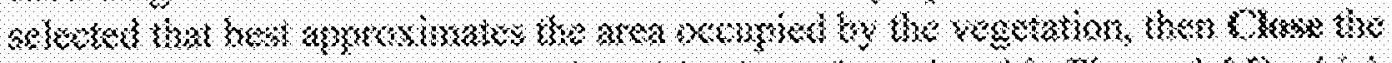

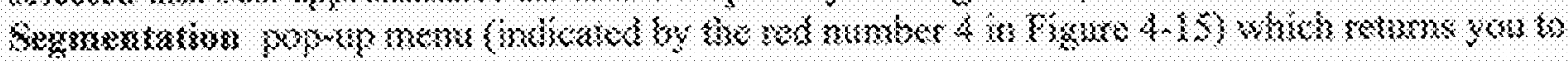

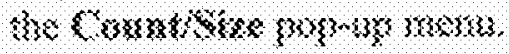




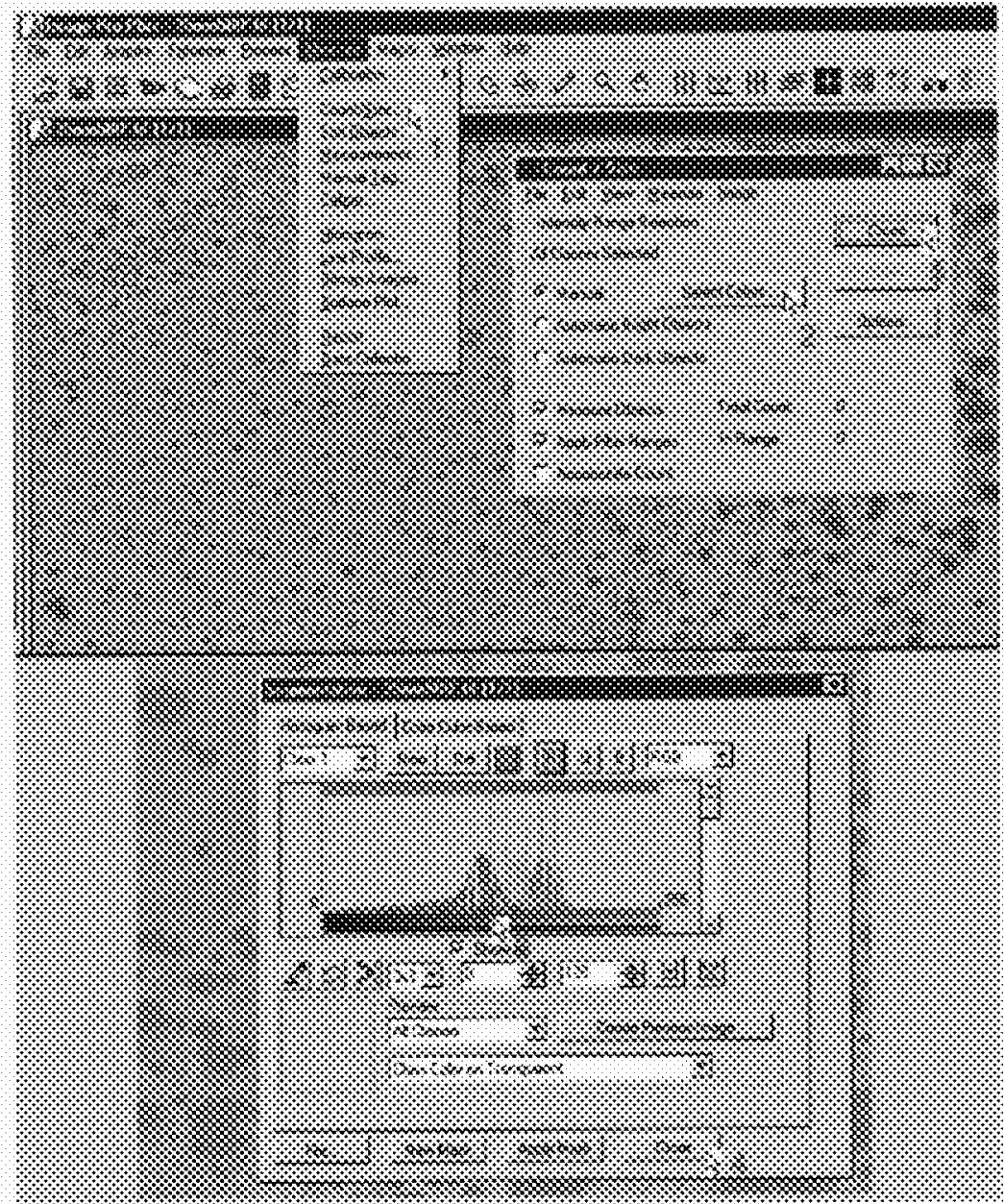

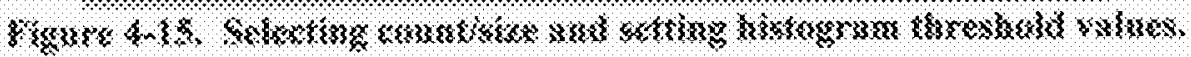

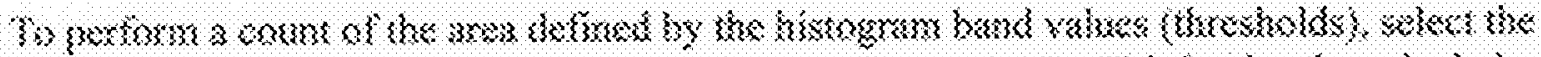

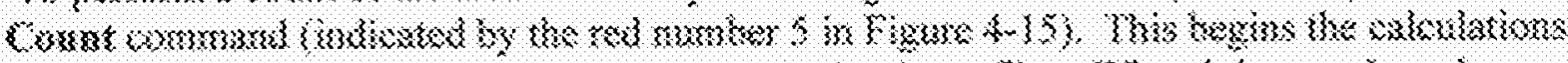

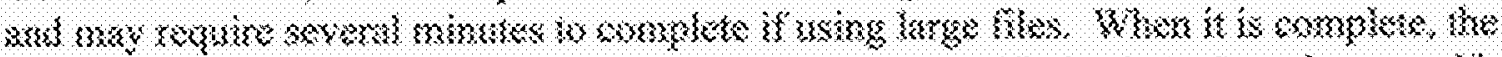

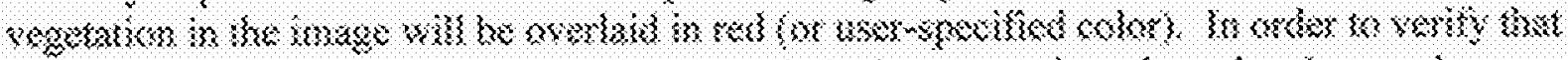

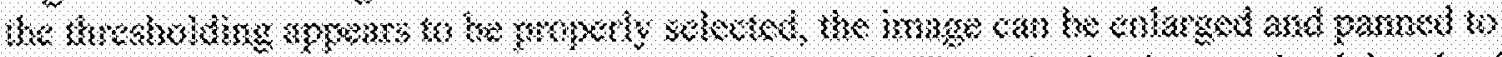

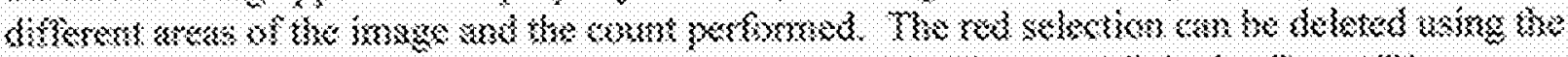

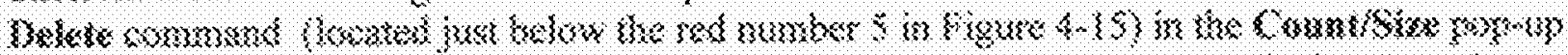

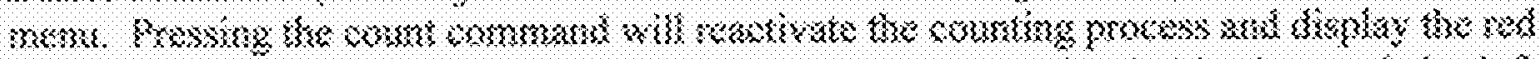

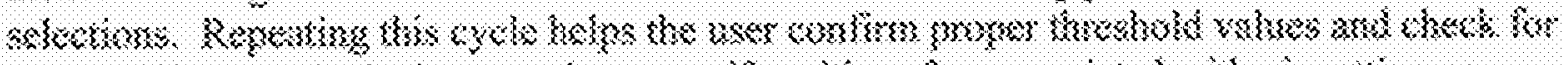

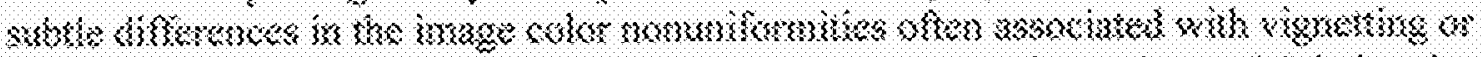

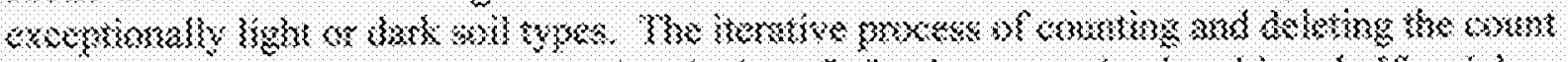

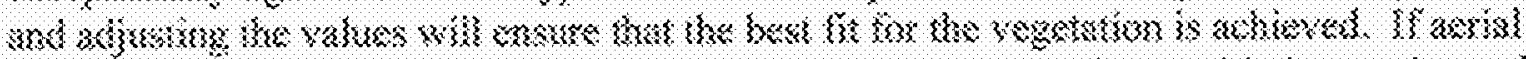

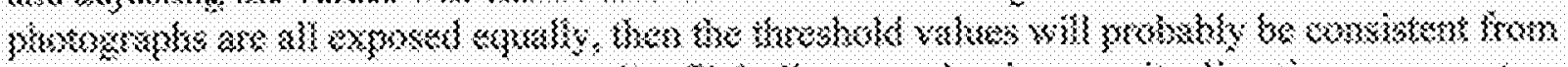

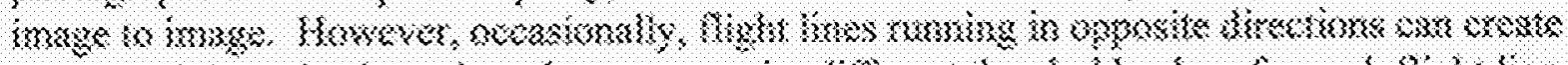

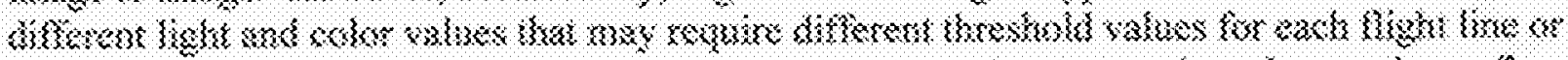

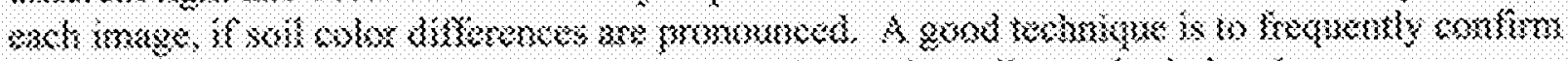

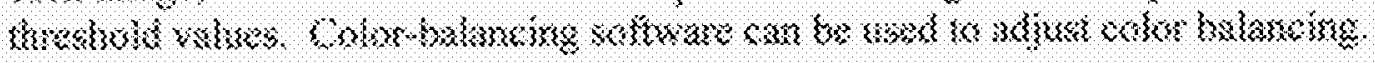




\subsubsection{Whonate cometrion}

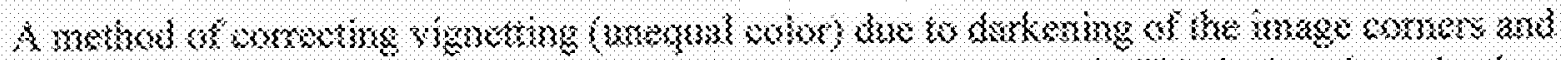

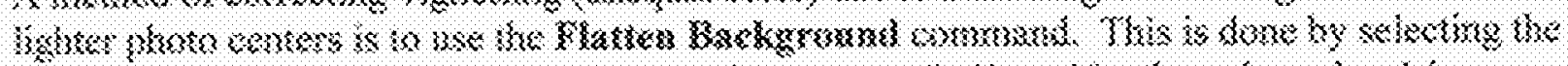

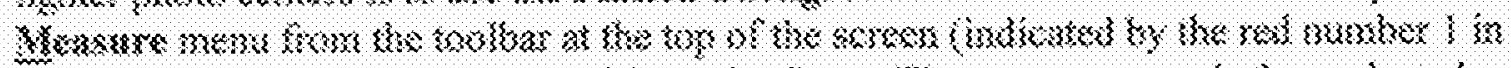

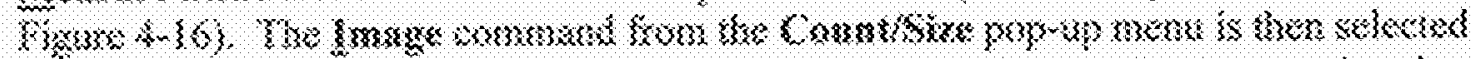

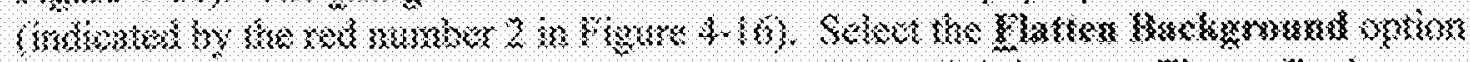

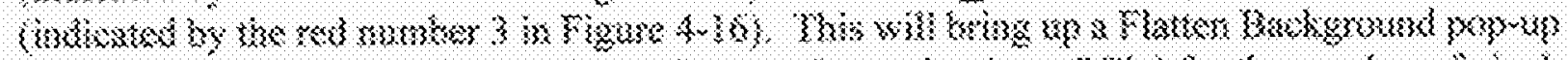

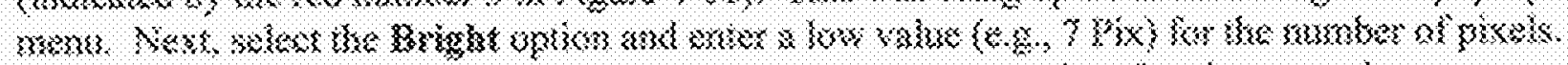

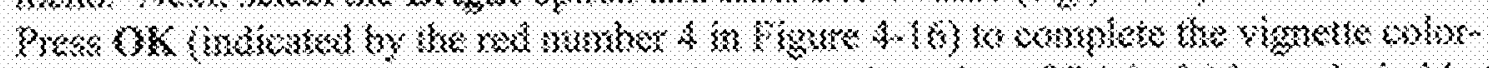

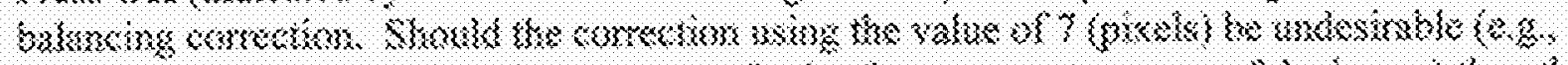

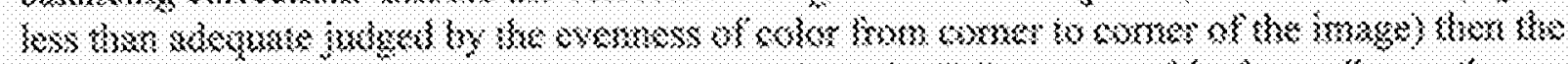

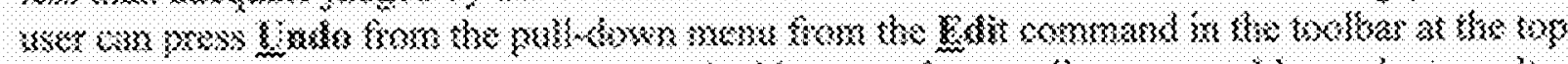

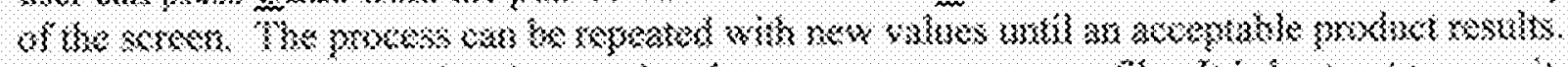

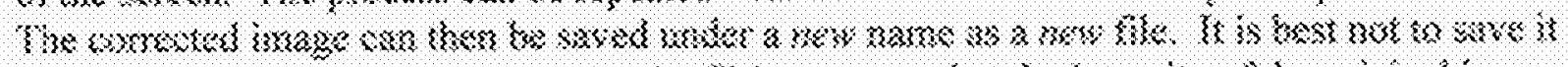

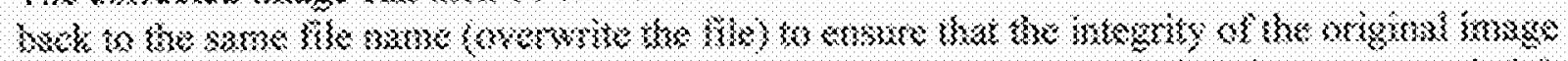

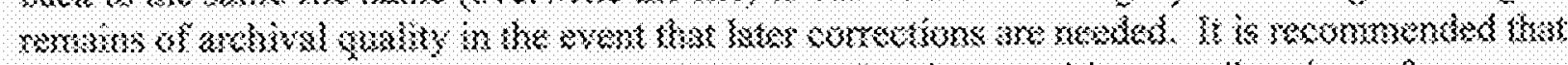

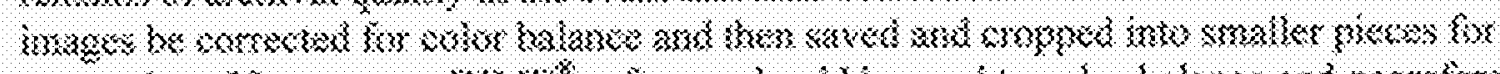

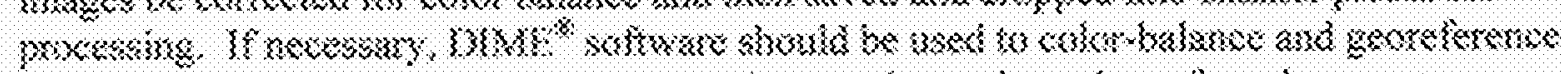

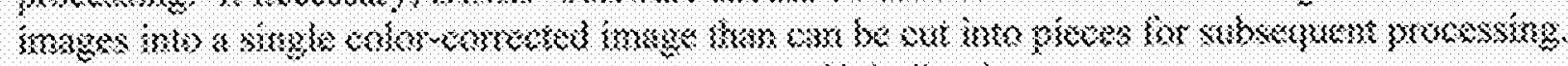

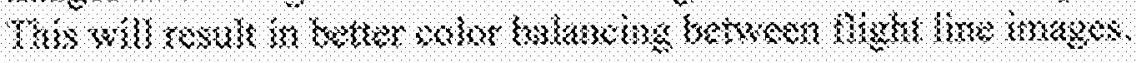

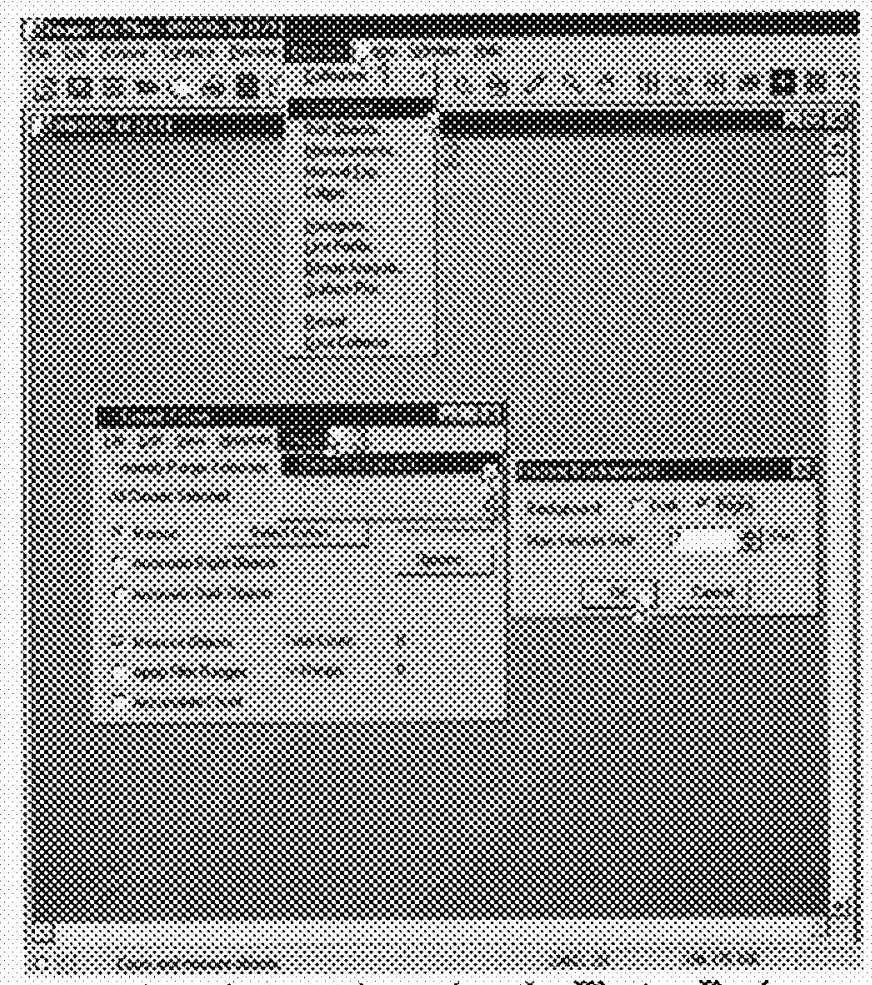

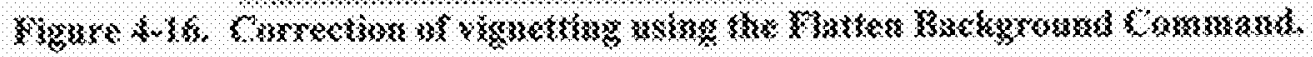




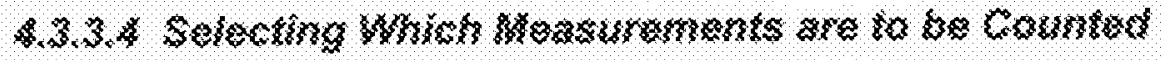

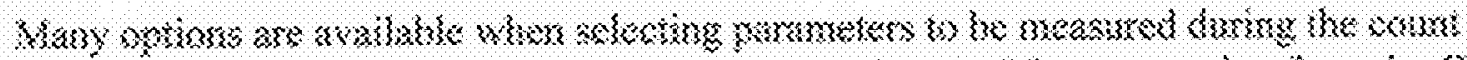

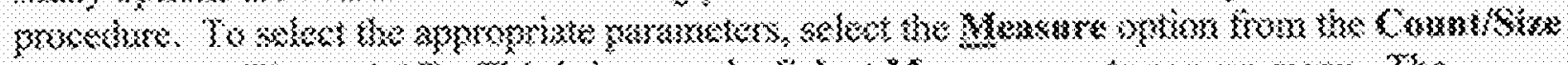

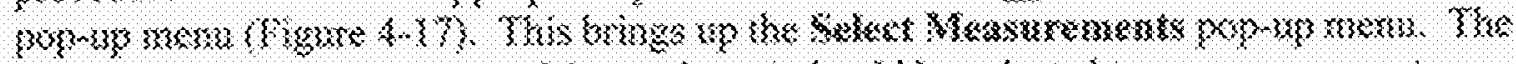

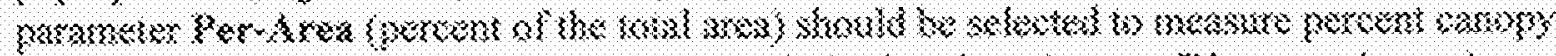

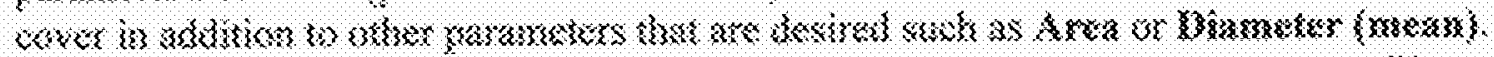

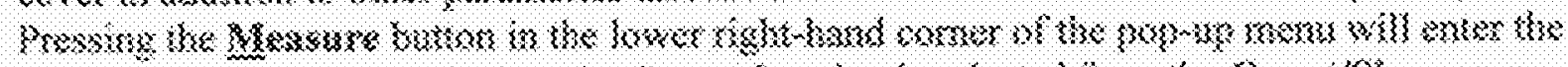

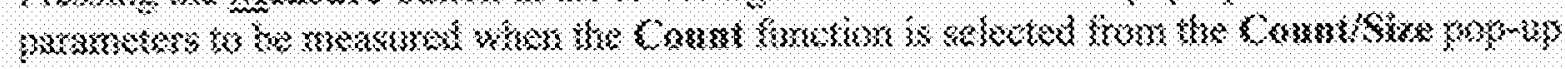
mæs:mss.

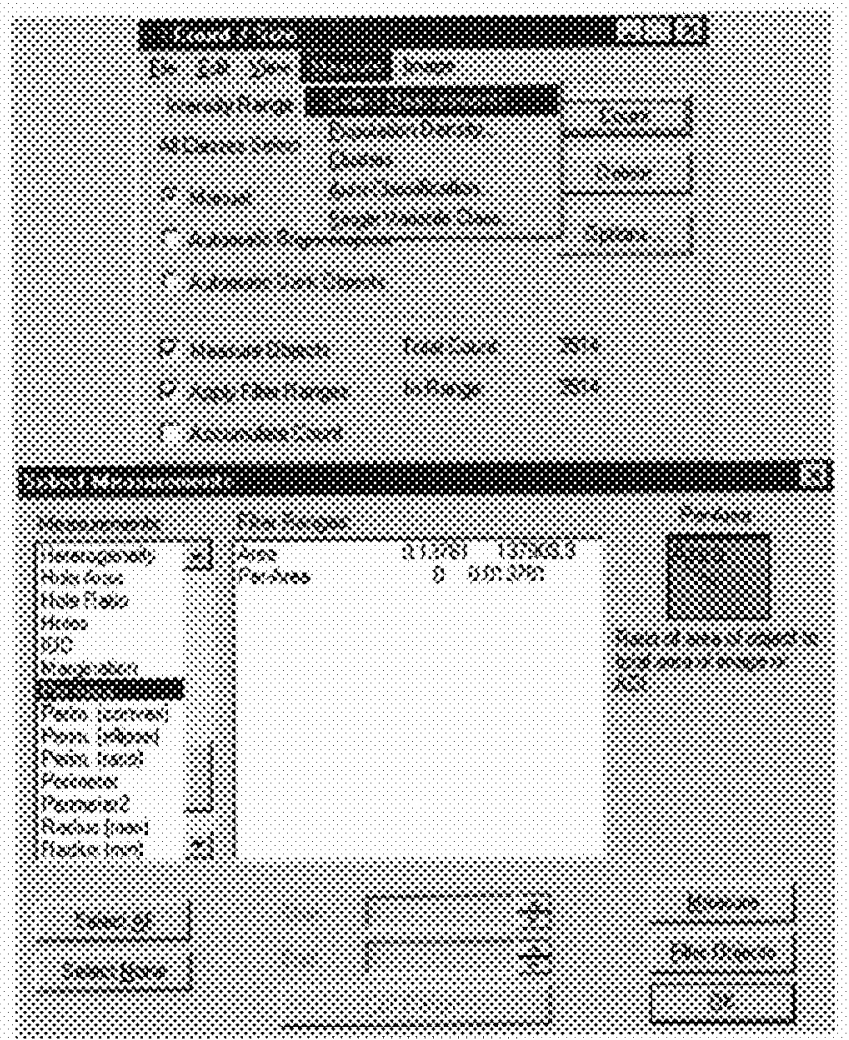

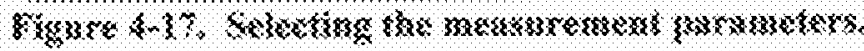

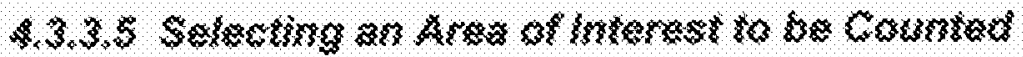

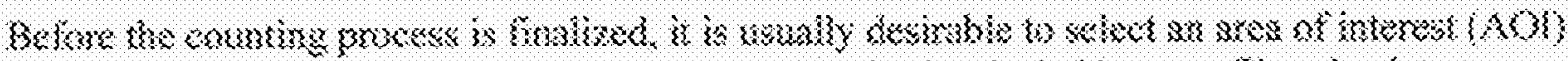

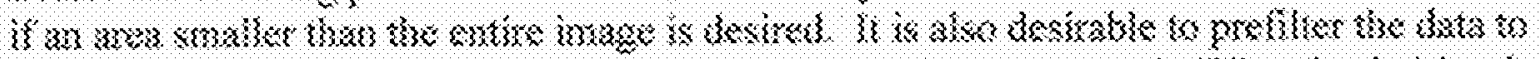

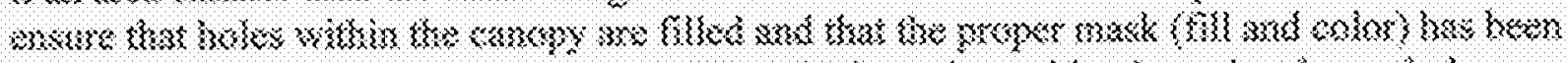

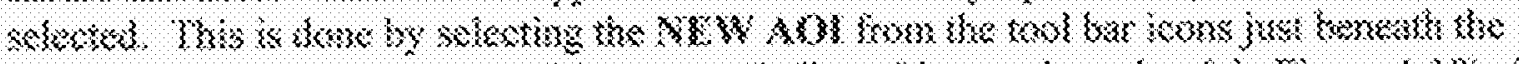

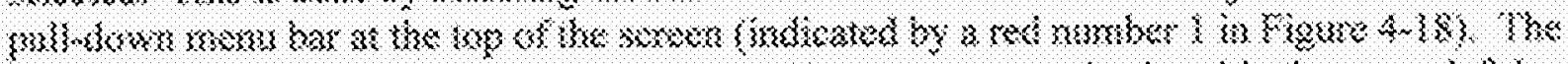

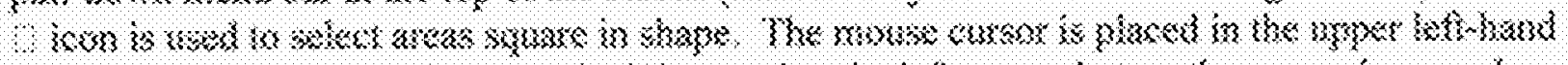

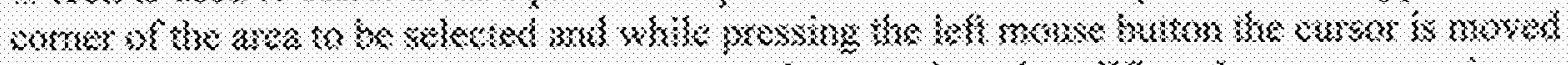

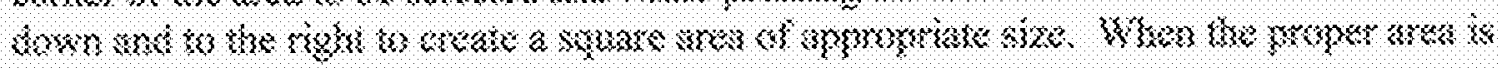




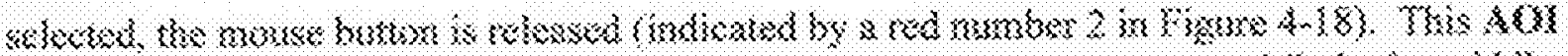

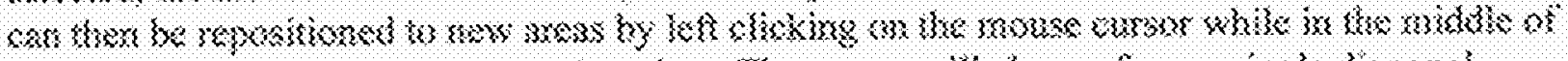

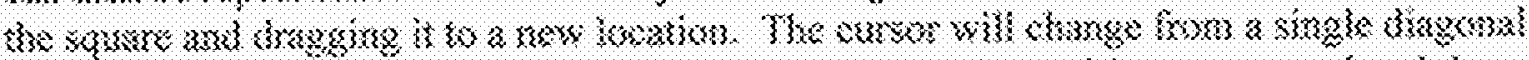

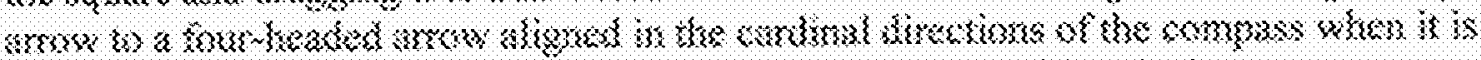

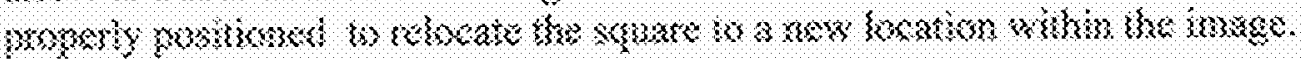

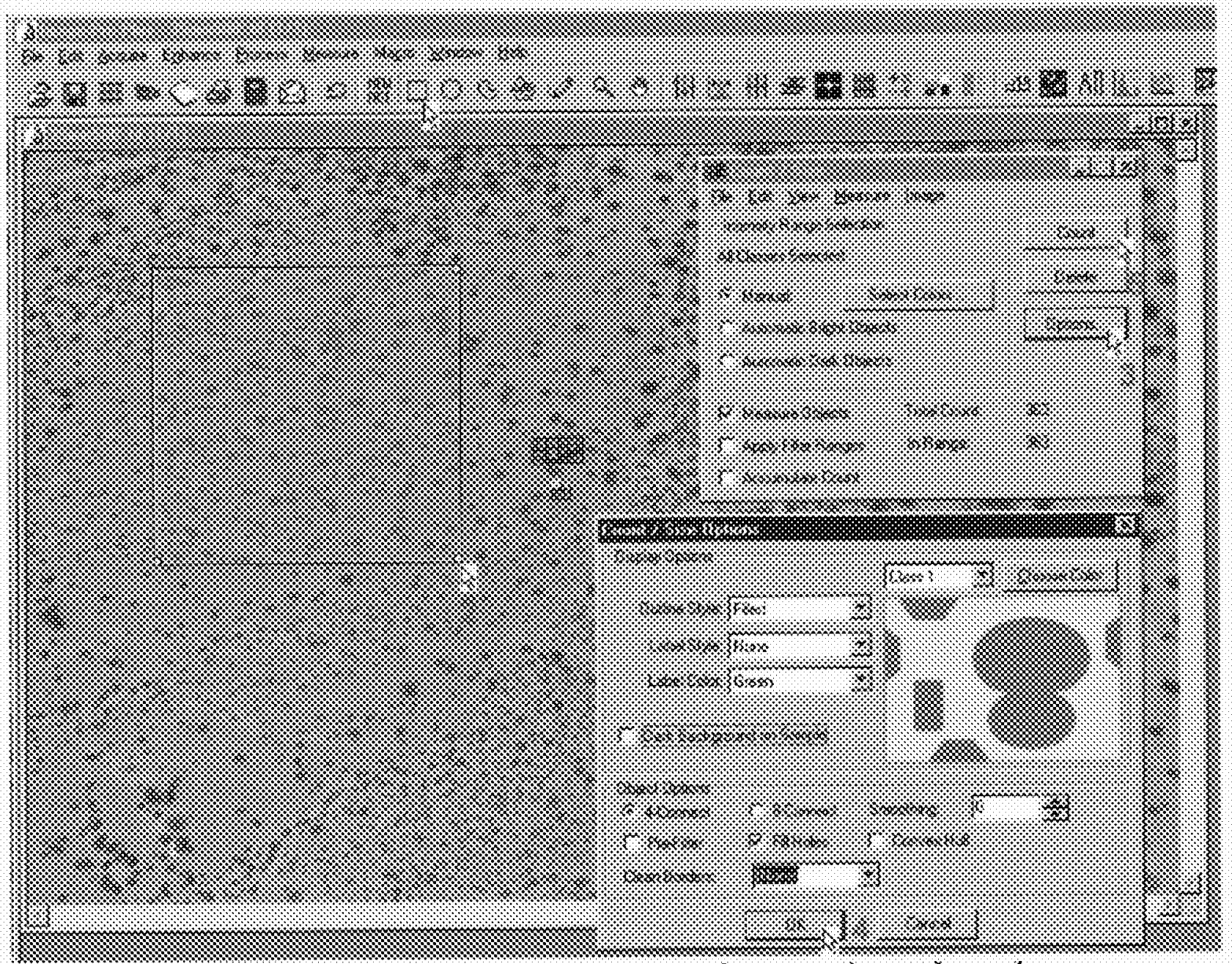

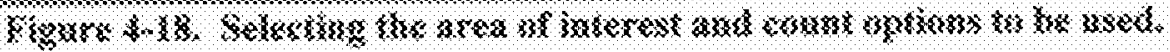

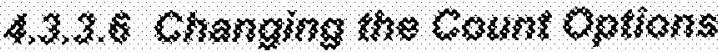

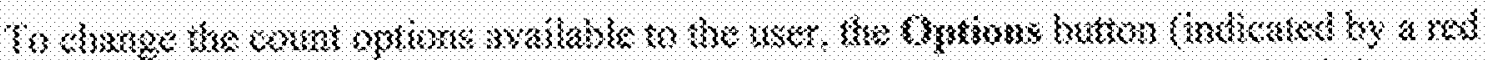

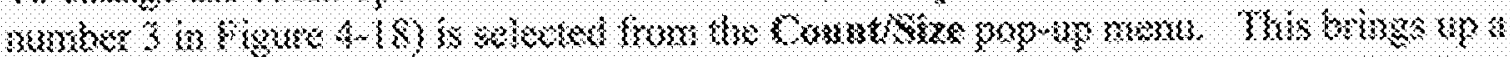

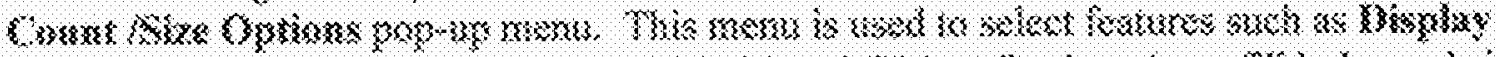

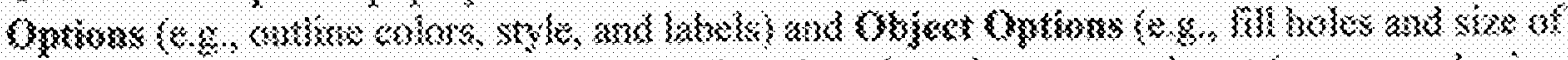

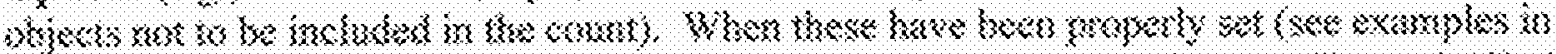

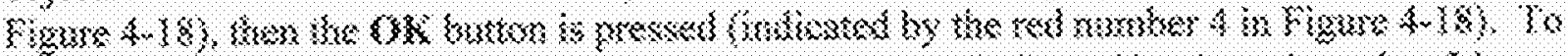

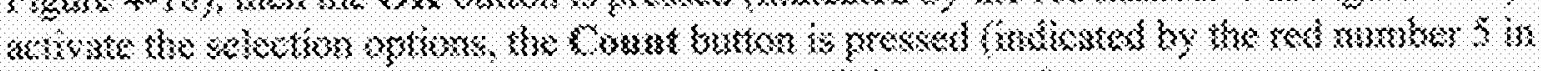

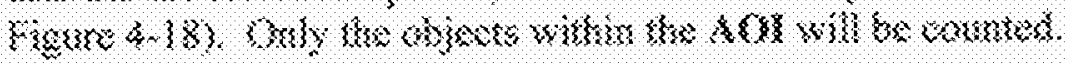




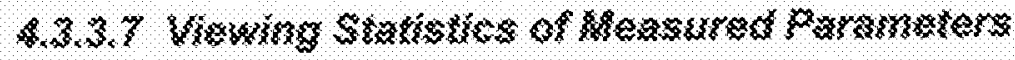

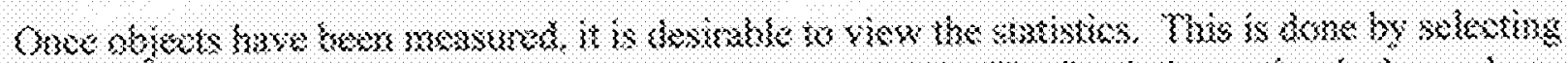

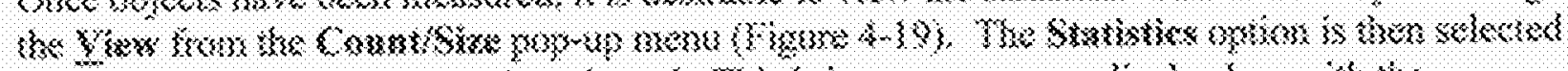

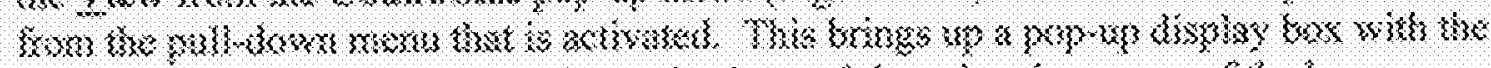

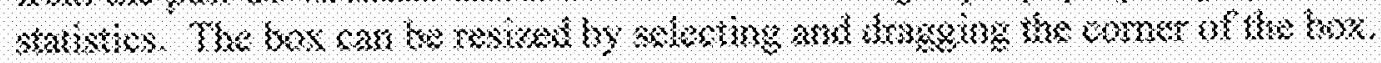

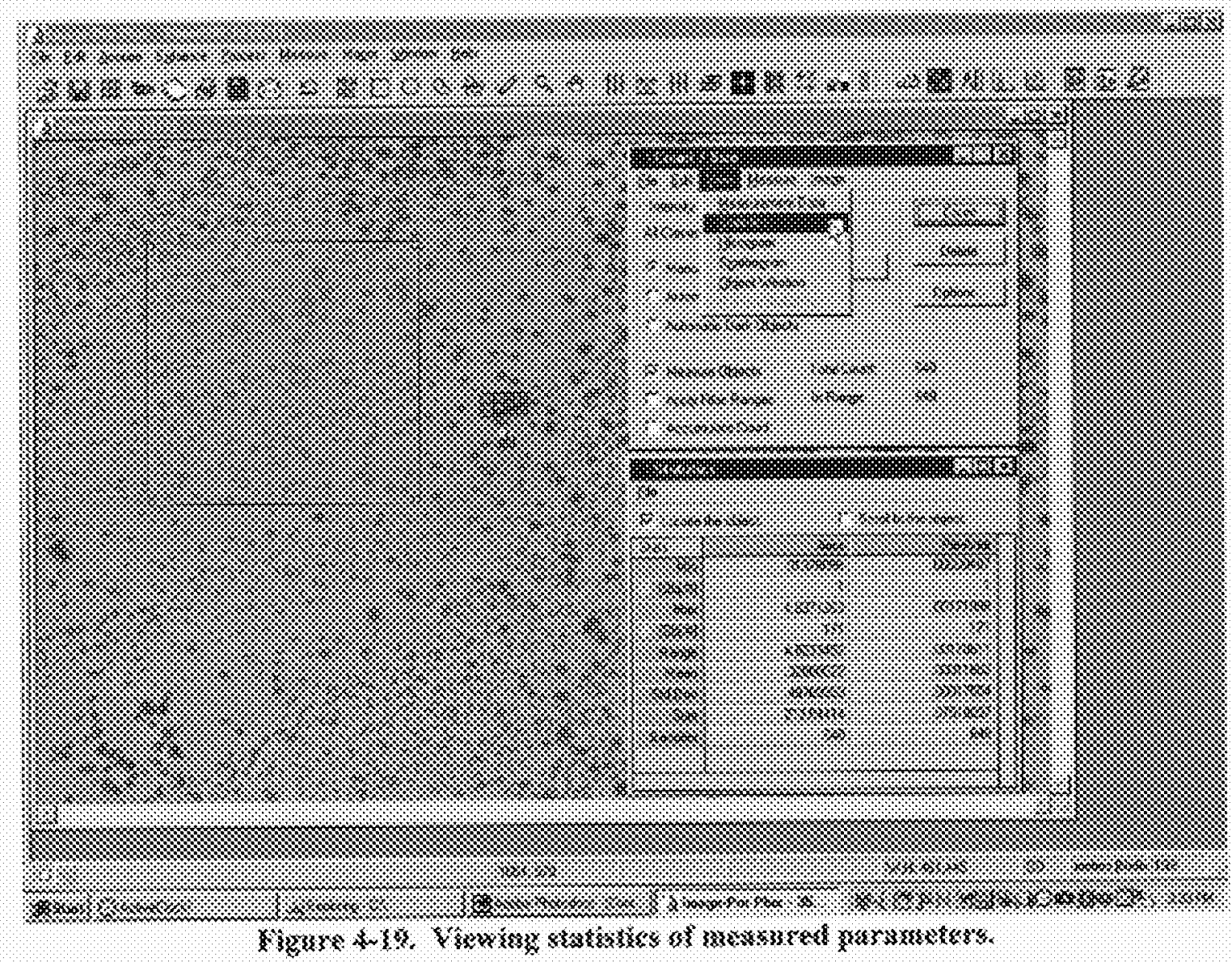

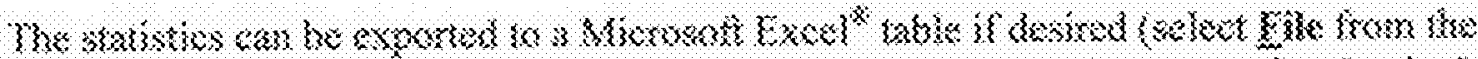

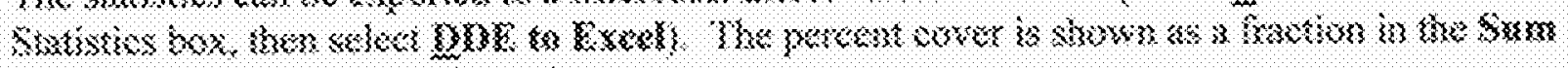

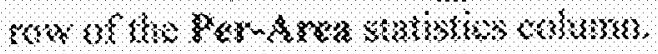

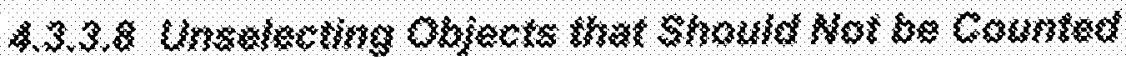

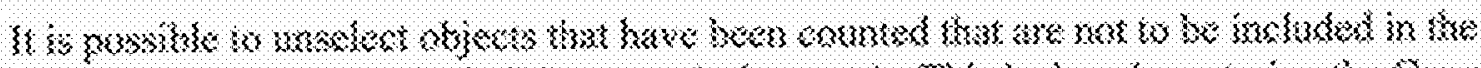

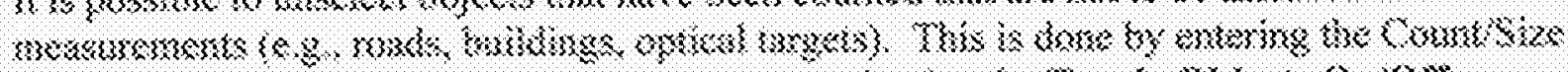

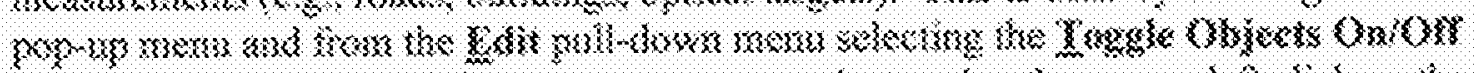

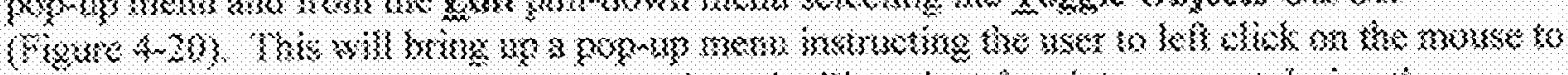

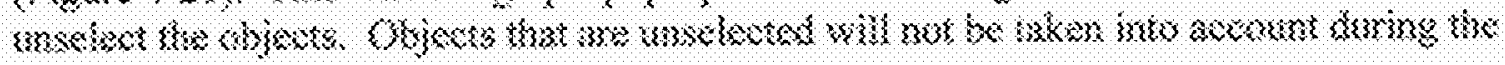

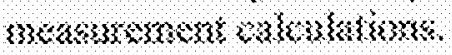




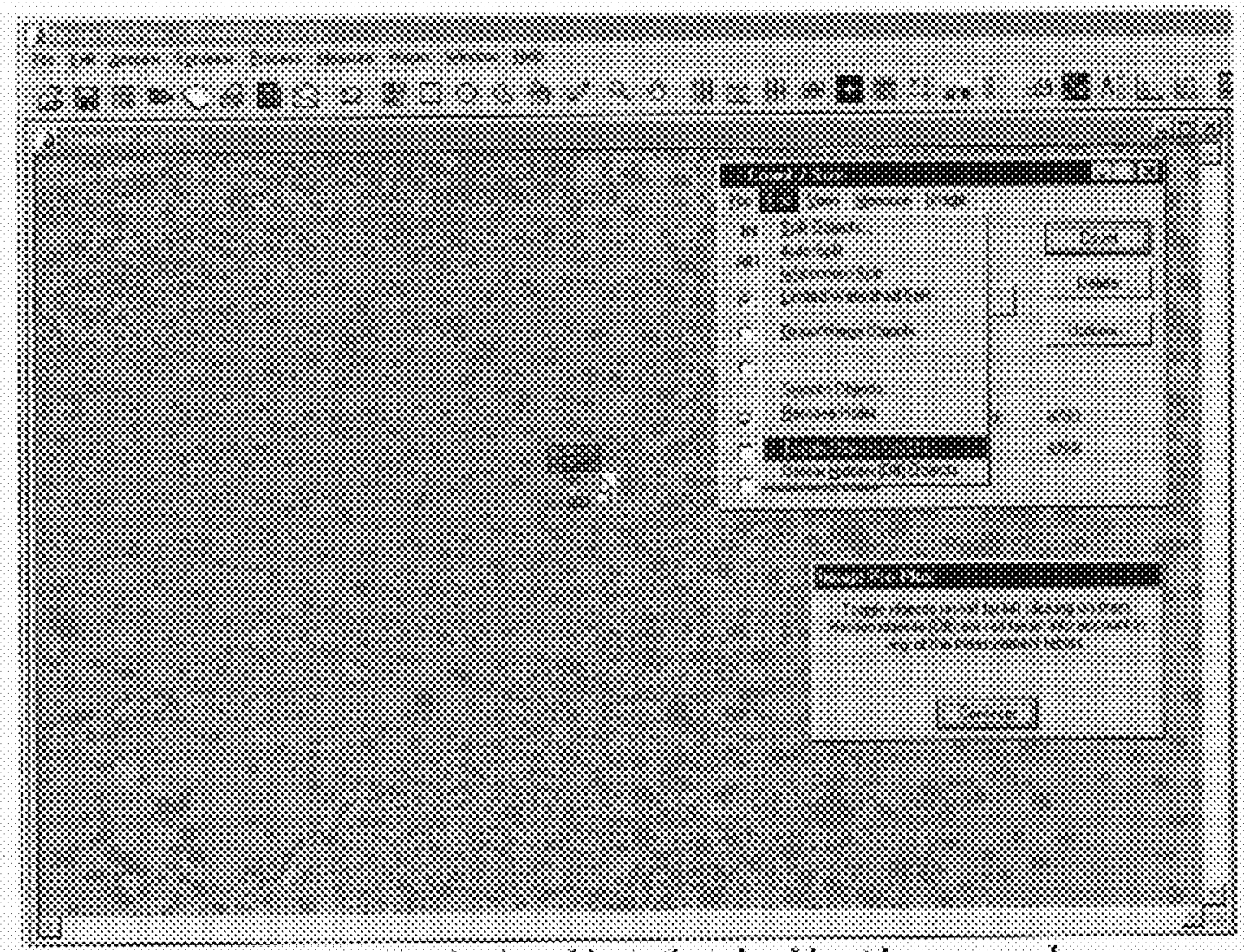

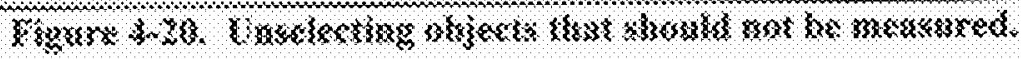

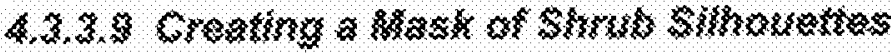

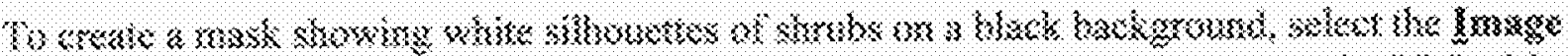

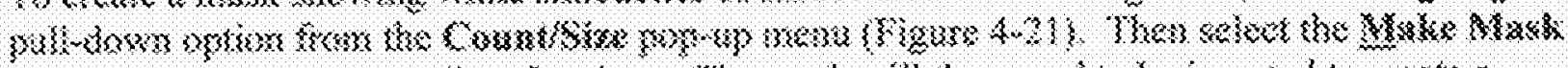

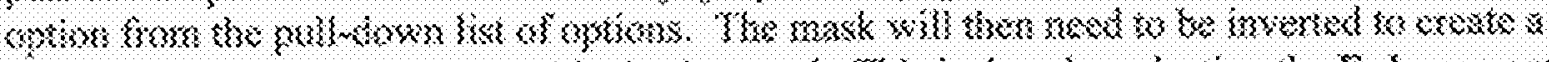

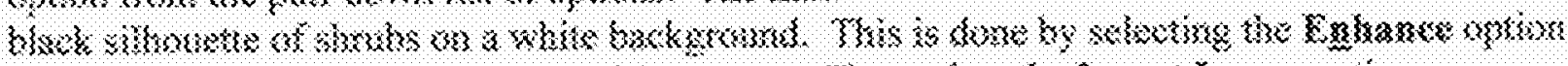

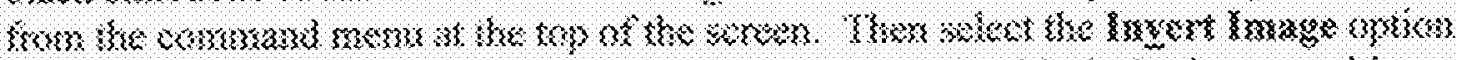

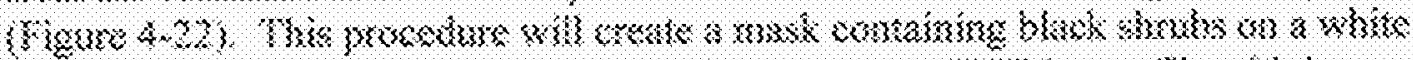

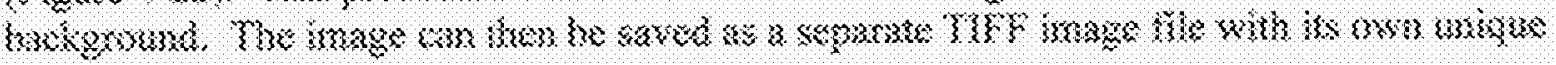
nest yame

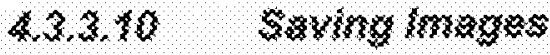

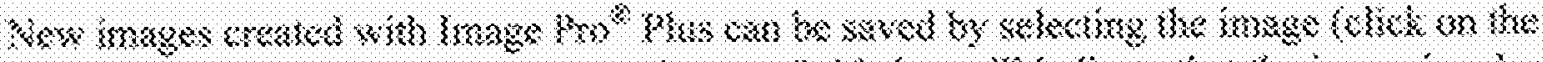

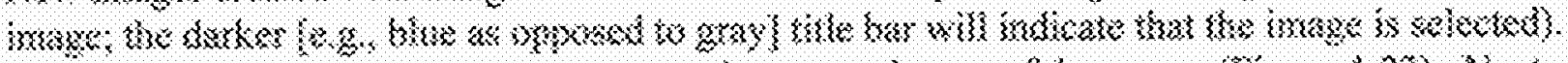

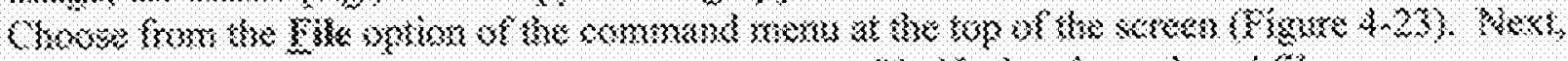

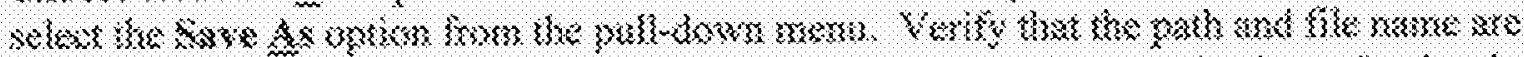

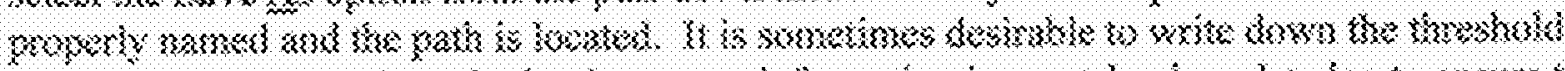

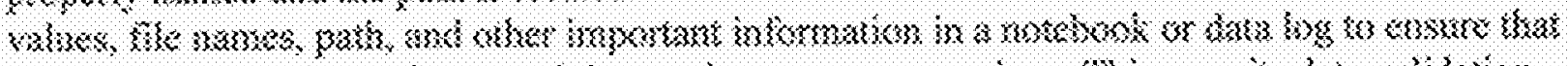

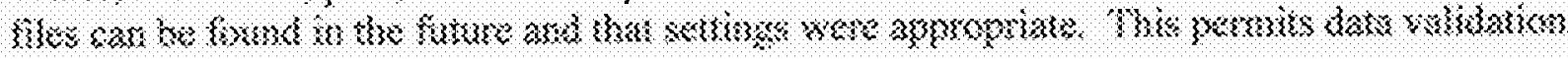
ky coksers. 


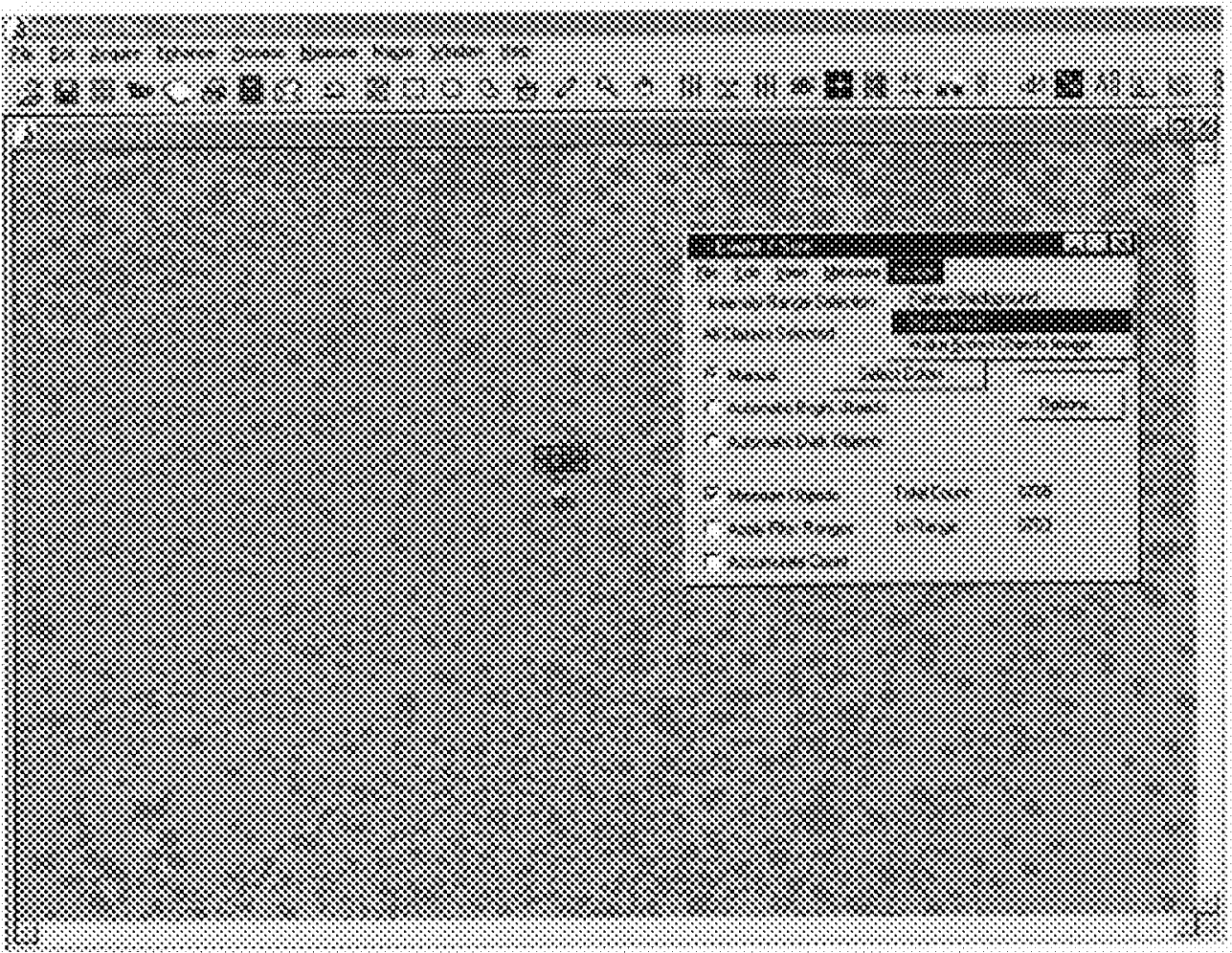

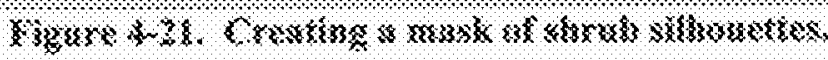

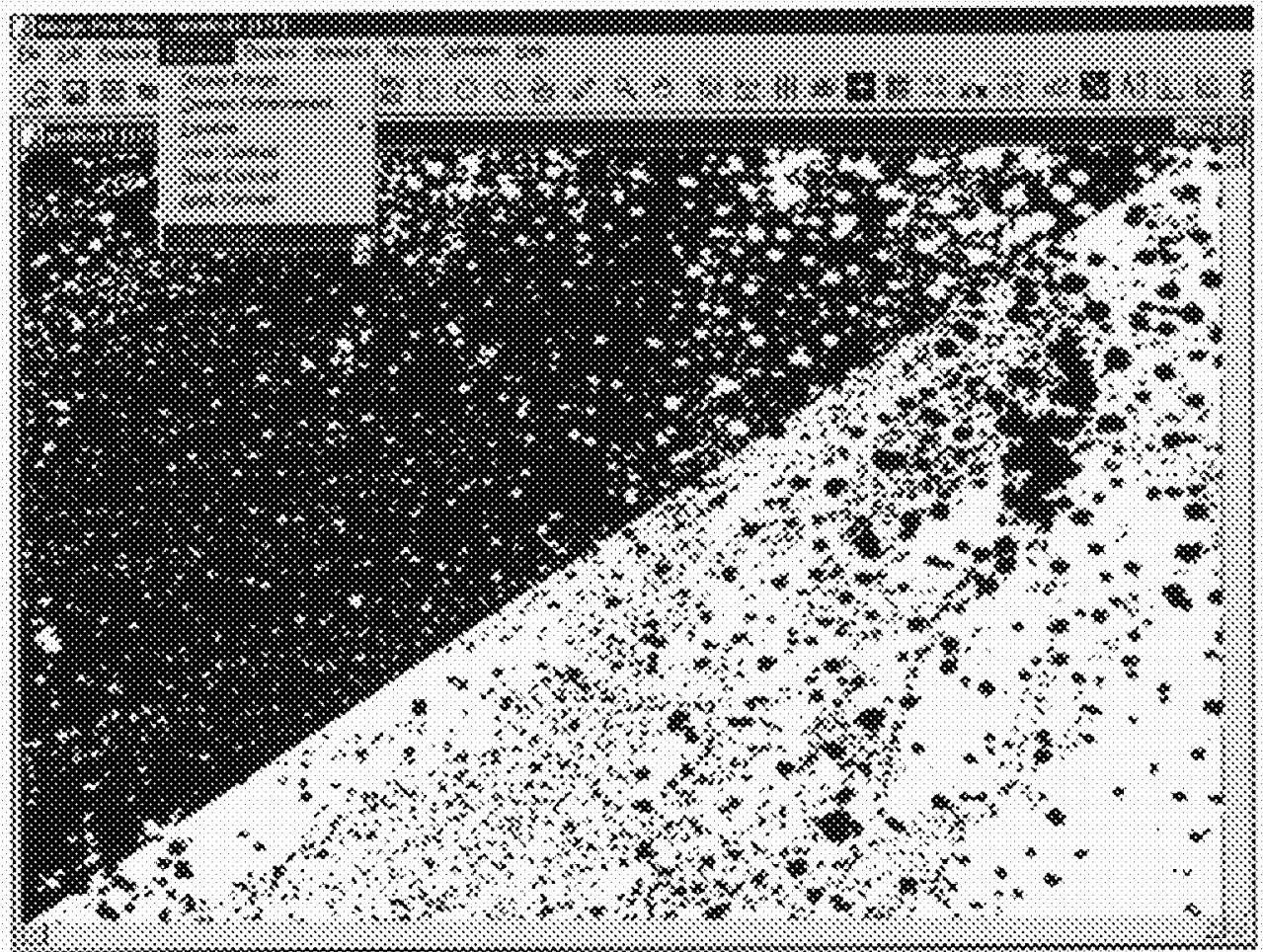

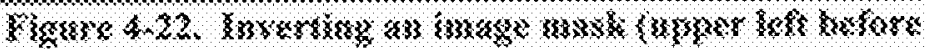

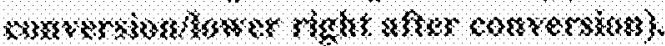




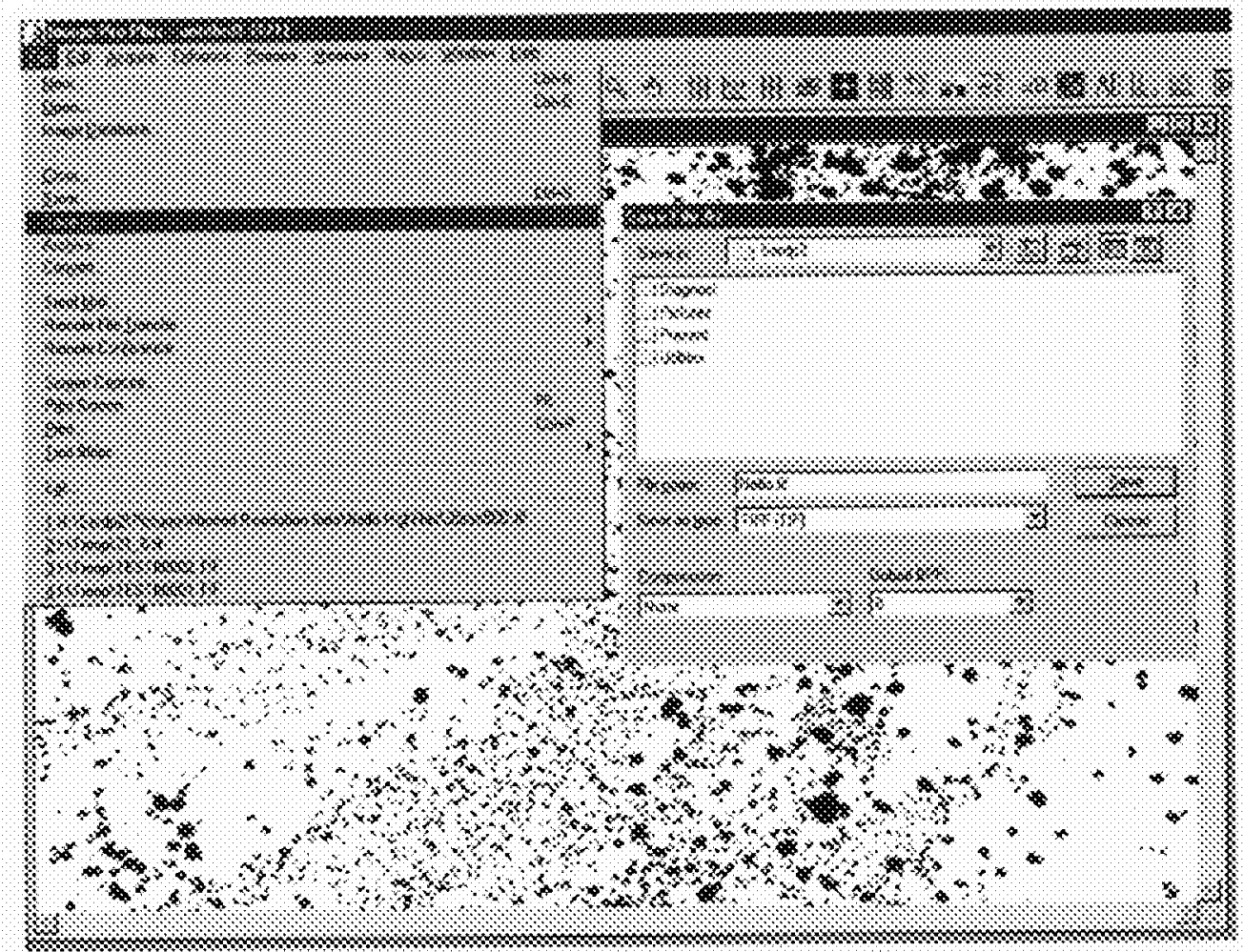

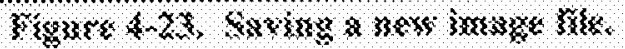

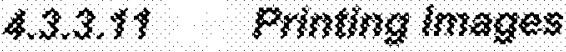

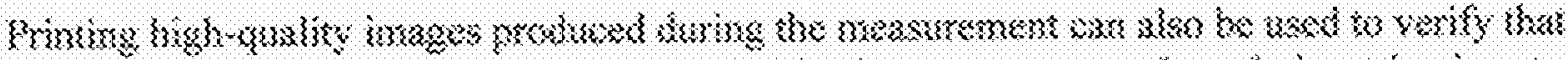

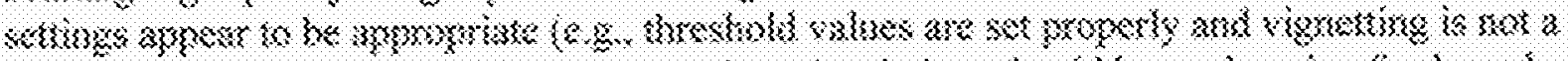

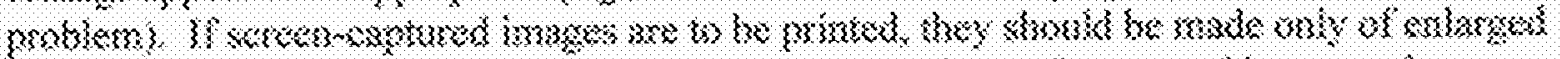

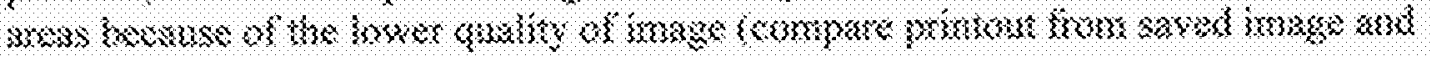

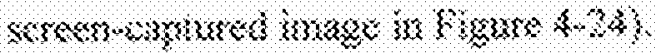

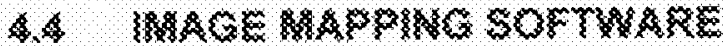

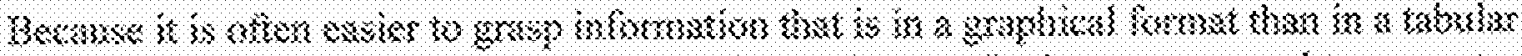

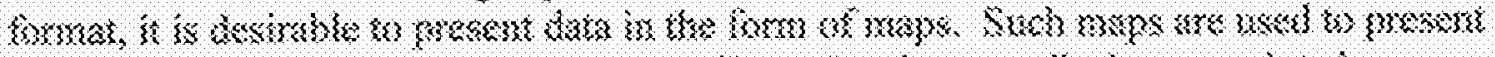

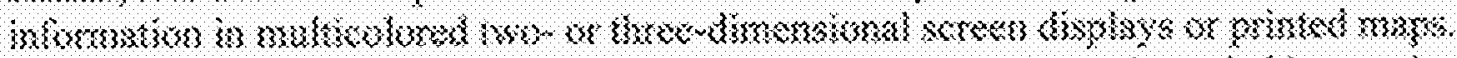

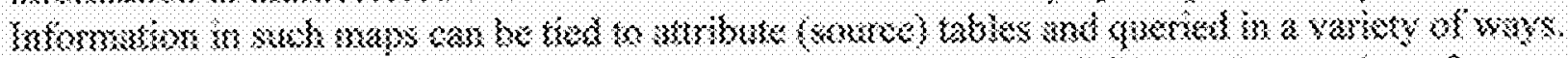

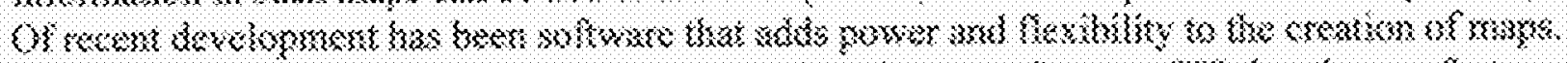

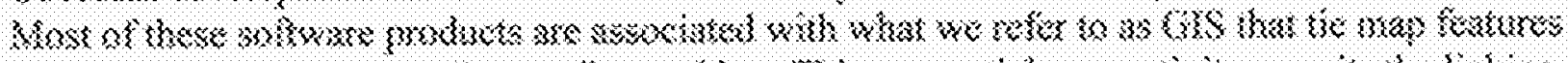

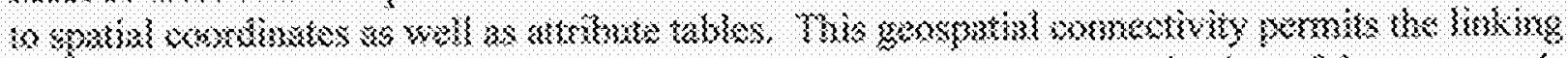

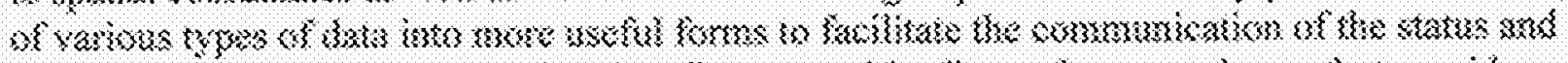

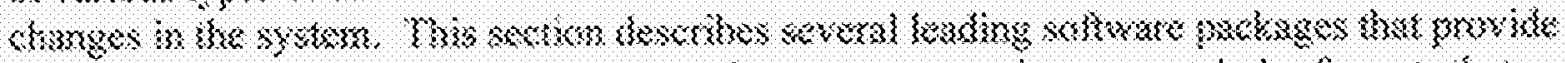

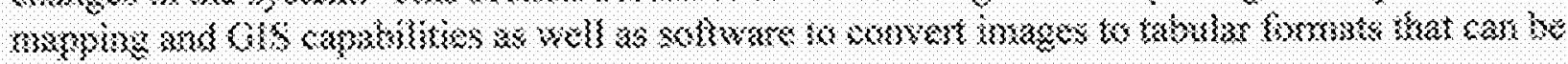

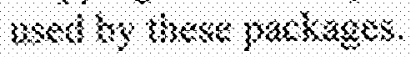


This page cannot be converted.

Please view the native document

for the original page. 


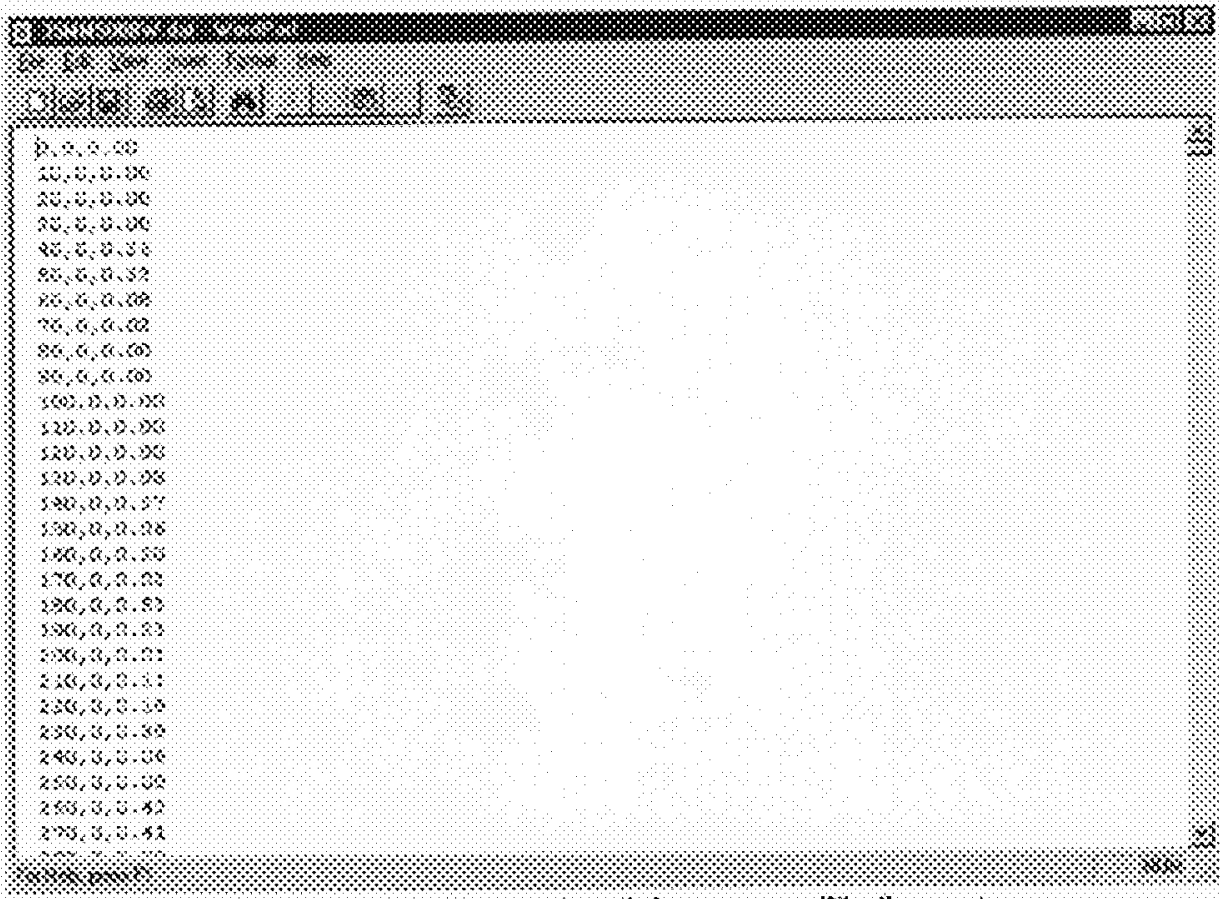

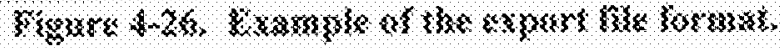

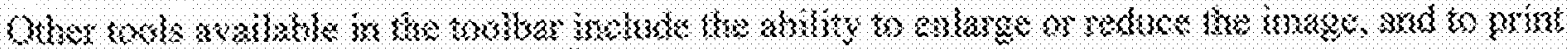

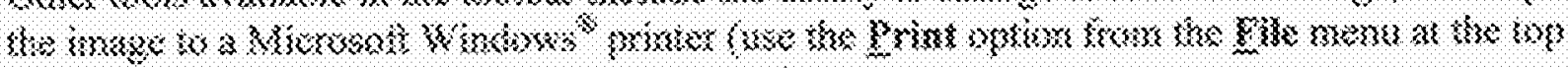

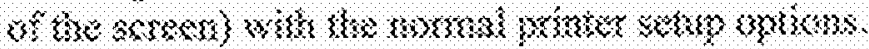

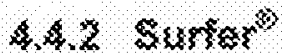

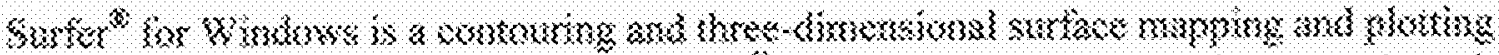

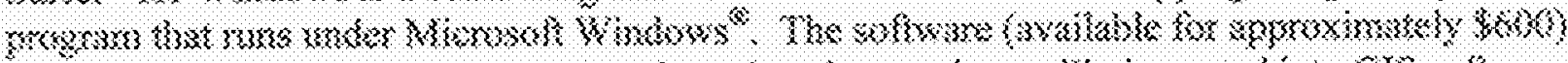

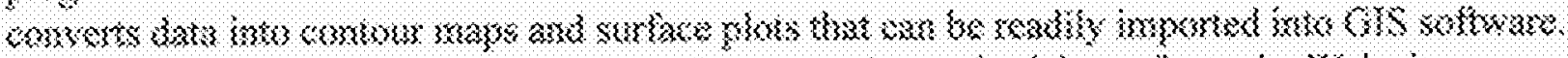

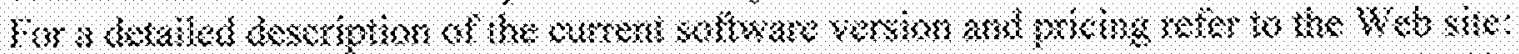

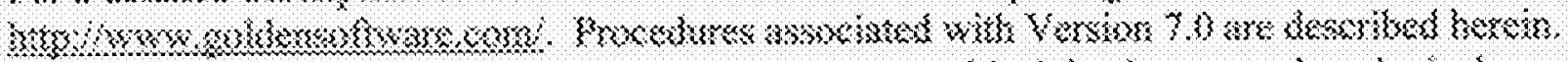

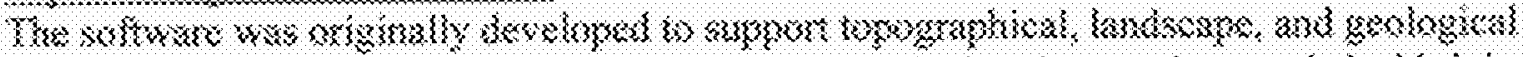

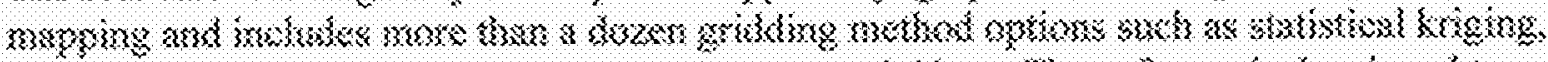

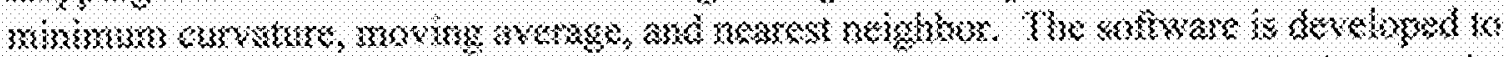

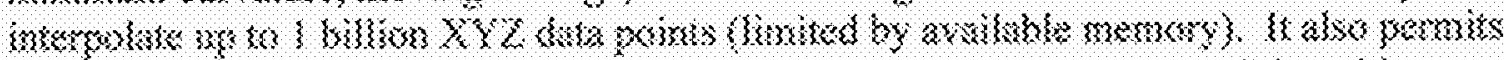

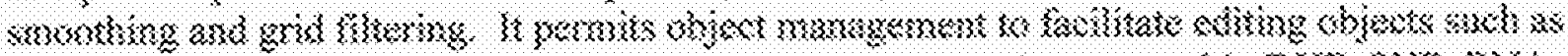

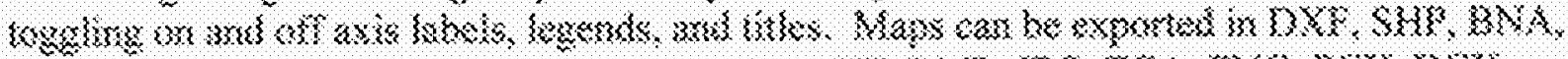

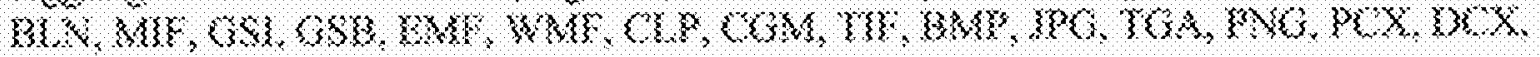
BWO, and K( T kmons.

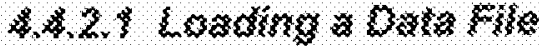

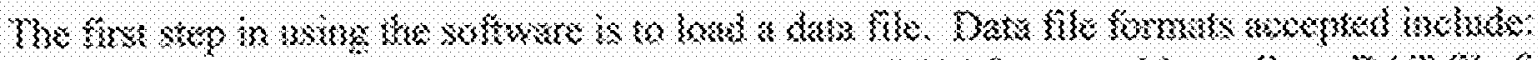

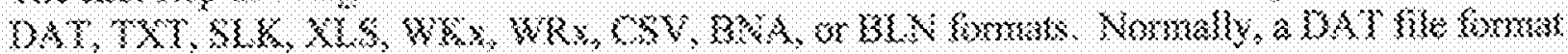




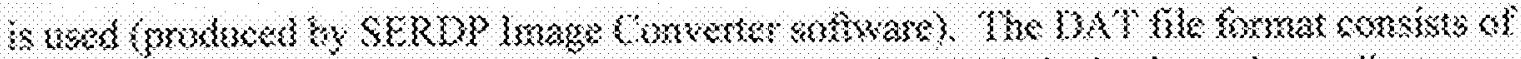

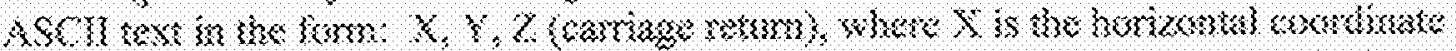

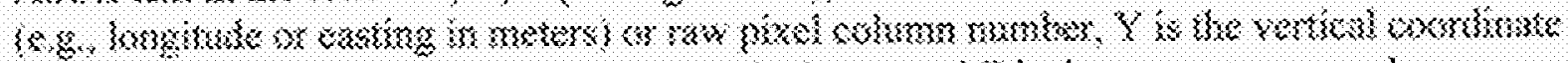

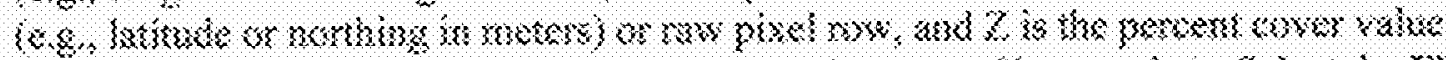

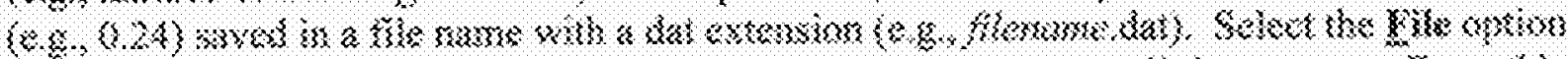

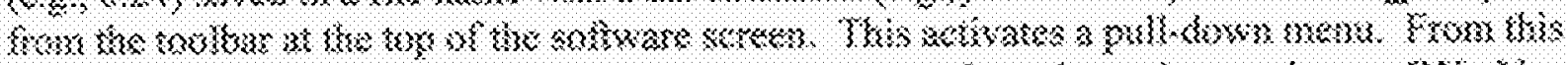

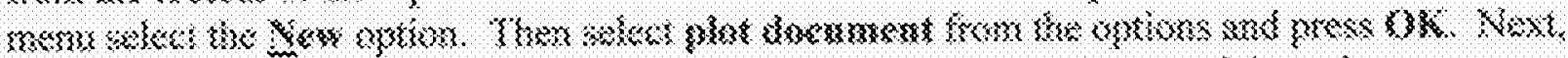

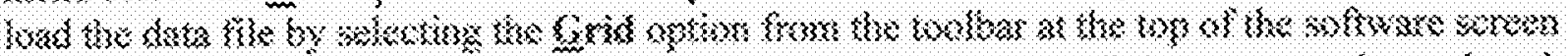

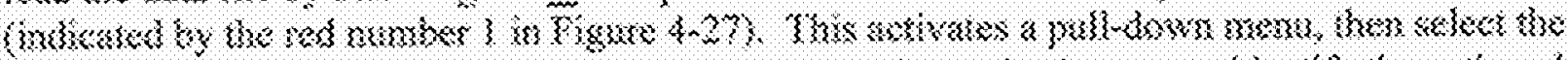

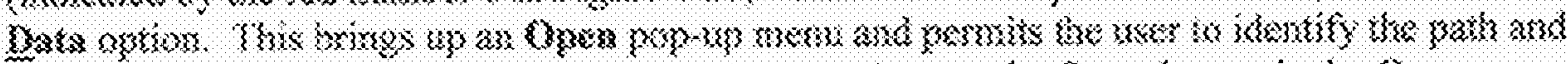

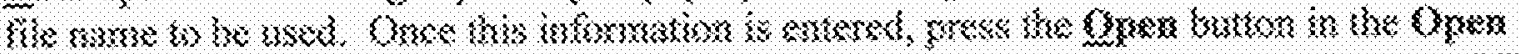

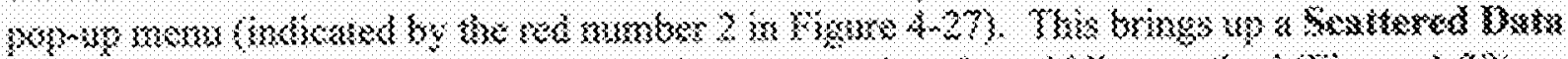

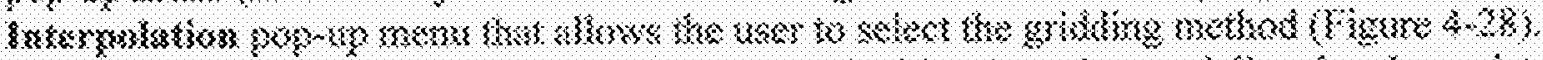

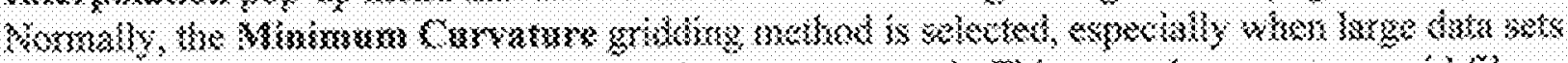

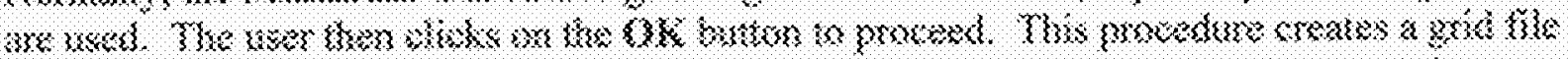

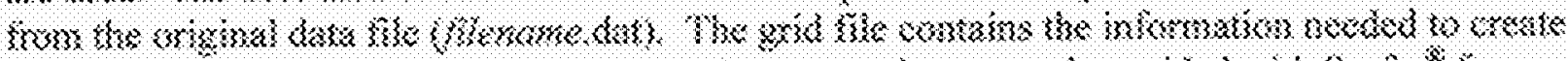

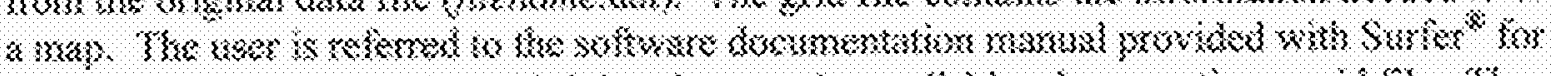

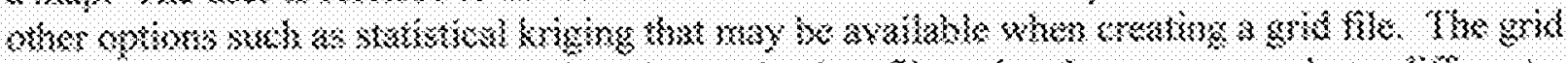

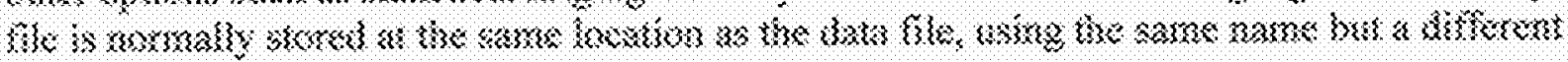

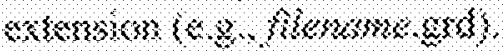

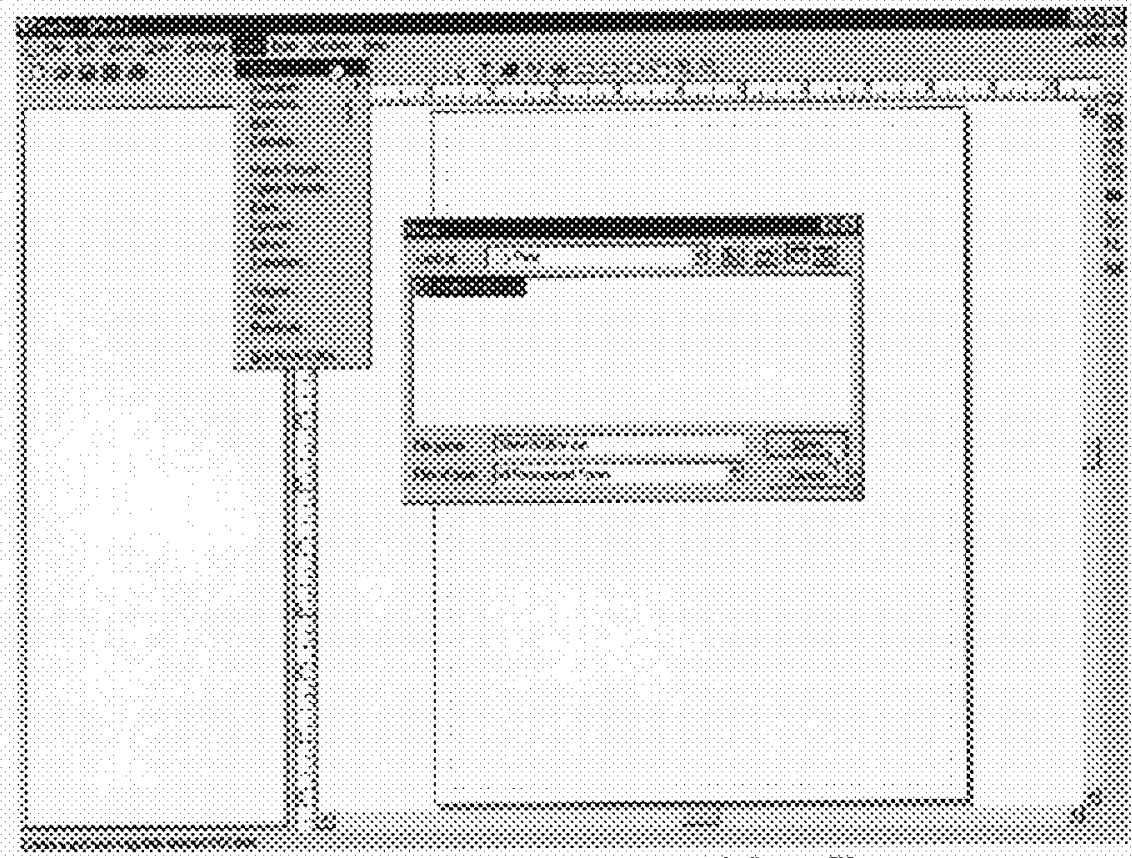

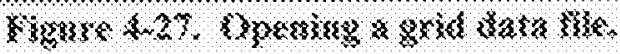




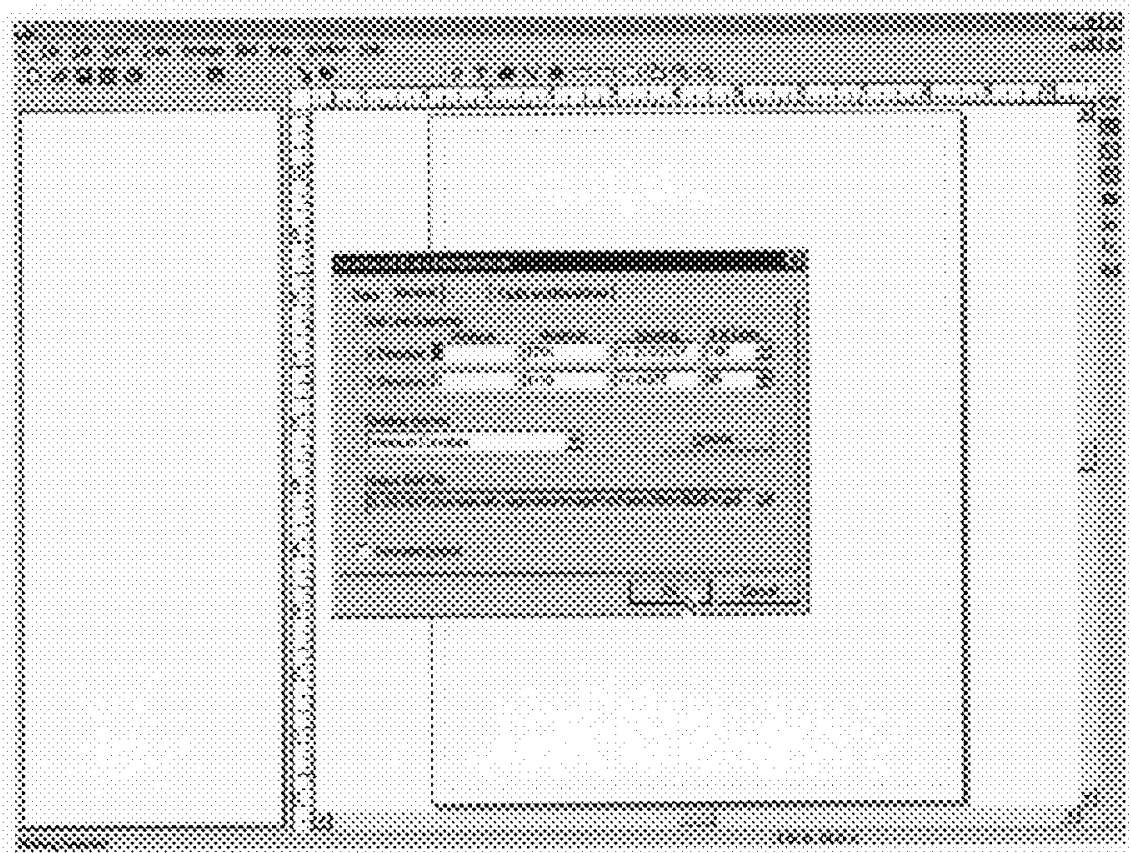

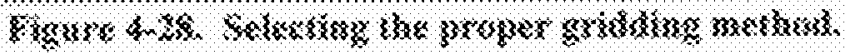

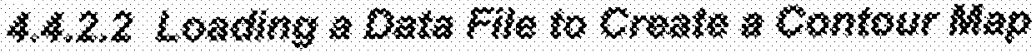

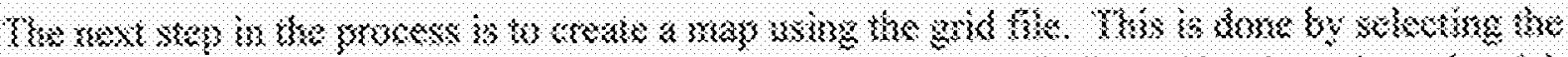

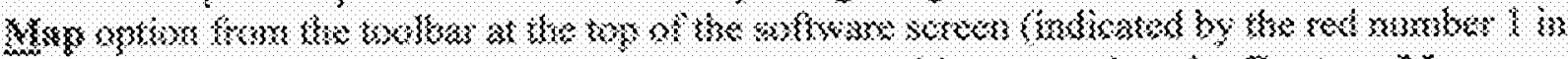

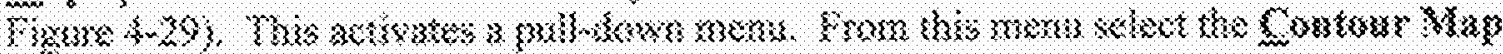

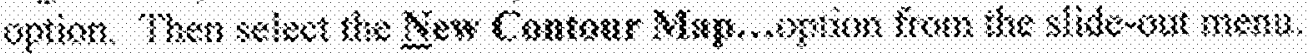

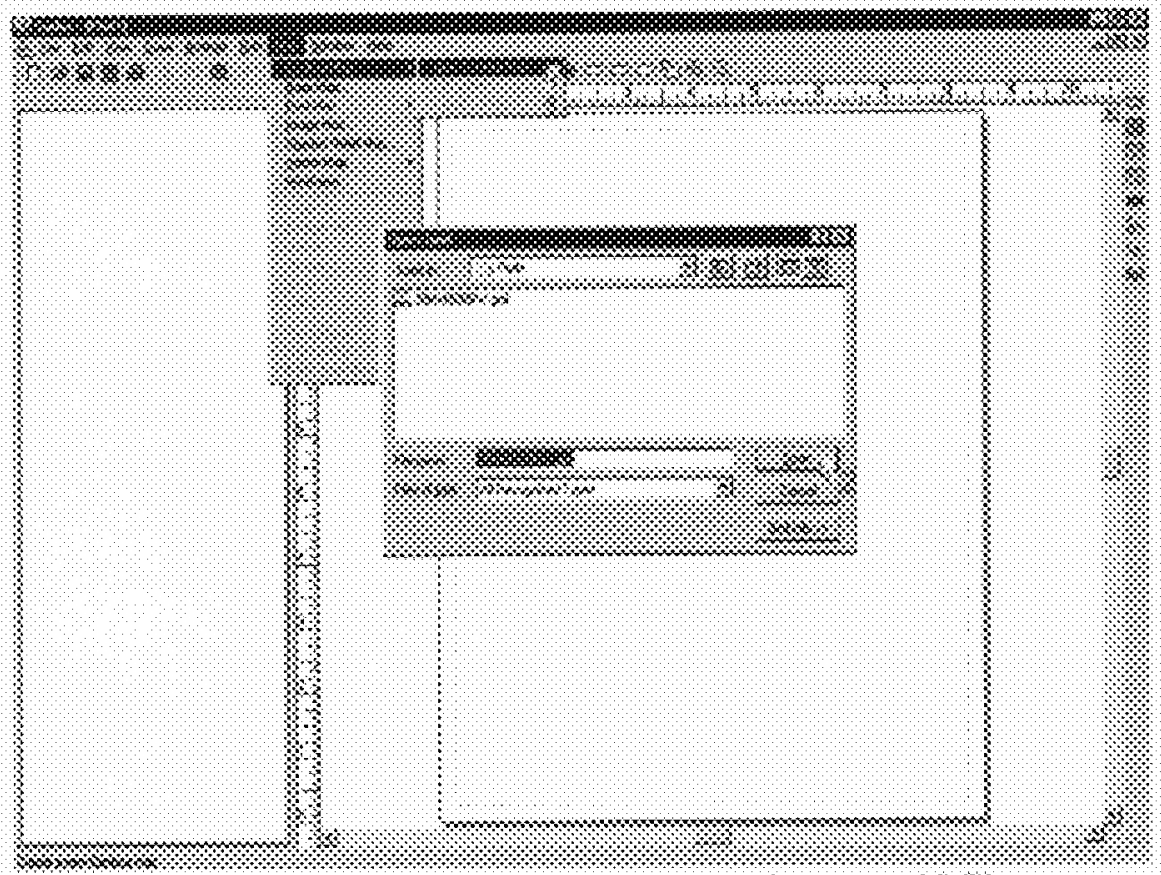

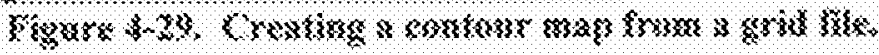




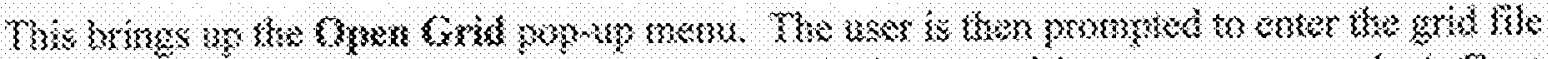

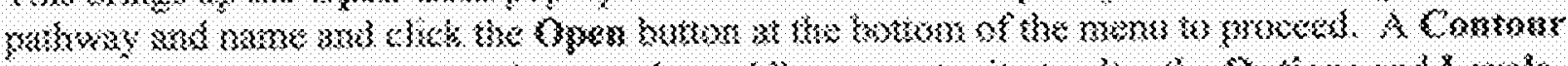

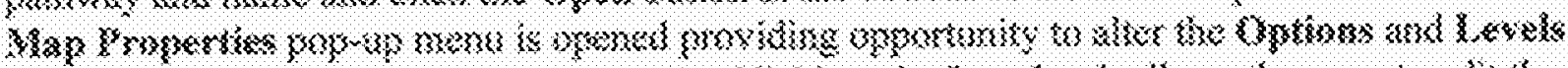

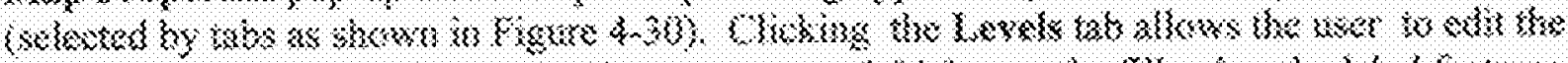

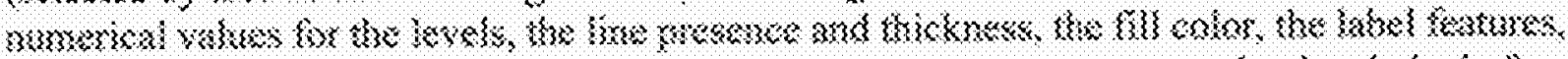

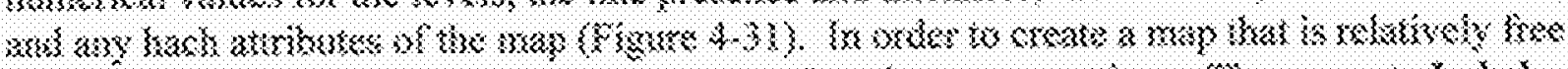

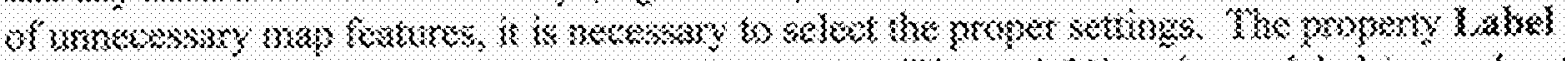

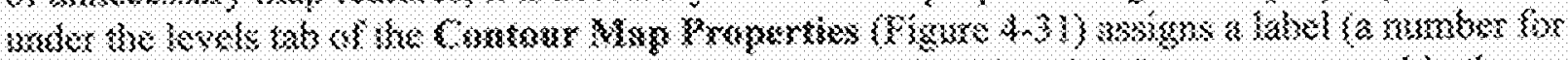

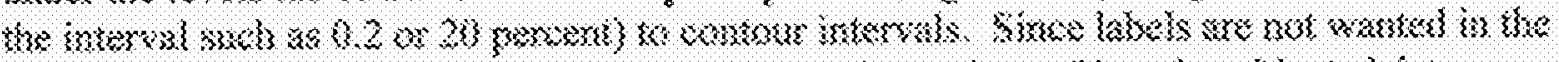

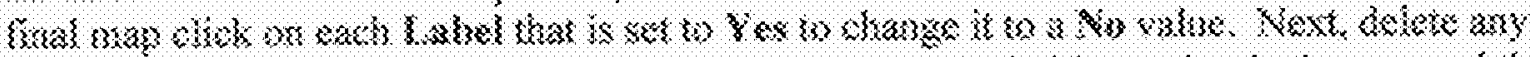

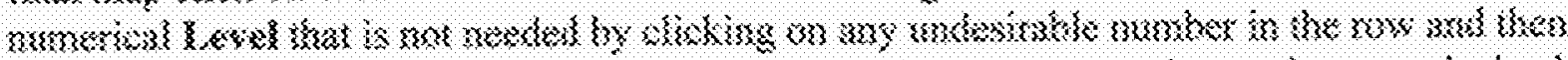

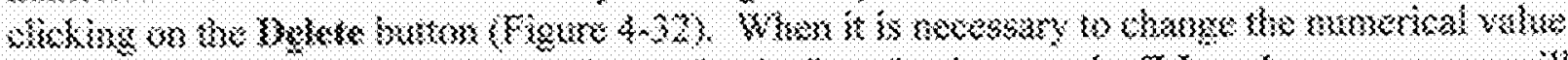

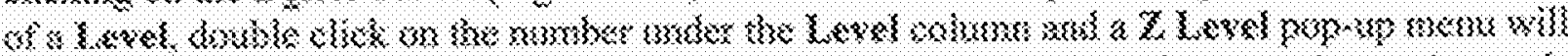

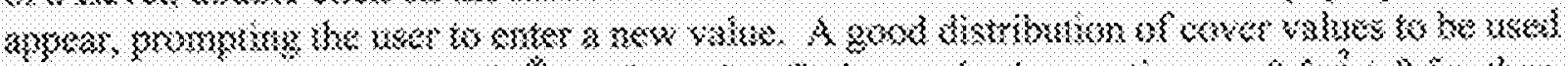

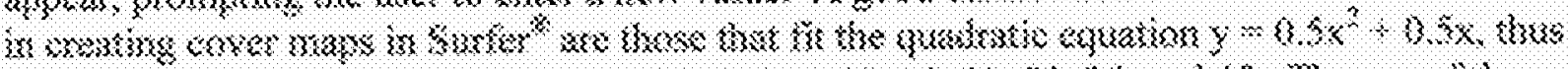

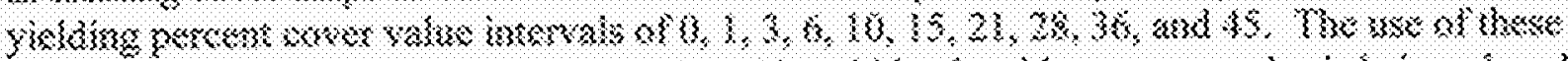

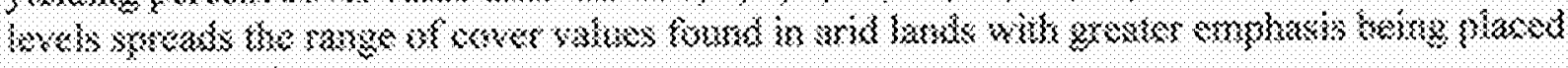
an bor on wex whoss.

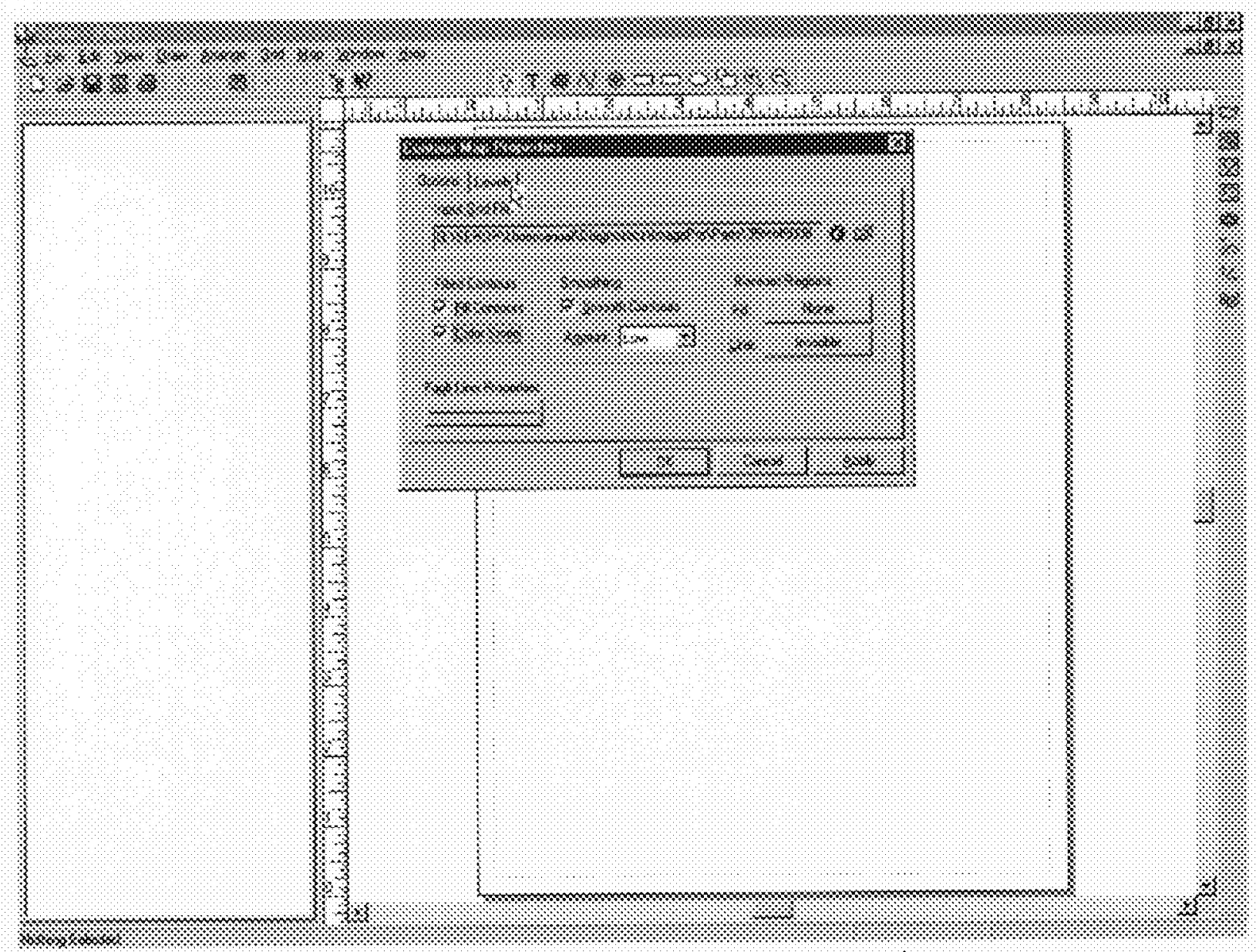

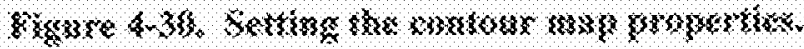




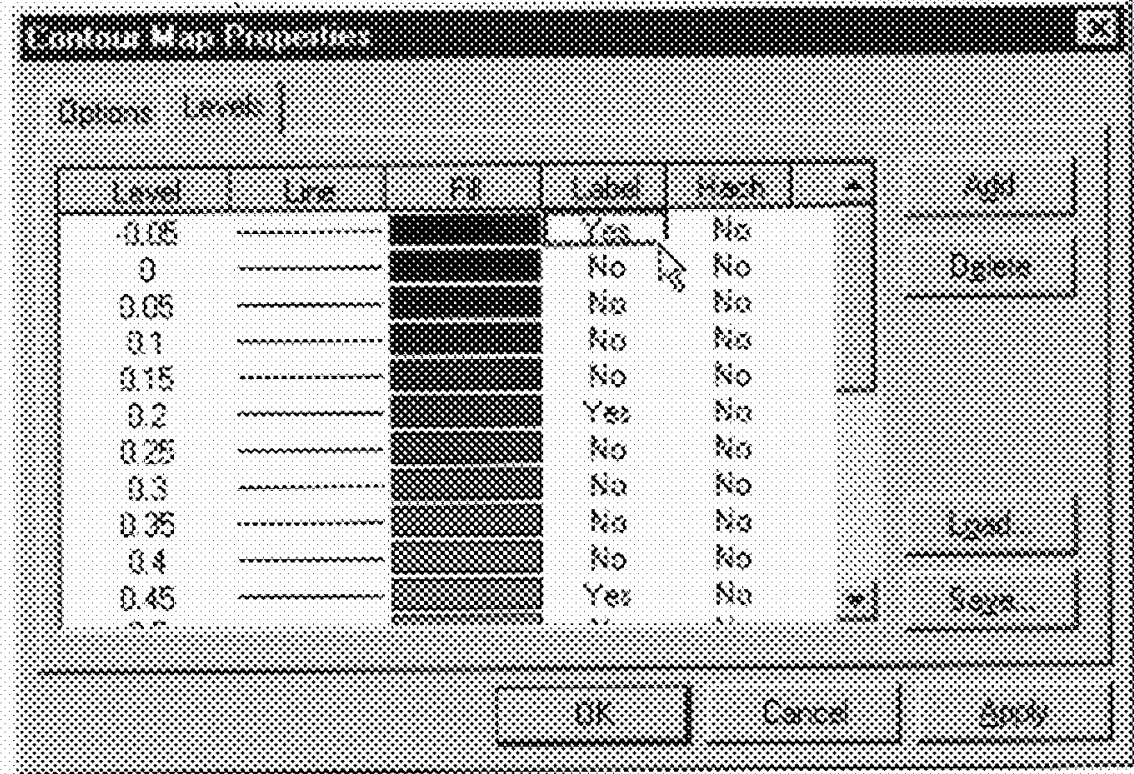

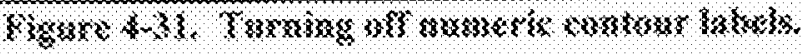

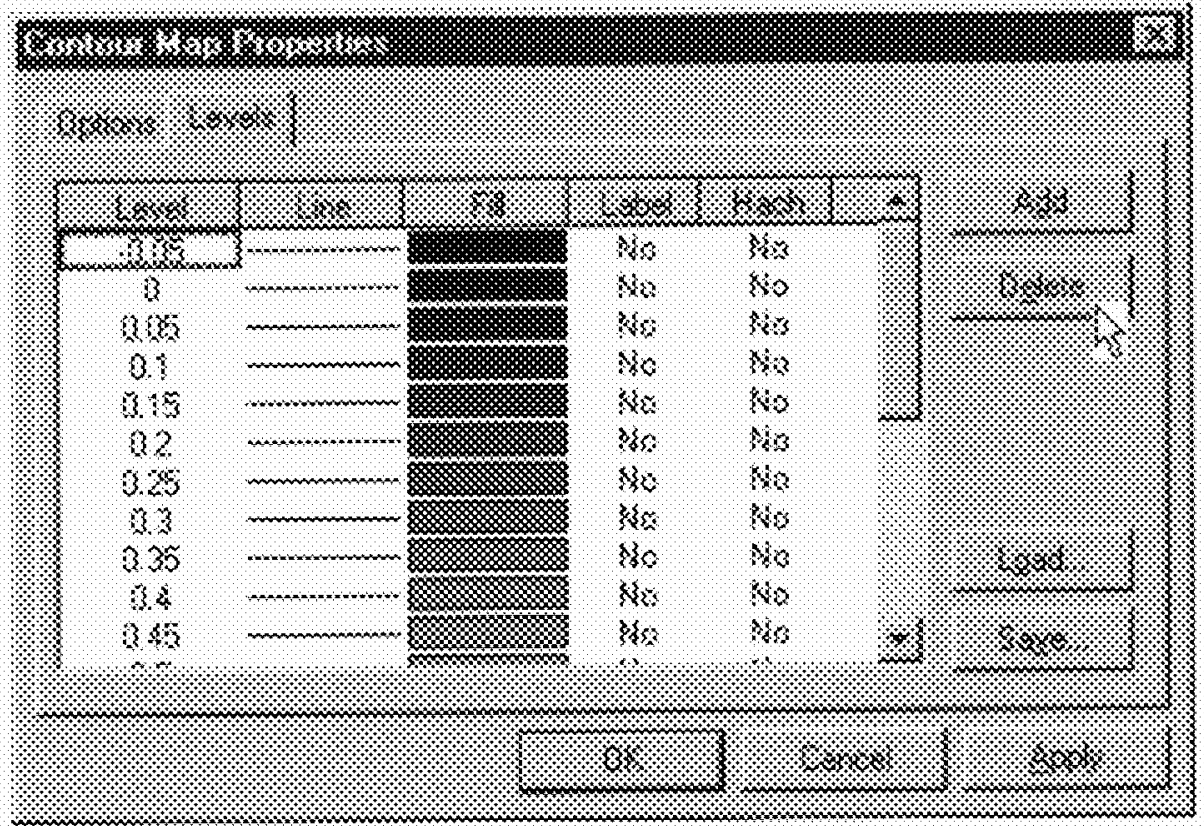

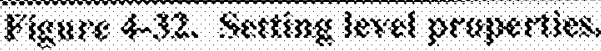

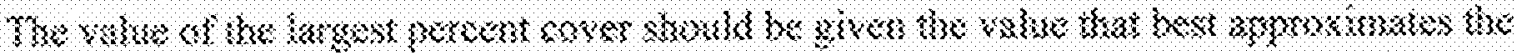

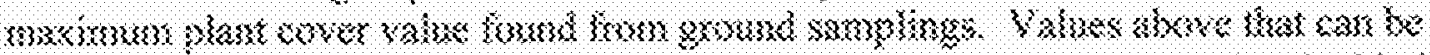

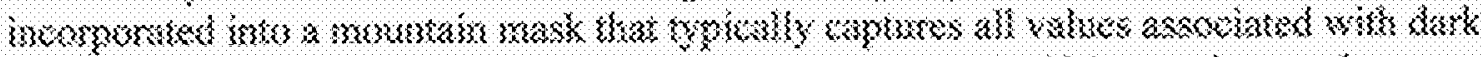

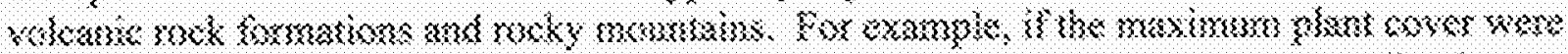

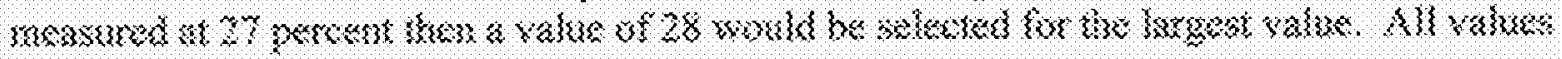




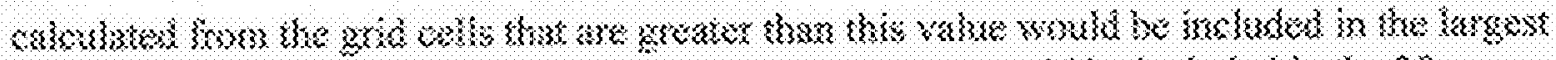

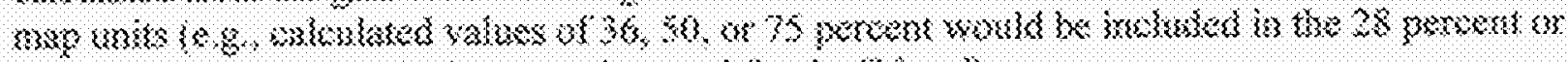

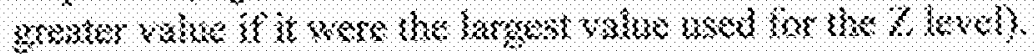

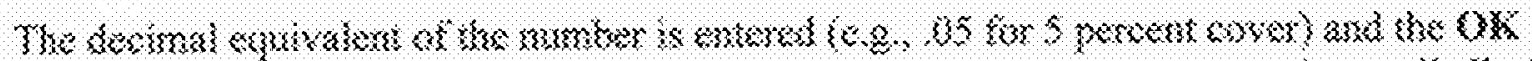

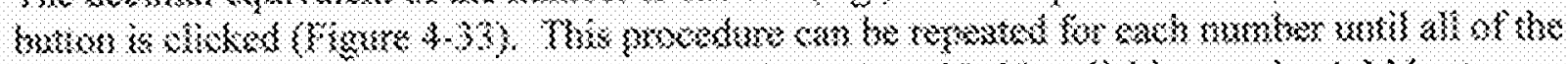

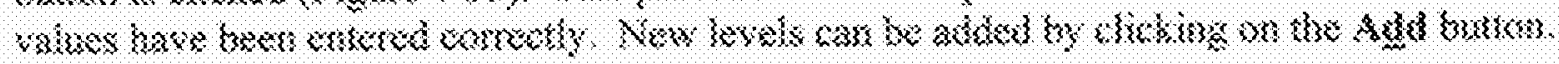

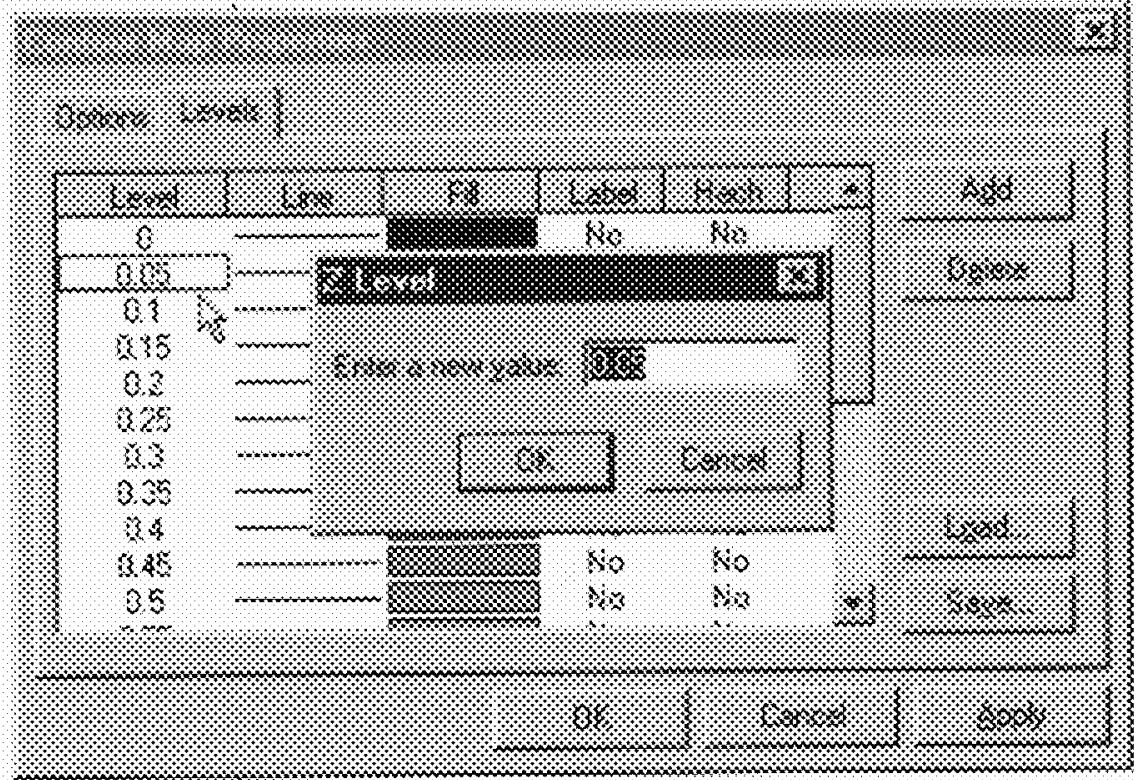

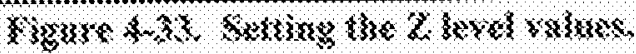

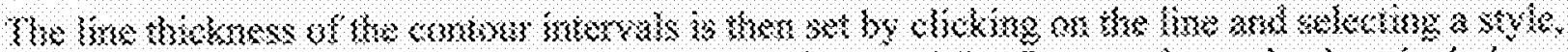

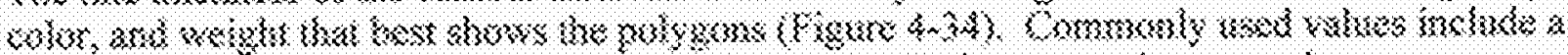

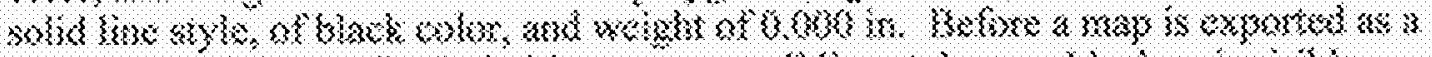

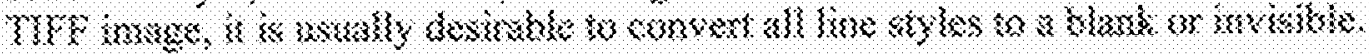

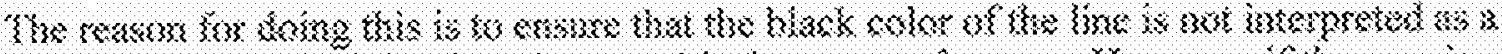

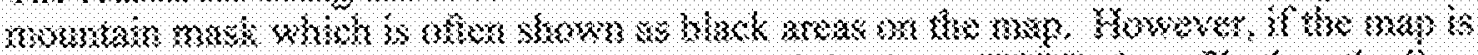

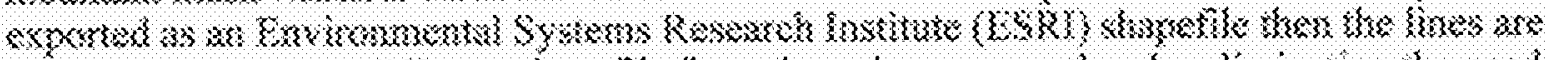

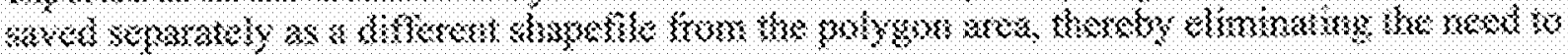

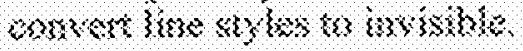

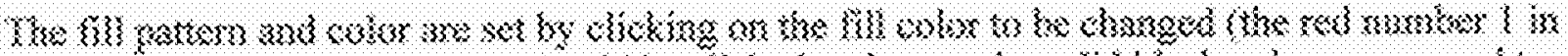

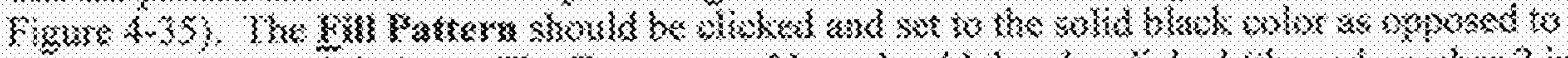

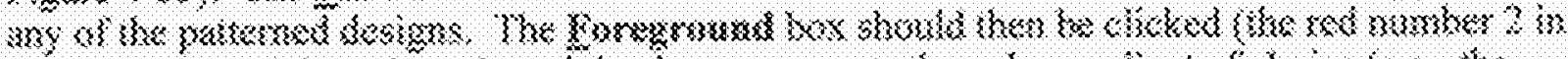

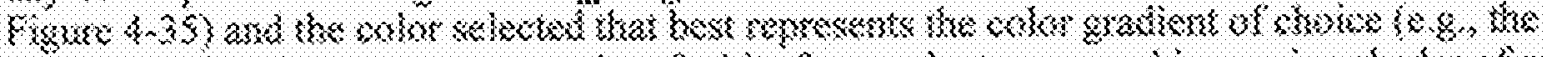

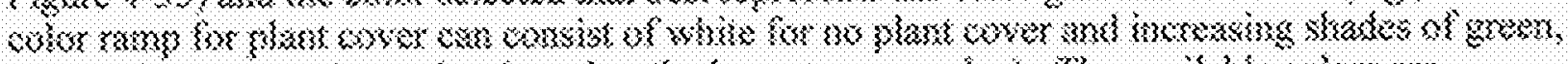

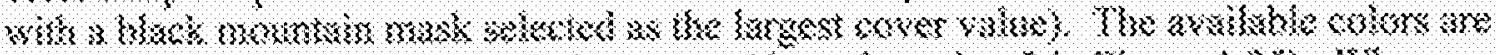

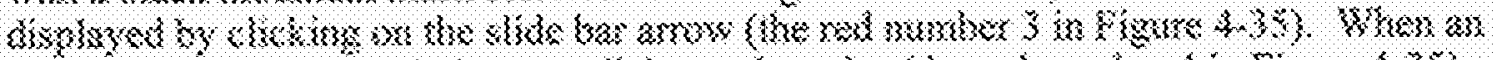

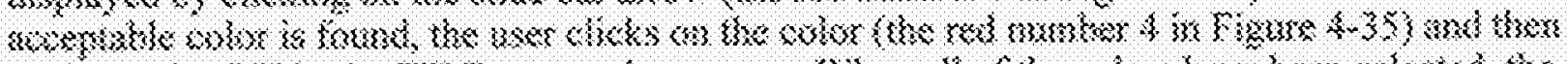

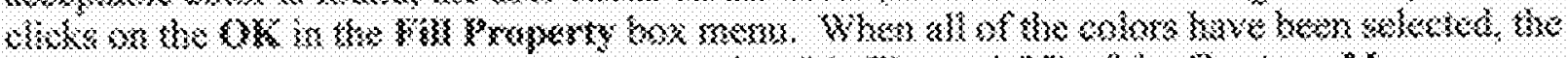

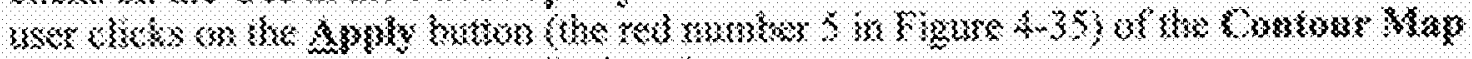

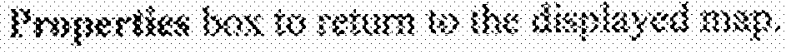




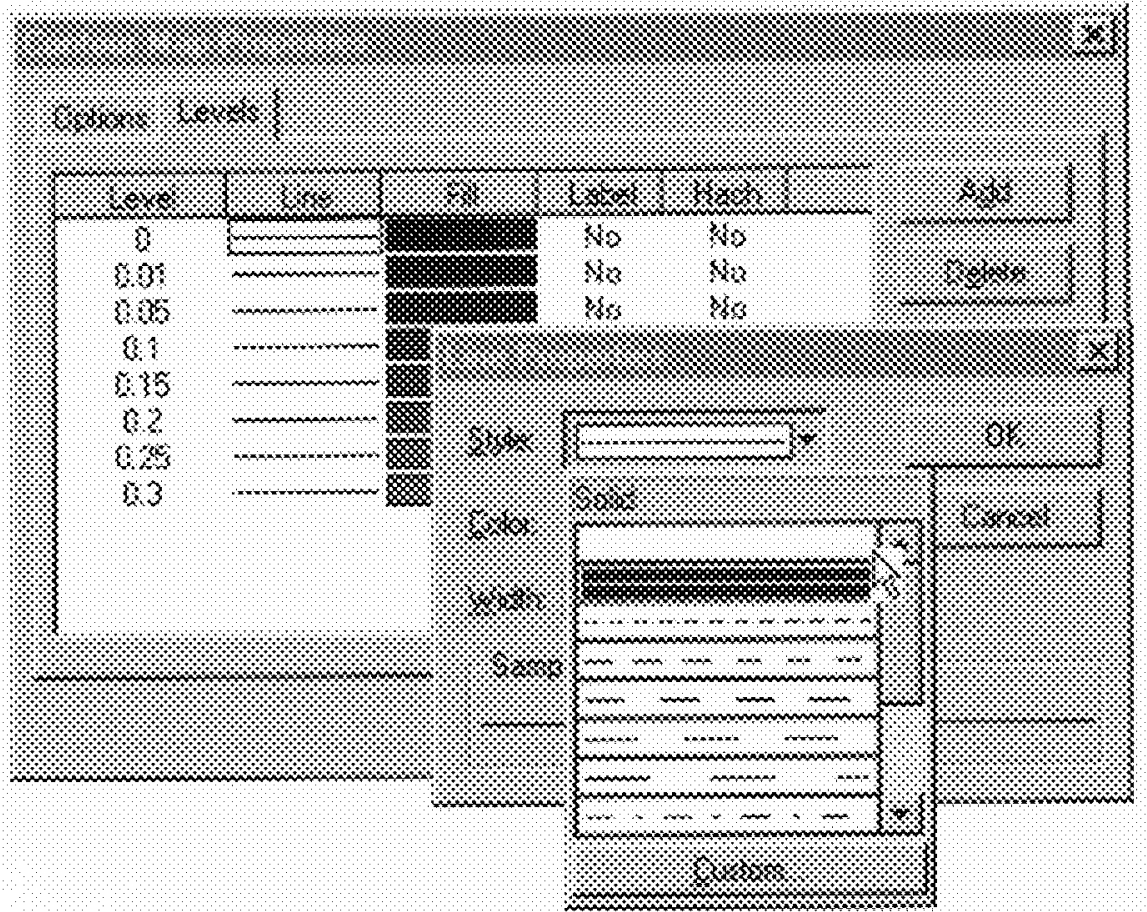

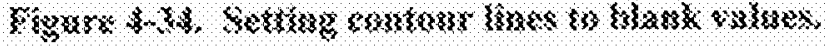

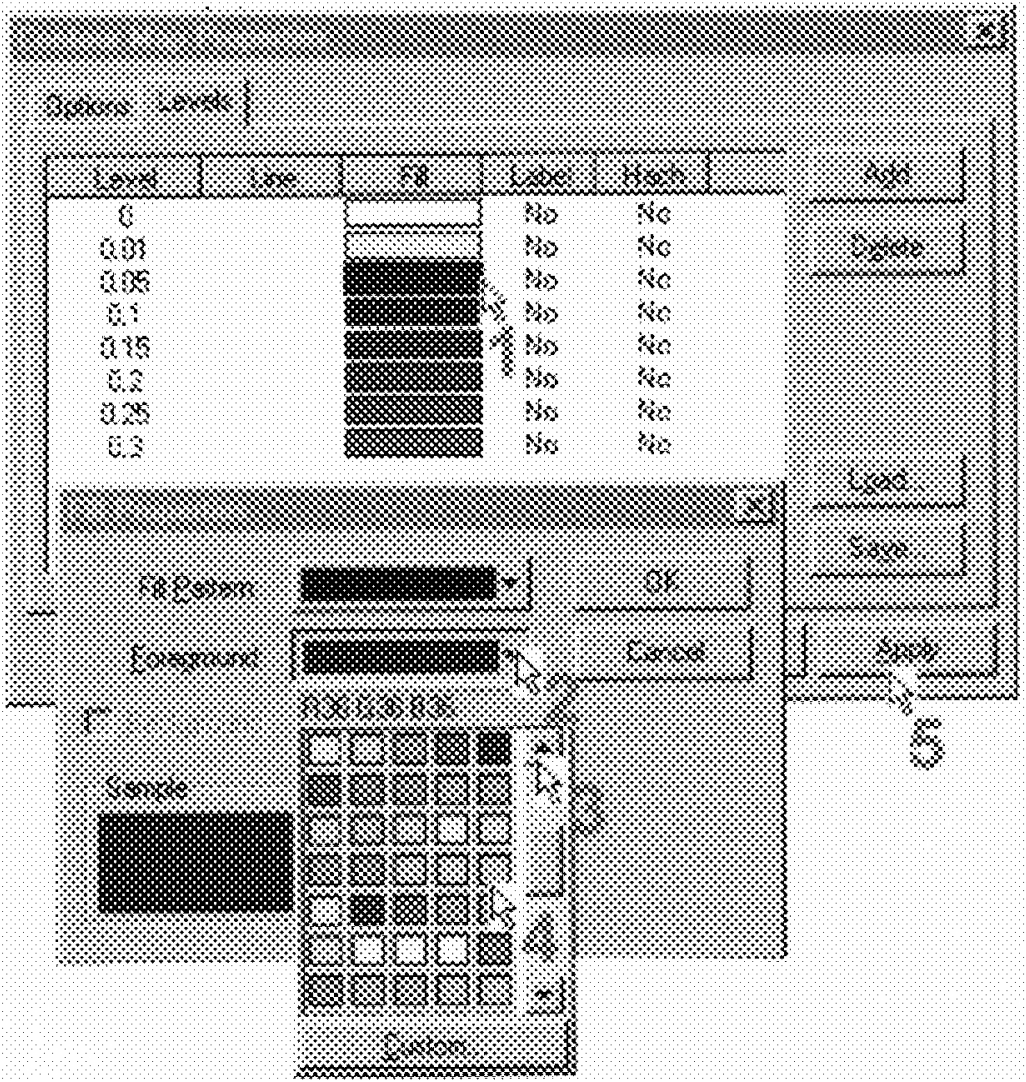

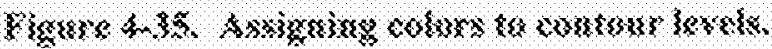




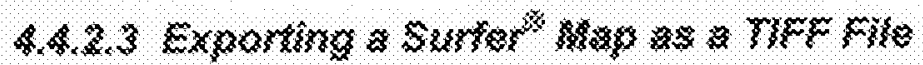

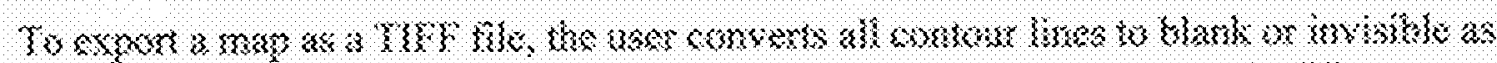

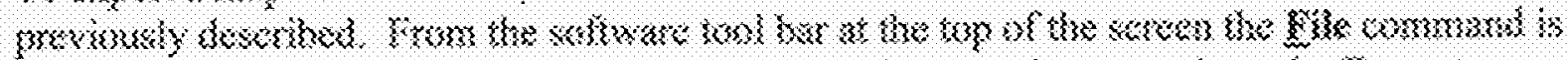

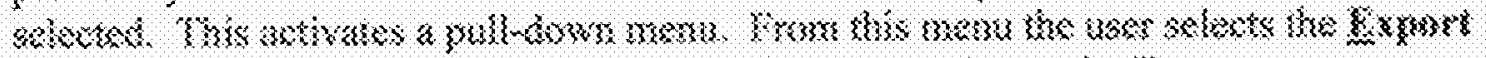

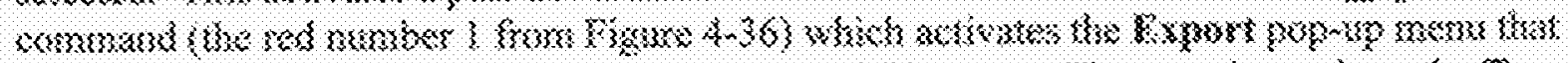

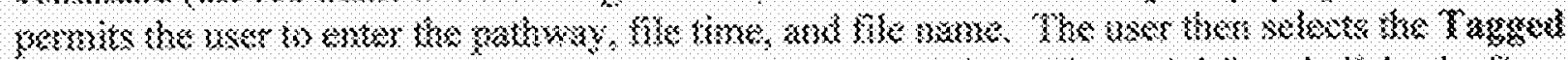

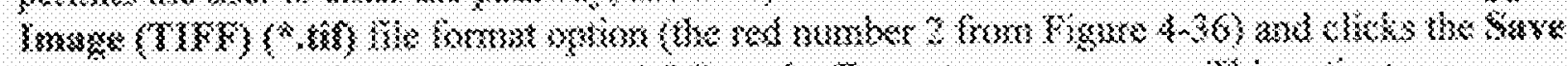

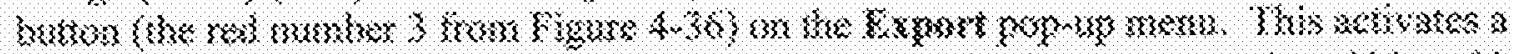

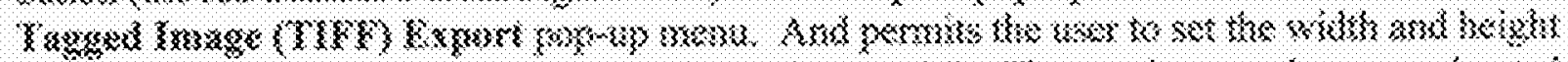

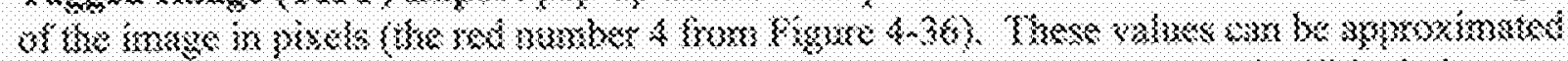

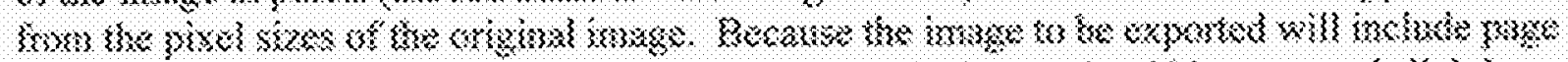

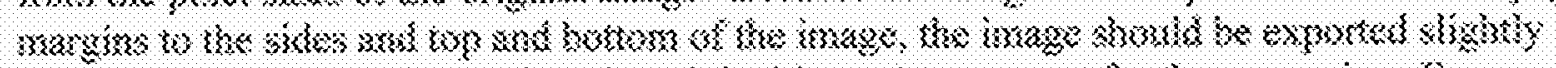

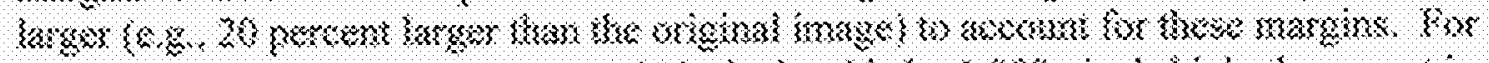

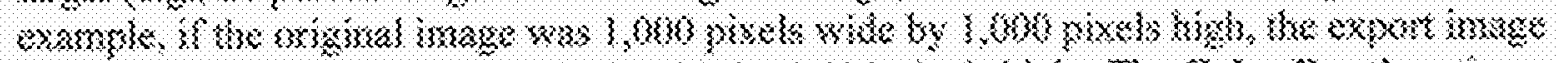

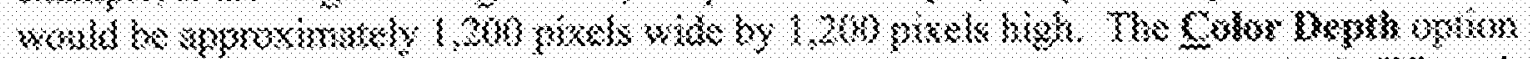

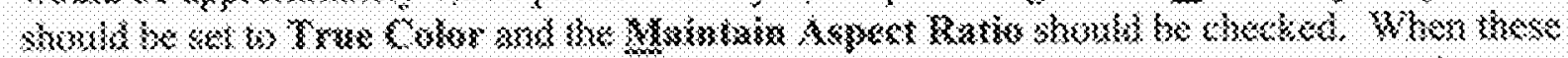

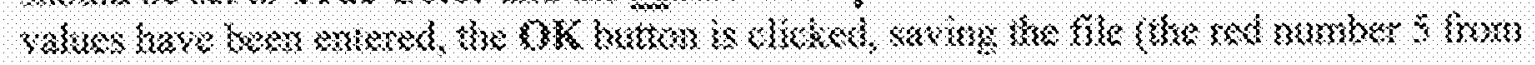
Figw: 4.363 .

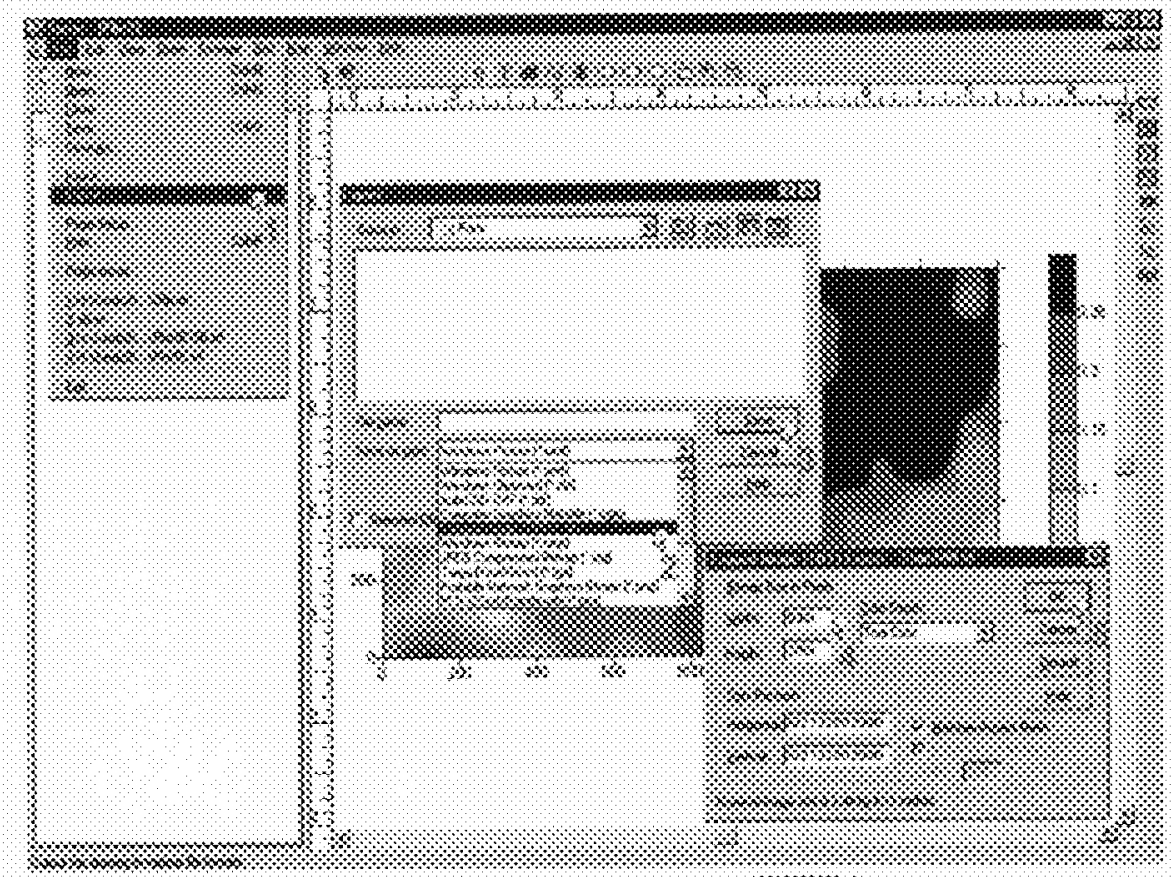

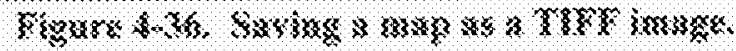

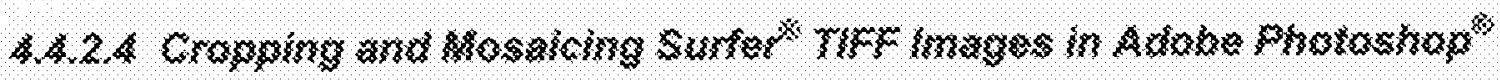

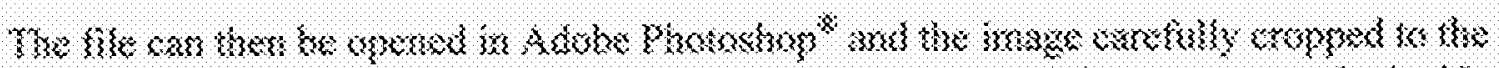

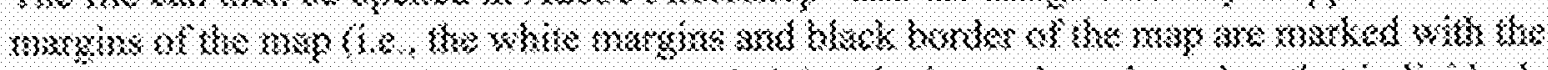

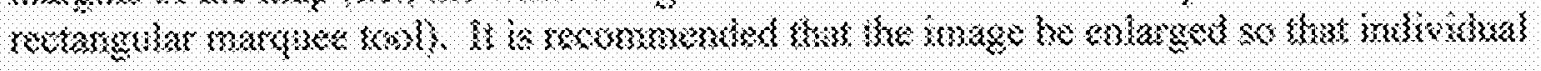


pixels can be seen (otherwise the exact edge of the image may not be selected). Starting at the upper-left-hand corner of the image click and pull the marquee tool to the lower left-hand corner. Note that starting in other corners like the lower right-hand corner will not permit scrolling of the window to the other corners. The image is cropped by clicking on the Image pull-down menu and selecting the Crop command. This reduces the image to only the map area defined by the marquee line (called by users the "marching ant") line.

The image should then be resized to exactly the same number of pixels (width and height) as the original image used to calculate plant cover. This is done by selecting the Image command from the software tool bar at the top of the screen which activates a pull-down menu. Next, select Image Size... which brings up an Image Size pop-up menu. The number of pixels for the image should be entered for width and height.

The Constrain Proportions and the Resample Image options should be checked. In the Resample Image option, space should be set to the "Nearest Neighbor" option. This ensures that any new pixels that are created in stretching or shrinking the image to the proper size will be only of the colors assigned to the polygon contour areas (e.g., all areas will be black or white). Other options such as "Bicubic" create new intermediate colors halfway between the two adjacent colors (e.g., gray pixels between white and black polygons), thereby creating extra categories of pixels unrelated to the two original types (i.e., black and white) previously created by the graphing software. The area represented by these new intermediate colors is not accurately placed within the proper class (color) and thereby contributes inaccuracies to the new GIS theme. The document size and properties can remain as the default values. When all of the values have been entered the OK button is clicked in the Image Size pop-up menu. The image is then saved as a cropped and resized image.

When several adjacent images have been created, it is desirable to mosaic four to nine images together into one large file. The ability to mosaic images in Adobe Photoshop ${ }^{\circledR}$ is limited by printer type and computer memory to about two to three images wide by two to three images high. It is done by selecting a starting image (usually at one of the corners). From the Image command of the tool bar at the top of the software screen, the Canvas Size option is selected. This brings up a Canvas Size pop-up menu box. Next, enter the new size of the canvas in pixels. For example, if the image size were 100 pixels wide by 50 pixels high and if the user wanted to add nine images (three images wide by three images tall), the user would enter a canvas size of 300 pixels wide by 150 pixels high. The user would indicate which corner the image would be placed into by checking on the corner of the grid box shown in the Anchor option. An alternative method of sizing the canvas is to select percent as the unit of value. In this example the user would enter 300 percent wide by 300 percent high if nine images were to be mosaiced together. The OK button would then be clicked showing a new image in the corner of a blank canvas.

The images to be added to the expanded canvas are then opened, copied, and pasted. Each image is copied by selecting it with the rectangular marquee tool, and then selecting Copy from the pull-down menu (the Edit command from the toolbar at the top of the software screen). The original image with the expanded canvas is then reselected and the Paste command (the Edit command from the toolbar at the top of the software screen). The new image will be pasted into the center of the image with the expanded canvas. The move icon (located to the right of the 
rectangular marquee icon and indicated by a cursor and a plus sign) is selected (it is the default tool after a paste) which allows the image to be positioned next to the starting map image. The user may want to enlarge the view to ensure that the newly placed image is not overlapping the adjacent image (an overlap of a few pixels can create slight distortions in the resulting mosaic). Each new map image to be added is opened, selected, copied, pasted, and positioned into place. If prior images need to be repositioned, the user selects the Show Layers (from the Windows toolbar at the top of the software screen). The user then selects the image icon corresponding to the image that is to be repositioned, clicks it, and selects the move icon from the icon tool bar. The user can then position that layer within the canvas. When all of the images have been correctly added, the mosaiced images are merged into one image using the Flatten Image from the Layer command from the toolbar at the top of the software screen). The merged image is then saved as a new image (with a new name). Opening the Image Size pop-up menu (from the Image command) will permit the user to verify that the mosaic contains the correct dimensions in terms of the number of pixels (width and height). Slight corrections, if needed, can be made by resizing the image using the procedures described above.

\subsubsection{Exporting Surfer Images as an ESRI Shapefile}

To export an image as an ESRI shapefile using Surfer ${ }^{\circledR}$, the user first prepares the map by turning off all nonessential map features such as map legend, axis, title, etc. This is done by unchecking these features from the object manager visible in the upper left-hand corner of the software screen. Only the contour objects should be checked. Next, the area around the map should be eliminated. This is done by double clicking on the Right Axis object which brings up the Right Axis Properties pop-up menu (Figure 4-37). Select the General tab and uncheck the Show box of the Labels option. Next, select the Ticks tab and set the Minor Ticks and Major Ticks to None. Repeat this procedure for each axis. If the procedure has been done properly the black and white squares at the sides of the map will appear at the edge of the map (Figure 4-38) as opposed to being separated from the map with space in between as in Figure 4-37. If the squares are not immediately adjacent to the map, select the axis where the space appears and recheck/reset the properties of the axis. This will ensure that only the map area is exported and not additional white space that may have been reserved for the placement of label tick marks associated with the axes.

Next, click on the File command from the software tool bar at the top of the screen. This activates a pull-down menu. From this menu the user selects the Export command (the red number 1 from Figure 4-38) which activates the Export pop-up menu. This menu permits the user to enter the pathway, file type, and file name. The user then selects the ESRI Shapefile ( ${ }^{*}$ shp) file format option (the red number 2 from Figure 4-38) and clicks the Save button (the red number 3 from Figure 4-38) on the Export pop-up menu. This activates an ESRI Shapefile Export pop-up menu, and permits the user to set the georeference grid coordinates for the lower left-hand corner and the upper right-hand corners of the shapefile (Figure 4-39). These values can be entered in any planar coordinate system, such as latitude and longitude, or state plane, or Universal Transverse Mercators (UTMs) (e.g., decimal degrees, meters, or feet) that is consistent with the units to be used later with ESRI's software. Note that longitude values are entered as negative values in the Western Hemisphere (North and South America). Values exported as shapefiles may need to be corrected to ensure that they fit the new projection system. This can be done using ESRI's ArcView ${ }^{\circledR}$ Image Analysis (use the Align Tool) or ERDAS Imagine ${ }^{\circledR}$ software. 


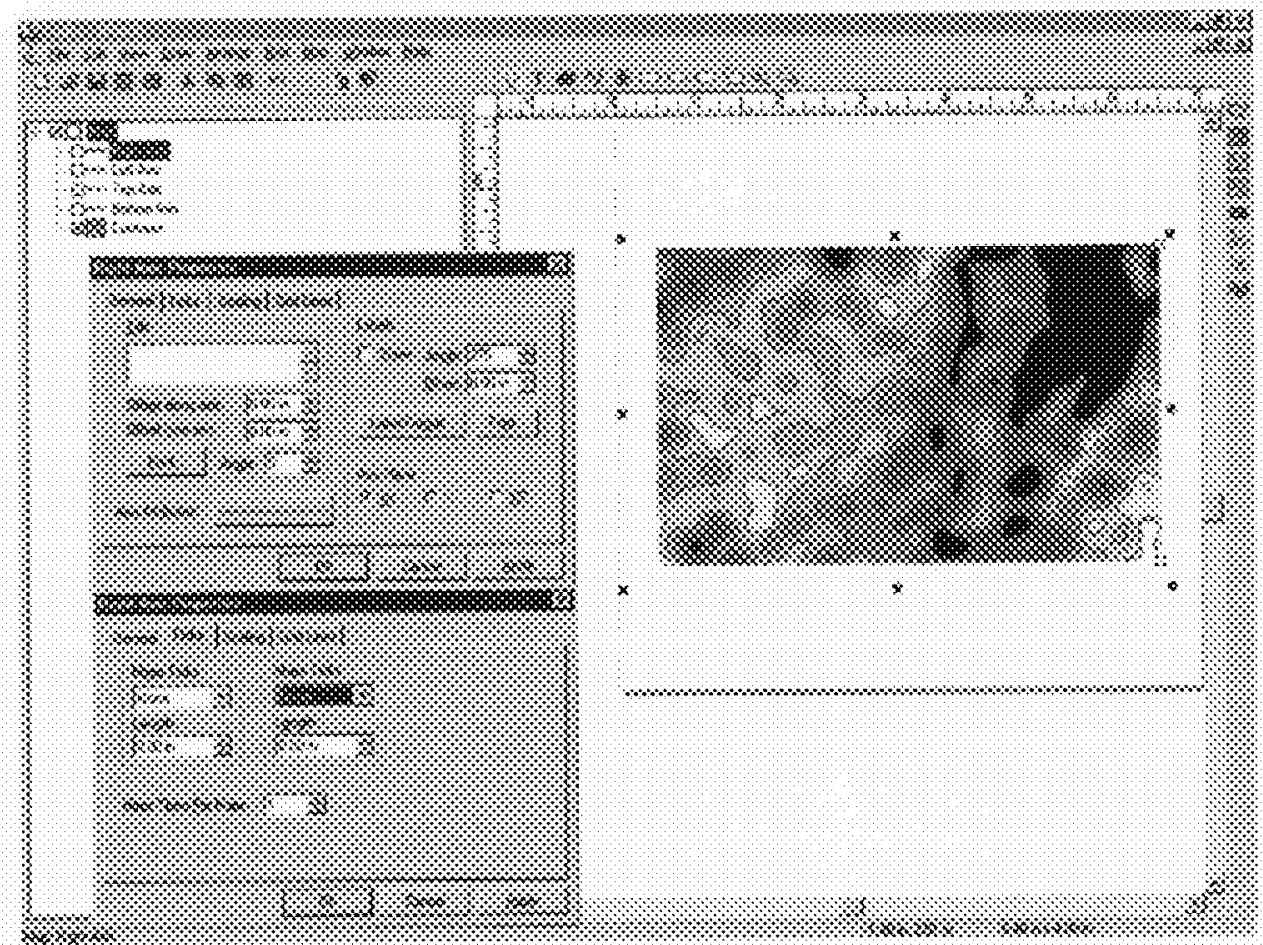

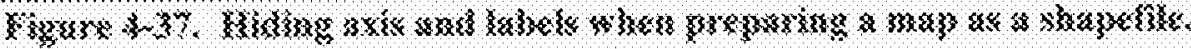

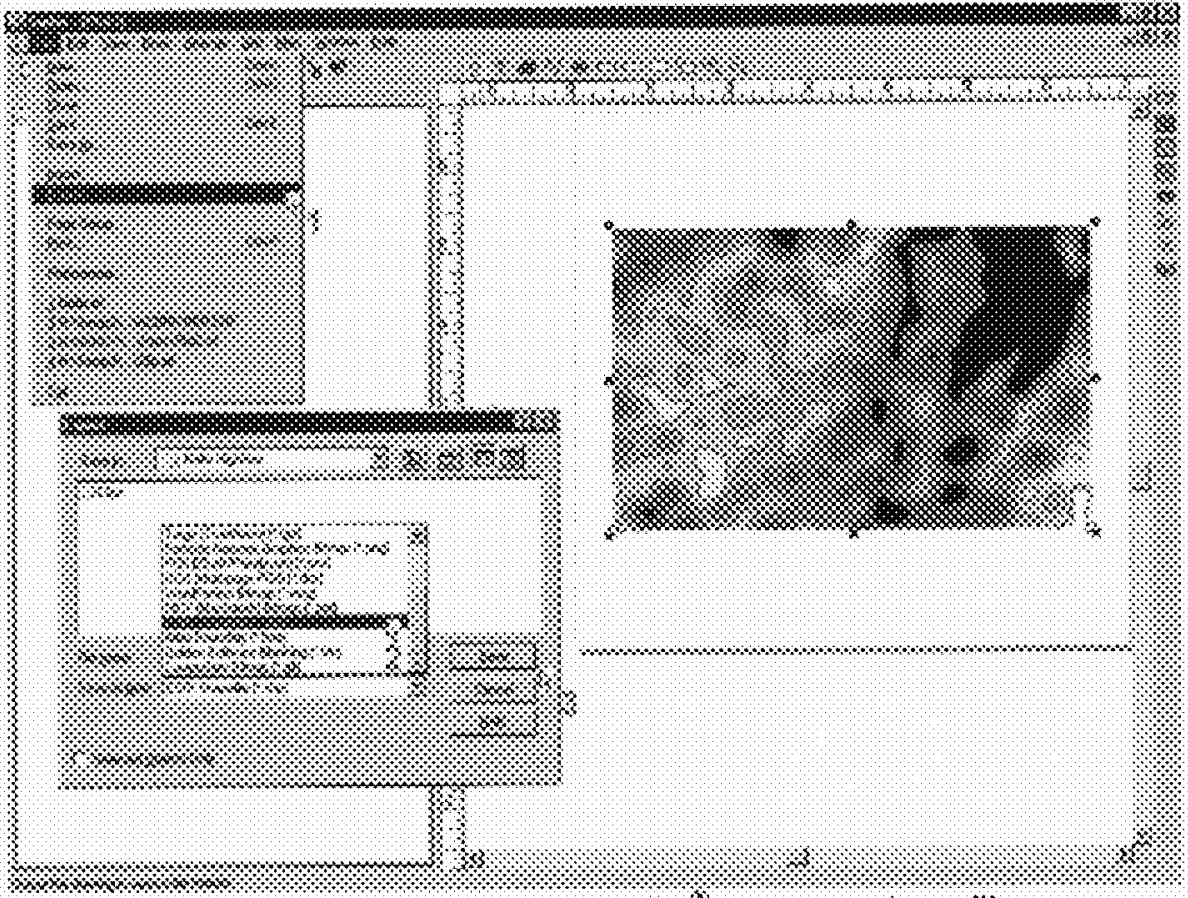

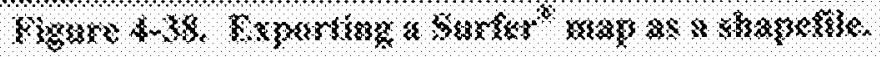




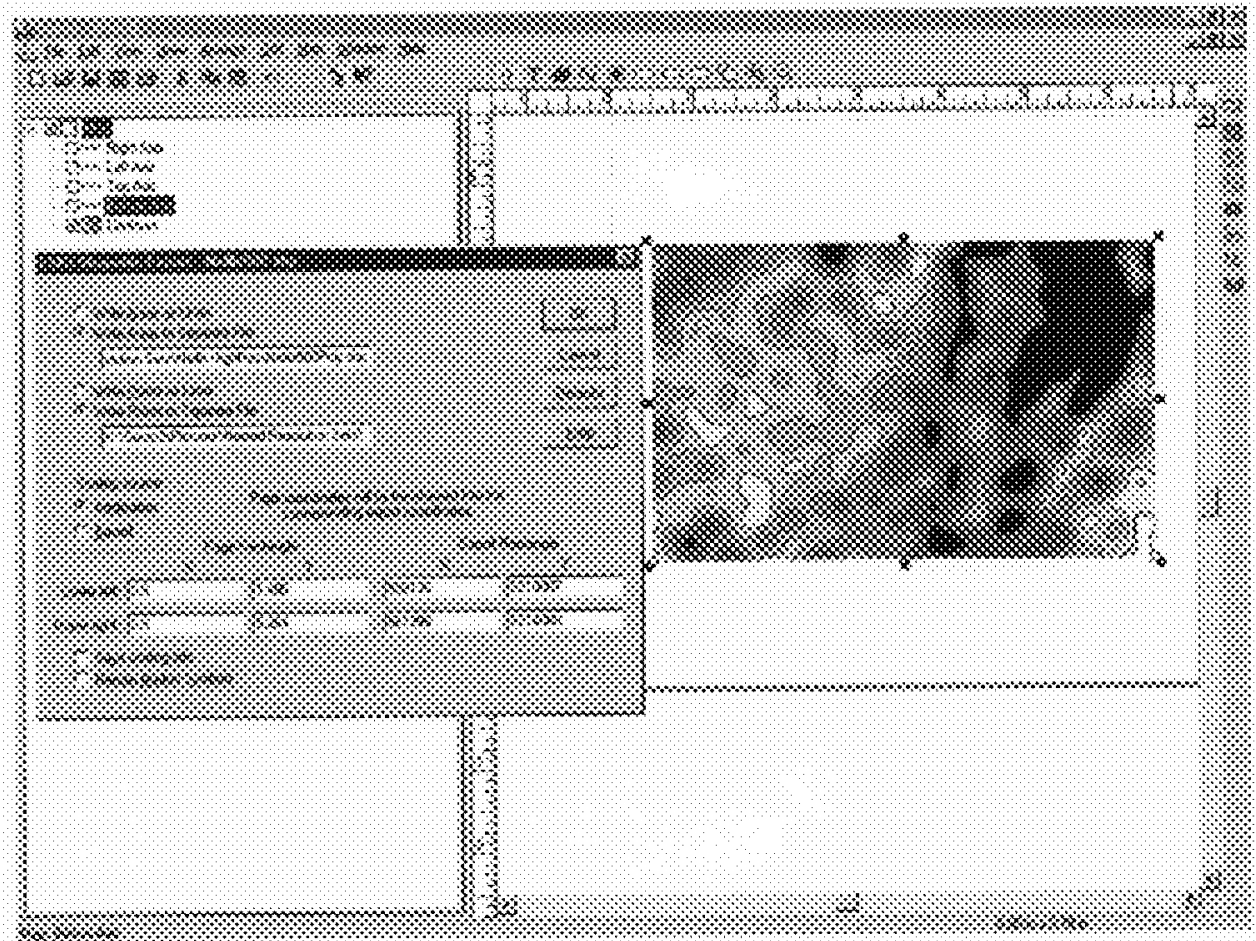

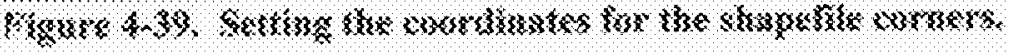

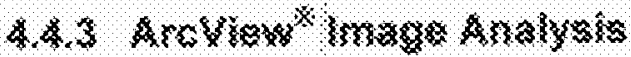

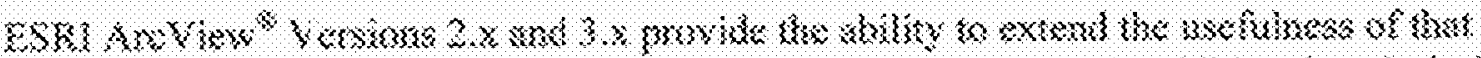

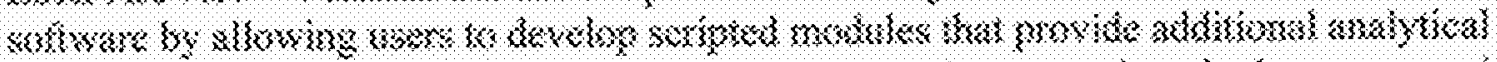

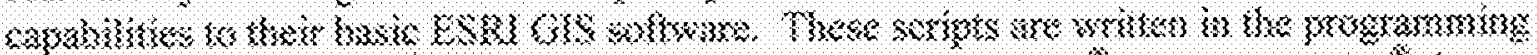

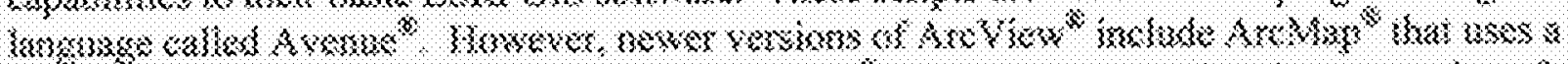

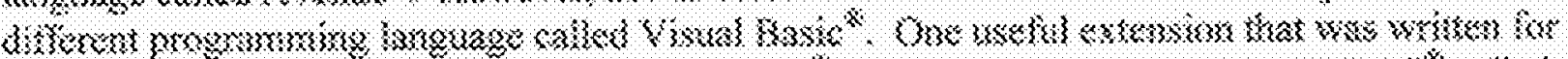

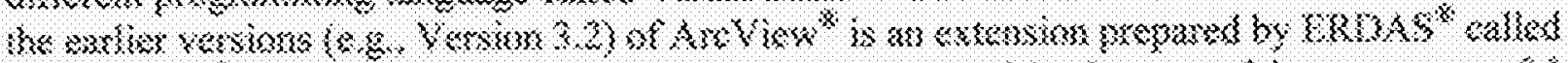

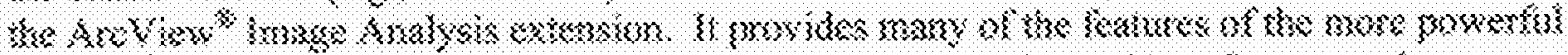

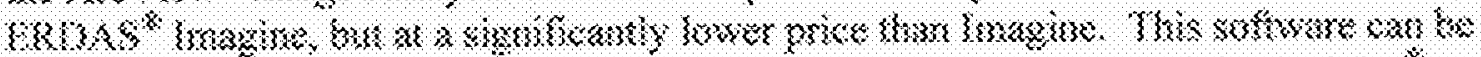

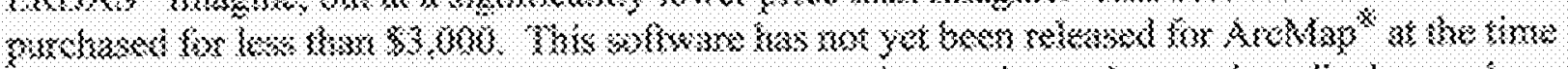

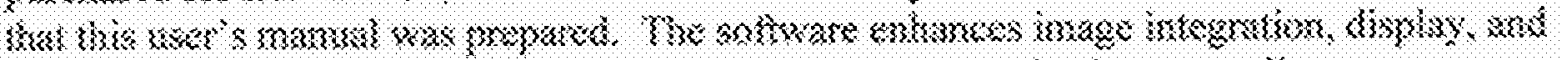

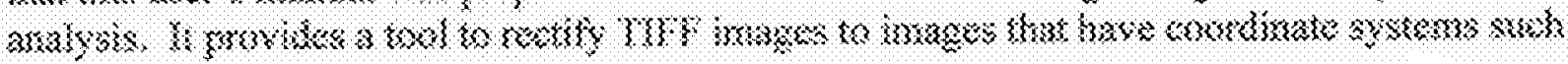

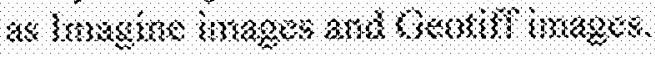

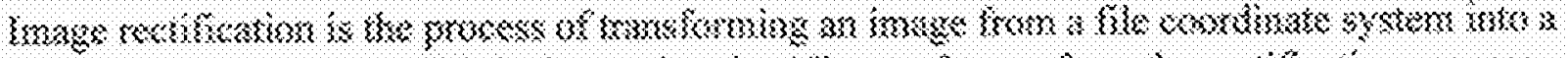

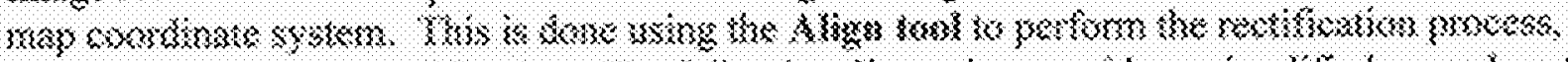

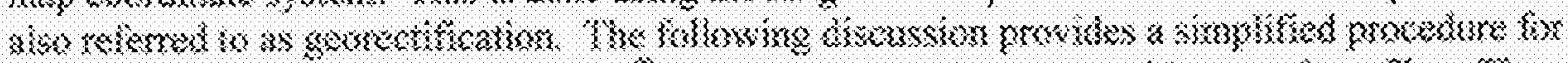

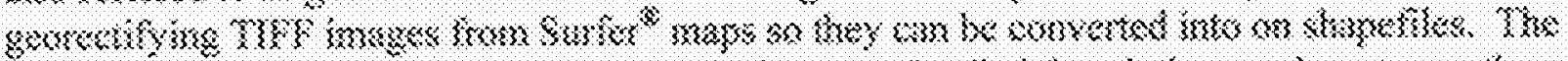

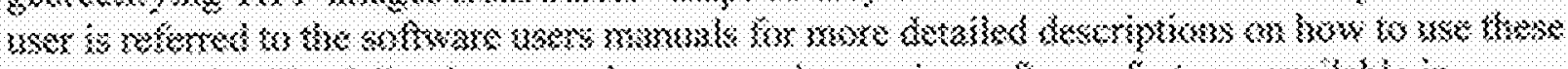

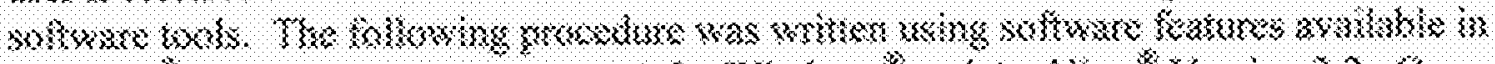

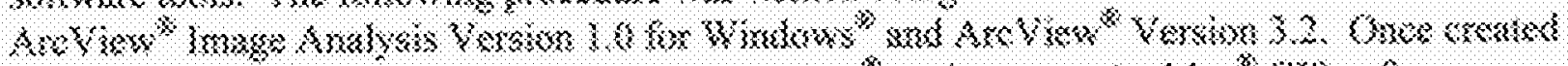

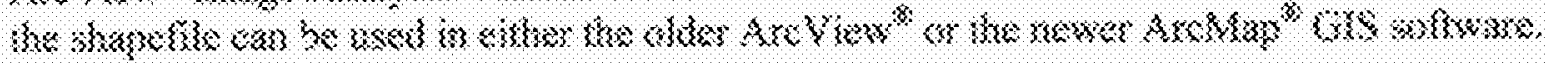




\subsubsection{The Image Rectification Procedure}

The first step is to install ArcView ${ }^{\circledR}$ and ArcView ${ }^{\otimes}$ Image Analysis software and ensure that they are working properly by using the quick start tutorials. Also, make sure that the Image Analysis extension is selected and active. This is done by selecting File from the toolbar at the top of the ArcView ${ }^{2}$ screen. Then select Extensions... from the drop-down menu. Use the scroll bar to reveal the Image Analysis option. Check (left mouse click or equivalent) the box to the left of the Image Analysis option and click OK to activate the Image Analysis extension. When properly installed, the pull-down option: Image Analysis will appear on the toolbar at the top of the software.

The next step is to load a base image that is georectified and the new TIFF image that is to be aligned and georectified with this base image. This is done by selecting (click on) the Add Theme icon (a plus sign on top of a white diamond). Alternatively, the user can select View from the toolbar at the top of the software screen. Then select Add Theme... to add the georectified base image or feature (e.g., a topographic map). An Add Theme pop-up menu will appear and prompt the user to enter the drive, directory path, and file name. Click OK when the information is correct. The data Source Type should read: Feature Data Source (e.g., for a topographic map) or Image Data Source (e.g., for a geotiff or an Imagine image). It should not read: Image Analysis Data Source (this will be used to load in the unrectified TIFF image in the next step). Next, use the Zoom In button on the tool bar to zoom in on the area of the base image where the new non-georectified image will be placed. Create a rectangle slightly smaller than the boundaries using the Zoom In tool. The new image will be placed within this area. If the base image is too small, the added image may obscure the underlying image and make the alignment process more difficult. The approximate boundaries of the alignment corners should be visible when the new image is placed on top of the base image.

Next, add the TIFF image you want to be rectified and aligned. This is done by selecting the Add Theme icon from the toolbar to add the nongeorectified image. An Add Theme pop-up menu will appear and prompt the user to enter the drive, directory path, and file name of the image to be aligned. The data source type should read: Image Analysis Data Source (not Image Data Source nor Feature Data Source). Click OK when all information is correct. A pop-up menu will appear called: "Calculate Pyramid layers for (image name)?" The menu displays the following message: "This image does not have pyramid layers. They allow for rapid display at varying scales. Do you wish to create them Now?" The user can respond Yes, No, or seek additional information by selecting the help option. The pyramid layers are similar to thumbnail size images that can be displayed at various scales, they permit the user to zoom in and out of the image and facilitate the rapid display of the image. Normally the user would respond Yes to this question.

The preceding steps will load the TIFF image into memory, but will not display the image yet. Next, click on the name of the newly loaded TIFF image which should appear in the View panel of the screen. The theme name will have a box around it and a check mark to the left of the image. Select the Align Tool icon (a black square with a diagonal arrow emerging to the upper right-hand of the square). If this icon does not appear, the extension is not properly installed or selected (i.e., the extension checked as first described in this procedure). Once the Align Tool and the theme are selected, the image will be positioned within the center of the area defined by 
the Zoom In tool as described previously. Size (i.e., zoom in) the view of the two new images to ensure that the corners of the "From" image (nongeorectified image) and the corners of the "To" image (georectified image or feature) are clearly visible.

The next step is to choose alignment points from the two images to be matched up. This is done by positioning the cursor over the corner of the nongeorectified image. Select this corner by clicking on the left mouse button (or equivalent). This will position a moving line anchored at the "From" corner point. Next, position the cursor by moving the mouse to the "To" corner and left mouse clicking (single click not a double click) to select the new coordinate. An alternative to this manual method of locating the "To" corner is to right-click on the mouse once the left mouse button has been clicked on the "From" corner. Next, hold down on the right mouse button (this brings up an option box) and move down the options until the Enter "To" Coordinate is highlighted. Release the right mouse button. The To Point pop-up menu will be activated and prompt the user to enter the $\mathrm{X}$ and $\mathrm{Y}$ coordinates of the "To" corner. When the values (e.g., UTMs value) have been entered, click OK. This will align the new image to the one that has the proper spatial coordinates. If a mistake is made, right-click on the mouse and select the Delete Selected Link from the options box. This will undo the last linkage. Repeat the "From" and "To" coordinates until at least four pairs of control points (the corners) are selected (a pair is a "From" and a "To" coordinates). This will align the new image to the one that has the proper spatial coordinates. Control points may be edited using the Pointer tool as described in the user's manual for ArcView ${ }^{\circledR}$ Image Analysis.

\subsubsection{Saving the Georectified Image}

The last step in the procedure is to save the new image as a shapefile that has been rectified. This is done by selecting the Theme menu from the toolbar at the top of the software screen. Next, choose Save Image As. A Save Control Points dialog box appears asking the user if they want to save the control points as a separate shapefile. These may be useful to verify proper positioning of the corners and alignment of several such georectified images. Click Yes to save these control points as a shapefile. Next, a Save Name of Image As menu appears. Give the new image a name and select the appropriate drive and directory path. Click OK to save the new georectified image. The new image will be saved as a georectified image of either an Imagine Image or Tiff Image (select type by using the List Files of Type: option window). The new image can now be used in standard GIS queries to estimate area of different training areas with different shrub cover percentages.

\subsubsection{New GIS Software Tools}

The development of new GIS software has had a significant impact on the way land managers at military and government facilities view data and approach problem solving over large areas. It has facilitated the ability to summary data and effectively communicate it to others. This software is growing in sophistication and complexity, however, there is a rather steep learning curve before users master it. The fact that the software provides its own programming language adds to its power, allowing the user to develop new applications. This has resulted in the development of many applications that can be used by managers at military and government 
facilities. It is anticipated that new software extensions will be available in the future with even greater enhanced capabilities. Many of these software packages will make earlier software obsolete and simplify the image analyses process.

The user is encouraged to contact Internet Web sites (for examples see Appendix 7-3) to stay current with the latest releases. A variety of workshops and conferences are also held to inform users of new developments and applications. The integration of remote-sensing techniques and GIS is relatively well developed and forms the basis for standard geographic analyses using small-scale imagery (e.g., satellite imagery) and image-processing. It is beyond the scope of this user's manual to describe these techniques. This manual has focused more on large-scale imagery and new image-processing techniques that bridge the gap between conventional GIS and more labor-intensive field techniques. A brief description of selected software follows.

\subsubsection{ArcView $^{\circledR} /$ ArcGis $^{\circledR}$}

ArcView $^{\circledast}$ and ArcGIS ${ }^{\circledast}$ provide the foundation for most GIS applications. It provides the ability to query spatially-related data and create maps for displaying resulting information. Because of the level of sophistication required to use this software, the user is referred to ESRI at http://www.esri.com for more information about their products and training. Instruction on how to use the software is beyond the scope of this user's manual. Specific applications are available on their Web site. Training is available at most colleges and universities in addition to training provided by ESRI.

\subsubsection{Feature Analyst ${ }^{T M}$ Extension for Arc View ${ }^{\circledR} 8.2$}

This extension to ArcView ${ }^{\otimes}$ is available for Versions 3.X and 8.2. The software permits the identification of image features based not only on image intensity values selected at specific thresholds, but offers additional power by evaluating pixels surrounding the feature. Once the features are identified, they can be saved as points, lines, and polygons in ESRI shapefiles. One of the strengths of the software is its ability to learn based on inputs from the user (e.g., selecting areas that are properly and improperly classified once the initial classification has been made). It also works directly with rectified images (e.g., geoTIFF and Imagine ${ }^{\circledR}$ images) so georectification is not required; however, it will also permit the user to use nonrectified images as well.

This Feature Analyst ${ }^{\mathrm{TM}}$ software is a rather new addition (introduced in the fall of 2001 and made available for ArcView 8.2 in the spring of 2002) to the image-processing software currently on the market and promises to meet many of the needs. Because Feature Analyst ${ }^{\mathrm{TM}}$ is relatively new, we have not had the opportunity to evaluate it in detail in time to be included in this user's manual. This software (demonstration and authorization key once purchased) is available from Visual Learning Systems in Missoula, Montana (http://www.vls-inc.com/). The cost of Feature Analyst ${ }^{\mathrm{TM}}$ is approximately $\$ 6,800$ for a lifetime subscription. Yearly maintenance includes upgrades and support and is available for approximately $\$ 750$. 


\subsubsection{ENV', Geomatica', and Imagine ${ }^{\oplus}$}

Several software packages have been developed to process satellite images and aerial photographs. Most of these have been applied to satellite imagery for the purpose of remotely sensing changes to land cover. These software are very specialized and have relatively steep learning curves. They are frequently used to prepare imagery for use with other GIS software. They tend to be rather expensive (e.g., more than $\$ 5,000$ ) for professional versions and typically require a larger investment of hardware to support and run them effectively. They are usually very powerful and may require more extensive training. No attempt is made here to describe them in detail. The user is referred to the Internet Web sites that support these products:

Environment for Visualizing Images $\left(\mathrm{ENVI}^{\circledR}\right)$ can be reached at: http://www.rsinc.com/envi/

Geomatica ${ }^{\circledR}$ can be reached at: http://www.pcigeomatics.com/

ERDAS Imagine ${ }^{\circledast}$ can be reached at: http://www.erdas.com/

These software packages all incorporate higher-order classification algorithms, image enhancement, and contrast stretching capabilities as well as registration and mosaicing functions. Another added feature of each of these suites is that they all include scripting capabilities that allow the user to create custom routines.

Some of the more familiar higher-order algorithms used for image classification are the maximum likelihood, minimum distance, and parallelpiped decision rules. The overall objective of image classification procedures is to automatically categorize all pixels in an image into classes or themes based upon empirical relationships. In the case of each of the classifiers mentioned here, the user provides training areas prior to execution. That is, the user chooses pixels that fall into a predefined category such as 'Forest,' 'Grassland,' 'Soil,', "Water,' etc. The spectral patterns in these training areas are evaluated in the computer using a user defined decision rule to determine the category of each pixel in the image. The output of image classification can be in the form of graphic products, tabular data, or digital information files that can be input into a GIS.

Image enhancement techniques improve the ability to visually interpret an image by increasing the inherent distinction between features in a scene. This process attempts to optimize the complementary abilities of the human eye and the computer monitor.

Contrast stretching is a term commonly used in computer enhancement, where the density values in a scene are expanded over a great range. Consider an image whose digital number range between 30 and 100. Only a narrow portion of the full 256-bit range of possible display levels is shown. A more expressive display would result if the entire dynamic range of values, from 0 to 255, was utilized. Enhancement techniques common to the aforementioned suites include linear, square root, and equalization stretches. Figure 4-40 shows an example of an applied linear stretch. It is apparent from looking at the images that enhancement techniques generally make the task of identifying image features easier for the user. 


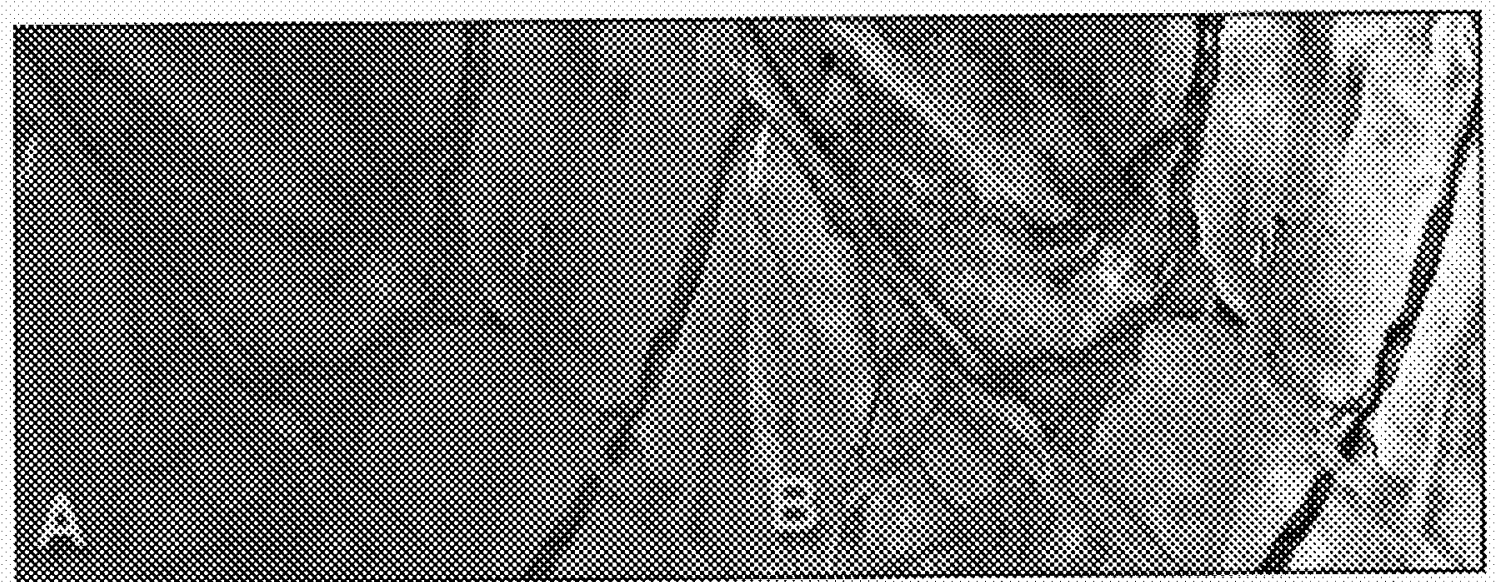

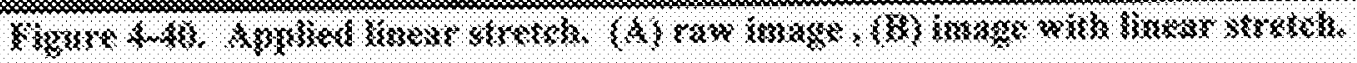

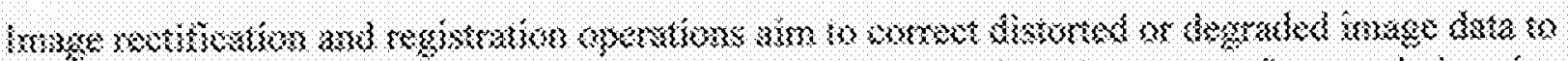

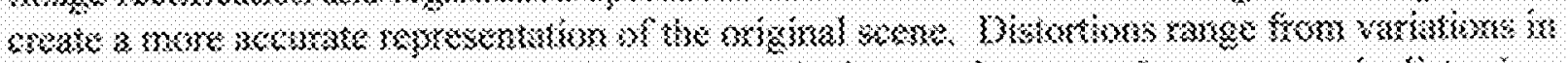

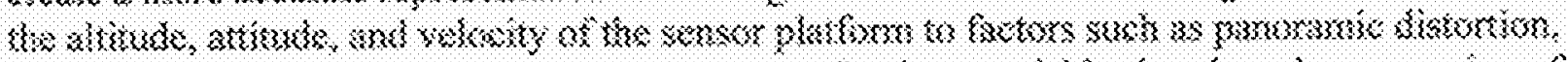

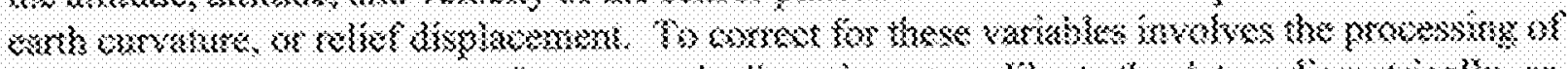

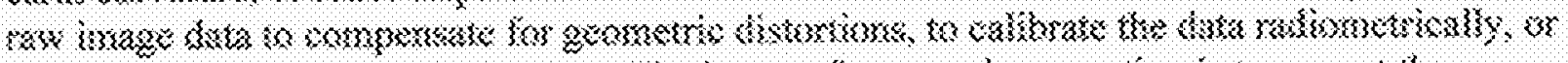

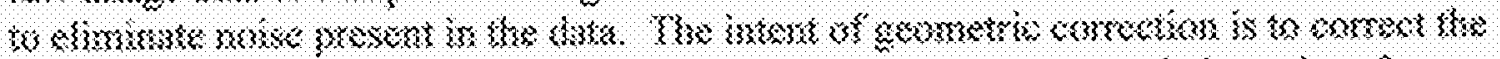

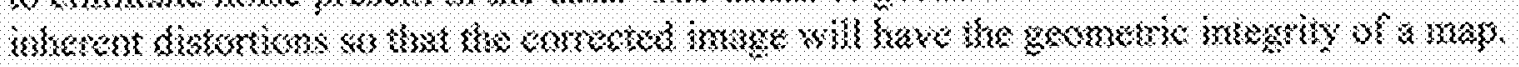

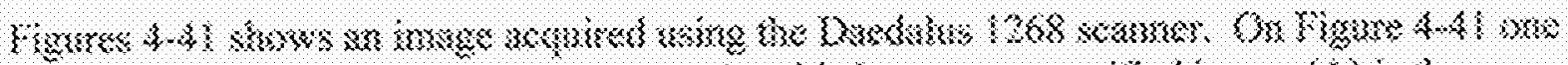

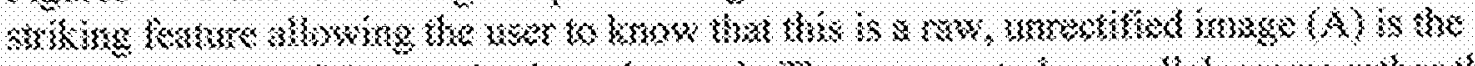

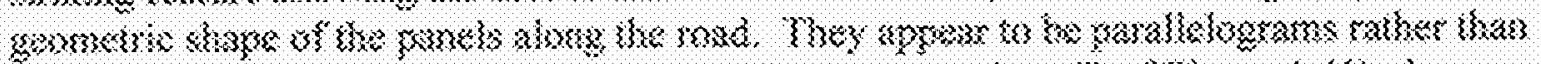

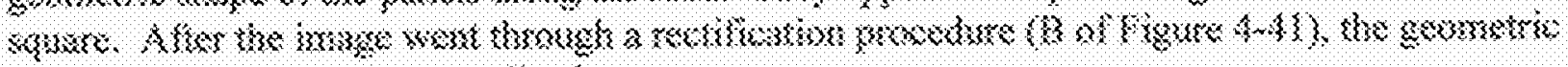

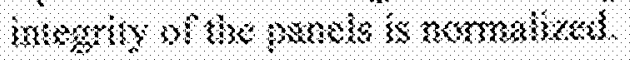

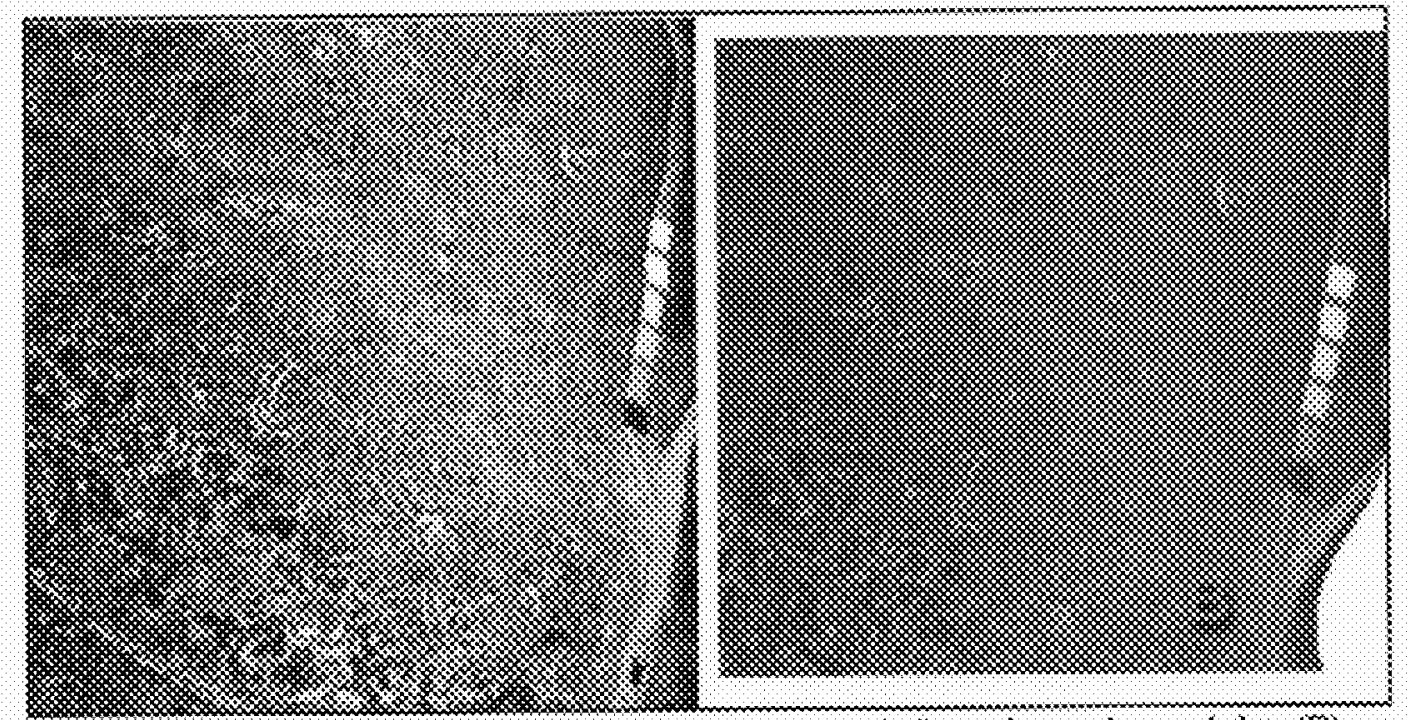

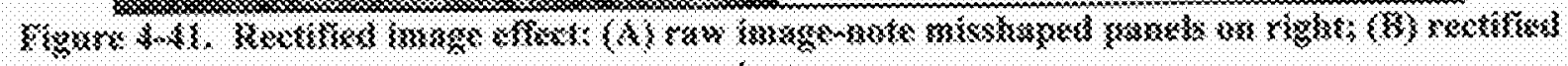
image, 
Choosing an image-processing package depends upon the user's needs and capabilities. RSI's ENVI focuses on extensive radiometric calibration techniques and holds the market on hyperspectral image analysis. ERDAS Imagine is not only an image-processing tool but it also has extensive GIS capabilities and interfaces directly with ESRI products. PCI Geomatics is an overall image-processing tool that contains many modules to adapt its capabilities to include photogrammetric processing that allow the user to create ortho-rectified images and digital elevation models.

Prices for the various software packages vary. ENVI ranges from $\$ 4,900$ to $\$ 6,600$ for Windows and up to $\$ 9,800$ for UNIX licenses. Geomatica licenses start at $\$ 5,000$ for Windows and $\$ 7,500$ for UNIX. Additional Geomatica modules cost up to $\$ 3,000$. 


\subsection{CONCLUSIONS AND RECOMMENDATIONS}

Based upon findings from many small experiments during this project and from practical experience gained in actually using techniques, several conclusions can be drawn and recommendations made:

- The use of small-scale satellite imagery (e.g., 10 to 30 meters per pixel resolution) is of limited value in detecting cover changes in shrubs at canopy cover percentages below 10 percent. Satellite imagery should be used to obtain the "big" picture and aerial photography used to obtain the "details."

- The use of large-scale satellite imagery (<1 meter per pixel resolution) shows promise for future use, but does not capture all of the shrub details. It should only be used as an index of changing shrub cover.

- The use of helicopters is faster and more efficient than using blimps or kites for small areas on most military installations of a small size. However, large areas are best photographed using fixed-wing aircraft specifically designed for such photo acquisition.

- Film scales of 1:1000 to 1:4000 yield the best estimates of plant cover. Scales smaller than this (e.g., 1:15000 to 1:24000) should only be used as an index of shrub cover.

- Scanning rates of about 300 dpi for photos of optimal scale (e.g., 1:1000 to 1:4000) are sufficient to capture canopy cover details and scanning rates of higher values do not increase cover accuracy, only file size.

- Camera lenses should be as fast as possible to avoid motion blurring when shooting aerial photographs by hand from an aircraft. Purchase only fast lenses even though they are usually more expensive than slower lenses, but worth the extra quality.

- Cameras that focus automatically often create unpredictable timing of the exposure due to ground motion created by the aircraft and the lack of vertical structure needed to focus on an image area. The camera's focus should be set manually to infinity when possible to avoid this problem.

- Photographs should be clear (sharp) enough to identify plant canopy edges if they are to be used for rapid assessment of vegetative structure image processing. Commercial imagery should be tested and evaluated to ensure that aircraft, camera, and film types provide the quality that is needed before large-scale projects are funded. Digital images should be georectified and color-corrected as part of commercial services to be provided.

- Statistical differences are measurable between technicians using image-processing software (e.g., setting threshold values); however, the differences are not greater than errors measured for mean canopy cover using ground methods to sample vegetation, where line-intercept techniques are frequently misused and the vegetation undersampled in the interest of time. 
- Shadows, dark-colored rocks, or straw-colored litter may yield false signals, especially when smaller scale imagery is used. Higher resolution imagery may help compensate for these false signals by enabling the software to better identify the canopy cover of vegetation. Test runs of small areas may help avoid expensive photo projects that provide less-then-optimal results on larger areas.

- Vignetting and unequal lighting (e.g., north- and south-facing slopes, or different colored soils) in the same photograph should be corrected with color-balancing software before further processing to eliminate false signals due to color intensity differences.

- Measurements of object size classes are readily obtained, but differentiation of individual species is limited and users should use other ground-based methods every five years to collect trends in plant community composition.

- Ideally, site-wide imagery should be taken every year, however, budgets usually restrict the imagery to about once every two to five years. Areas receiving more frequent and heavy use for training should be photographed annually.

- Measurements of vegetation and other digital objects with commercially available image processing software are encouraging and can be used with other computer software to produce GIS themes.

- Three to six software packages may be needed to edit images, process images, and create acceptable GIS themes. A high-ended computer should be selected to reduce processing time (faster processing and greater memory is essential).

- Quality image processing assumes a high level of technician skill. When turnover in personnel is high ( $<1$ year average time period at the installation), a program of adequate training and additional incentives to retain employees should be considered to ensure that learning skills are transferred to new personnel.

- There are many excellent Web sites that should be utilized for acquiring skills and information about digital photography and image processing. Web sites referenced in this user's guide and links found at those Web sites should be periodically revisited for new information.

- A forum for information exchange in the form of a remote-sensing workshop should be provided biennially to all military branches (not just the Army's ITAM Workshop) to encourage the sharing of techniques and new ideas. The U.S. Department of Agriculture's Forest Service's Remote Sensing Program (http://www.fs.fed.us/eng/rsac/) provides an excellent program model or example of how to promote this exchange of information. 


\subsection{LITERATURE CITED}

Benton, Charles C. 2002. Kite Aerial Photography. Web status as of September 2002,

- http://arch.ced.berkeley.edu/kap/.

Bonham, C. D. 1989. Measurements For Terrestrial Vegetation. John Wiley and Sons, New York. $338 \mathrm{pp}$.

Bright, 'T. A., S. Getlein, J. Jarrett, S. Tripp, and J. Moeller. 1997. Remote Sensing Users' Guide. Version 1.0. January 1997. U.S. Army Environmental Center and Topographic Engineering Center.

Chambers, J. C., and R. W. Brown. 1983. Methods for Vegetation Sampling and Analysis on Revegetated Mined Lands. General Technical Report INT-151. October 1983. Intermountain Forest and Range Experiment Station, Ogden, UT, U.S. Department of Agriculture. pp. 15-17.

Falkner, E. 1995. Aerial Mapping, Methods, and Applications. Lewis Publishers, Boca Raton, Florida. $322 \mathrm{pp}$.

Fulton, W. 2000. A few scanning tips. Fulton Press, fulton@scantips.com. 256 pp. Also available at http://www.scantips.com. September 21, 2000.

Hessing, M. B., G. E. Lyon, G. T. Sharp, W. K. Ostler, R. A. Green, and J. P. Angerer. 1996. The Vegetation of Yucca Mountain: Description and Ecology. B000000000-017175705-00030. CRWMS. U.S. Department of Energy, Yucca Mountain Site Characterization Project. Las Vegas, Nevada. 69 pp.

Kent, M., and P. Coker. 1992. Vegetation Description and Analysis. CRC Press, Boca Raton, Florida. $363 \mathrm{pp}$.

Kodak. 1999. Kodak Professional Film or Digital? About film. Internet information posted at: http://www.kodak.com/global/en/professional/hub/law/filmdig/film.shtml on April 26, 1999.

Koren, N. 2002. Norman Koren Photography. Understanding image sharpness part 2: resolution and MTF curves in scanners and sharpening. Internet site at: http://www.normankoren.com/ as of February 25, 2002.

Lee, C. 1995. Correlation of Biodiversity to Landforms at the Fort Irwin National Training Center: A Remote Sensing Analysis: Year Two. Contract No. DACA009-93-D-0027. Robert D. Niehaus, Inc., Santa Barbara, California.

Lyon, I. 2002. Photoshop Tutorials. Computer Darkroom, online at http://www.computerdarkroom.co.uk/ as of July 8, 2002. 
Ostler, W. K., D. C. Anderson, D. B. Hall, and D. J. Hansen. 2002. SERDP USERS MANUAL, New Technologies to Reclaim Arid Lands. DoD/DOE/BN11718-731, Bechtel Nevada, Ecological Services, Las Vegas, NV 89193.

Parker, K. W., and D. A. Savage. 1944. Reliability of the line interception method in measuring vegetation on the Southern Great Plains. J. Am. Soc. Agron. 36:97-110.

Plumb, T. R., and N. H. Pillsbury (Technical Coordinators). 1986. Multiple-Use Management of California's Hardwood Resources. USDA Forest Service General Technical Report PSW-100. Pacific Southwest Forest and Range Experiment Station, Berkeley, California.

Tweddale, Scott A., Thomas D. Frank, and Sarah J. Lenschow. 2002. Assessing the Effect of Spatial Resolution on Vegetation Cover, Developing and Testing a Procedure to Scale-up Vegetation Cover Estimates, and Development of Procedures and Models to Estimate Standing Woody Biomass. U.S. Army Corp of Engineers CERL, and University of Illinois at Urbana-Champaign. Interim Report. Research Funded by Stategic Environmental Research and Development Program, Washington, D.C. http://hayduke.sdal.uiuc.edu/serdp/ipr_4_2002/finalrep.pdf

Uuttera, J., A. Haara, T. Tokola, and M. Maltamo. 1998. Determination of the spatial distribution of trees from digital aerial photographs. Forest Ecology and Management. 110: 275-282. pp 275-282.

Warner, W. S., and J. Kværner. 1998. Measuring Trail Erosion with a $35 \mathrm{~mm}$ Camera. Mountain Research and Development, Vol. 18, No. 3, 1998. pp. 273-280. Centre for Soil and Environmental Research, Jordforsk, 1432 Ås, Norway. 


\section{APPENDICES}

Appendix A Cover Mapping at Fort Irwin, California, Using Aerial Photography and Image Analysis Software

Appendix B Plant Damage Assessment Technique for Evaluating Military Vehicular Impacts to Vegetation in The Mojave Desert 


\section{APPENDIX A \\ COVER MAPPING AT FORT IRWIN, CALIFORNIA, USING AERIAL PHOTOGRAPHY AND IMAGE ANALYSIS SOFTWARE}

(see attached report) 


\title{
COVER MAPPING AT FORT IRWIN, CALIFORNIA USING AERIAL PHOTOGRAPHY AND IMAGE ANALYSIS SOFTWARE
}

\author{
Brian Croft \\ Charis Corporation, Fort Irwin, California
}

\section{Introduction}

The amount and type of military training that goes on at Fort Irwin, California can have adverse effects on vegetation and other types of ground cover that hold soil particles in place. This can leave areas of the installation open to increased levels of wind and water erosion. One of the keys to combating this problem lies in the rehabilitation efforts of the LRAM (Land Rehabilitation and Maintenance) office. The job of this office is to determine areas of the installation that have undergone increased levels of degradation due to military training and then to employ various techniques to rehabilitate them. The use of LCTA (Land Condition Trend Analysis) spatial data can be extremely useful in the selection of areas of the base that need to be targeted for LRAM efforts. In the past the Fort Irwin LCTA program has used field-collected data and GIS tools, such as spatial analyst, to interpolate grids of percent cover. This method statistically analyzes the field collected data and then creates contour lines of similar percent cover values. The use of this technique has been utilized to determine general areas of similar percent cover values. Because of the statistically small sample size (295 vegetation plots) it is difficult to obtain the level of detail that would be required by the LRAM office to effectively target rehabilitation efforts. The LCTA office is now conducting new remote sensing technologies developed by Dennis Hansen and Kent Ostler of Bechtel Nevada to solve this lack of specificity in vegetative cover analysis. The new methods uses current aerial photographs of Fort Irwin (1:24000) and image analysis software to develop a more specific index of percent cover.

\section{Using Sigma Scan Prö}

Sigma Scan Pro@ is a program that has the ability to analyze the pixels of a digital photograph and select pixels that are darker than the ones that surround them. With desert plants that are usually somewhat darker than the soil background it can be very useful in picking out vegetative cover from a photograph. This software also allows the user to "threshold" the image analysis. This means that you can vary the intensity at which an image is analyzed. Sigma Scan Pro employs a tool called an Color Histogram that can show what percentage of each color of the visual spectrum a given pixel is comprised of. A technique known as a "Histogram Stretch" can be used to make certain intensity values of the spectrum show up better (i.e., contrast is improved). This can be extremely valuable when trying to differentiate shrubs from their background (soil) by making them darker and easier to detect. An Intensity Histogram may be more useful for this process because it is better at differentiating between shrubs and other non-vegetative "noise", such as shadows or dark colored soils. Using a combination of the two histograms may be the most beneficial in differentiating shrubs (for photography of 1:16000 or greater, the use of a color histogram is not valuable). Overlay filters can also be used to erode out features that are smaller than a certain pixel size. This can be helpful in getting rid of non-vegetative "noise" such as animal burrows or other landscape features that may appear dark on an aerial photograph. The "measurements menu" can be used to determine how many pixels within the photography are comprised of the selected shrub features. These features can then be masked on to a white background for easier analysis.

Steps: 1) Open the digital image that you wish to analyze in Sigma Scan Pro®.

2) Zoom the image into a point just before you begin to see the pixels show up.

3) Select Intensity Threshold from the Image menu. This will overlay a red mask on certain pixels in the image with a default intensity value. Before it does this it will ask you to convert the image to gray scale.

4) Convert the image to gray-scale unless you wish to use the color histogram to threshold the image (color thresholding is not necessary on images at 1:24000 scale). If you already have a threshold value selected for the analysis of all your images, then do not convert to gray scale to save processing time. 
5) Once the thresholding window comes up use the "histogram slider" to determine the correct value based on how much of the overlay red covers the shrubs being analyzed. (Once a threshold intensity has been done for one picture, the same threshold value can be used for all pictures being analyzed in a given area.

6) Select Overlay Filters from the Image menu and use them to drop out all features that are smaller than a certain pixel size. (You will have to play around with this feature to determine what pixel size is right to use for.that image). Overlay filters should not be used for 1:24000 photography.

7) Use the Masking feature under the Image menu. Select "With overlay 1 (Red)". This will remove all of the threshold selected features and mask them on a white background.

8) Save this masked image as a 24-bit TIFF file.

\section{Using the SERDP Tiff Converter}

Once you have the image of the shrubs on a white background it is then time to do the statistical analysis for vegetative cover. The TIFF converter overlays a grids onto the TIFF image, and then analyzes each individual grid square and determines which portion of that square is dark in color and which portion is white. In this way it can compile a list of percent cover statistics for the image.

Steps: 1) Open the 24-bit TIFF in the Converter program (disable the preview window).

2) Export the file at grid size 10 pixels $x 10$ pixels.

3). The program will create a table of statistics in a ".dat" file.

4) The tiff converter will ask you if you want to view the output file. Click no to decrease processing time.

\section{Using Surfer@ 7.0}

The Surfer@ 7.0 software takes the statistics created in the Tiff converter and uses them to create contour lines of similar percent cover values for that image.

Steps: 1) Select "Data" from the "Grid" menu. Open the ".dat". file created by the tiff converter.

2) Adjust the Wire Frame settings to make the analysis more exact (100x100 is a good place to start). $100 \times 100$ is a good wireframe to use for 1:24000 photography. Also make sure that the gridding method is Minimum Curvature. This will create a Surfer Grid (.grd) file.

3) Choose New Contour Map from the Map Menu. Open the grid that was created from the ".dat" file in Surfer.

4) From the Contour Map Properties menu choose Fill Colors, Color Scale, and Smooth Contours.

5) Under levels on the same menu you can choose what \% cover classes to use.

6) Fill Properties on the same window allows you to select what colors to use to represent each cover class from the Foreground Color Window. (The line on the $0 \%$ level can be made invisible.

7) Make all of the boundary lines between classes invisible.

8) Once a legend is created for the contours, save it so that you can use it on all subsequent photos in a given analysis.

9) Export the completed map as a tiff file. Saving it over the original masked image created in Sigma Scan will save hard drive space.

\section{Using Adobe Photoshop ${ }^{8}$}

Steps: 1) Bring the exported file up in Adobe Photoshop@.

2) Use the Crop Tool to cut out the map image, not including the black border of the map. Zoom all the way in to decide where to place the cursor.

3) Save the cropped image over the exported Surfer Tiff file. 
4) The images from several photographs can then be pieced together on a canvas within Adobe Photoshop(B. (Make sure to make the canvas only large enough to accept all the pixels for the images being mosaiced). To know how large to make the canvas, open a cropped image and choose image size from the image menu. This will tell you how many pixels high and wide you cropped, exported Surfer Tiff is. Then multiply these dimensions based on how many photos make up the length and width of your desired mosaic. When performing the mosaic, make sure to zoom all the way in so that you can line up the images properly with each other and the edge of the canvas.

5) Once all images have been mosaiced, save the image as a copy of a tiff. (mosaiced images must be either square or rectangular for georefrencing purposes).

\section{Writing the TIFF World File}

Each section of the cover map must be georefrenced so that it can be opened within ArcView@. This is done by writing a TIFF World File (.tfw) for the "copy of a tiff" that was saved within Adobe Photoshop®.

Steps: 1) Open the notepad accessory on you computer.

2) Open ArcView $B$ and add the orthocurrent.shp file. Label the tiles within this file.

3) Determine the UTM coordinate of the upper left and the lower right hand corners of your mosaiced cover map.

4) If you know the label numbers for the photos used in the mosaiced cover map, they will correspond to the labeled orthocurrent tiles. (Orthocurrent.shp is the coverage for the 1997 labels. 2001 photography will be labeled differently).

5) You can create a new theme within ArcView@ that adds points to the comers mentioned for he mosaiced image, and then use the "addxycoor" script to determine their UTM coordinates. (You may want to zoom all the way in so that you can place the points accurately on the corners).

6) Open the notepad and follow the following instructions for writing the lines of the TIFF world file:

a. Line 1:

([x-value of lower right corner] - [x-value of upper left corner]) / [image width]

Ex: $=(559500.0000-549000.3595) / 2157$ pixels $=4.868$

b. Line 2:

Assume to be 0 (zero)

c. Line 3:

d. Line 4:

Assume to be 0 (zero)

([y-value of lower right comer] - [y-value of upper left corner]) / [image height]

Ex: $=(3894750.00001-3936750.0000) / 8616$ pixels

$=-4.875$

e. Line 5:

[x-value of upper left-hand corner]

f. Line 6:

Ex: $=549000.3595$

[y-value of upper left-hand corner]

Ex: : $=3936750.0000$

The Written Text file should look like this: 4.868 
7) Once the file is written save it as a ".txt" file using the exact same name used to save the mosaiced cover map within photoshop.

8) Open "Explore" under the start button on the desktop and navigate to the folder where both the mosaiced map and world file are saved. They must be saved in the same spot.

9) Change the file type from ".txt" to ".tfw" by renaming the file, but do not change the actual name, only the ending.

10) Once a world file is written for one section of the base it can be used for all other sections of the base by simply changing. lines 5 and 6 to correspond to the UTMs of the upper-left corner of the new mosaiced image. The new world file will have to be saved to correspond to the correct name of the new mosaiced image. (This is important because you may have to piece several mosaiced images together to cover the whole base, each of which will need its own world file).

\section{ArcView@ Image Analysis Extension (ArcView 3.2a)}

After your mosaiced sections have been georefrenced they need to be converted to shapefiles within ArcView. This is done using the ArcView@ Image Analyst extension.

Steps: 1) Open ArcView $\otimes$ and enable the Geoprocessing Wizard and Image Analysis extensions.

2) Add your mosaiced image as an Image Analysis Data Source, not an Image Data Source.

3) Pick a feature in the cover map from your lowest cover class and zoom in on it. (It is best to Pick a small oval or regularly shaped feature).

4) Under "Seed Tool Properties" on the Image Analysis Menu make sure that the "Include Island Polygons" box is checked and the "Seed Radius" is set to 5 pixels.

5) Use the Seed Tool from the Image Analysis Toolbar to drag a small rectangle within the cover class feature.

6) The analysis will place a green line around what it considers to be the boundary of the image. (Since resolution is low on these image files, the feature may have fuzzy edges where it is hard to tell where the boundary between features of two cover classes exists).

7) Click on the ArcView@ Vertex Tool. This will make drag boxes appear on the green boundary line. Drag the boundary line in so it is completely contained within the correct color of the cover class for the feature being looked at.

8) Select the pointer tool from the ArcView(8) Toolbar. This will remove the drag boxes from the new boundary line. With the boundary line still selected (black boxes around the line); choose Find Like Areas" from the Image Analysis Menu.

9) In the "Find Like Areas" window click the "New" button and name the "Output Image Theme". Make sure the "Selected Graphics" box is checked.

10) Label the "Class Name" to correspond to the cover class you are trying to convert. Hit enter and then press $O K$. This will select all of the areas within the image whose pixels have the same color as the cover class being converted.

11) Repeat steps 3 through 10 for all cover classes within the image. In the "Find Like Areas" window (step 9) keep the "Output Image Theme" name the same, but change the "Class Name" to correspond to the cover class being analyzed.

12) Once all of the cover classes have been analyzed, and the output image theme is complete, you must then convert this theme to a shapefile by selecting the theme and choosing "Convert to Shapefile" from the Theme Menu. A separate shapefile theme must be generated for each mosaiced section of the base.

13) Once all of the mosaiced sections of the installation have been converted to shapefiles, you can merge the individual themes using ArcView $($ Geoprocessing Wizard, which will appear under. the View Menu. Choose the merge option, select all of the themes to be merged, and press enter. 


\section{Removing Mountain Noise in the Analysis}

The image analysis in Sigma Scan Pro® can tend to confuse shadows in the mountainous areas for extremely high cover, so it may be necessary to clip the shapefiles to remove areas in the mountains. This is beneficial to the ITAM office at Fort Irwin because we are only concerned with training lands $(>20 \%$ slope).

Steps: 1) Create a slope coverage from a Digital Elevation Model (DEM) using ArcView@ Spatial Analyst. Select the DEM theme and then choose "Derive Slope" from the Surface Menu.

2) Select the new slope theme.

3) Choose "Map Query" under the Analysis Menu. In the "Map Query" window select the slope theme from the layers box by double clicking. Make sure that it shows up in the equation box, then click the ">" button and type 20 into the equation box. Click "evaluate". This will create a "Map Query" theme.

4) Select the "Map Query" theme and convert it to a shapefile.

5) Open the new shapefile theme's attribute table. Use the "Query Builder" to select all records with a Gridcode $=1$.

6) Select "start editing" from the Table Menu. Then select "delete records" from the Edit Menu, then click "stop editing" and save the edits. This removes from the new theme any area $>20 \%$ slope.

7) Open the Geoprocessing Wizard and select "clip themes". Clip the cover map based on the new slope theme. This removes any cover polygons in the areas of the base greater than $20 \%$ slope.

It may not be possible to clip the entire installation cover map based on the slope theme. You may have to clip it one section at a time, in which case it would be helpful to clip the slope theme to a size that approximates the sections size. Then you would have to merge all of the clipped sections.

\section{.Selecting the Correct Thresholding Value for Comparability}

In order to look at changes in cover from one set of photography to the next you need to make sure that the Sigma Scan Pro® software is looking at the two sets of images in the same way. Sometimes photography from one year can have different brightness and contrast factors that can affect the analysis of the photography. In order to make the photograph sets comparable it is necessary to choose a threshold value for the second set, which looks at the shrubs in the same way that it did for the previous set of photography.

Steps: 1) Open a tiff image from the first set of photographs to be analyzed within Sigma Scan Pro®. It is best to choose a photograph from an area where changes in the shrubs has not occurred.

2) Shrink down the image so that you can bring up the corresponding photograph from the new set of photography.

3) Select a shrub in each image that does not appear to have changed much. Sigma Scan Proß has a feature in the lower left hand comer of the screen that identifies the coordinates of the cursor on the photograph. You can select a shrub in one image and copy down the coordinates, and then go to the next photograph and move the cursor around until you find the shrub with the same coordinates. If the shrub does not appear to have changed, then this will be a good shrub to use for the analysis.

4) Follow the instructions listed in "Using Sigma Scan Pro®" to apply the threshold that was used to analyze the first set of photographs. Make sure to zoom way in on the photograph to a point just before you begin to see pixels in the image. The threshold you choose will overlay a red mask on top of all of the shrubs to the extent that your thresholding value determines.

5) Follow the procedures used to apply a thresholding value to the image from the second set of photos. This time you will want to convert the image to a gray-scale.

6) Once the new image is converted to a gray scale you can use the "Histogram Slider" to apply different threshold values as you move it along the histogram, and see how much of the shrubs get covered by the mask with different values. With both images opened on the screen, and the 
correct threshold value applied to the first photograph, simply slide the histogram slider back and forth until the mask over the shrub being looked at in the new image matches the mask over the same shrub in the old image.

7) When the mask for the second image matches the mask for the first image simply read the thresholding value off of the thresholding window and apply the same value to the rest of the photographs in the analysis.

\section{Making a Map of Shrub Cover Change}

Once cover maps are made for both sets of photography it is then possible to make a map that shows areas of shrub cover increase and decrease. The maps must be made as instructed above so that they can be compared accurately. It is very unlikely that you will be able to use the same thresholding value to analyze photographs from two different years, so make sure to follow the instructions listed in the last section. It is also a good idea to use the same slope mask to clip both years maps.

Steps: 1) Add the Spatial Analyst Extension to ArcView $\$$ and open both cover maps.

2) Select one of the cover map themes and choose "convert to grid" from the Theme Menu. Do the same for the other year's cover map so that both themes are converted to raster coverages.

3) Select "Map Calculator" from the Analysis Menu. Use the calculator to subtract the older cover map from the more recent one, and press evaluate. This will subtract all of the individual cell values within the raster coverages so that the output will contain cell values for a given area that are either a positive number, negative number, or a 0 (zero). Positive numbers represent varying levels of increase in cover, negative numbers represent decrease in vegetative cover and 0 shows areas of no change.

4). Use a dichromatic scale from the new themes legend to more easily differentiate increase, decrease, and no change areas.

\section{The Importance of Ground Truthing}

Remote sensing data is almost useless without ground-truthing that will apply real world numbers to the classes that you come up with in an analysis. The cover classes that are arrived at in this analysis are arbitrary and do not mean much to the user without ground-truthed cover values.' They can provide information about levels of change from year to year however. Because of the variability in photographic contrast and brightness levels from year to year and other variables in this type of analysis it is a good idea to do some ground-truthing. This way the cover classes will provide more information to the end users. Here at Fort Irwin LCTA permanent plot data will be used to ground-truth the photography.

Steps: 1) Simply overlay the LCTA \% cover data that corresponds to the year you are trying to groundtruth. Make a text table (.txt) within Excel@ that contains the \% cover values and UTM coordinates for the LCTA plots and add it to the ArcView project. Then use the "Add Event Theme" option under the View Menu to create a point theme from it.

2) Use the "Assign Spatial Data" feature of the Geoprocessing Wizard look at which cover class each LCTA plot falls into. This will add new fields to the LCTA plots theme attribute table. One of these fields will be the cover class associated with each LCTA plot.

3) Use the "Query Builder" to select all records from a given cover class and export the records as a text file.

4) Open this text table within Excel@. Look at the range of \% cover values and determine the range of percent cover values for this cover class. Make sure to throw out any outliers that may be the result of analysis noise. Repeat the same steps for all cover classes to get the range of percent cover values that are represented by each cover class. 


\section{APPENDIX B}

\section{PLANT DAMAGE ASSESSMENT TECHNIQUE FOR EVALUATING MILITARY VEHICULAR IMPACTS TO VEGETATION IN THE MOJAVE DESERT}

(see attached report) 


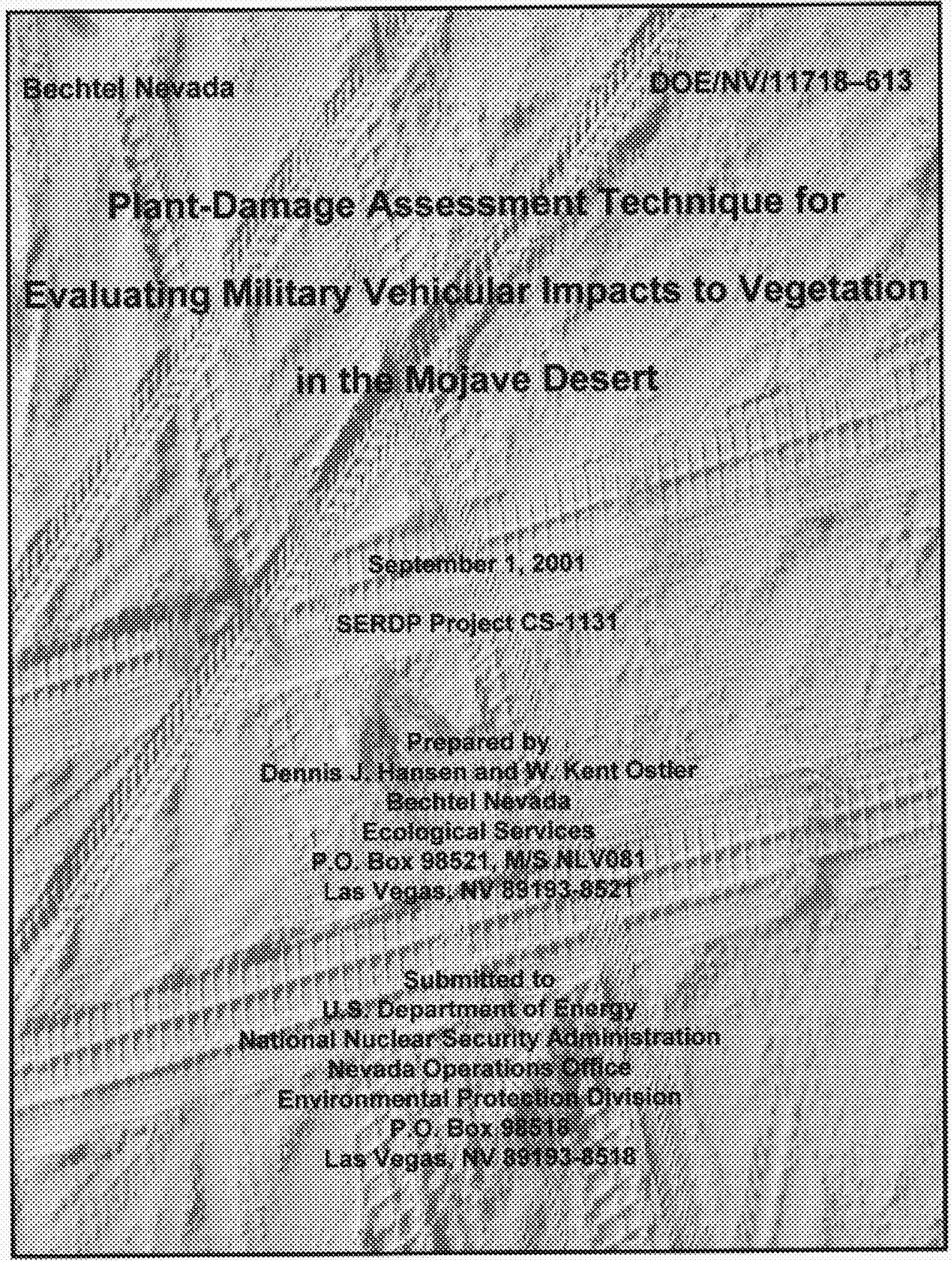




\section{DISCLAIMER STATEMENT}

Reference herein to any specific commercial product, process, or service by trade name, trademark, manufacture, or otherwise does not necessarily constitute or imply its endorsement, recommendation, or favoring by the U.S. Government or any agency thereof or its contractors or subcontractors.

\section{AVAILABILITY STATEMENT}

Available for sale to the public from:

U.S. Department of Commerce

National Technical Information Service

5285 Port Royal Road

Springfield, VA 22161-0002

Telephone: $800-553-8647$ or $703-487-4650$

Fax: 703-605-6900

E-mail: orders@ntis.fedworld.gov

Online ordering: http: //www.doe.gov/bridge

Available for a processing fee to U.S. Department of Energy and its contractors, in paper, from:

U.S. Department of Energy

Office of Scientific and Technical Information

P.O. Box 62

Oak Ridge, TN 37831-0062

Telephone: 865-576-8401

Fax: 865-576-5728

E-mail: reports@adonis.osti.gov 


\section{ACKNOWLEDGMENTS}

Work was performed under the Strategic Environmental Research and Development Program (SERDP) Project CS-1131 and was supported by the U.S. Department of Energy's National Nuclear Security Administration Nevada Operations Office, the U.S. Army's National Training Center (NTC) at Fort Irwin, and Charis Corporation, Inc., who facilitated access to training areas at the NTC. 
Disclaimer Statement . .............................................................................................. i i

Availability Statement ..................................................................................... i

Acknowledgements.... .................................................................................................... ii

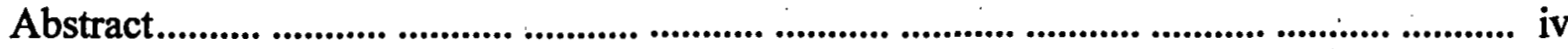

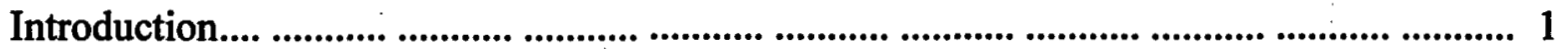

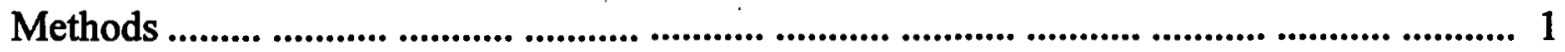

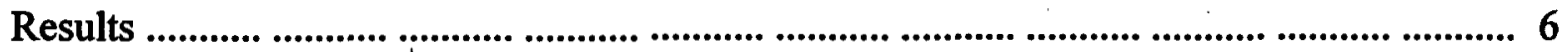

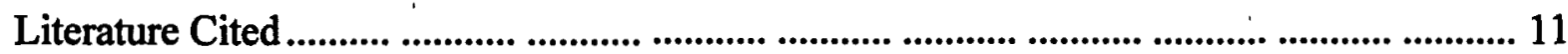

Appendix A .... ........................................................................................................... 12

Number $\quad$ Page

Figure 1 Diagram of typical field conditions for assessing plant damage from

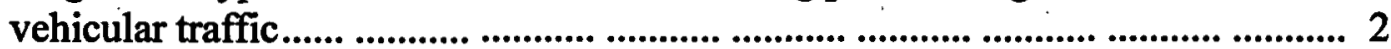

Figure 2 Prior Plant Damage Classes ................................................................... 2

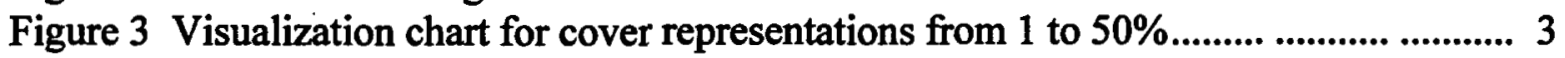

Figure 4 Example of Plant Damage Assessment Form .................................................... 5

Figure 5 Percentage of shrubs at Fort Irwin sites by prior damage to vegetation codes.

\section{LIST OF TABLES}

Number

Page

Table 1 Comparison and ranking of plant species percent mean survival after vehicular traffic.

Table 2 Mean percent survival for plants by prior damage class after vehicular impact. 
ABSTRACT

A new plant-damage assessment technique was developed by plant ecologists from Bechtel Nevada at the U.S. Department of Energy's National Nuclear Security Administration Nevada' Operations Office and funded by the Strategic Environmental Research and Development Program Project CS-1131 in cooperation with the U.S. Army's National Training Center (NTC) at.Fort Irwin, California. The technique establishes linear transects the width of vehicle tracks from evidence of vehicle tracks in the soil (usually during a prior training rotation period of 30 days or since the last rain or wind storm), and measures vegetation within the tracks to determine the area of plant parts being run over, the percent of the impacted parts damaged, and the percent of impacted parts expected to recover. It documents prior-damage classes based on estimates of damage that plants have apparently experienced previously (as assessed from field indicators of damage such as plant shape and height). The technique was used to evaluate different vehicle types (rubber-tire wheels vs. tracks) in six areas at the NTC with different soils and training intensity levels. The technique provides tabular data that can be sorted and queried to show a variety of trends related to military vehicular impacts. The technique also appears suitable for assessing other non-military off-road traffic impacts. Findings report: (1) differences in plant sensitivity to different vehicular impacts, (2) plant cover and density by species and training area, (3) the degree to which wheels have less impact than tracks, and (4) the mean percent survival is inversely proportional to the degree of prior damage received by the vegetation (i.e., plants previously impacted have lower survival than plants not previously impacted). 


\section{INTRODUCTION}

This study was conducted by plant ecologists from Bechtel Nevada and was funded by the Strategic Environmental Research and Development Program Project CS-1131 in cooperation with the U.S. Department of Energy's National Nuclear Security Administration Nevada Operations Office and the U.S. Army's National Training Center at Fort Irwin, California. Plant damage caused by vehicular traffic passing over the vegetation can be estimated by a simple plant damage assessment technique that incorporates the collection of field data and its analyses. The technique is relatively rapid and efficient. It yields considerable information about plant community structure, vehicular impacts, and plant recovery, and it provides a means of comparing sites to evaluate their relative degree of past plant disturbance. It not only permits the evaluation of plant community data, but also provides details about individual species response and their relative sensitivity to military or recreational vehicular impacts.

The technique is designed to assess recent impacts (e.g., one to four weeks) rather than cumulative impacts (e.g., one to four years). Cumulative impacts are better assessed by other techniques, such as the Land Condition Trend Analysis (U.S. Army Environmental Center, 1999) or comparable techniques that provide quantitative values of reductions in canopy cover and shifts in plant community composition (Bonham, 1989; Kent and Coker, 1992). The plant damage assessment technique requires recent vehicular activity in an area where the density of vehicle tracks are sufficiently spaced so as to be able to clearly identify individual tracks and the impacted vegetation. It is limited when tracks are too numerous (e.g. multiple passes), too old, or not clearly discernible as might result from a recent rain, or when crushed vegetation blows away during a wind storm. Ideally, it is performed in the spring of the year when vegetation is green and a week or more after the vehicular impact to permit time to determine surviving plant parts, such as leaves, branches, or new sprouts.

\section{METHODS}

Field equipment required for measurements includes a simple centimeter tape measure (a spring-. loaded metal tape works best) or ruler, pencil and data form, or palmtop computer with spreadsheet capabilities. Data analyses are best performed on a desktop personal computer with spreadsheet, statistical, and database software capabilities, although they can also be calculated by hand. A simplified diagram of typical field conditions is shown in Figure 1. The assessment technique consists of identifying a vehicle track of interested in a selected area. This can be done by driving along a road and observing intersecting tracks of interest such as the type of track (e.g., wheeled versus tracked types and their widths). A starting point is determined for the survey. This may be done by using a random number of paces in from the road in areas where vegetation is present and representative of the area to be evaluated. Global positioning satellite coordinates are recorded or the position marked on aerial photographs or topographic maps. The width of the vehicle track is then measured using a tape measure (in centimeters). This should include the outermost measurement where evidence suggests the widest width of the track. For 


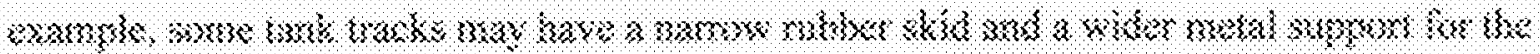
inok.

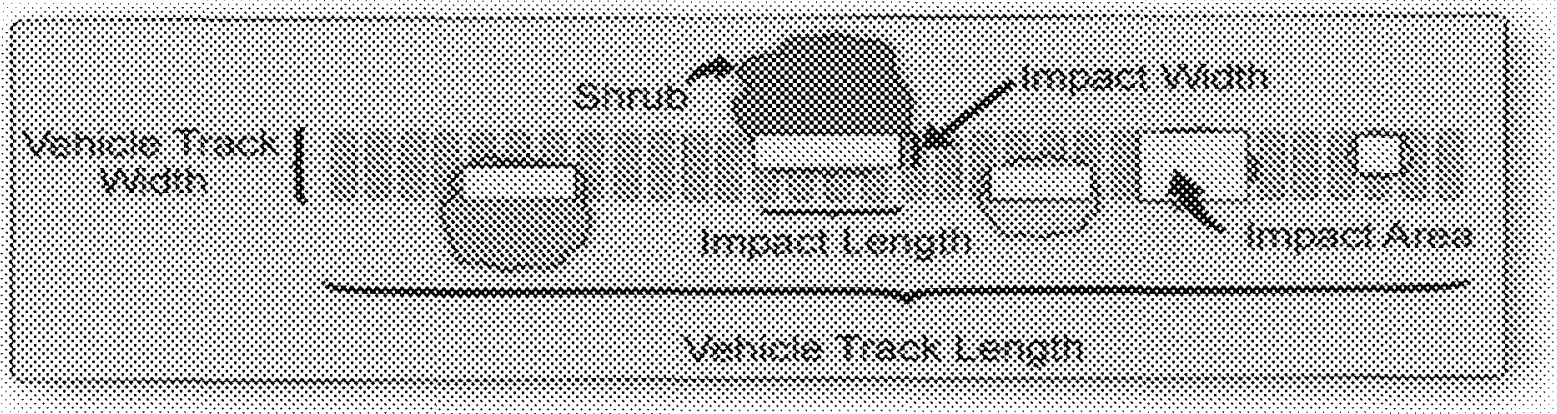

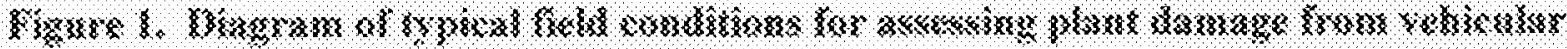 bxirk}

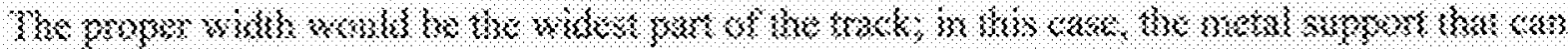

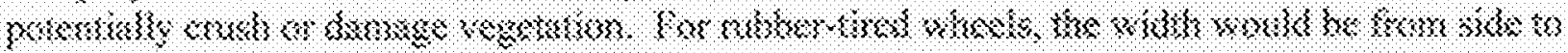

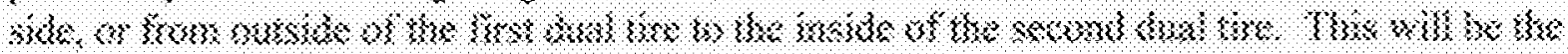

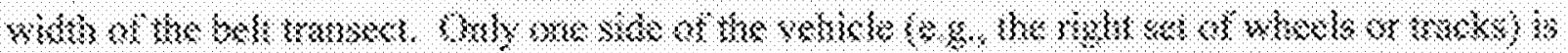

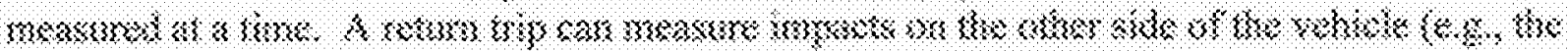

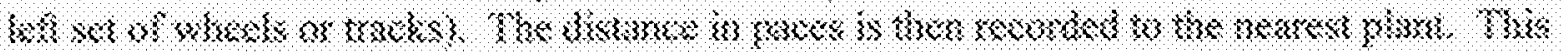

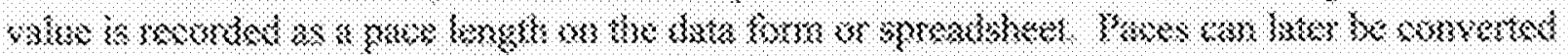

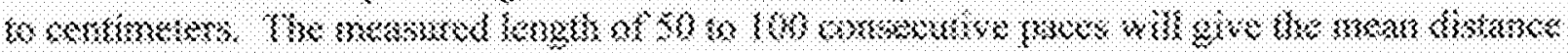

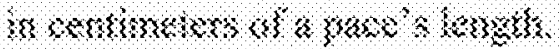

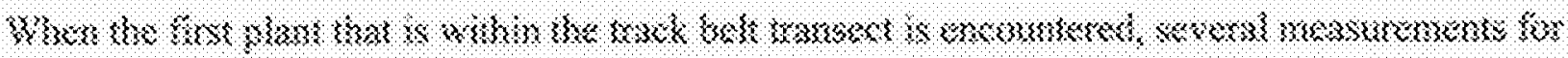

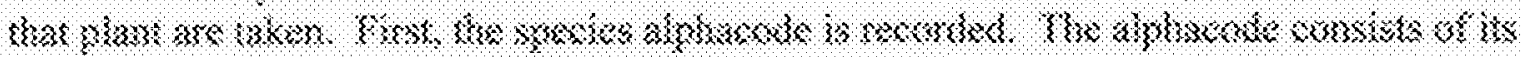

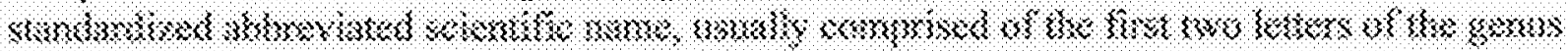

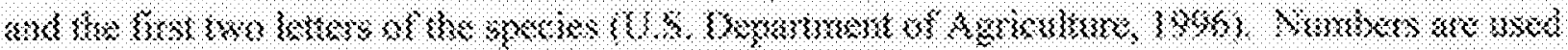

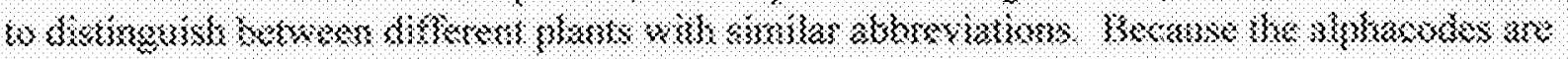

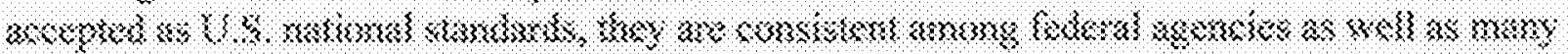

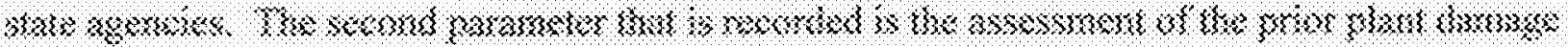

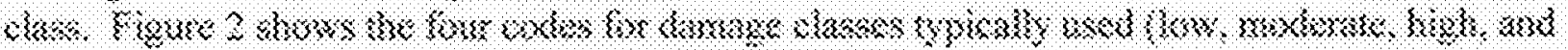

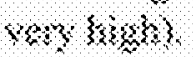

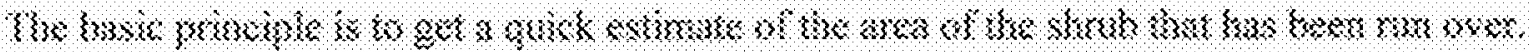

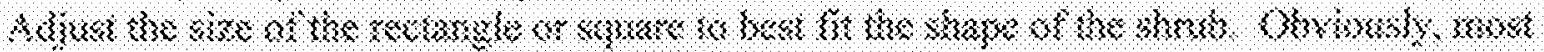

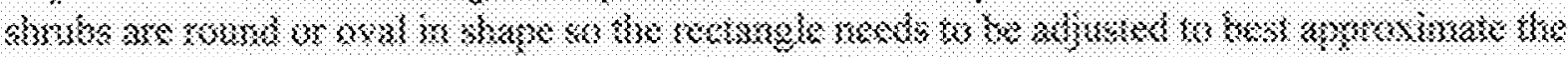

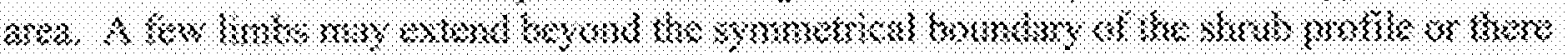

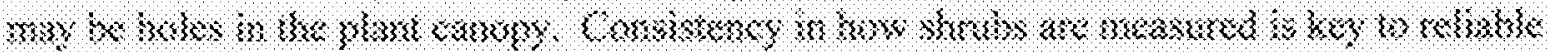

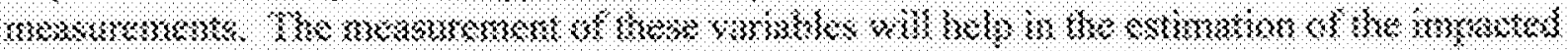

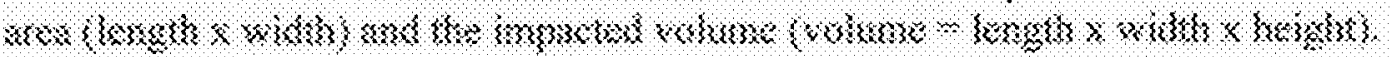



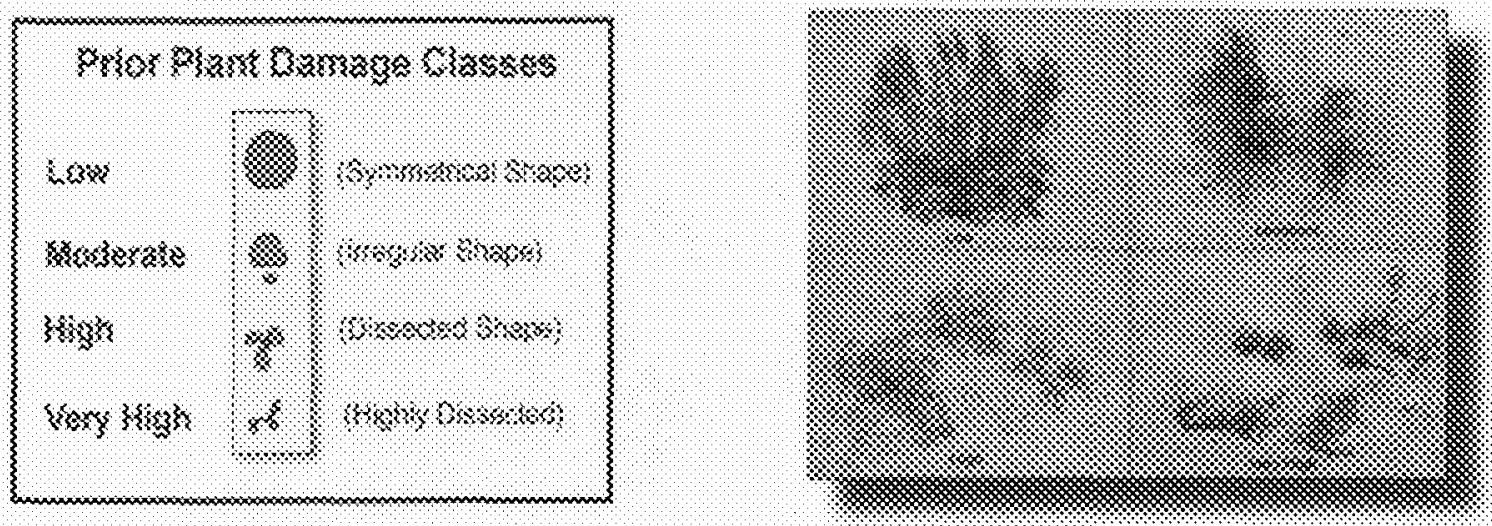

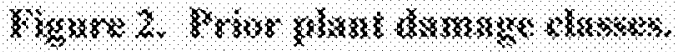

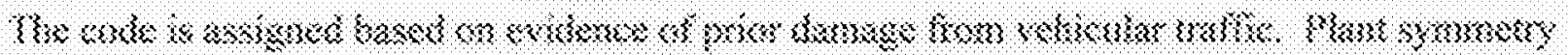

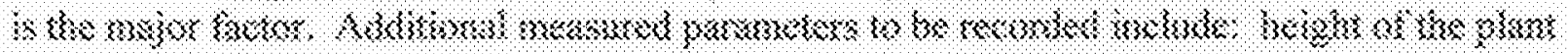

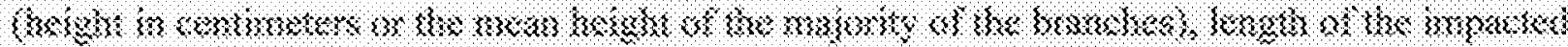

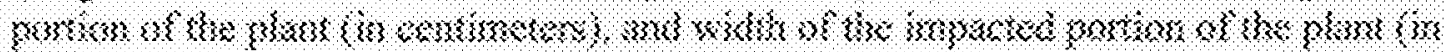

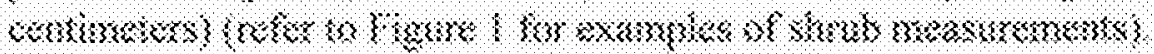

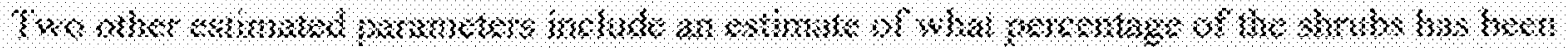

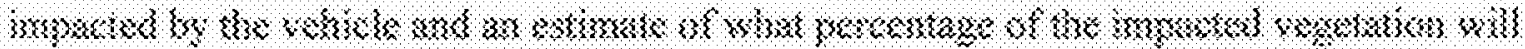

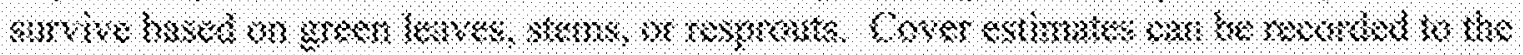

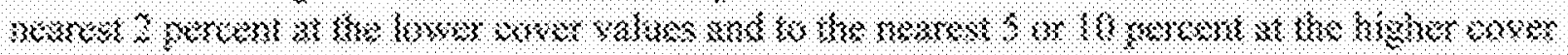

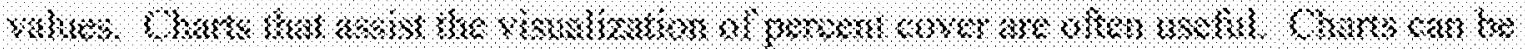

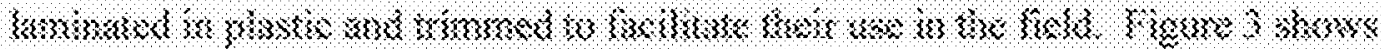

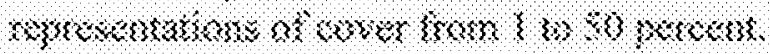

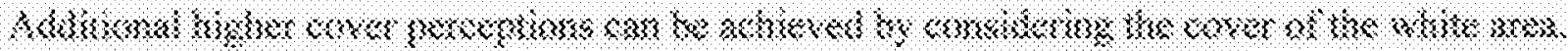

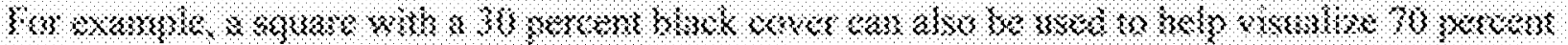

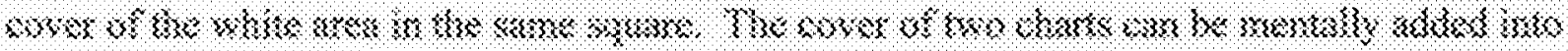

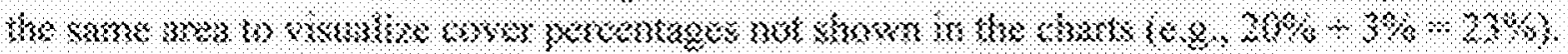

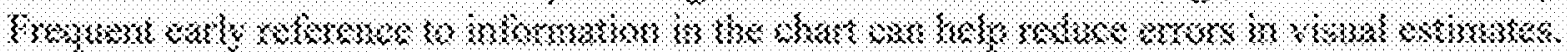

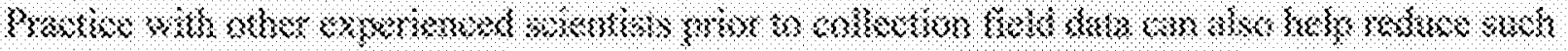
arox.

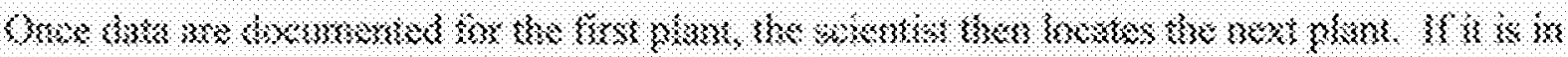

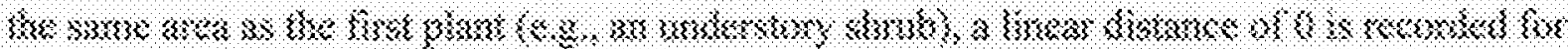

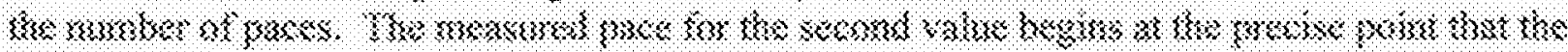

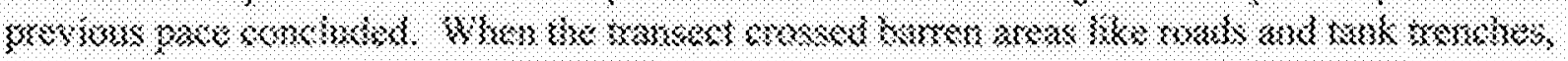




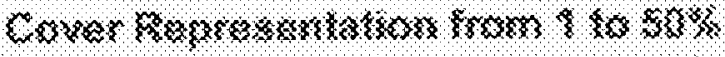

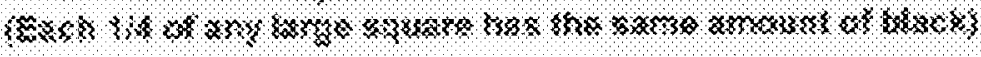

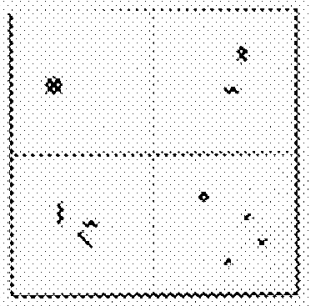

$3 \times$

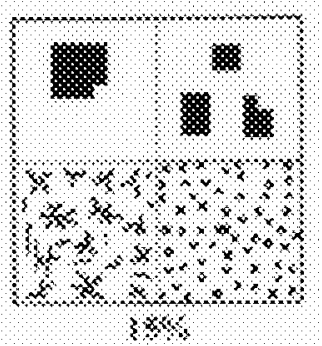

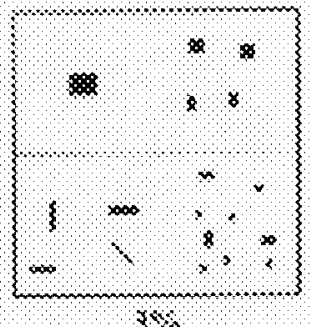

38

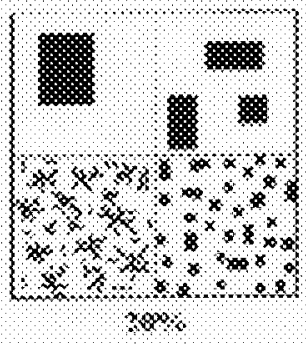

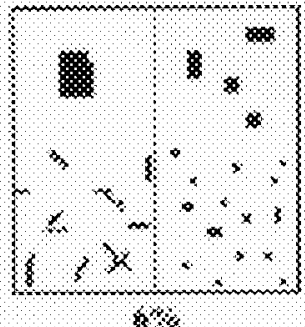

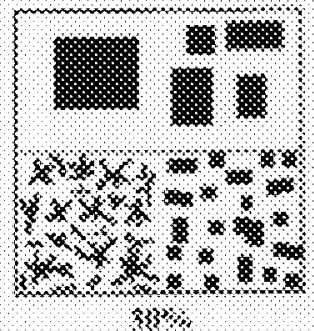

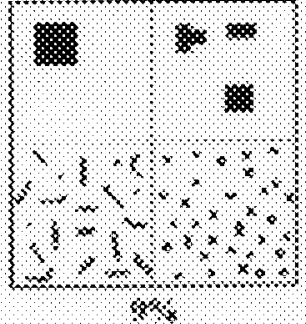

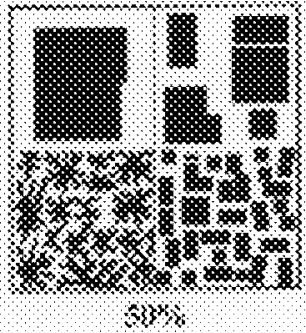

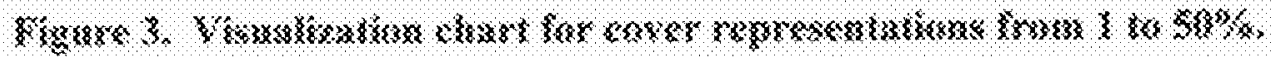

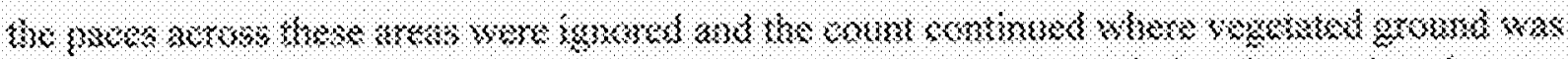

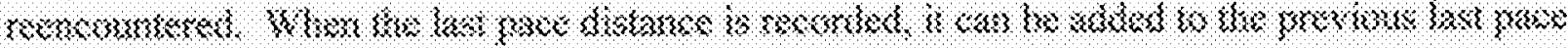

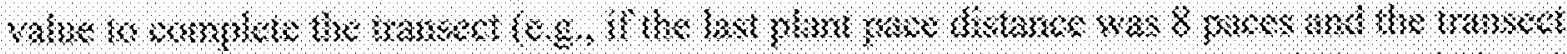

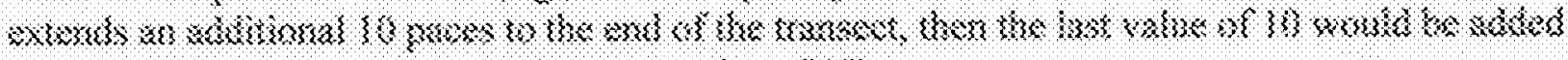

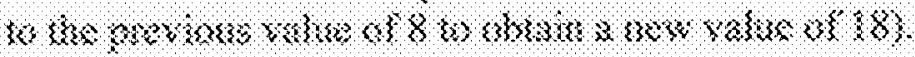

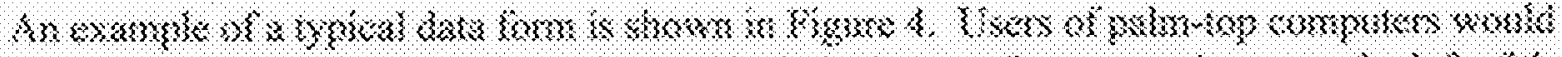

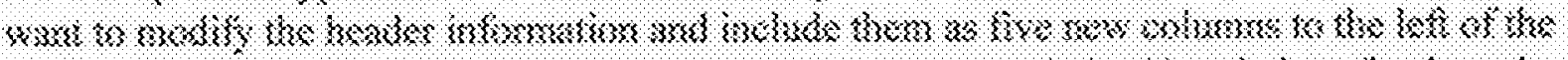

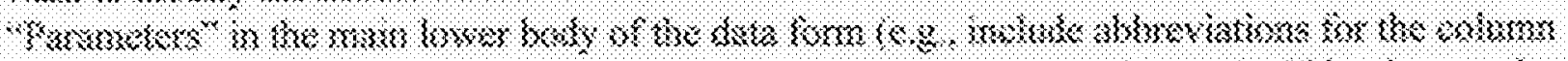

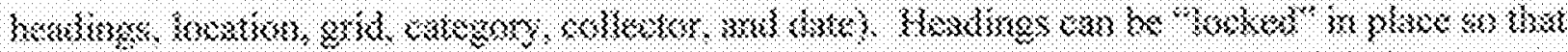

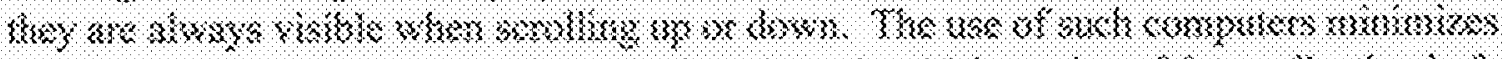

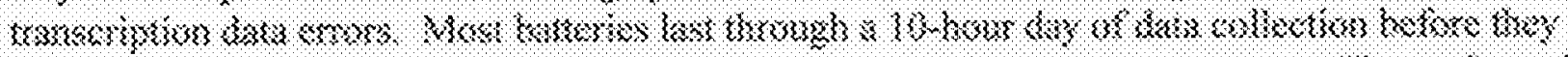

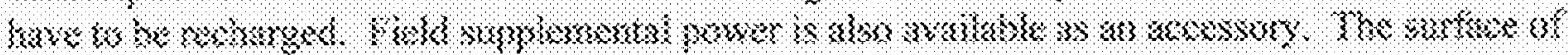

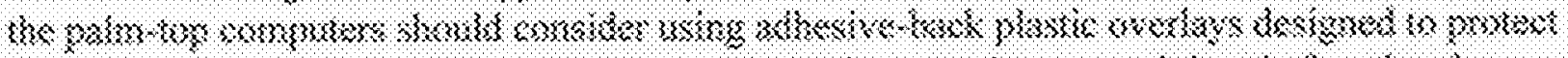

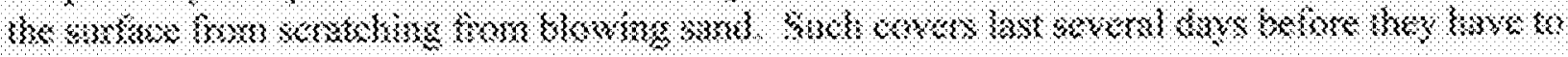
$308,3 \times 2,3$ 
Formulas and variables used for calculating values associated with the plant damage assessment technique include:

$$
\begin{aligned}
& \mathrm{C}_{\mathrm{T}}=\sum \mathrm{C}_{\mathrm{s}} \\
& \mathrm{C}_{i}=\left(\sum \mathrm{A}_{\mathrm{s}}\right) / \mathrm{V}^{*} 100
\end{aligned}
$$

where,

$\mathrm{C}_{\mathrm{T}}=$ Total plant cover summed over all species (species $i$ through species $j$ ), expressed as a percent of the total vehicular impacted area

$=$ Total vegetative damage impact created by the vehicle, expressed as a percent of the total vehicular impacted area

$C_{i}=$ Percent cover of the $i$ th perennial plant species

Species $_{i}=$ The $i$ th perennial plant species identified within the vehicular impacted area

$\mathrm{V}=$ Vehicle impacted area in square centimeters $=\mathrm{L}_{\mathrm{t}} * \mathrm{~W}_{\mathrm{t}}$

$\mathrm{L}_{\mathrm{t}}=$ Length in centimeters of the vehicular track that is sampled

$\mathrm{W}_{\mathrm{t}}=$ Width in centimeters of the vehicular track

$D_{t}=$ Distance in paces along $L_{t}$ from the starting point or plant to the next plant or finish point

$\Sigma=$ Sum of the individual measurements for species $i$ through species $j$

$\mathrm{A}_{i}=$ Area in square centimeters of the $i$ th species $=\mathrm{L}_{i} * \mathrm{~W}_{i}$

$\mathrm{L}_{i}=$ Length in centimeters of the $i$ th species that was run over by the vehicular track

$\mathrm{W}_{i}=$ Width in centimeters of the $i$ th species that was run over by the vehicular track

Other descriptive statistics and statistical tests can be used to stratify the data by site, species, prior damage class, and survival values.

In order to test the assessment technique, six different areas at Fort Irwin, California, were selected for sampling. Each area had slightly different soils and microclimate. Prior use varied among sites. Military training activities were sufficiently ongoing at each of the areas to yield numerous vehicular tracks across the sites. Severely impacted areas within these sites were 


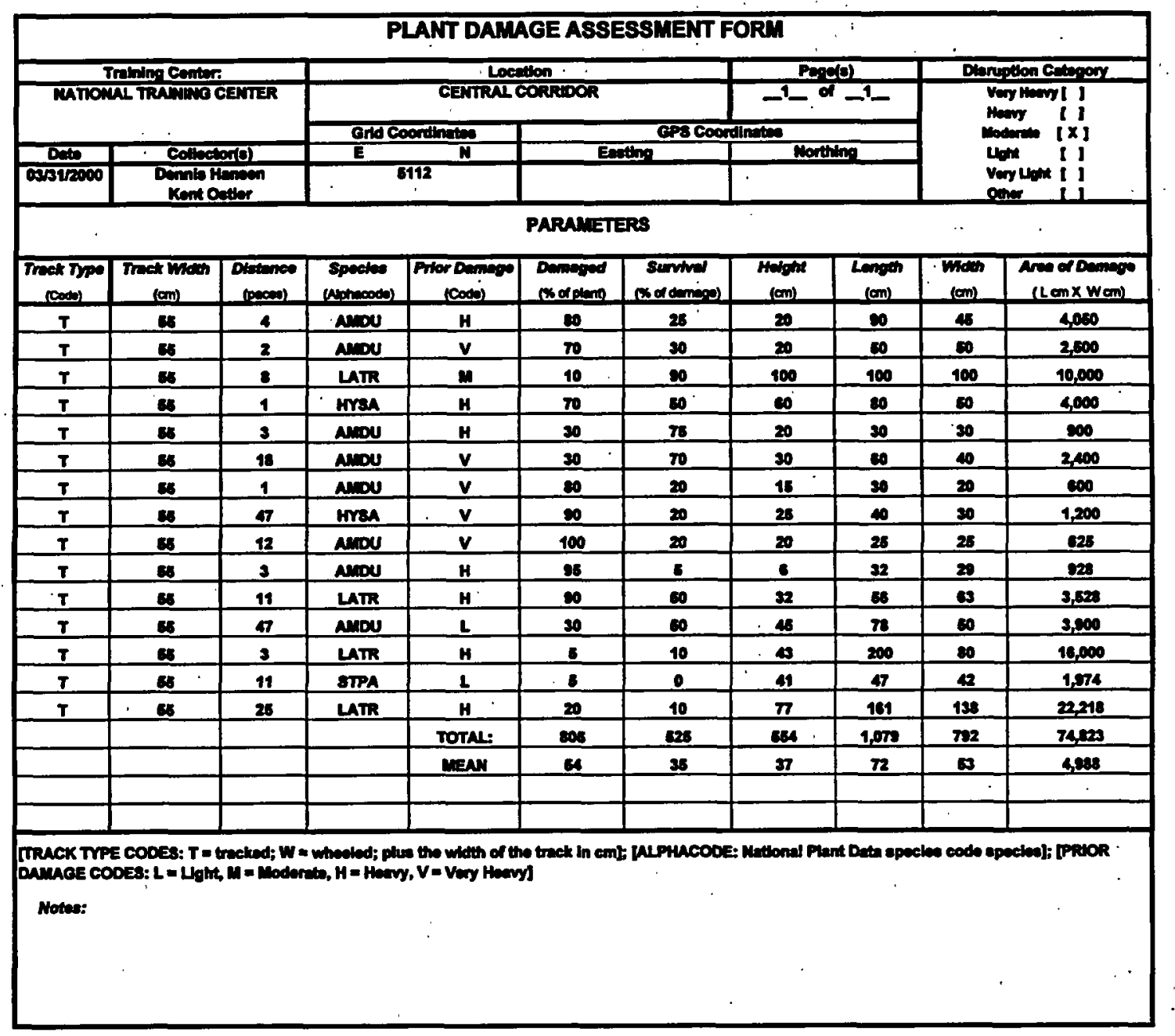

Figure 4. Example of a Plant Damage Assessment Form.

avoided because of the sparseness and lack of diversity of vegetation and the amount of time needed to encounter the next plant. Most areas would be classified as a mosaic of moderately to highly disturbed. Areas were sampled during a relatively dry spring from April 3 to May 31, 2000 , and from June 30 to July 1, 2000, at the ends of training rotations (e.g., three weeks of training activities).

Data were collected into palm-top computers (3Com PalmVx) running Quicksheet 4.0 (Palm Computing ${ }^{\text {) }}$ and later transferred to spreadsheet software on a desktop computer for analyses. Analytical packages used were: Microsoft $^{\oplus}$ Excel 97, Microsoft ${ }^{\circledR}$ Access 97, and Minitab Release 12.1. 


\section{Results}

Approximately 20 tracks and nearly 500 shrubs were sampled at the six different areas at Fort Irwin to evaluate the plant damage assessment technique. The technique provided rapid and relatively comprehensive data upon which to evaluate the impacts to perennial vegetation. The technique was evaluated under conditions that provided a good test of the technique, because it was a relatively dry year with little precipitation. This was due to the fact that plant damage is greater under dry conditions than moist conditions and it is more difficult to determine survival of plant matter that is relatively dormant (i.e., living twigs without leaves). Additionally, resprouting after vehicular damage is also delayed more under dry conditions than during periods of adequate precipitation.

Vehicle tracks consisted of two types, those from wheeled vehicles such as rubber tires on humvees or trucks, and tracks from vehicles such as armored personnel carriers or tanks. Our analyses focused on impact damage from vehicles moving in a straight line, not during turns when soil displacement and damage is much greater, and more difficult to compare and assess. One-way analysis of variance for the mean percent survivability of vegetation after being run over by ten different tract or wheel widths suggests that there were significant differences $(p<$ 0.001 level) in the mean survivability between track widths. In general the wider the track or wheel, the lower the survivability of the vegetation, probably suggesting that wider tracks support greater weights of vehicles resulting in greater damage near the root crown. A comparison of tracked vehicular damage versus wheeled vehicular damage using one-way analysis of variance suggest that there was a significant difference $(p<0.001)$ between the two types. Tracked types across all plant species had a mean percent survivability of 27 percent ( $n=288$ observations) while wheeled types had a mean percent survivability of 39 percent ( $n=188$ observations).

Survivability of individual plants varied by species with some species being more sensitive than others. A comparison of percent survivability using one-way analysis of variance suggests that there was a significant difference $(p<0.05)$ between plant species percent mean survival values. -Percent mean survival is the estimated percentage of the vegetation that has been run over that is expected to survive. Field evidence of survivability included green stems still attached to the root crown, respouting of old stems or crowns, or remaining green, leafy plant parts. A ranking of the predominant shrubs and their associated mean survival values is shown in Table 1.

Prior damage to vegetation by vehicular traffic varied by site at Fort Irwin. The percent of all shrubs at each site falling into the four following prior damage classes - low, moderate, high, and very high - is shown in Figure 5.

Survivability following vehicular impact also appeared to be dependent on the physiological condition of the plant as determined by prior damage. Table 2 shows the differences in percent survival for different damage classes across all sites, species, and for all track types and widths. 
Table 1. Comparison and ranking of plant species percent mean survival after vehicular impact.

\begin{tabular}{|l|l|c|c|c|}
\hline \multicolumn{1}{|c|}{ Scientific Name } & Common Name & $\begin{array}{c}\text { Percent Mean } \\
\text { Survival }\end{array}$ & $\begin{array}{c}\text { Standard Error } \\
\text { of the Mean } \pm\end{array}$ & $\begin{array}{c}\text { Number of } \\
\text { Measurements }\end{array}$ \\
\hline Lycium pallidum & rabbit thorn & 12.8 & 4.4 & 15 \\
\hline Hymenoclea salsola & white burrobush & 18.0 & 4.6 & 36 \\
\hline Cassia amata & spiny senna & 32.1 & 8.3 & 17 \\
\hline Ambrosia dumosa & white bursage & 32.5 & 1.9 & 293 \\
\hline Larrea tridentata & creosote bush & 38.9 & 3.6 & 84 \\
\hline
\end{tabular}

In general, plants that have little prior damage tend to have higher mean percent survival values than plants with higher prior damage. Plants with a better physiological status appear to be better able to recover after impact. An exception to this is with plants that have been very highly damaged previously. These plants are usually very small, with prostrate branches that resist further damage and result in a higher percent survival than larger plants with more upright branching patterns that are more susceptible to damage. Because they are very small, they often fit between the tracks escaping further damage completely.

When mean percent survival was considered at specific sites and for specific track types and widths, many specific patterns were observed. Some sites like John Wayne Hill, Red Pass; and Valley of Death are too disturbed by previous training activities to have any plants that fit into the "low" prior damage class.

Table 2. Mean percent survival for plants by prior damage class after vehicular impact.

\begin{tabular}{|l|c|c|c|}
\hline Prior Damage Class & Mean Percent Survival & SE Mean' () & $\mathbf{N}$ \\
\hline Low & 51.4 & 6.5 & 35 \\
\hline Moderate & 29.3 & 2.6 & 139 \\
\hline High & 25.9 & 2.5 & 144 \\
\hline Very High & 32.8 & 3.7 & 91 \\
\hline
\end{tabular}

Drink Water on the other hand had such low previous disruptions that there were no plants that fit into the "very heavy" prior damage class. 


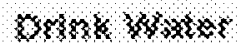

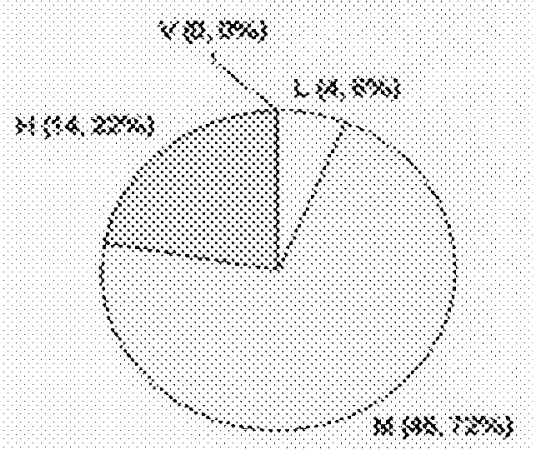

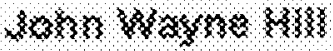

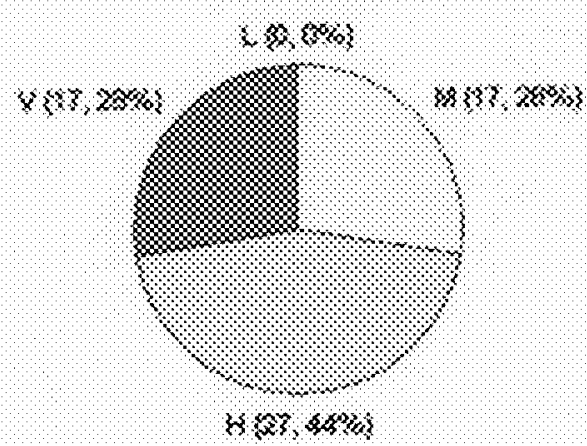

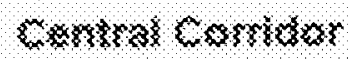

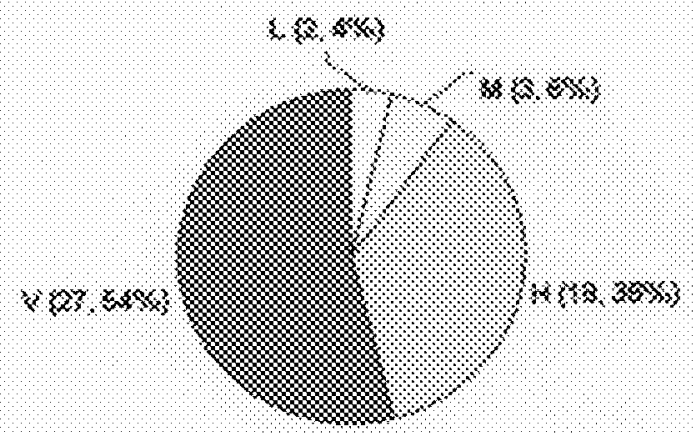

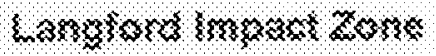

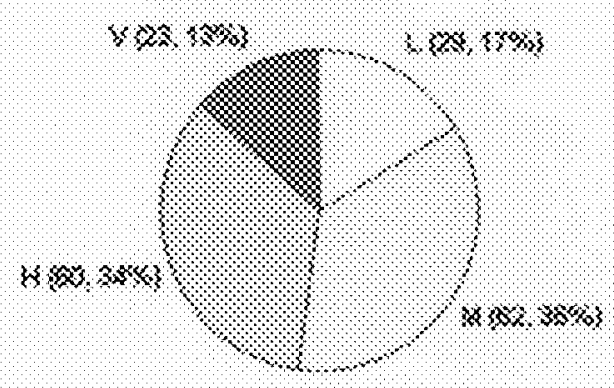

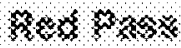

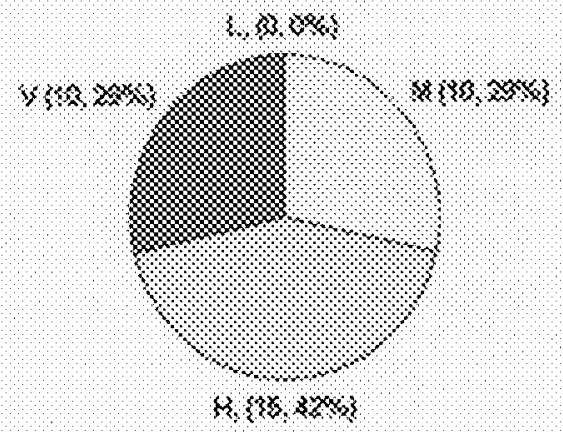

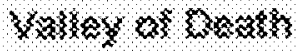

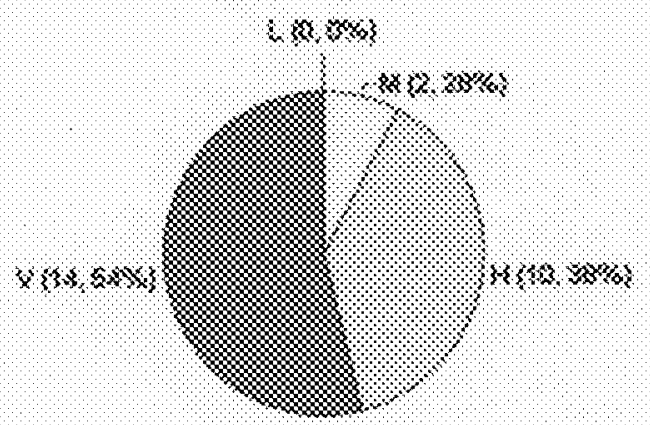

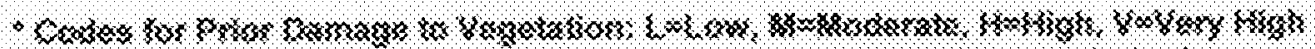

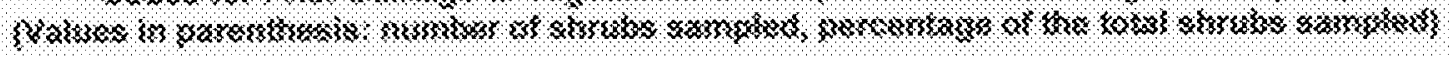

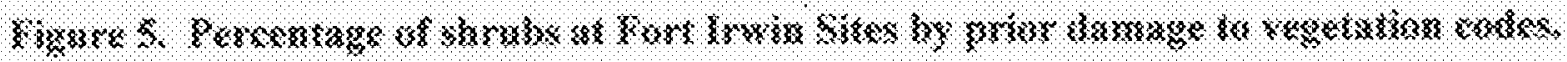


It is apparent that the patterns described for each site reflect the past training levels and current plant community structure of the site. For example, Red Pass has been impacted so heavily in the past and has very sandy soils, making it more susceptible to damage, that the site is covered by a nearly complete monoculture of creosote bush. Certainly shifting sands created by secondary impacts once vegetative cover is removed tends to bury other shorter and smaller plants.

Reductions in shrub cover due to vehicular traffic is a function of the track type, the plant cover prior to disturbance, the survivability characteristics of the plant species, and the degree of previous plant damage. Mean reduction in plant cover per pass of tracked vehicles was 74 percent, while mean reduction in plant cover per pass of wheeled vehicles was 69 percent. In other words between 69-74 percent of all vegetation run over by vehicles was killed in the sampling transect. Percent mean reduction in plant cover per vehicle pass was also higher in areas of initial higher plant cover than in areas of initial lower plant cover. Regression analysis for percent reduction in plant cover versus percent plant cover for wheeled and tracked vehicles were both statistically significant $(p<0.001)$, although the amount of variation being accounted for was generally low $\left(r^{2}=23.3\right.$ percent for wheeled and $r^{2}=70.3$ percent for tracked vehicles). The reason for this relationship appears to be that initial impact to relatively undisturbed vegetation is greater than impacts to vegetation that have been run over several times, thereby selecting for branching patterns and plant sizes that are better able to withstand vehicular traffic.

This plant damage assessment technique appears to provide a rapid means of assessing impacts of vehicular traffic in areas moderately to heavily disturbed. Its use is limited in areas where prior severe plant damage has occurred resulting in low species cover (i.e., less than 3 percent canopy cover) and large sampling distances required to provide statistically adequate sampling of the vegetation. Examples of additional plant community parameters are shown in Appendix A. 


\section{LITERATURE CITED}

Bonham, Charles D. 1989. Measurements For Terrestrial Vegetation. John Wiley and Sons, New York, 338 pp.

Kent, Martin, and Paddy Coker. 1992. Vegetation Description and Analysis. CRC Press, Boca Raton, FL, 363 pp.

U.S. Army Environmental Center. 1999. Ecological Monitoring on Army Lands. Land Condition Trend Analysis II. LCTA II Technical Reference Manual, June 1999. Aberdeen Proving Ground, MD (available as down-loadable chapters in Adobe Acrobat Portable Document Format (PDF) at: $\mathrm{http}: / / \mathrm{www}$.army-itam.com/main.htm. Internet retrieval as of $9 / 1 / 2001$ ).

U.S. Department of Agriculture, 1996. The PLANTS Database. National Plant Data Center, Baton Rouge, Louisiana. 70874-4490 USA. (Also available via the Internet: Natural Resource Conservation Service, Biological Conservation Services Division, at: http://plants.usda.gov/. Internet retrieval as of 9/1/2001). 


\section{APPENDIX A}

Example of Possible Formats for Information Obtained Using the Plant Damage Assessment Technique 


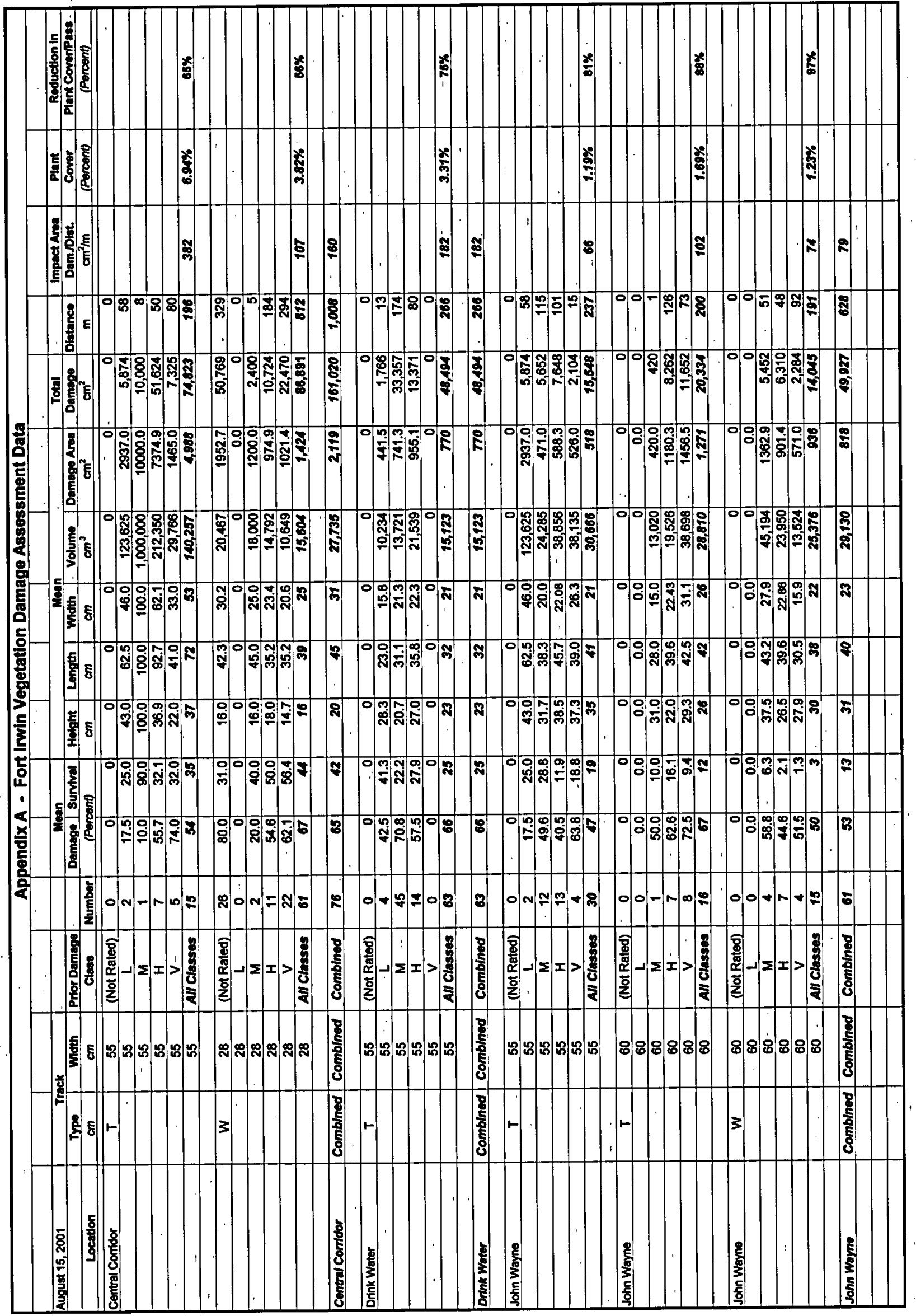




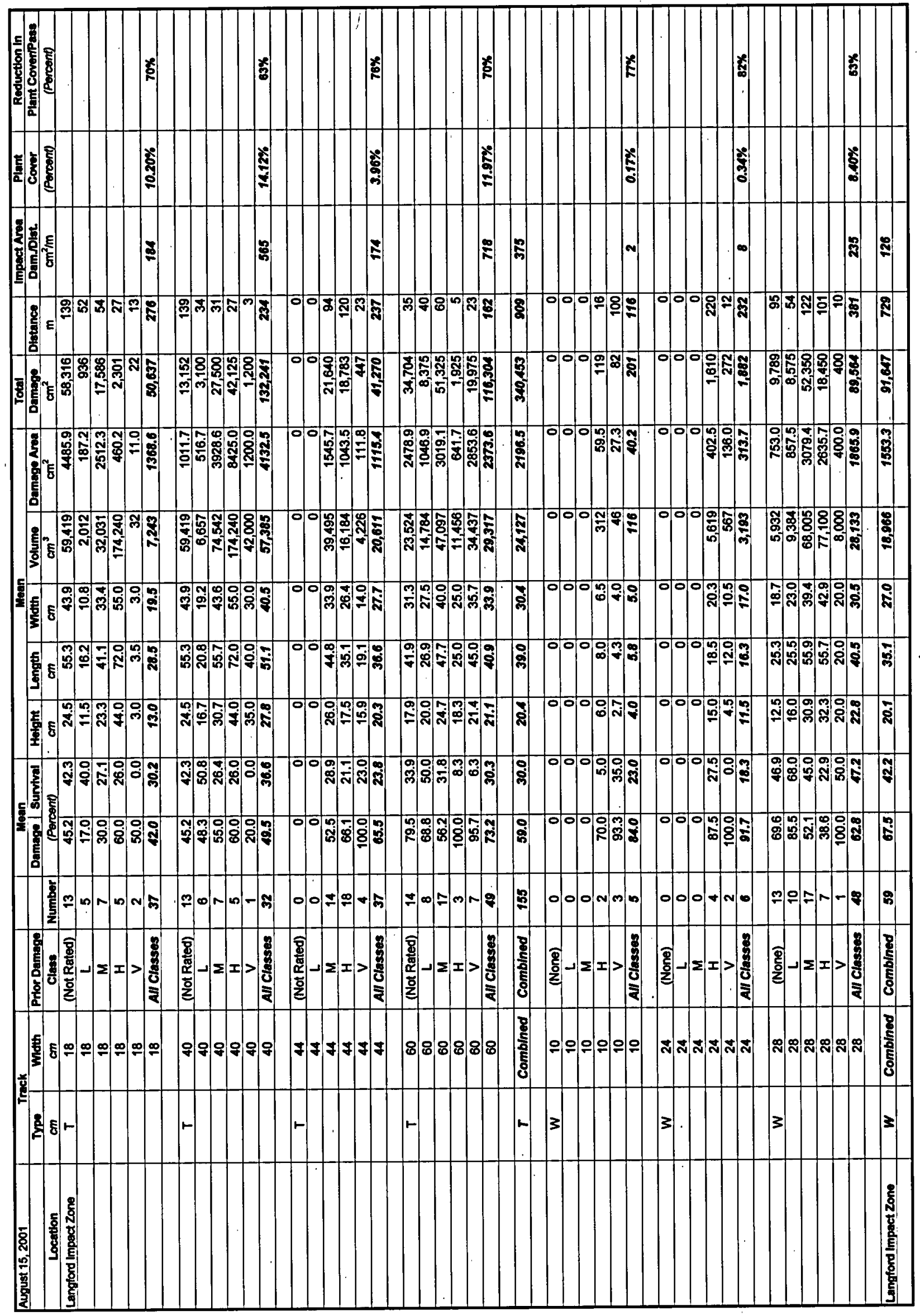




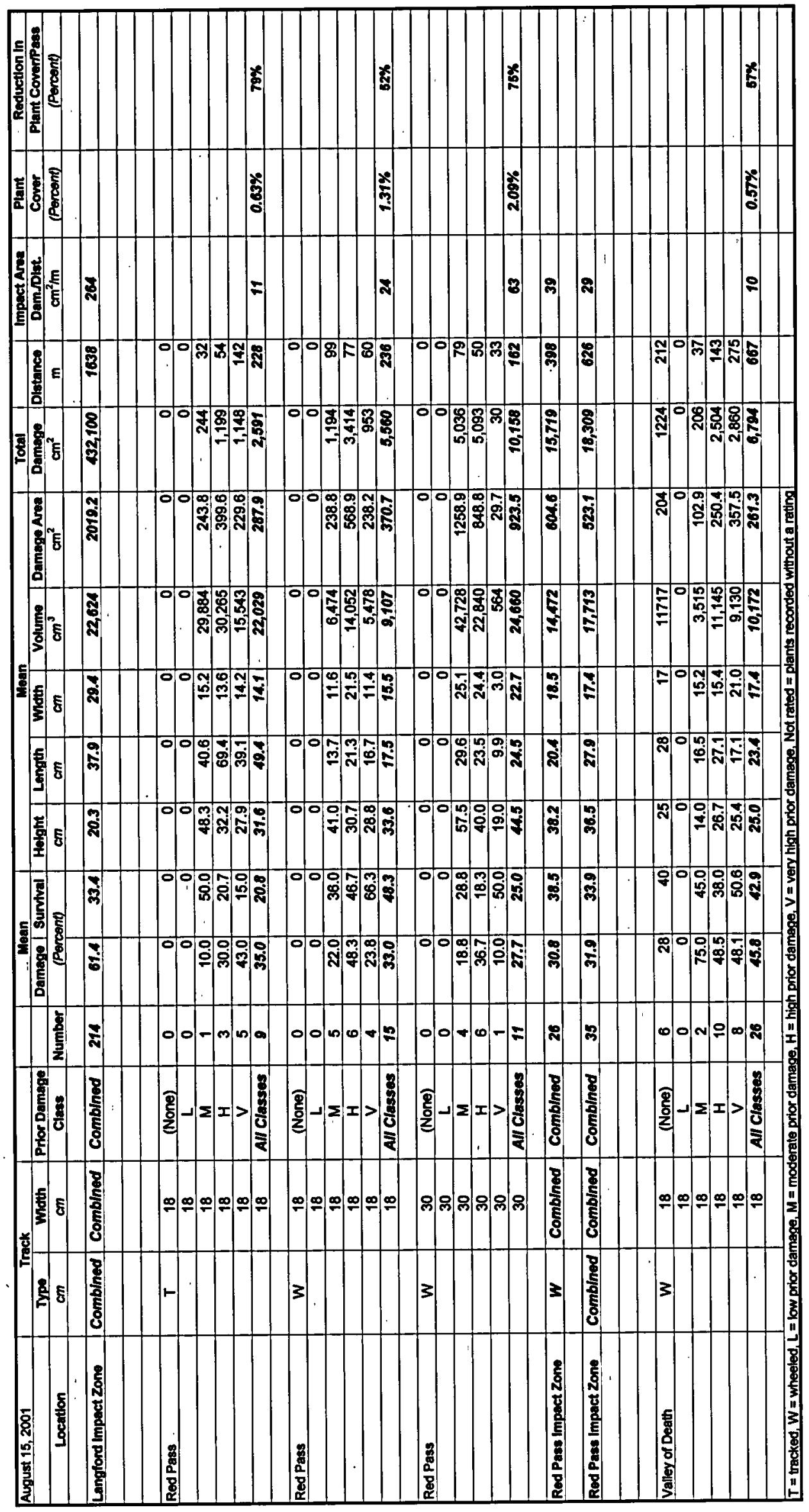




\subsection{INTERNET WEB SITES AND LINKS}

\subsection{Internet Web Sites for Remote-Sensing and Diagnostic Techniques}

One of the valuable resources available to scientists today are the many World Wide Web Internet sites that post information and provide links to other related Web sites. The access of information on the Web is dynamic and nearly always in a state of change with new Web sites being added, old Web sites revised or moved, and links established nearly hourly. Anyone who has used the Internet has encountered links to sites that no longer exist. The best attempts to be current are often by using search engines on the Internet itself. Included here are a few key websites that may help users locate pertinent information it is not meant to be exhaustive nor complete, and while every attempt has been made to ensure that the sites listed here are active, it is likely that one or more of the sites will change during the next few months.

Reference herein to any specific commercial product, process, or service by trade name, trademark, manufacturer, or otherwise, does not necessarily constitute or imply its endorsement, recommendation, or favoring by the U.S. Government or any agency thereof or its contractors or subcontractors.

\subsubsection{Strategic Environmental Research and Development Program (SERDP)} http://www.serdp.org/

\subsubsection{SERDP Projects or Linked Web sites}

Colorado State University's Center for Environmental Management of Military Lands http://www.cemml.colostate.edu/

Utah State University's Remote Sensing for Ecosystem Assessment: http://www.gis.usu.edu/ serdp.

University of Illinois's Spatial Data Analysis Laboratory: http://www.sdal.uiuc.edu/

University of Nevada Reno: http://www.ag.unr.edu/serdp/

U.S. Army Corps of Engineers Engineer Research and Development Center, Construction Engineering Research Center:

http://www.cecer.army.mil/td/tips/index.cfm 


\subsubsection{Remote Sensing}

U.S. Department of Agriculture's Forest Service Remote Sensing Applications Center: http://www.fs.fed.us/eng/rsac/

Remote Sensing, WWW Virtual Library at: http://www.vtt.fi/tte/research/tte1/tte14/virtual

American Society for Photogrammetry \& Remote Sensing (ASPRS), http://www.asprs.org

Color balancing and mosaicing software: DIME $^{\mathscr{D}}$ software at: http://www.possys.com/dime.html

Mosaicing software: Multiresolution Seamless Image Database (MrSID $\left.{ }^{\oplus}\right)$ software at: http://www.lizardtech.com

Military version of MrSID GeoViewer Version 2.1 at (note: https nor http): https://trms.7atc.army.mil

\subsubsection{Digital Photography}

Flatbed scanning tips:

http://www.scantips.com

Digital Photography Tutorial by Norman Koren at:

http://www.normankoren.com

Digital editing software, Picture Window Pro, Digital Light \& Color at: http://www.dl-c.com

Technical information about digital photography at Computer-Darkroom: http://www.computer-darkroom.co.uk

\subsubsection{Kite Aerial Photography}

Kite Aerial Photography E-Resources at: http://www.fortunecity.com/marina/nelson/479/

Kite aerial photography:

http://arch.ced.berkeley.edu/kap/ 


\subsubsection{Helium Blimps}

Skyview blimp services:

http://www.skyview-usa.com.

\subsubsection{Image Processing}

Image Tool, University of Texas Health Science Center, San Antonio, Texas (UTHSCSA). Version 3.0 of UTHSCSA ImageTool at: http://ddsdx.uthscsa.edu/dig/itdesc.html

Image Pro ${ }^{\circledR}$ Plus User's Group at:

http://www.solutions-zone.com/ipednld/subscriber.asp or http://www.mediacy.com) Users may also search the archive files available at Image Pro ${ }^{\otimes}$ Plus User's Group Archives: http://www.mediacy.com/tech/ipts ugml.html

SigmaScan $\otimes$ Pro: http://www.spssscience.com/SigmaScan/

Feature AnalystTM, Visual Learning Systems in Missoula, Montana http://www.vls-inc.com/

Environment for Visualizing Images $\left(\mathrm{ENVI}^{\circledR}\right)$ can be reached at: http://www.rsinc.com/envi/

Geomatica ${ }^{\circledR}$ can be reached at: http://www.pcigeomatics.com/

ERDAS Imagine ${ }^{\circledR}$ can be reached at: http://www.erdas.com/ 